\title{
TOPO-EUROPE: The geoscience of coupled deep Earth-surface processes
}

\author{
S.A.P.L. Cloetingh ${ }^{*, 1}$, P.A. Ziegler, P.J.F. Bogaard, P.A.M. Andriessen, \\ I.M. Artemieva, G. Bada, R.T. van Balen, F. Beekman, Z. Ben-Avraham, J.-P. Brun, \\ H.P. Bunge, E.B. Burov, R. Carbonell, C. Facenna, A. Friedrich, J. Gallart, \\ A.G. Green, O. Heidbach, A.G. Jones, L. Matenco, J. Mosar, O. Oncken, \\ C. Pascal, G. Peters, S. Sliaupa, A. Soesoo, W. Spakman, R.A. Stephenson, \\ H. Thybo, T. Torsvik, G. de Vicente, F. Wenzel, M.J.R. Wortel, \\ TOPO-EUROPE Working Group ${ }^{2}$
}

\begin{abstract}
TOPO-EUROPE addresses the 4-D topographic evolution of the orogens and intra-plate regions of Europe through a multidisciplinary approach linking geology, geophysics, geodesy and geotechnology. TOPO-EUROPE integrates monitoring, imaging, reconstruction and modelling of the interplay between processes controlling continental topography and related natural hazards. Until now, research on neotectonics and related topography development of orogens and intra-plate regions has received little attention. TOPO-EUROPE initiates a number of novel studies on the quantification of rates of vertical motions, related tectonically controlled river evolution and land subsidence in carefully selected natural laboratories in Europe. From orogen through platform to continental margin, these natural laboratories include the Alps/Carpathians-Pannonian Basin System, the West and Central European Platform, the Apennines-Aegean-Anatolian region, the Iberian Peninsula, the Scandinavian Continental Margin, the East-European Platform, and the Caucasus-Levant area. TOPO-EUROPE integrates European research facilities and know-how essential to advance the understanding of the role of topography in Environmental Earth System Dynamics. The principal objective of the network is twofold. Namely, to integrate national research programs into a common European network and, furthermore, to integrate activities among TOPO-EUROPE institutes and participants. Key objectives are to provide an interdisciplinary forum to share knowledge and information in the field of the neotectonic and topographic evolution of Europe, to
\end{abstract}

\footnotetext{
* Corresponding author.

${ }^{1}$ Netherlands Research Centre for Integrated Solid Earth Science, Faculty of Earth \& Life Sciences, Vrije Universiteit, De Boelelaan 1085 , 1081 HV Amsterdam, The Netherlands, e-mail address: sierd.cloetingh@falw.vu.nl (S.A.P.L. Cloetingh).

2 TOPO-EUROPE Working Group: U. Achauer, A. Adam, A. Barabas, J. Behrmann, A. Beylich, J.M. Bonow, J. Braun, S. Buiter, L. Csontos, J. Dehls, P. Dèzes, C. Dinu, E. Dombradi, J. Ebbing, E. Eide, T. Fancsik, L. Fodor, O. Fredin, W. Frisch, L. Gemmer, J. Genser, G. Grenerczy, J.M. Hagedoorn, S. Harangi, E. Hegedus, A. Helge, B. Hendriks, F. Horváth, E. Horvath, G.A. Houseman, H. Igel, P. Japsen, J. Kiss, V. Klemann, J. Kuhlemann, A. Lankreijer, E. Larsen, J. Lauterjung, O. Longva, J. Ludden, E. Lundin, A. Madarasi, P. Maguire, G. Molnar, A. Nador, J. Negendank, F. Neubauer, A. Novak, O. Olesen, P.T. Osmundsen, C. Pascal, C. Puigdefabregas, L. Rise, Z. Ruszkiczay, M. Sacchi, S. Schmid, M. Smelror, W. Stackebrandt, K. Stalsberg, R. Steel, B. Steinberger, C. Szabo, P. Szafian, L. Szarka, B. Szekely, O. Sztano, M. Tesauro, A. Thieken, G. Timar, L. Toth, J. van Enst, J.D. van Wees, G. Varga, Z. Weber, M. Wilson, D. Wolf. For affiliation and e-mail addresses of authors and members of TOPOEUROPE Working Group, see http://www.topo-europe.eu.
} 
promote and encourage multidisciplinary research on a truly European scale, to increase mobility of scientists and to train young scientists. This paper provides an overview of the state-of-the-art of continental topography research, and of the challenges to TOPO-EUROPE researchers in the targeted natural laboratories.

Keywords: environmental Earth System Dynamics; neotectonics; continental topography; source/sink relations; lithosphere/surface processes

\section{Rationale for TOPO-EUROPE}

Continental topography is at the interface of deep Earth, surface and atmospheric processes. Topography influences society, not only as a result of slow landscape changes but also in terms of how it impacts on geohazards and the environment (Fig. 1). When sea-, lakeor ground-water levels rise, or land subsides, the risk of flooding increases, directly affecting the sustainability of local ecosystems and human habitats. On the other hand, declining water levels and uplifting land may lead to higher risk of erosion and desertification. In the recent past, catastrophic landslides and rock falls have caused heavy damage and numerous fatalities in Europe. Rapid population growth in river basins, coastal lowlands and mountainous regions and global warming, associated with increasingly frequent exceptional weather events, are likely to exacerbate the risk of flooding and devastating rock failures. Along active deformation zones, earthquakes and volcanic eruptions cause short-term and localized topography changes. These changes may present additional hazards, but at the same time permit, to quantify stress and strain accumulation, a key control for seismic and volcanic hazard assessment. Although natural processes and human activities cause geohazards and environmental changes, the relative contribution of the respective components is still poorly understood. That topography influences climate is known since the beginning of civilization, but it is only recently that we are able to model its effects in regions where good (paleo-) topographic and climatologic data are available.

The present state and behaviour of the Shallow Earth System is a consequence of processes operating on a wide range of time scales. These include the long-term effects of tectonic uplift, subsidence and the development of river systems, residual effects of the ice ages on crustal movement, natural climate and environmental changes over the last millennia and up to the present, and the powerful anthropogenic impacts of the last century. If we are to understand the present state of the Earth System, to predict its future and to engineer our use of it, this spectrum of processes, operating concurrently but on different time scales, needs to be better understood. The challenge to Geosciences is to describe the state of the system, to monitor its changes, to forecast its evolution and, in collaboration with others, to evaluate modes of its sustainable use by human society.

\subsection{Topography and natural hazards}

To gain a better understanding of the interrelation between topography, geohazards and the environment, the temporal evolution of topography needs to be assessed, not only during the recent past but also during the last 10 or so million years. There are however some complex problems inherent to paleo-topography analysis. Apart from dealing with topography that no longer exists, the dimensions and timing of events and the underlying dynamic processes that controlled its development, as well as the topographic life cycle, pose major challenges, the complexity of which cannot be solved by a single sub-discipline but requires support by other disciplines. The geographic scope of the proposed TOPO-EUROPE programme demands co-operation on a European scale to avoid a fragmented approach. Mountain ranges (increasing surface topography) and adjacent sedimentary basins (decreasing surface topography) record signals and proxies that tell the story of the topographic life cycle. In this, the source-to-sink relationship is of key importance. However, signals and proxies are still poorly understood and we only have started to decipher the few we are aware of. A major challenge is to extract all available information contained in the system and to interpret it in terms of processes. Innovative analytical techniques, improvement of methodologies, back-to-back with innovative conceptual and quantitative modelling, are required to resolve these problems.

The main challenge in topography-related geological hazard research is to create and verify physical models of hazardous Earth Systems that integrate all relevant data, describe hazards as a function of time, and understand them as resulting from a non-linear system evolution under which processes acting on various temporal and spatial scales can become catastrophic. In this context it must be understood that topography plays a prominent role as it results from the interaction of shallow and deep Earth processes, and as such permits, 


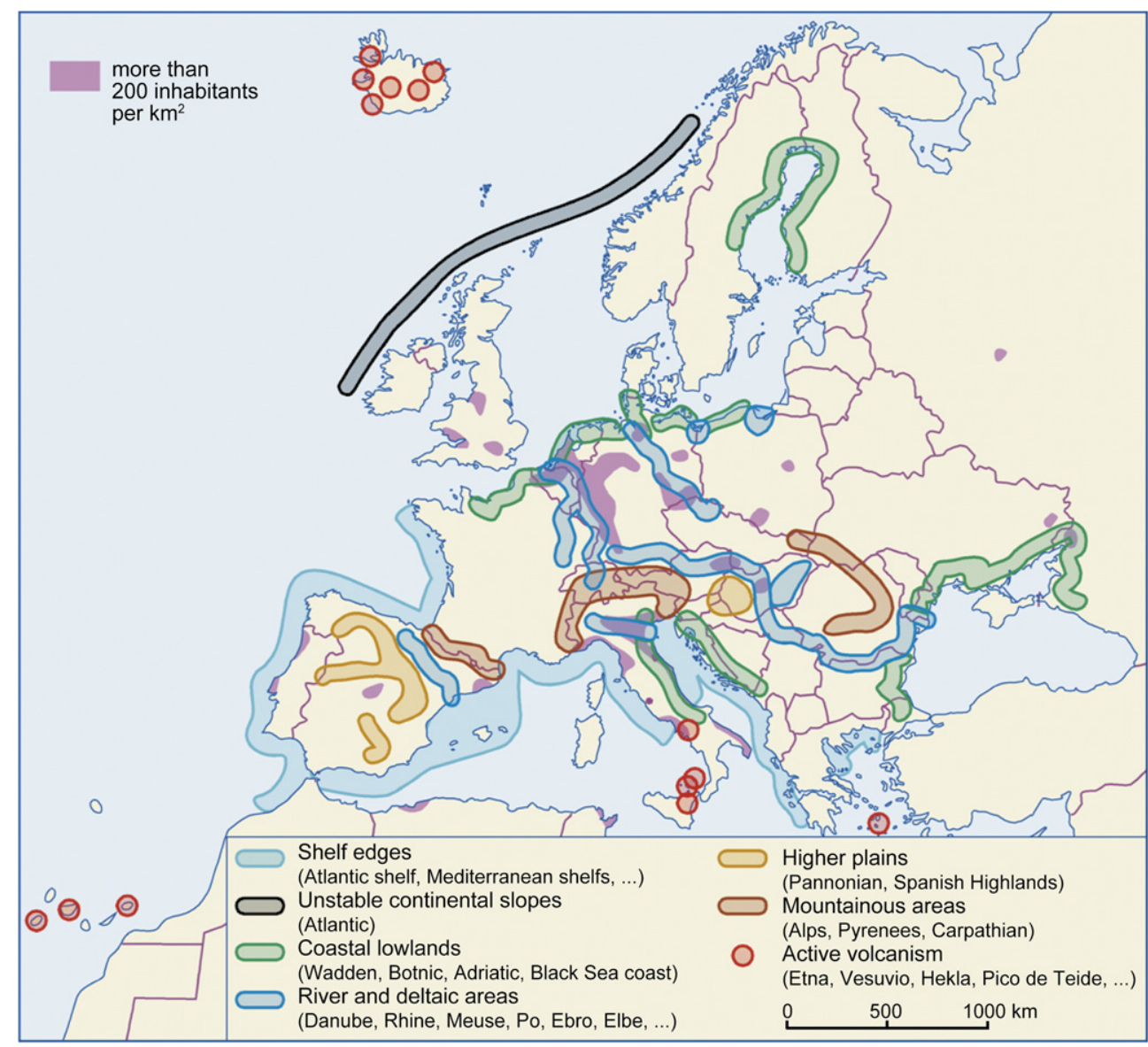

Fig. 1. Areas of vulnerability due to vertical movements in Europe, demonstrating the link between demography and environmental tectonics in Western and Central Europe (after Cloetingh et al., 2006b).

in combination with other parameters, to assess the state of stress and its change through time.

There are obvious relations between geological hazards and topography. Topography is a major factor controlling slope instabilities, which can lead to the development of landslides, both on- and offshore. Uplift of e.g. Fennoscandia and the Romanian Vrancea area has caused increased landslide and rock-fall hazards. The second important parameter for catastrophic earth movements is the internal friction of soil, which in turn depends largely on the hydrological conditions and water input by precipitation. Regional climate changes when associated with a precipitation increase tend to cause increased slope instability and corresponding landslide activity.

Earthquakes result from crustal-scale fault-related deformation and occur in various parts of Europe (Fig. 2). Although areas with a high frequency of large magnitude earthquakes are mostly bound to the Medi- terranean domain, the strong concentration of people and high-value infrastructure in densely populated areas in Europe can in these regions turn moderate hazards into large risks. The currently used ' 3 rd generation' hazard assessment method can be coined 'seismotectonic probabilism'. This method largely relies on historical and paleo-seismological earthquake records, and results in maps giving an annual exceedance probability of a certain damage parameter (Fig. 3). The challenge to Solid-Earth science researchers lays in developing 4th generation hazard assessment methods, relying much more on a physical understanding of processes leading to earthquakes and on assessment of the actual state of stress on faults. The state of stress is strongly influenced by surface topography, but also by the topography of lithospheric boundaries (Moho, lithosphere-asthenosphere boundary). Highly sophisticated models for time-dependent hazard assessment that link several processes, such as mantle dynamics, structure and 


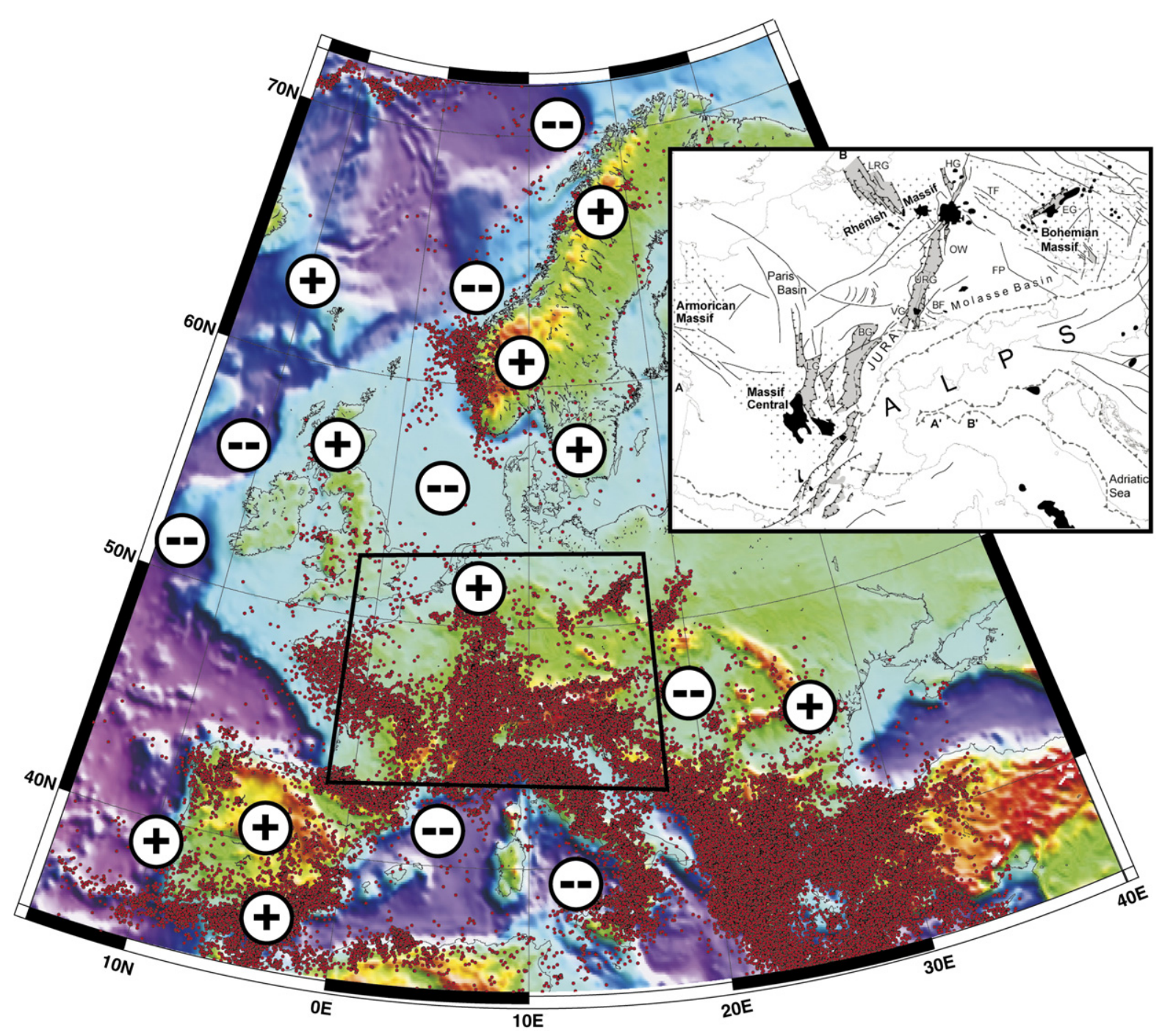

Fig. 2. Seismicity map of Europe, illustrating present-day active intraplate deformation. Also shown are intraplate areas of Late Neogene uplift (circles with plus symbols) and subsidence (circles with minus symbols). Background elevation images are extracted from the ETOPO2 data set. Earthquake epicentres are from the NEIC data centre, and are shown as red dots. Inset map: Cenozoic rift system of Europe (after Dèzes et al., 2004).

rheology of the crust and mantle, change in topography, mass re-distribution by erosion and sedimentation, and post-seismic relaxation, can be established today. Verification of these models requires data on recent deformation (both from GPS and geological reconstruction for the Holocene/Pleistocene) and tectonic stress (e.g. through the World Stress Map project). This can yield substantial new insights into the stress and strain evolution of the key seismogenic areas of Europe. This type of modelling may prove a particularly valuable approach to constrain extreme events with their high societal impact.

Intraplate seismicity is still poorly understood and tends to follow episodic intermittency patterns rather than quasi-periodic earthquake activity more characteristic for plate boundaries. TOPO-EUROPE will establish a database that allows for a systematic combination of lithospheric data (e.g. geometry of boundaries, temperature, stress, structure) and recent movements, including topography changes over an area that covers all levels of seismicity, such as highly active plate boundary domains, moderate intraplate activity, and seismic quiescence.

Europe is exposed to recurrent flooding events that pose major hazards to population and industrial agglomerations. The damaging potential of floods is intrinsically linked to even minor topographic changes that control the depth of inundation. Thus, it will be a challenging 


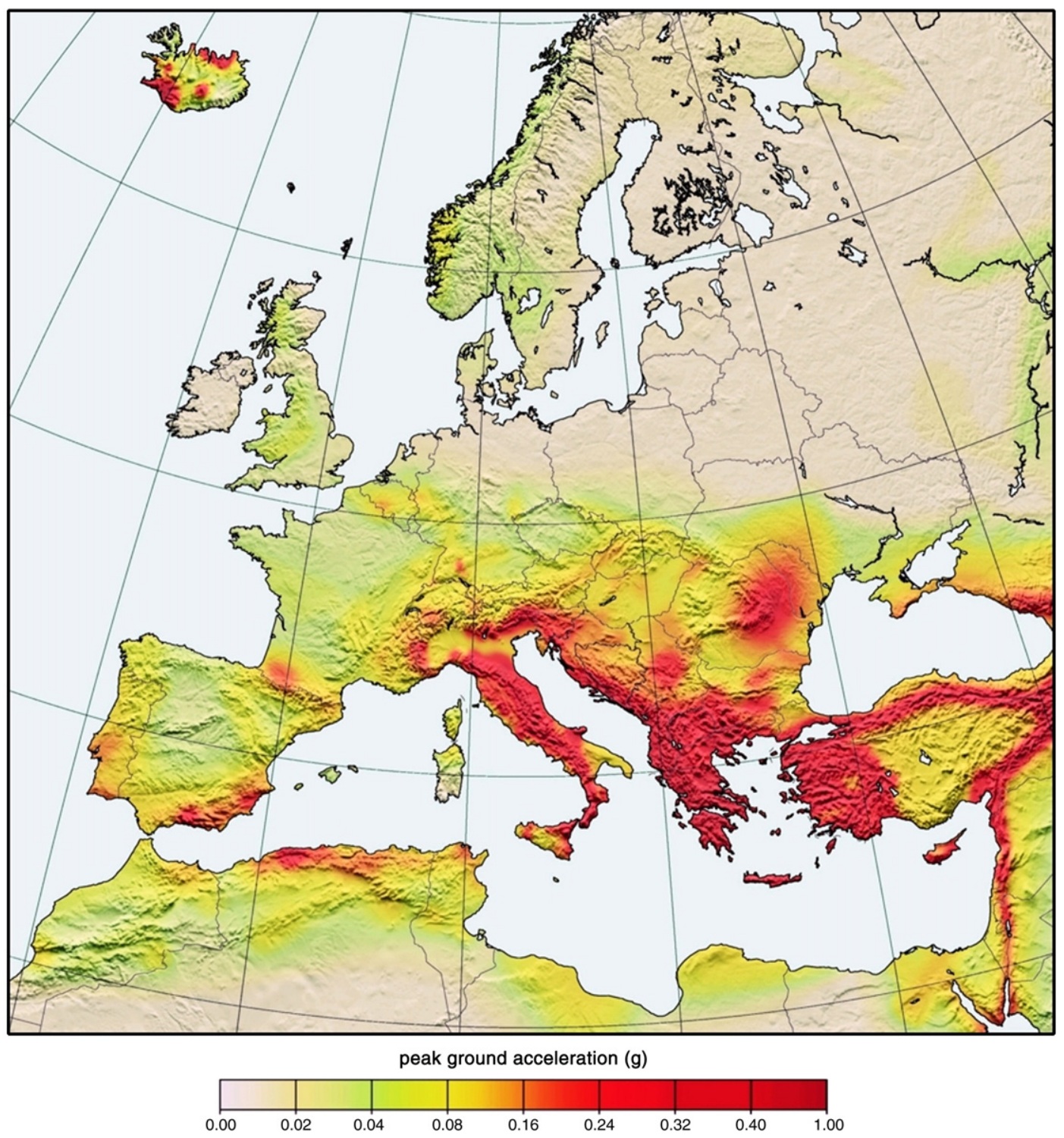

Fig. 3. Peak ground acceleration SESAME map (Jiménez et al., 2003) for a 90\% non-exceedence probability within 50 years.

task for TOPO-EUROPE to combine regional climate predictions with changes in sea and river level and topography during the Holocene to fully assess Europe's future flood hazards.

The main risk generating factor for the human society is the increased exposure and vulnerability of its assets (buildings, infrastructure, and social systems). However, during the past 150 years anthropogenic modification of the planetary environment has caused changes in the hazard potential itself. For instance, extraction of large amounts of ground water beneath and near cities modifies surface elevations and thus their inundation potential during floods. At the same time this impacts on the stability of the subsurface with consequences for ground motion during future earthquakes, associated liquefaction potential, and landslide hazard. Again, TOPOEUROPE opens avenues to systematically address these issues on a European scale.

\subsection{The TOPO-EUROPE network}

The TOPO-EUROPE network was officially launched during a symposium held in October 2005 in Heidelberg, Germany with the objective to tackle the challenges in continental topography research. TOPOEUROPE aims at integrating European communities 
that hitherto have been active under discrete research and implementation schemes in the field of continental topography research. Subjects that have been addressed include land subsidence and uplift, and fluctuations of the erosional base level in response to sea-level changes and local tectonics.

The TOPO-EUROPE network serves as a vehicle to:

(i) advance the understanding of processes controlling topography development and related geohazards;

(ii) promote Europe as international scientific leader in the new field of continental topography research;

(iii) provide improved working opportunities for highlevel researchers; and

(iv) counteract the brain drain to areas outside Europe.

With the establishment of a strong network of collaborating institutes, the international TOPO-EUROPE project will be able to tackle a set of outstanding questions pertaining to lithospheric, surface and climaterelated processes controlling the on-going topography evolution and related natural hazards of the Alps/ Carpathians-Pannonian Basin System, the West and Central European Platform, the Apennines-AegeanAnatolian region, the Iberian Peninsula, the Scandinavian Atlantic Margin, the East-European Platform and the Caucasus-Levant area. These natural laboratories comprise some of the best-documented orogens, sedimentary basins and continental margins worldwide. As such, they offer key study areas for the development of a new generation of models for on-going lithospheric deformation and its effect on continental topography development, both on regional and local scales.

Research will focus on the interplay between active tectonics, topography evolution, and related sea-level changes and drainage pattern development. This includes the development of an integrated observation and analysis strategy, focusing on large-scale changes in vulnerable areas of Europe. Geoprediction in poly-phase deformed and tectonically active orogenic systems requires multidisciplinary efforts and, therefore, the interaction and collaboration of researchers covering a broad field of expertise. Among other eminent scientific disciplines, geology, geophysics, geodesy, hydrology, climatology, as well as various fields of geotechnology will be integrated. TOPO-EUROPE will address several scientific issues of key relevance, such as:

(i) the 4-D development of Europe's topography;

(ii) the quantification of source-to-sink relations to quantify sediment budgets; (iii) the quantification of land subsidence in the basins and deltas of Europe;

(iv) the quantification of land uplift in orogenic and intraplate domains;

(v) the quantification of tectonically controlled river evolution; and

(vi) the effects of climate changes.

This paper aims at giving an overview on continental topography research, its future challenges and expected breakthroughs. Its first part summarizes old and new methods and techniques available to TOPO-EUROPE researchers. Its second part discusses the state of research in some of the 'natural laboratories' that have been selected as targets for TOPO-EUROPE research during the next 10 year. In the third part of this paper the TOPO-EUROPE science plan is presented, including specific targets and expected deliverables of the programme in the years to come.

\section{Scientific approach: monitoring, imaging, reconstruction, process modelling}

To trace, quantify and forecast the evolution of topography in response to Solid-Earth processes and movements of surface waters, it is essential that researchers proficient in a wide range of sub-disciplines interact and collaborate. TOPO-EUROPE researchers will endeavour to convolve the results of geomorphologic, geological, geophysical, geodetic, remote sensing and geotechnologic investigations. Such an integrated, multidisciplinary approach has yet to be implemented on a truly European scale. A consortium of national research centres, geoscience institutes of universities and national geoscience surveys, each with proven strengths and capabilities in distinct scientific fields, will come together to develop research strategies that aim at an improved understanding of Europe's dynamic topography and enhanced forecasting capabilities. Twin goals are (i) to simulate the recent past by "inverting" geological data and (ii) to forecast the future by connecting the past, present and future evolution of the system as a whole. TOPO-EUROPE is linked via its members to a series of programs that focus on specific aspects of European topographic evolution (Fig. 4). Certain research activities are directed by regional groups, addressing sensitive areas such as densely populated river basins, lowlands, low lying flood-and/or tsunami-prone coastal areas, subsiding deltas and earthquake-prone areas.

The main progress in quantitative prediction is expected at the interface of modelling and observation where scientific hypotheses are confronted with the observed reality. In its most advanced version, the integrated sequence "observation, modelling, process quantification, 


\begin{tabular}{|c|c|c|}
\hline Area & Why & How \\
\hline $\begin{array}{l}\text { The Alps/Carpathians-Pannonian Basin } \\
\text { System }\end{array}$ & $\begin{array}{l}\text { Mountain building and the development of } \\
\text { deep continental basins have created } \\
\text { Europe's weakest crust, prone to major } \\
\text { earthquakes, land slides and flooding. }\end{array}$ & $\begin{array}{l}\text { Coupling surface to deep processes for } \\
\text { innovative reconstruction and for modeling } \\
\text { landform evolution }\end{array}$ \\
\hline The Western-Central European Platform & $\begin{array}{l}\text { In this region the continent is breaking apart, } \\
\text { land is subsiding below sea level and much } \\
\text { of Europe's population and infrastructure are } \\
\text { concentrated }\end{array}$ & $\begin{array}{l}\text { Multi-scale seismic imaging, monitoring and } \\
\text { modeling of environmental (neo-)tectonics }\end{array}$ \\
\hline $\begin{array}{l}\text { The Aegean-Anatolian and Apennines- } \\
\text { Tyrrhenian regions }\end{array}$ & $\begin{array}{l}\text { Seismicity, volcanism and mountain building } \\
\text { in the region result from the ongoing collision } \\
\text { of the European and African-Arabian plates } \\
\text { during the final closing stages of an ocean. }\end{array}$ & $\begin{array}{l}\text { From deep structure to the surface for large- } \\
\text { scale process understanding }\end{array}$ \\
\hline The Iberian Peninsula & $\begin{array}{l}\text { Discrimination is needed between deforma- } \\
\text { tions induced by plate boundary forces and } \\
\text { by deep-seated thermal anomalies }\end{array}$ & $\begin{array}{l}\text { Detailed imaging of the upper mantle } \\
\text { (PICASSO-project) and coupling to surface } \\
\text { processes }\end{array}$ \\
\hline The Scandinavian Continental Margin & $\begin{array}{l}\text { Continental rupturing resulted in opening of } \\
\text { an oceanic basin and the development of } \\
\text { ocean-continent boundary zones rich in } \\
\text { hydrocarbons. }\end{array}$ & $\begin{array}{l}\text { Constraining and modeling differential } \\
\text { vertical motions and continental break-up } \\
\text { mechanisms at ocean-continent boundaries }\end{array}$ \\
\hline The East-European Platform & $\begin{array}{l}\text { Ancient tectonic analogues of modern } \\
\text { geodynamic processes and on-going } \\
\text { subsidence of the southern margins. }\end{array}$ & $\begin{array}{l}\text { Imaging the detailed structure of the upper } \\
\text { mantle to evaluate the effect of deep mantle } \\
\text { processes on reworking of lithosphere }\end{array}$ \\
\hline The Caucasus and the Levant & $\begin{array}{l}\text { Interaction between continental collision and } \\
\text { continental extension }\end{array}$ & $\begin{array}{l}\text { Source-to-Sink reconstructions of uplift, } \\
\text { erosion, sedimentation and differential } \\
\text { topography development }\end{array}$ \\
\hline $\begin{array}{l}\text { Analogues, such as the Andes, the western } \\
\text { USA and the Middle East }\end{array}$ & $\begin{array}{l}\text { Regions where processes analogue to those } \\
\text { in Europe result in contrasting topographic } \\
\text { expressions }\end{array}$ & $\begin{array}{l}\text { Effects of tectonics/climate interaction on } \\
\text { topographic expression }\end{array}$ \\
\hline
\end{tabular}

Fig. 4. Examples of TOPO-EUROPE natural laboratories, focusing on specific aspects of European topographic evolution (see Section 3 for detailed descriptions).

optimization and prediction" is repeatedly carried out, both in time and space. Such an iterative approach is vital for the development and verification of fundamentally new concepts.

The TOPO-EUROPE research approach centres on the following four interrelated components:

Component 1 'Monitoring the Earth system'.

Component 2 'Imaging and high-performance computing of the deep Earth and lithosphere'.

Component 3 'Dynamic topography reconstruction'.

Component 4 'Process modelling and validation'.

These four components are inherent to the very nature of the Earth sciences, placed in the context of recent advances and challenges in science and technology. The relationship between the present and the past has - in a qualitative way - always been at the heart of Earth sciences. Owing to recent developments in observational, analytical and computational capabilities, this fundamental relationship can now be addressed in a quantitative manner. Within individual TOPO-EUROPE groups, this has already resulted in a number of pioneering contributions to the integration of observational and modelling studies.
In the TOPO-EUROPE network, the full coupling between processes in the mantle and lithosphere with those active at or near the Earth's surface will be further pursued, particularly in sedimentary basins, at continental margins and in tectonically active intraplate areas. Understanding these processes and their coupling is of fundamental importance in the exploration for and the management of Earth resources and the risk reduction of geological hazards, like landslides and earthquakes. By striving for a close cooperation with the industry, TOPOEUROPE will be able to contribute to a closer interaction between fundamental and applied geosciences. Research objectives and potential frontier science opportunities of the four components are presented below.

\subsection{Component 1 'Monitoring the Earth system'}

One of the major challenges of Solid-Earth research concerns establishing quantitative "depth-to-surface" relations, namely the relationship between present-day surface deformation and processes affecting the lithosphere and sub-lithospheric mantle. Addressing surface deformations is fundamental for detailed studies of plate collision zones, intraplate stress and strain, sedimentary 
basin development, earthquake-induced deformation, seismic and volcanic hazard assessment and prediction, and relative sea level changes.

To understand dynamic processes within the Earth we need to know its physical parameters, composition and temperature-pressure conditions. Actual space geodetic measurements of plate motions and deformations provide direct information about such processes. The resolution of these methods has improved so much in recent years that it is now possible to accurately determine rates of ongoing horizontal and vertical motions of the Earth's surface. The multidisciplinary approach of TOPOEUROPE permits to integrate this information with new high-resolution images of the Earth's interior in 2, 3 and even 4 dimensions (component 2), and with past rates of geological processes (component 3).

\subsubsection{Existing data and maturity of the research field}

Digital databases containing information on the topography and the Earth structure of Europe have been steadily growing. High-resolution digital terrain models are readily available for some countries, but are either non-existent or of very low resolution in others. Geological, tectonic, gravimetric and magnetic maps cover most regions of Europe, but the quality and density of observations is highly variable. Regional scale information is available on the European geodetic field and the electrical properties of the Solid Earth under our continent. In selected areas, targeted research projects have provided comprehensive details on land uplift and subsidence rates and more complete subsurface electrical resistivity data. Hydrological and geotechnical information is usually collected and interpreted at local levels, leaving large areas with only poor coverage.

Basic information on the Earth's structure and the distribution of seismic parameters beneath large tracts of Europe has already been gathered from numerous active seismic refraction and reflection surveys and passive tomographic experiments, and from extensive seismic monitoring networks. An important limitation on tomographic images is their dependence on the reliability of generally poorly constrained background models. Furthermore, existing images either have low resolution or cover only relatively local structures. The quality of regional scale models suffers from a non-uniform distribution of seismological stations, and consequently from highly variable and limited spatial resolution.

To meet the ambitious objectives of TOPO-EUROPE, information on European topographic and geodetic field, electrical, thermal and seismic properties, and hydrological conditions needs to be significantly enhanced. Not only is improved information on the spatial distributions of these parameters required, but also on their temporal variations. These requirements, as well as the dependence of tomographic interpretations on chosen reference models and on a more uniform distribution of seismological stations, can only be met by considerably increasing the density and quality of satellite- and Earthbased observation networks.

TOPO-EUROPE has at its avail or will acquire:

- new information from several large observation and monitoring programs based on satellite, surface and borehole measurements;

- excellent geomechanical, geochemical and geobiological laboratory facilities;

- expanding databases containing historical data on global and regional changes of key parameters combined with improved information on the vulnerability of natural and human habitats;

- state-of-the-art computational facilities for numerical modelling of 4-D fluid and solid dynamical systems, including advanced parallelised computers and sophisticated process modelling software;

- outstanding research teams with expertise in geomorphology, geology, geophysics, geodesy, remote sensing, geotechnology, and know-how at the forefront of combined numerical and analogue modelling of dynamic processes and hazard assessment.

Co-operation with the astrophysical community will provide the TOPO-EUROPE research network with access to an ultra-high speed pan-European glass fibre network and massive computing power. This permits rapid data transmission between the TOPO-EUROPE natural laboratories collecting large amounts of new data. The availability of facilities and databases, and the scientists' intention to contribute to an integrated research program will set the stage for a highly competitive European position in continental topography research. Significant additional strategic data will be acquired under the auspices of TOPO-EUROPE. In fact, the need for high-quality and continuous databases and time series can hardly be underestimated, as today we generate the basis for future analyses, modelling and decisionmaking.

\subsubsection{Monitoring surface motion with GPS and Galileo}

In Europe, the number of high quality GPS stations, the time series they provide and their precision has steadily increased over the last years. Furthermore, the recently started GALILEO project of European satellite systems will in the future provide access to fundamental data on contemporary kinematics and deformation of the 
Earth's surface (Fig. 5). These observations will have a major impact on qualitative and quantitative research on geodynamic processes and physical properties of the crust and upper mantle by delivering independent constraints on the boundary conditions and rheological properties of numerical models of plate tectonic forces (Fig. 6). Since GPS data first became available, numerical modelling research also commenced. Only recently however, increased computer power has permitted to construct high resolution numerical models that reflect the geometrical complexity of the crust and its heterogeneous material properties. GPS data will play a major role in the 4th generation of seismic hazard assessment. Here, 4-D deterministic numerical models of stress evolution will permit to quantify stress concentrations in the seismogenic crust and their evolution on time scales of several seismic cycles.

To accurately use GPS signals as independent constraints for numerical stress evolution models, the causes of these signals need to be fully understood and quantified. In seismogenic regions, first order contributions to the GPS signal come from two groups of sources acting on different spatial and time scales, namely from (1) tectonic plate boundary forces, such as slab pull, ridge push, gravitational collapse of elevated regions and mantle drag, and (2) co-seismic displacements (Fig. 7). In seismogenically active intraplate regions, extensional and compressional intraplate deformations, including lithospheric folding may also contribute to the signal.

Second order causes involve a wide range of other processes such as visco-elastic relaxation of co-seismically induced stress changes in the lower crust and upper mantle (e.g. Hergert and Heidbach, 2006), after slip and after creep (e.g. Melbourne et al., 2002), silent slip (e.g. Douglas et al., 2005), poroelastic rebound (e.g. Cocco and Rice, 2002), and mass redistribution due to deglaciation, sedimentation and erosion (e.g. Fischer et al., 2004). In relatively stable regions, characterized by low

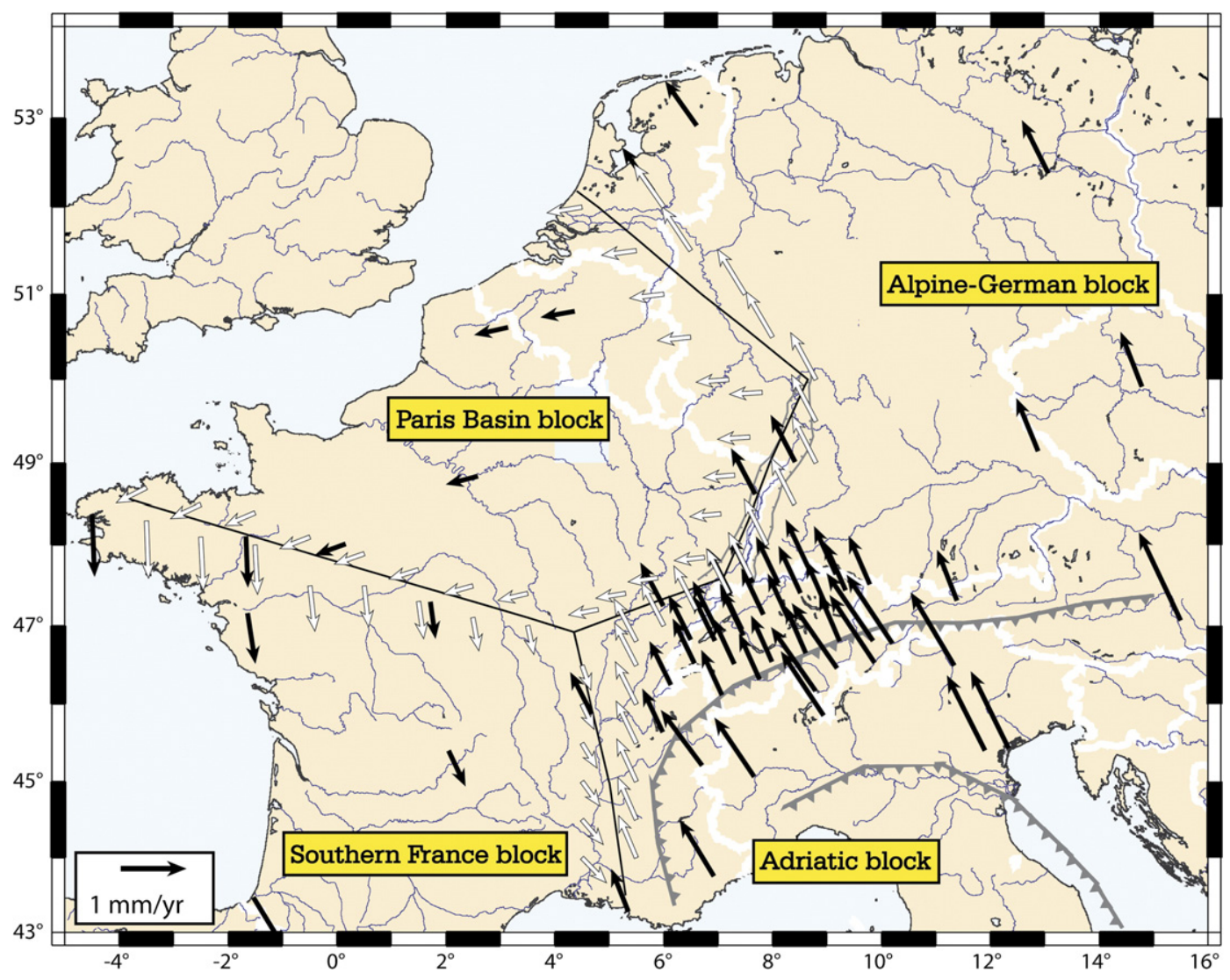

Fig. 5. Velocities of crustal motion for a four-block model of Europe calculated by least-squares estimation. The velocities at permanent GPS stations are shown as black arrows, while rates at virtual points, taken $50 \mathrm{~km}$ on average close to the border of the blocks, are shown as white arrows. Black lines represent the generalized borders between the Alpine-German block in the NE, the Paris Basin block in the NW, and the Southern France block in the SW, while the Alpine chain is taken as the border between the Alpine-German block and the Adriatic block in the SE. White contour lines denote the national borders (after Tesauro et al., 2005). 


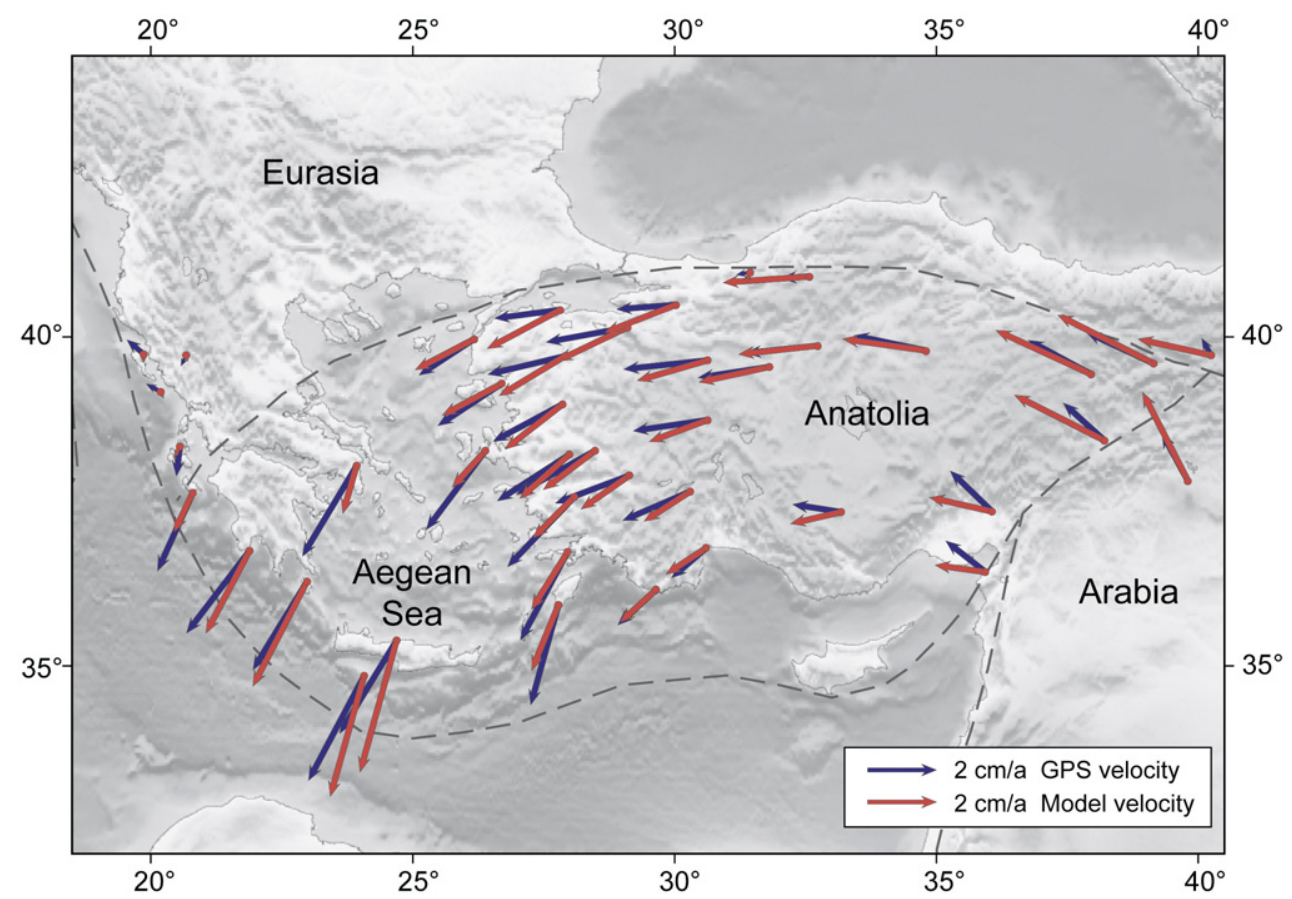

Fig. 6. Comparison of GPS observed velocities in the Eastern Mediterranean relative to a fixed Eurasia plate (McClusky et al., 2000) with results of a 3D numerical model with non-linear, temperature controlled visco-elastic-plastic rheology (Heidbach and Drewes, 2003). The model is driven by slab pull forces, the indentation of the Arabian plate into the Eurasia plate and gravitationally induced body forces due to the changing Moho depth. Major results are that trench suction due to roll-back of the Hellenic arc and collisional forces are required to promote lateral extrusion of the AnatoliaAegean complex, as observed by the GPS data.

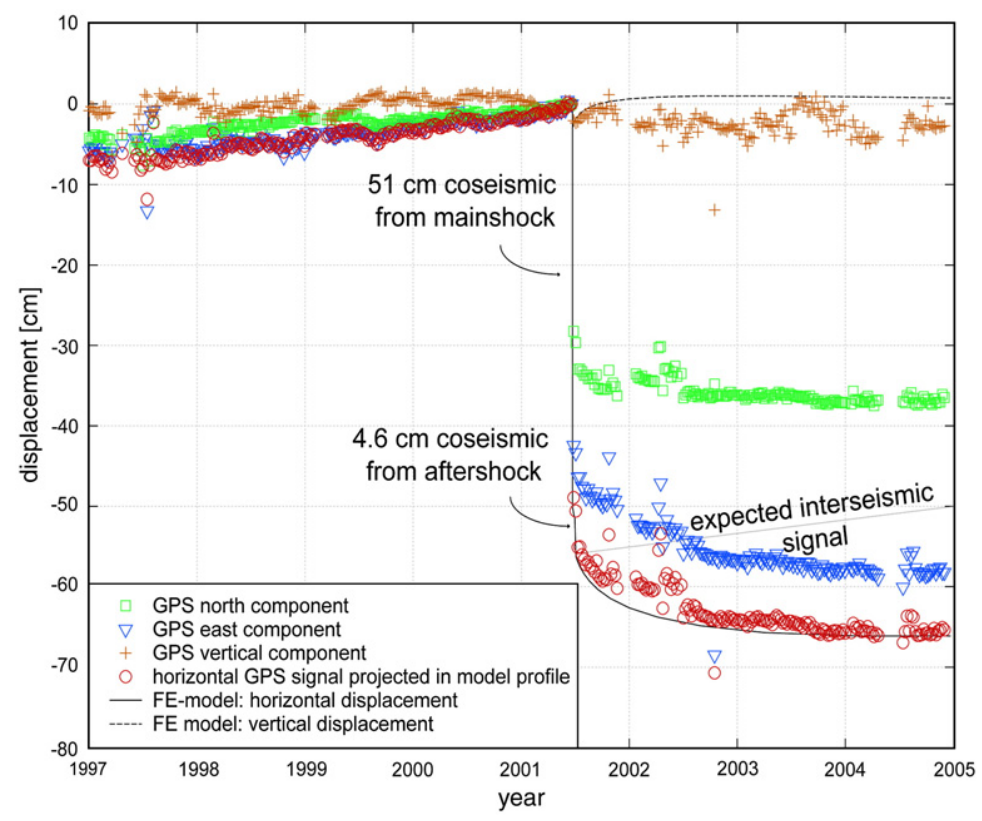

Fig. 7. Observations at the permanent GPS station Arequipa in Peru before and after the June $2001 \mathrm{Mw} 8.4$ earthquake in South-Peru. Interseismic (tectonic) movement, co-seismic displacement and post-seismic signal are clearly distinguishable. The results of a 2-D finite element model can explain the unexpected post-seismic signal with the relaxation of tensional stresses in the lower crust and upper mantle (Hergert and Heidbach, 2006). GPS data were provided by the German Geodetic Research Institute (DGFI) in Munich (Wolfgang Seemüller, personal communication, 2005). 
seismicity, first order mechanisms play a subordinate role whilst second order processes are probably the driving mechanism of displacements.

Incorporation of time series from dense networks of continuously observing GPS stations permits to set up 4-D numerical stress evolution models for time-dependent seismic hazard assessment. Currently the European permanent GPS station network of EUREF consists of 189 stations. In addition, a large number of regional and local networks is available, which provide additional detailed kinematics data (McClusky et al., 2000; Roberts and Ganas, 2000; Bürgmann et al., 2002; Calais et al., 2002; Caporali et al., 2003; Fernandez et al., 2003; Hollenstein et al., 2003; Lenk et al., 2003; Van der Hoeven et al., 2004; Wdowinski et al., 2004; Tesauro et al., 2005).

\subsubsection{Novel geoscientific technology, key to a TOPO- EUROPE database}

TOPO-EUROPE researchers will benefit from new fundamental geoscientific technologies and significant refinements to existing methods and analytical techniques that have been introduced over the past decade. For example, data provided by the CHAMP, GRACE and ØRSTEDT and later-on GOCE and SWARM geophysical satellites will provide new insights into the European magnetic, gravimetric and geodetic fields (Fig. 8). Combinations of synthetic aperture radar (SAR, InSAR), global positioning (GPS and GALILEO) and related satellite-based data will permit to monitor local-, regionaland continental-scale changes in surface topography with unprecedented precision. Additionally, the geophysical satellites provide an opportunity to detect density and temperature inhomogeneities governing the dynamics of surface deformations. Near-instantaneous movements of land caused by earthquakes, rock falls and collapsing underground mines, as well as much slower natural and anthropogenic-generated subsidence can be resolved. A better understanding of active tectonic processes requires improved characterizations of active deformation. In addition to information provided by satellite-based observations, geological and geophysical mapping of the shallow and deep geometry of seismogenic faults and analysis of fault kinematics and slip rates over geological and historical time scales is required. Shallow underground variations, including ground-water flow, will be monitored using novel surface and borehole hydrological and geophysical methods. TOPO-EUROPE plans to incorporate innovative methodologies and datasets such as semiautomated processing of ARES (Airborne hyperspectral sensor) reflective and emissive data, extraction and fusion of spectral and spatial information, spectral mixture modelling and quantification, multi-temporal modelling and change detection, and improved InSAR processing for detection of land subsidence and uplift.

\subsection{Component 2 'Imaging and high-performance computing of the deep Earth and lithosphere'}

Information on the present-day structure of the Earth's crust (Fig. 9) and its deeper interior (Fig. 10) at various scales is of fundamental importance to the Solid-Earth sciences. Close constraints on the crustal and mantle structure permit to model presently active internal processes, as well as processes that have ceased to be active, the memory of which is preserved in the present-day configuration of the crust and lithospheric mantle (connection to components 3 and 4). Controls on the gravity field and internal structure of the Earth, combined with monitoring of active processes (e.g. earthquake activity, surface deformation) play an important role in this component - and in TOPO-EUROPE in general - by providing constraints for modelling (component 4 ) of the past and present dynamic state of the crust and mantle system and underlying processes. Information on the detailed history of the crust-mantle system provides the backbone for paleo-topography reconstructions (component 3) and for explaining controls on present-day surface topography (component 1).

\subsubsection{Seismology and seismic imaging - EUROARRAY}

During the past decade, the analysis and understanding of dynamic crust-mantle processes has greatly progressed owing to major advances in the field of seismic tomography at global and regional scales (e.g. Bijwaard et al., 1998). Tomographic imaging techniques are applied to observations of body and surface waves, and provide spectacular 3-D images of mantle structures. These images can readily be linked to global plate tectonic processes, such as past and active subduction of lithospheric plates (Fukao et al., 2001). Tomographic evidence for mantle plumes originating at great depth (Bijwaard and Spakman, 1999; Goes et al., 1999; Romanowicz and Gung, 2002; Montelli et al., 2004) suggests links between mantle plumes and such surface processes as intra-plate volcanism, rifting and vertical surface motions.

For the European-Mediterranean domain, recently developed tomographic models of mantle structure (e.g. Piromallo and Morelli, 1997; Bijwaard et al., 1998; Spakman et al., 1999; Bijwaard and Spakman, 2000; Piromallo and Morelli, 2003) have greatly advanced the linking of lithosphere-mantle processes to the past and on-going tectonic evolution of the Earth's crust (Fig. 11). 


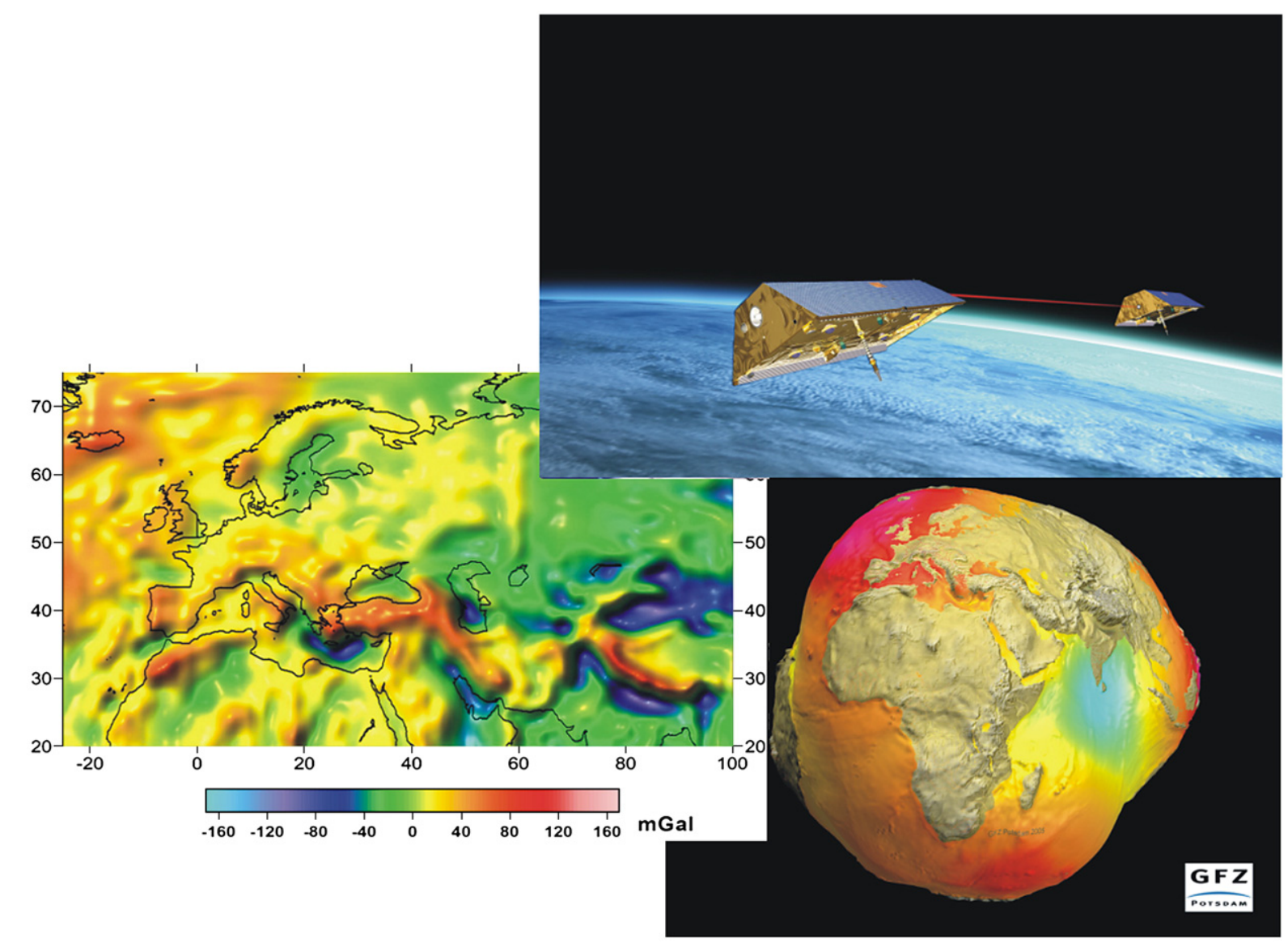

Fig. 8. Recent (micro-) satellite missions, in part coordinated by TOPO-EUROPE partners, have led to great improvements in the resolution of gravity measurements. Picture shows an artists' impression of the GRACE satellites and gravity models of Europe and the Earth (Courtesy GFZ-Potsdam).

Conceptual models of mantle dynamics derived from tomography and analogue lab-models emphasize the role of a variety of mantle processes as driving mechanisms of major tectonic processes, the mechanical evolution of the lithosphere, and surface deformations (e.g. Wortel and Spakman, 2000; Bellahsen et al., 2003; Faccenna et al., 2003; Faccenna et al., 2004; Funiciello et al., 2004; Spakman and Wortel, 2004; Van Hinsbergen et al., 2005a; Faccenna et al., 2006).

European-scale tomographic models are based on a global observation network of seismological stations with a very heterogeneous spatial distribution. This leads to a strongly non-uniform data density and consequently to a strong spatial variability in model resolution varying between $50 \mathrm{~km}$ and hundreds of $\mathrm{km}$. In some regions of Europe, temporary seismological networks with a dense spatial distribution $(30-60 \mathrm{~km})$ were installed during the past decades for relatively short periods of 6 months to $1 \mathrm{yr}$ in order to address specific phenomena (e.g. Massif Central [Southern France], TOR [Sweden, Denmark, northern Germany], SVEKALOPCO [Finland], EIFEL [Eastern France, Western Germany], CALIXTO [Vrancea, Romania]). These and other successful experiments targeted important lithospheric transition zones, mantle plumes and subduction zones. Importantly, these experiments demonstrated the presence of detailed $(10-30 \mathrm{~km})$ crust-mantle structure associated with dynamic processes affecting surface deformation. This was only possible owing to the high resolving power that can be attained with dense observation networks. The short period of network employment, however, restricted the data volume, whilst the spatially localized nature of these experiments has prevented to obtain a contextual image of mantle structure and processes. Furthermore, by the very nature of the tomographic experiments conducted, mantle structure could only be imaged relative to an unknown background of absolute wave speed.

The shortcomings of continental-scale tomographic experiments and of local experiments with dense temporary networks can only be overcome by acquiring 


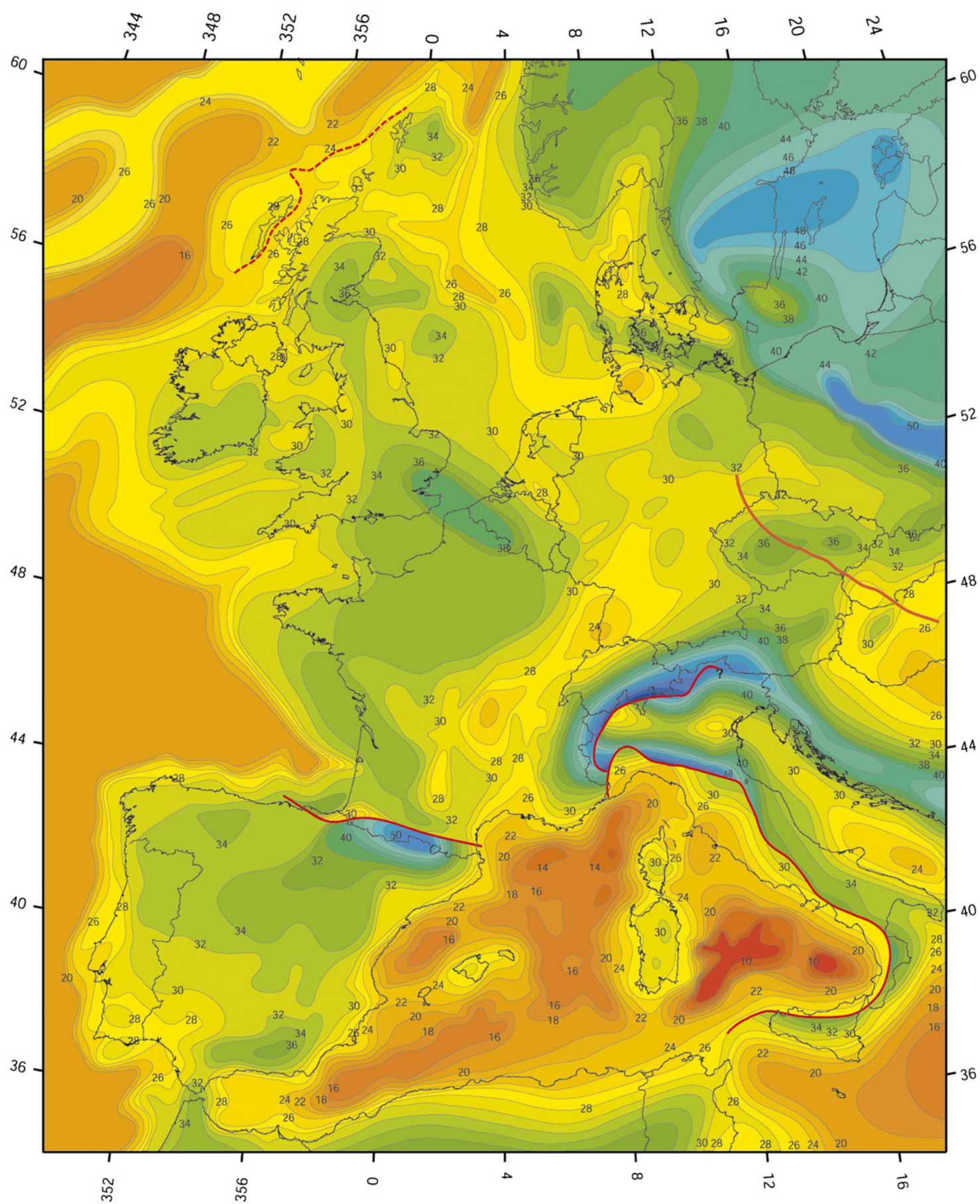

䜣

$\begin{array}{llllllllllllllllllllllllllll}10 & 12 & 14 & 16 & 18 & 20 & 22 & 24 & 26 & 28 & 30 & 32 & 34 & 36 & 38 & 40 & 42 & 44 & 46 & 48 & 50 & 52 & 54 & 56 & 58 & 60 & 62 & \text { Kilometres }\end{array}$

Projection: Lambert Azimuthal Equal Area; Centre: $04^{\circ} .00^{\prime \prime} / 48^{\circ} .00^{\prime \prime}$; Region : W/E/N/S = 350 $/ 28^{\circ} / 62^{\circ} / 34^{\circ}$; Ellipsoide wgs-84

Fig. 9. Depth (km) to the Mohorovicic discontinuity, obtained from an integration of geophysical data. Data sources are listed on http://compl.geol.unibas.ch/ (after Dèzes et al., 2004). 

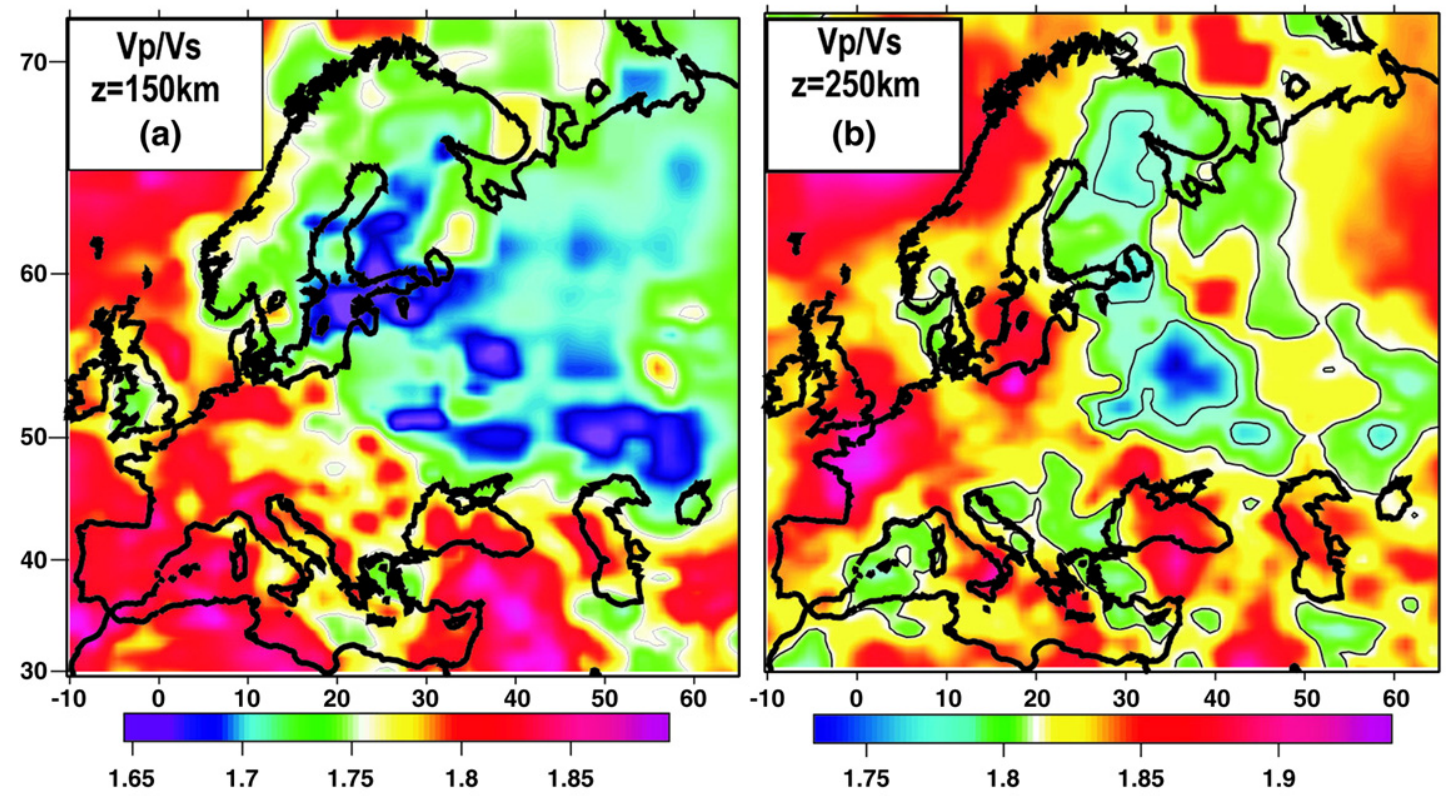

Fig. 10. Vp/Vs at (a) $150 \mathrm{~km}$ and (b) $250 \mathrm{~km}$ depth calculated from smoothed and filtered P-wave (Bijwaard and Spakman, 2000) and S-wave (Shapiro and Ritzwoller, 2002) tomography models for Europe. Variations in Vp/Vs ratio suggest differences in lithospheric composition (after Artemieva, 2006).

observations from a spatially more uniform and dense European network. A considerable densification and extension of the existing European seismological network would allow the development of a new generation of crust-mantle models based on surface wave and body wave data with a much more homogeneous spatial resolution. Models will be obtained in absolute wave speeds giving strong constraints on the temperature and compositional fields of the mantle, and on associated mantle processes. Highly improved crust-mantle models (temperature and composition) are a fundamental prerequisite for numerical modelling of crust-mantle processes and the resulting surface deformation both for reconstruction of topography and for establishing the current dynamic state of European topography (surface motions, state of stress and strain-rate build-up). Technologically, tomographic methods are advanced enough to deal with a heterogeneous crust, ray bending effects, finite frequency effects, and even 3-D reference models of the Earth's structure. The forward leap towards much more advanced models is only hampered by the (spatial) availability of data.

A very important part of a new generation of structural crust and mantle models are the discontinuities in material properties that occur around the crust-mantle interface (the Moho; a compositional transition as well as the granulite-eclogite transition), around $410 \mathrm{~km}$ depth (dominated by the olivine to spinel transition) and around $660 \mathrm{~km}$ depth (dominated by the spinel to lowermantle-oxides transition). Special seismological techniques can be used, and developed, to detect the topography and sharpness of these (and related) phase transitions, the precise nature of which is still a matter of active research. Receiver Function analysis of seismic data has proved to be a powerful method for the detection of the phase transition interfaces (e.g. Vinnik et al., 1996; Kind et al., 2002). The topographic configuration of these discontinuities is in fact dynamic, owing to the interaction of mantle flow (slabs, plumes) impinging on these interfaces with the physics of phase transitions. Dynamic surface topography is strongly diagnostic for the type and local nature and thermal characteristics of mantle flow. In long-wavelength mantle flow models, the dynamic surface topography is related to the dynamic topography of the internal surfaces. One of the key problems in understanding surface topography is the interaction between the mantle induced dynamic topography and other (shallow) topography generating processes.

Studies on mantle rocks, both xenoliths and tectonically emplaced samples, show that the mantle is heterogeneous at all observable scales, down to crystal dimensions. Recent seismological studies have shown that it is possible to image crustal and mantle structures and to determine their physical properties on a kilometer scale or finer, much smaller than the seismic wavelength. 


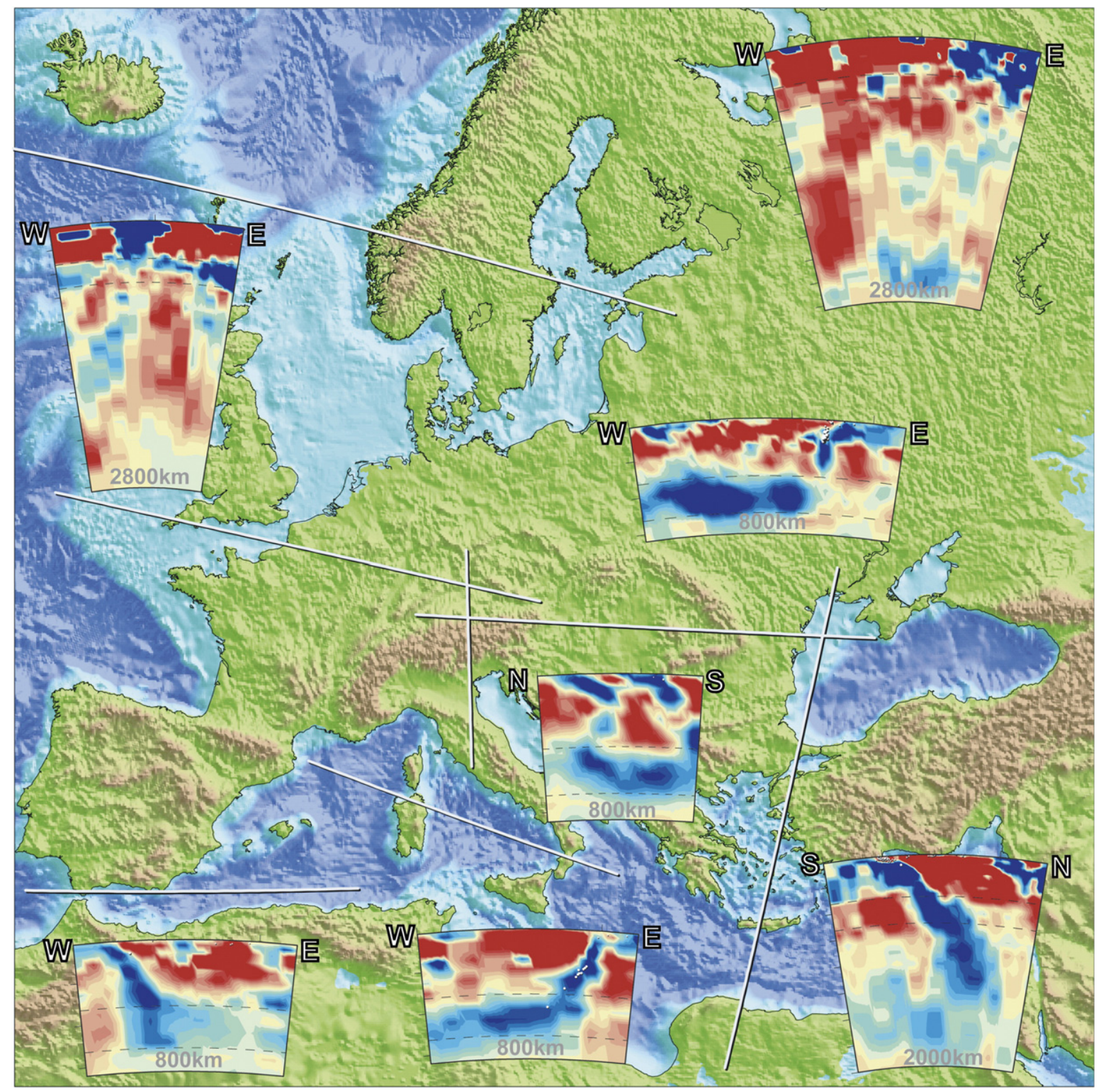

Fig. 11. Tomographic cross sections through key parts of the European continent (after Spakman et al., 1999).

Only recently, methods have been developed for extracting information on fine-scale heterogeneity of the crust and mantle from seismic data at scales which require a statistical representation of physical parameters (e.g. Holliger and Levander, 1994; Thybo and Perchuc, 1997; Ryberg et al., 2000; Nielsen et al., 2002; Baig and Dahlen, 2004; Shearer and Earle, 2004; Thybo, 2006; Thybo and Anderson, 2006). These methods push the attainable resolution below the usual detection limit, although they cannot provide unique solutions for the structure of the Earth.
New-generation models of the crust-mantle system can only result from a concerted effort of seismic tomography research, strong seismic-contrast and dynamictopography research, and fine-scale imaging of crustal and mantle properties (Fig. 12). For TOPO-EUROPE, such seismological studies can provide the principal source of information on the detailed structure of the European crust-mantle system. Data from existing global networks (FDSN, IRIS, GEOFON, EarthSCOPE) and from existing European networks are, however, insufficient to make the necessary step forward toward 

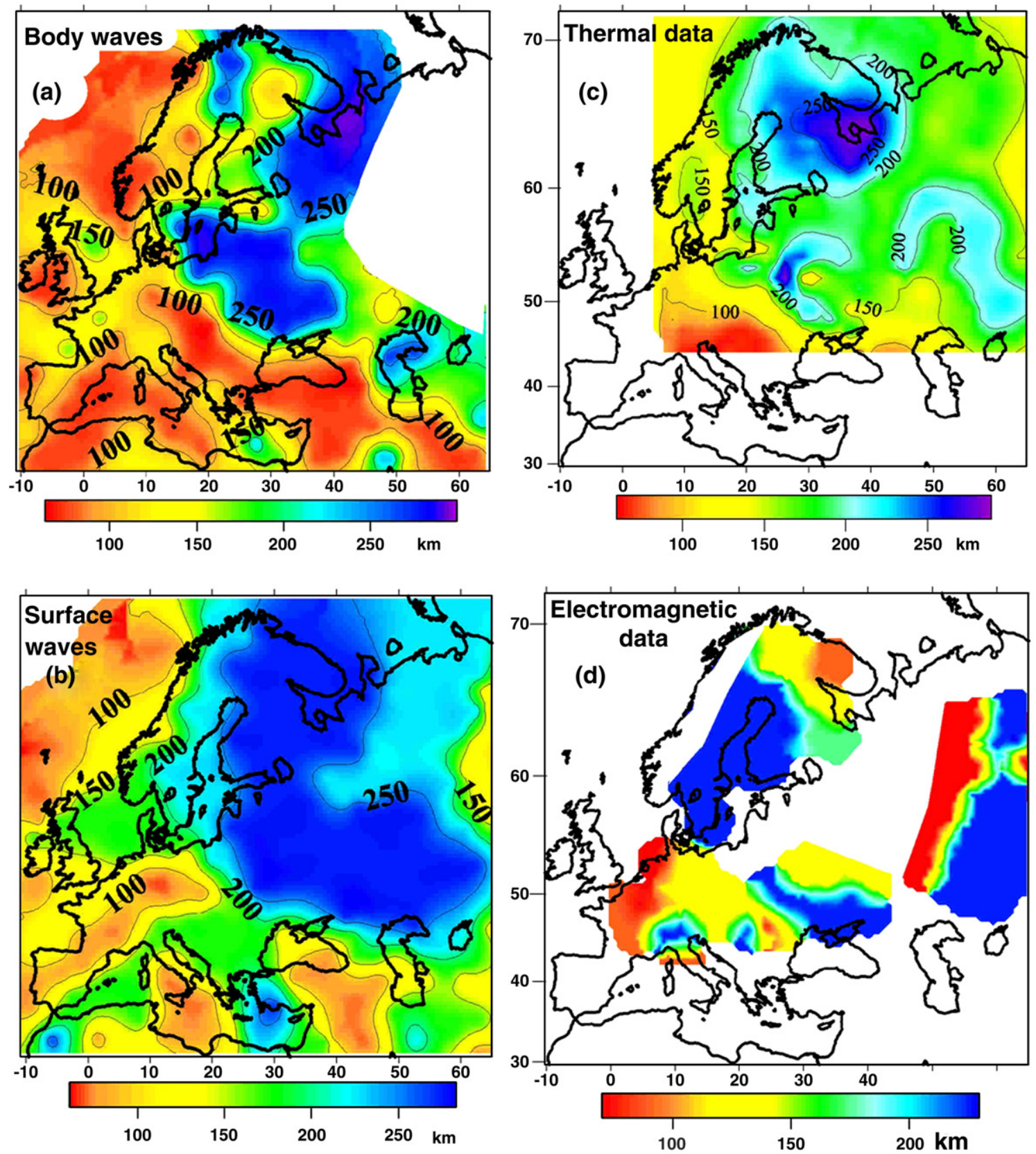

Fig. 12. Thickness of the European lithosphere as determined by (a) seismic tomography; (b) surface wave tomography; (c) geothermics; (d) magnetotellurics (after Artemieva et al., 2006).

the development of much more detailed crust-mantle models. This requires a much denser observation network, complementing the existing European seismological infrastructure. As a component of TOPO-EUROPE, the project EUROARRAY aims at developing such a dense network for monitoring surface deformations and acquiring Solid-Earth geophysical data all across Europe. Eventually, a spatially uniform and dense network
(60 km spacing) of co-located GPS, magnetotelluric and seismological instruments will complement existing European instrumentation for a wide variety of scientific purposes. EUROARRAY aims specifically at densification of the existing European seismological network that forms the backbone of the EU-funded seismological NERIES project. In addition, a dense roving network of co-located geophysical instruments is geared to focus on 
surface deformations and the subsurface structure of key areas of the TOPO-EUROPE natural laboratories (Section 3). In the spirit of TOPO-EUROPE, the EUROARRAY initiative will promote organisational and scientific collaboration across Europe for the benefit of the multidisciplinary Solid-Earth science community, implementing the latest in high-technology European infrastructure and providing an open data policy. The anticipated boost in quality, quantity and availability of data achieved through EUROARRAY will effectuate strong technological and methodological innovation, allowing Europe to maintain its internationally leading role in Solid-Earth sciences.

The existing international seismic network, complemented by a growing EUROARRAY of co-located instruments, combined with existing state-of-the-art analysis and new seismological very high resolution modelling techniques, will reveal the internal structure of Europe's lithosphere and sub-lithospheric mantle with unprecedented detail. This will permit to develop advanced tomographic models for the European lithosphere and mantle, greatly improving on presently available models:

- Determination of the detailed crustal structure beneath each station will lead to a high-resolution crustal model.

- Mantle heterogeneities will be revealed at scales exceeding the traditional resolution limit and with a much-improved, uniform spatial resolution.

- Dynamic topography of seismic discontinuities and the thickness of transition zones will be accurately and uniformly determined, allowing for the explicit detection of vertical mantle flow and associated temperatures.

- The lithosphere-asthenosphere boundary, lateral variations in lithospheric structure, and large lithospheric shear zones on which deformation concentrates, can be detected.

- Subducted lithospheric slabs, mantle plumes, and their relation to crustal structure and major continental deformation zones can be delineated in detail.

- Uniform sampling of the mantle permits detection of seismically anisotropic structures, which will in turn allow distinguishing between deeper mantle flow directions and anisotropy frozen in the lithospheric mantle.

Apart from its own merits, a new-generation model of crustal and mantle structure will provide the necessary input for advanced modelling of the European crustmantle system constrained by high-resolution satellite gravity and geodetic observations of active surface deformation. This provides the "depth-to-surface" relations required for the reconstruction of mantle induced surface topography. The current generation of tomographic models can and will, within limitations, be exploited for this purpose during the early phases of TOPO-EUROPE and for the development of 4-D modelling techniques of crust-mantle dynamics. This will work out well for some selected regions where current tomographic resolution is relatively high (e.g. Apennines-Aegean-Anatolia), but will lead to ambiguous results for Western, Central and Northern Europe where the spatial resolution is much lower. In parallel, EUROARRAY will focus on developing the Earth observation data-platform required for near-future SolidEarth science and topography research.

\subsubsection{Industrial reflection seismology}

During the last decades the international oil and gas industry has invested billions of dollars in advancing the science and technology of reflection seismology. Today, very advanced seismic recording instrumentation, processing technologies and very advanced seismic imaging algorithms generate astonishingly well-resolved and accurate images at a large depth range $(0.1-10 \mathrm{~km})$. Using state-of-the-art 3-D seismic imaging of today, it is possible to obtain a 3-D data cube representing the Earth below the plane of seismic measurements. 2-D depth slices through such data cubes are of such quality that geologists can readily interpret them in terms of depositional history and structural evolution. Time series of 3-D seismic cubes ("4-D time lapse seismics") can even provide information on the temporal evolution of a geological structure, e.g. as a result of hydrocarbon extraction or of $\mathrm{CO}_{2}$ injection.

On the other hand, a priori geological information is a requisite for constraining geophysical operations. A major task of sedimentary geologists in TOPO-EUROPE will be to formulate depositional models on the base of available borehole and seismic data that can be iteratively tested by reflection-seismic data sets. Notwithstanding the success of the seismic method, passive potential-field methods, such as gravity surveying and geomagnetic techniques, are valuable tools for prospecting deep sedimentary basins in which it is difficult to obtain high-quality reflection-seismic data. The reflection-seismic and potential-field methods complement each other. The seismic method delineates horizontal and vertical density and velocity contrasts, while gravity and geomagnetic data image only vertical density and magnetization discontinuities, respectively. Moreover, the seismic and potential-field methods differ in the scale of their resolution. Potential-field methods 
can provide first approximation information on the distribution of igneous rocks, the depth to crystalline basement, the thickness of sedimentary strata, and potentially the location of deep-seated structures.

\subsubsection{Crustal-scale reflection and refraction seismology}

During the last decades a large number of crustalscale reflection-seismic surveys were carried out in Europe, using many geophones in short aperture arrays, that successfully imaged the deep structure of orogenic belts, sedimentary basins, the fabric of cratonic crust, the crust/mantle boundary, and in places upper mantle reflectors (e.g. Hobbs and Klemperer, 1991; BABEL Working Group, 1993; MONA LISA Working Group, 1997; DEKORP-BASIN Research Group, 1998). In combination with extensive refraction-seismic data, providing information on the crustal and upper mantle velocity structure, and potential-field data, this has greatly advanced the understanding of the configuration and evolution of Europe's continental crust, and particularly of the transformation of orogenically destabilized crust into stabilized cratonic crust (e.g. Aichroth et al., 1992; ILIHA DSS Group, 1993; Guterch et al., 1999; Carbonell et al., 2000; Maystrenko et al., 2003; Thybo et al., 2003).

Continued technological advance, especially in the Earth Science community's capabilities to process and model seismic (and other geophysical) data, has led to many new conceptual and quantitative breakthroughs in the field of lithosphere tectonics. New data sets, collaboratively collected and interpreted in targeted multidisciplinary projects, allowed participants to actively integrate the geophysical data with geological surface and subsurface mapping. Particularly relevant to the TOPO-EUROPE programme has been the realization that the reactivation potential of pre-existing crustal discontinuities plays an important role in the deformation of intraplate domains, both under compressional and extensional stress regimes. Correspondingly, identification of such crustal discontinuities is of great importance in terms of localization of neotectonic deformation and the assessment of underlying controlling processes.

\subsubsection{Permanent Seismic Monitoring with LOFAR/BEL}

The Dutch astronomical community has recently received funding to build a synthetic radio telescope with a diameter of some $350 \mathrm{~km}$ in the Netherlands. This telescope, referred to as LOFAR (Low Frenquency Array) will consist of a wide network of small antennas that are linked via an ultra fast data transmission network $(\sim 10 \mathrm{Gbit} / \mathrm{s})$ to synthesize the telescope. The LOFAR network has provided a unique opportunity to develop a
PERmanent Seismic IMaging and MONitoring network (PERSIMMON), designed for monitoring 3-D structures and processes in the subsurface of the Netherlands, by connecting a large number of 3-component geophones to the LOFAR network. Initial research on the set-up of the network has shown that 'background noise' from the Earth could possibly be used for imaging and monitoring purposes in the light of PERSIMMON ('acoustic daylight imaging'). So far, its success has only been shown on synthetic data. Further investigations are required and, above all, field observations are needed to show whether this method can be applied successfully to PERSIMMON data.

In the first instance, the network will be used for monitoring the dynamic behaviour of the Netherlands' subsurface in two regions: (1) in the north-eastern Netherlands where earthquakes and subsidence result from major gas extraction; and (2) in the south-eastern Netherlands where earthquakes are related to the subsidence in the Roer-Valley Graben. In addition there are plans to further use the opportunities offered by LOFAR to connect low-frequency geophones $(<1 \mathrm{~Hz}$.) to the network. These can be used to image the deep crustal structure of the Netherlands down to the Moho discontinuity, the position of which is still poorly defined in large parts of the Netherlands. The network also offers opportunities to connect other types of sensors and generate real-time data. Options include e.g. atmospheric and GPS sensors (Fig. 13).

On a European scale, the GÉANT glass fibre network that is currently being rolled out over Europe offers similar possibilities as the LOFAR network. The Dutch astronomical organisation Astron is developing a European initiative to achieve this.

\subsubsection{High-performance computing and time-dependent Earth models}

2.2.5.1. Topical and Capacity Computing. Earth processes are complex and highly non-linear. Computational modelling has therefore become one of the most important tools to advance their understanding. Due to the dramatic advances in modern high-performance computing, great advances can be expected in our ability to model seismic wave propagation, rupture and fault dynamics, deformation of the lithosphere, or solid-state flow in the Earth's mantle. Combined with an unprecedented wealth of observational data becoming available from ground, airborne and space-borne monitoring this bodes well for pushing forward the frontiers of our understanding of the fundamental processes that govern large-scale tectonic activity on Earth. 


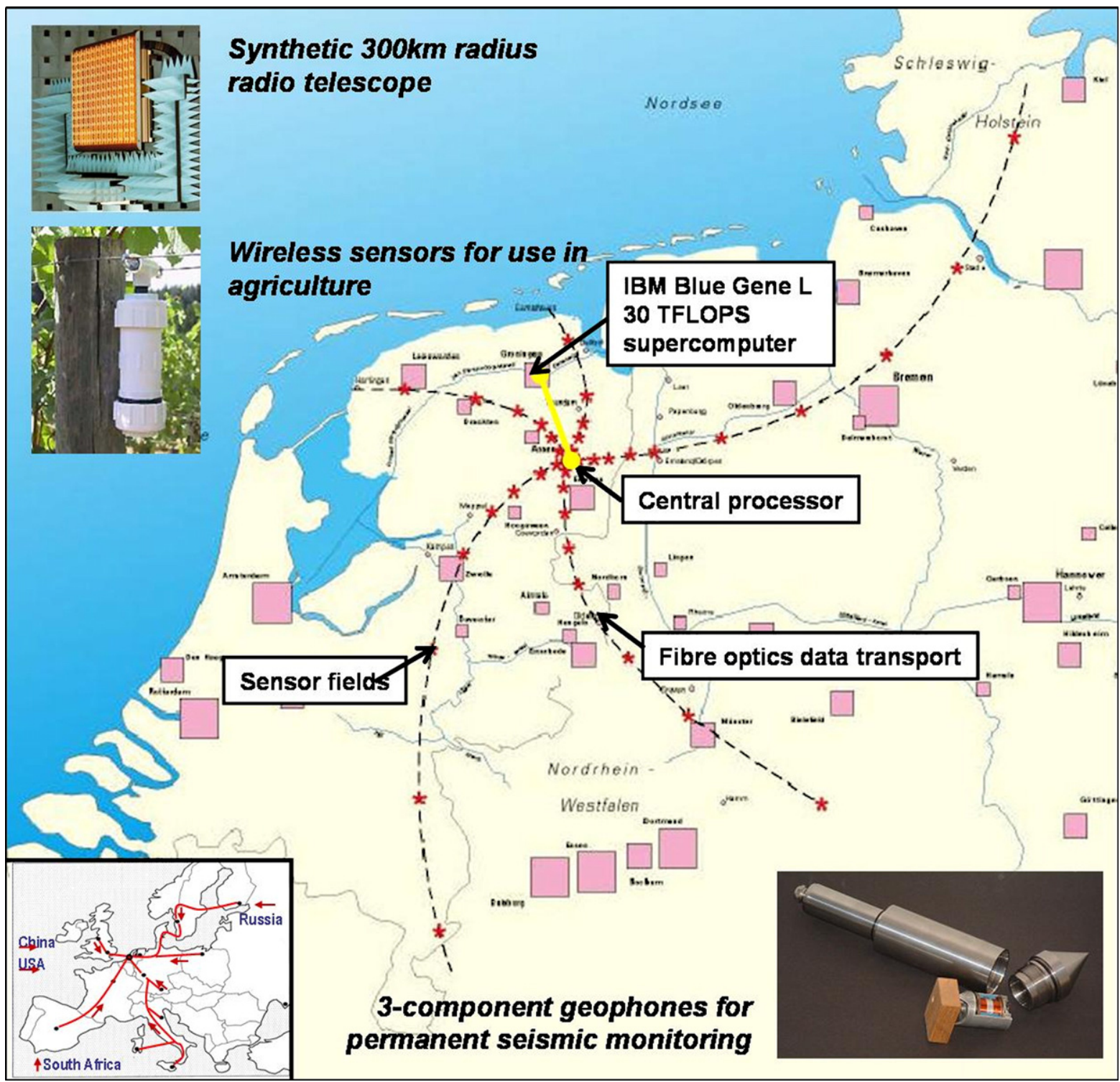

Fig. 13. The LOFAR (Low Frequency Array) radio telescope and infrastructure in the Netherlands. A synthetic, $300 \mathrm{~km}$ radius radiotelescope is created by connecting a large number of small radio antennas through a fibre optic data transport network to a central supercomputer facility. The LOFAR infrastructure can simultaneously be used for a range of other sensor applications, including wireless sensors for agricultural use and 3-D geophones for permanent seismic monitoring. Lower left inset shows extent of the European GÉANT network that may be employed in a similar fashion (courtesy LOFAR).

Earth models rank among the most challenging calculations computational physicists can perform today. Difficulties arise from the wide range of spatial and temporal scales that must be resolved. For example, failure processes in the brittle crust along plate margins may extend over distances of a few $10 \mathrm{~km}$, while the plates themselves are embedded in a global circulation system of the Solid Earth with length-scales on the order of $10,000 \mathrm{~km}$. Likewise, if we take global seismic wave propagation calculations performed at a dominant period of $5 \mathrm{sec}$ as an example, there are up to 100 billion degrees of freedom. This translates into 10-100 Terabytes of main memory and weeks of integration time. Such requirements tax even the largest supercomputers in Europe.

Reflecting the range of scales and the heavy computational burden it is easy to see that Earth models exceed the limitations of the largest high-performance computing 
system currently available to the European scientific community at national and European supercomputer centres. In addition to a tremendous demand in terms of the capability of computing systems (essentially the size of a computer) there is a rapidly growing demand in terms of the capacity (the amount of computing time or cycles actually available to a user) of the systems. Said differently, while there has been great progress at the highest end of supercomputing over the past decade there is a significant gap between local computing resources, such as desktop computers, and high-end systems. Measured against the leading systems, such as the Earth Simulator, the gap now spans close to four orders of magnitude in processing speed and main memory. To ease the limitations in computing capacity, several groups in TOPO-EUROPE are now at the forefront of installing state-of-the-art modelling infrastructures based on clusters of high-end PCs. These innovative mid-range parallel computer systems exploit the cost-advantage of massproduced PCs and deliver superior price/performance. They are well suited to supply the computation capacity required for Earth simulations. Typical clusters comprise any number of processors from, say, a few tens to several hundred. For example, Munich University employs a new Earth modelling cluster with 150 processors, which ranks among the largest tectonic simulators in Europe (Note: a similar cluster at Caltech employs 2000 processors). This cluster is optimized for key-applications, including seismic wave-propagation and tectonic simulations that perform at high efficiency. Earth modelling clusters are distinctly topical. We anticipate a strong role for capacity and topical computing in TOPO-EUROPE and note that TOPO-EUROPE will have advanced new facilities, as for example the Munich Earth cluster (see Fig. 14), at its disposal. Some of the calculations that can be performed on such systems include:

- Tectonic and lithospheric modelling.

- Modelling of seismic wave propagation.

- Mass-redistribution in the Solid-Earth system.

- Global circulation models of the Earth's mantle.

- Glacial rebound models.

\subsubsection{Time-dependent Earth Models and}

Data-Assimilation. Geophysical modelling has greatly benefited from the advent of modern parallel computers. Focusing on the Earth's mantle, resources on topical computers are now sufficient to model its global flow pattern with a near-Earth-like convective vigour in 3-D spherical geometry. To take the next step and model the geologic evolution of mantle flow and continental tectonics requires the use of sophisticated data-assimi-

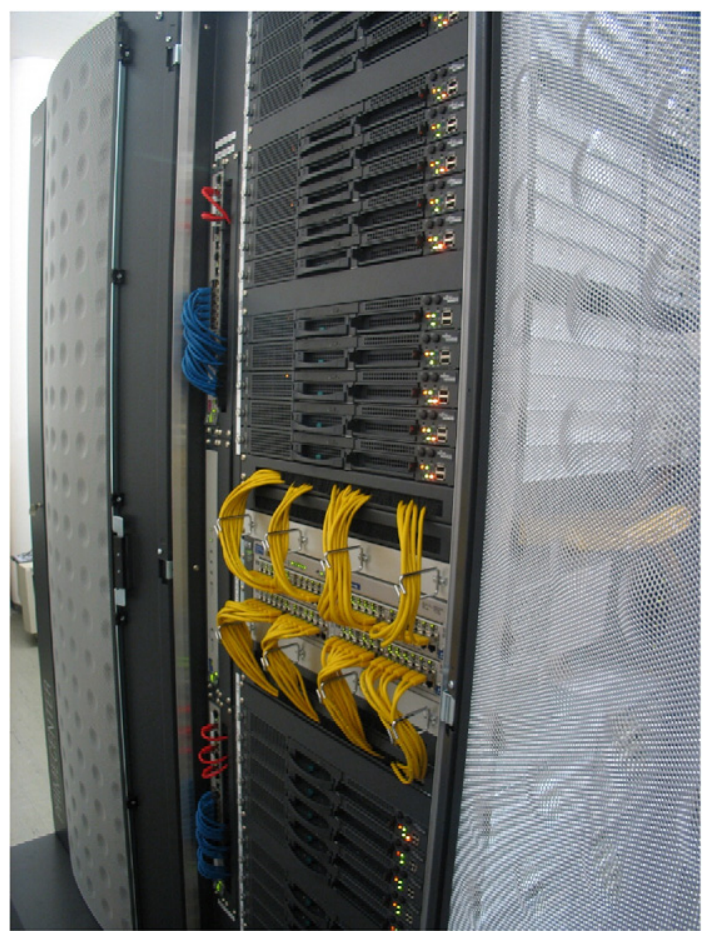

Fig. 14. Tectonic High Performance Simulator (Tethys) with 150 Processors, 150 Gbytes main memory and sustained performance for Earth System models in excess of 300 Gflops. This topical computing system is available to TOPO-EUROPE (courtesy H.P. Bunge).

lation techniques. These techniques will be brought to bear in TOPO-EUROPE primarily to overcome fundamental problems inherent to initial conditions. In other words, we don't know how to properly start geodynamic and tectonic simulation from some assumed initial conditions in the past, because these conditions are essentially unknown.

There are important reasons for trying to use dataassimilation techniques in TOPO-EUROPE and to overcome the initial-condition problem of tectonic modelling. Continental platform stratigraphy and marine transgressions were to a large part controlled by temporal changes of the Earth's dynamic topography in response to mantle convection. The current topographic elevation of southern Africa and the narrowness of its continental shelves are indicative of tectonic uplift that is probably supported by lower mantle flow. The dynamic origin of the South African topography is entirely consistent with independent evidence from seismic tomography, imaging a low velocity anomaly in the mantle beneath southern Africa. Similarly, dynamic processes in the deep Earth may have controlled the low topography of Europe during the Late Cretaceous. 
From an algorithmic point of view data-assimilation is usually implemented either by sequential filtering or by global smoothing methods. In sequential filtering the model is integrated forward in time for the period for which observations are available. Whenever an instant is reached for which observations are available, the model is 'updated' or 'corrected'. The model is then restarted from the updated state and the process repeated until all available information has been used. This approach is now well established in global mantle convection studies, in which it is used to compute so-called mantle circulation models (Fig. 15) from past plate motion reconstructions.

We expect that sequential data-assimilation will play an important role in TOPO-EUROPE in bringing theoretical and observational communities together. Sequential data assimilation is well adapted to geodynamic modelling studies, because it performs a constant update on the model state and uses each new observation for correcting the latest model state. There is, however, a fundamental drawback. Owing to the sequential character of the assimilation, each individual observation is used only once, thus influencing only the forward state of the model. Information propagates from the past into the future, whilst no information is carried back into the past.

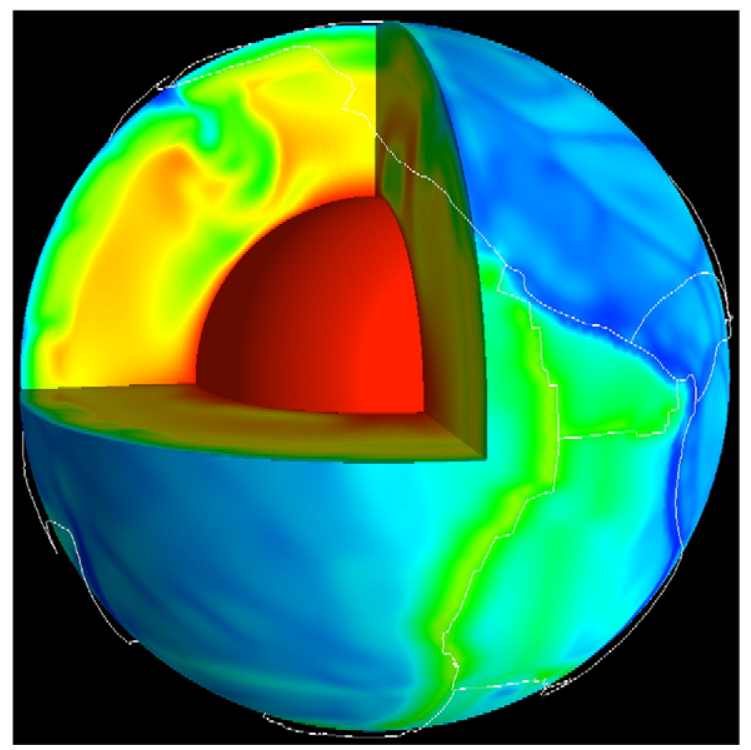

Fig. 15. Cut-away of the 3-D temperature field for a mantle circulation model seen from the Pacific hemisphere (GEMLAB: Geodynamic Earth Model of Los Alamos and Berkeley). The model was obtained by imposing the 119-Ma through present-day plate motion record, reflecting the history of subduction beneath the north-western Pacific. Blue is cold and red is hot. The upper $50 \mathrm{~km}$ of the mantle are removed in order to show the convective planform. Present-day plate boundaries are drawn for geographic reference (after Bunge et al., 1998).
We anticipate that this limitation will be of disadvantage in tectonic studies, as we have far more detailed knowledge on the present state of the system than on its past state. To overcome this limitation, TOPOEUROPE will explore more powerful data-assimilation algorithms capable of carrying information back in time. Within the framework of the TOPO-EUROPE project, one of the most important datasets on deep mantle flow and large-scale tectonic processes will come from tomographic imaging studies of the Earth's interior.

Tomographic images provide important constraints on present and past mantle flow that can be linked explicitly to the evolution of topography and large-scale tectonic activity via a data assimilation approach involving variational methods. In this approach a numerical adjoint code and the forward model are solved jointly in an iterative procedure. Variational data-assimilation is a familiar tool in numerical weather prediction and oceanographic models, where it has resulted in dramatically improved model forecasts. Importantly, synthetic tests of variational data-assimilation in mantle circulation and tectonic models show similar improvements in forecast accuracy. Results show that deformation can be reconstructed backward into the Late Cretaceous. Fig. 16 shows a snapshot of the 3-D temperature field in a dataassimilation model of the mantle for the past 100 million years. Unfortunately, 3-D modelling of mantle convection when combined with powerful numerical adjoint techniques comes at a heavy computational price. Weeks of integration time are necessary to solve such problems even on some of the most powerful parallel machines currently in use at national computing centres.

\subsubsection{Feedback between Topography and Plate} Tectonics. While it is generally assumed that plate tectonics and topography are linked through driving and resisting forces along plate boundaries, details of this linkage are not very well understood. Although buoyancy forces associated with subduction zones provide a significant driving force for plate convergence, the relative magnitudes of other driving and resisting forces are less clear, as are the main factors controlling long term changes in plate motions. The ability to consider past as well as present plate motions in the context of TOPO-EUROPE will provide important constraints, since changes in plate motion are necessarily driven by changes in one or more of the key driving forces, as can be inferred from independent data.

An important analogue region for TOPO-EUROPE is South America, and more specifically the development of high topography in the Andes (see also Section 3.8). Groups in TOPO-EUROPE have constructed a model that 


\section{Mantle Temperature (Reference Model)}

(a)

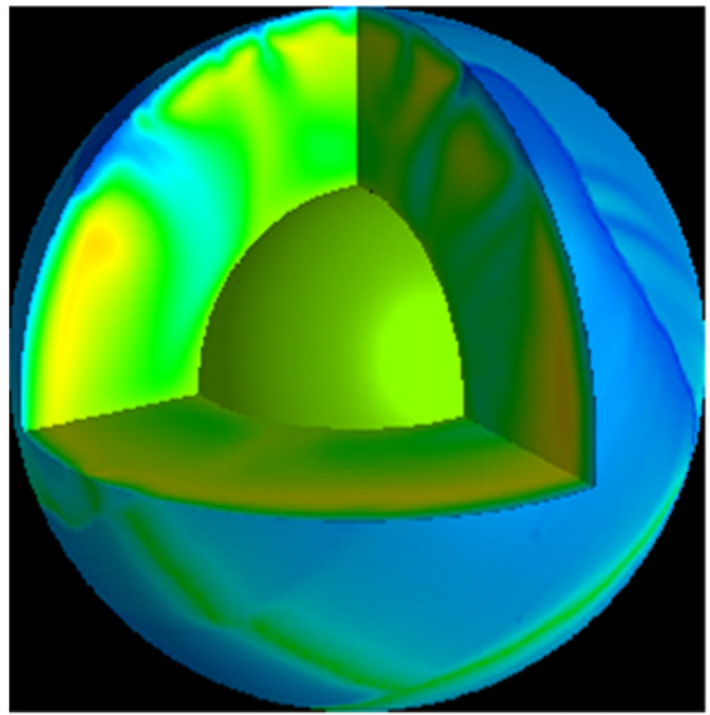

100 Myrs later

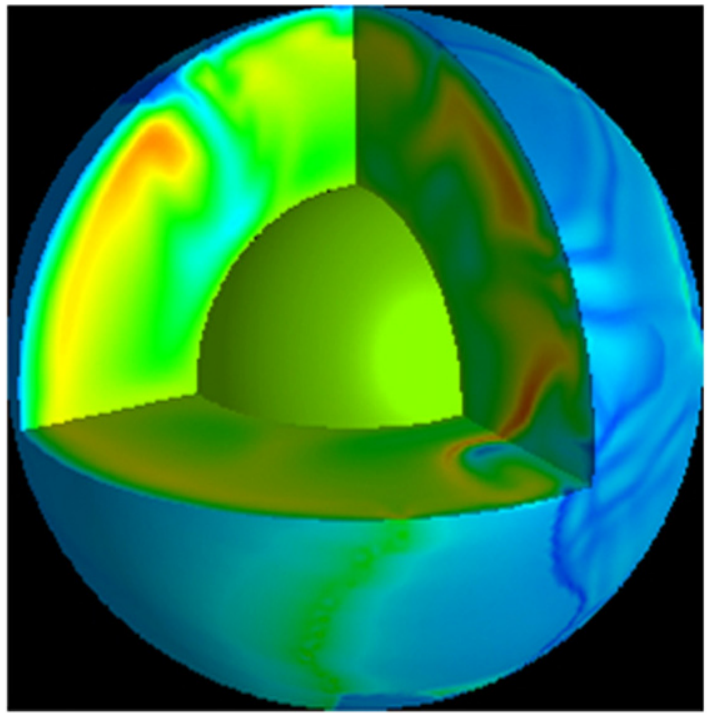

(b)

\section{Assimilated Plate Motion}

\section{Cretaceous to initialize}

(c)

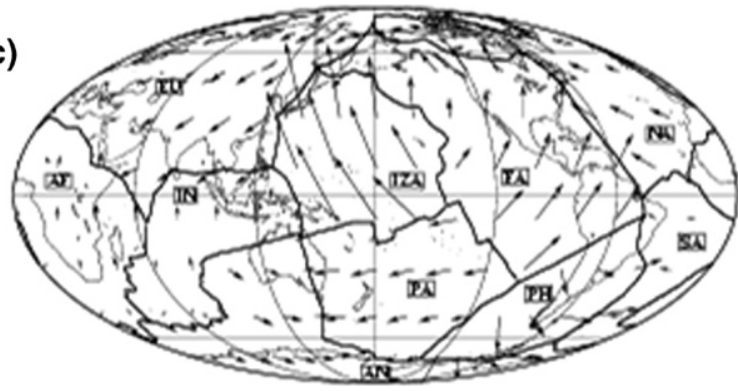

Present-Day from a) to b)

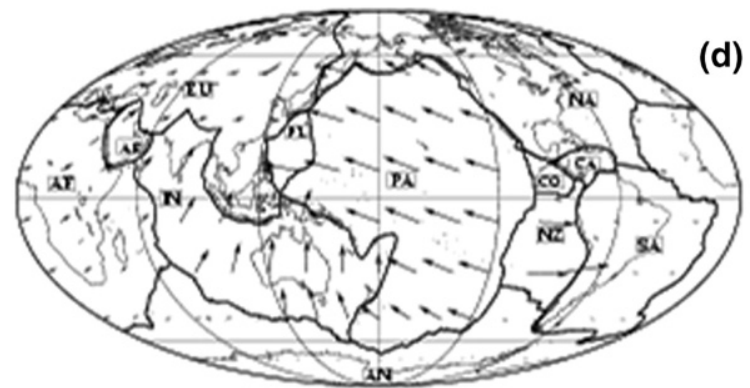

Fig. 16. (a) Cut-away of the 3-D temperature initial condition field for the reference mantle circulation model (see text) seen from the Pacific hemisphere. The model is obtained by imposing (assimilating) mid-Mesozoic plate motions (c) until quasi steady-state is reached. Blue is cold, and red is hot and the linear color scale ranges from 0 to $2300^{\circ} \mathrm{C}$. The upper $100 \mathrm{~km}$ of the mantle are removed to show the convective planform. Narrow hot zones near the surface reflect passive mantle upwelling at the Izanagi (IZA), Farallon (FA), Pacific (PA) and Phoenix (PH) spreading centers. The cold downwelling in the cross-sectional view under the northwestern Pacific results from subduction of the Izanagi and Farallon plates. (b) Same as (a) but after $100 \mathrm{Myr}$ of present-day plate motion (d) have been imposed. (c) Map of plate boundaries and velocities for the 119-100 Myr stage from Lithgow-Bertelloni and Richards (1998). The ancient Izanagi, Farallon and Phoenix plates occupy most of the Pacific Basin. (d) Same as (c) but for the present-day from Gordon and Jurdy (1986). The Izanagi, Farallon and Phoenix plates have largely disappeared (after Bunge et al., 2003).

explicitly links global mantle convection and lithosphere models to infer plate motion changes in this region as far back as Miocene times. These calculations accurately predict the observed slowdown in convergence rates during the last $10 \mathrm{My}$ and link it to the contemporaneous rise of the high Andes. This suggests that surface topography generated at convergent margins may have a strong bearing on plate motions (Fig. 17). The topographic load of large mountain belts and plateaus appears to absorb a significant amount of the available plate driving forces by increasing the coupling between the subducting and overriding plates. As such, this model may be applied and further evaluated in TOPO-EUROPE studies addressing the evolution of European orogenic belts, for which a large number of kinematic constraints will become available both from the analysis of past plate motions as from geodetic measurements on temporal variations of plate movements. These constraints will 

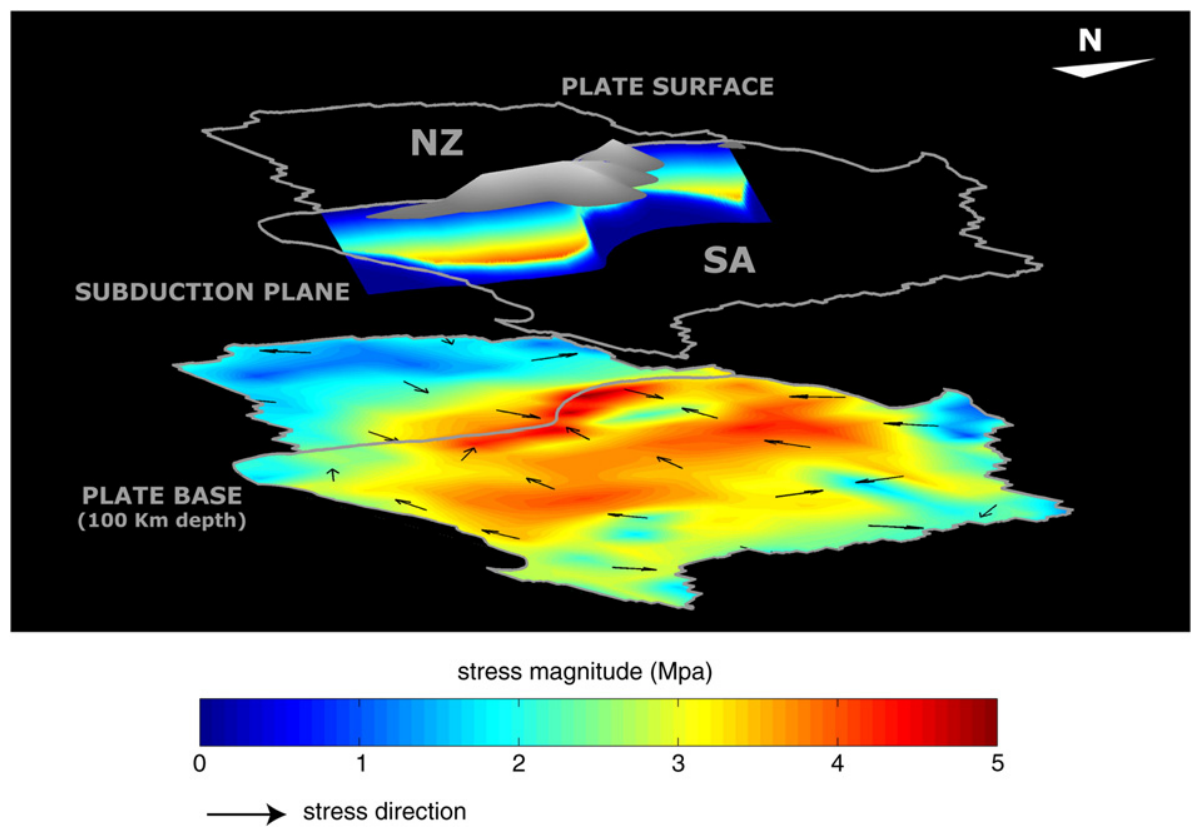

Fig. 17. Present-day subduction plane and plate base stresses inferred from a simulation for the Nazca and South American plates. Colour scale indicates stress magnitude in MPa. Plate boundaries are in black, Andes topographic elevation contours in grey. Resisting stresses along the subduction plane are comparable to plate driving shear traction of the mantle, particularly beneath highly elevated regions in the central Andes (after Iaffaldano et al., 2006).

permit to model the relative contribution of different plate driving forces (Ziegler, 1993).

\subsection{Component 3 'Dynamic topography reconstruction'}

Although the Solid Earth has continuously changed, it has retained a record of its evolution. A major challenge is to elucidate the role played by internal lithospheric processes and external forcing in controlling the rates of erosion and sedimentation. The sedimentary cover of the lithosphere provides a high-resolution record of changing environments, and of deformation and mass transfer at the Earth surface, as well as at different depth levels in the crust, lithosphere, and sub-lithospheric mantle. TOPO-EUROPE researchers have made pioneering contributions to explain the relationships between lithosphere-scale tectonic processes and the sedimentary record, demonstrating, for example, the intrinsic control exerted by lithospheric intraplate stress fields on stratigraphic sequences and on the record of relative sea-level change in sedimentary basins (Cloetingh et al., 1990; De Bruijne and Andriessen, 2002; Hendriks and Andriessen, 2002). By now, there is growing awareness that neotectonic processes can seriously affect the fluid flow in sedimentary basins and that fluid flow can have a major effect on the geothermal regime, and hence on calculated denudation and erosion quantities (Ter Voorde et al., 2004). Monitoring of the sedimentary and deformation record provides constraints for present-day deformation rates and thus feedback to components 1 and 2 .

Whereas in the analysis of sedimentary basins tectonics, eustasy and sediment supply are usually treated as separate factors, TOPO-EUROPE will pursue in carefully selected natural laboratories an integrated approach that is constrained by fully 3-D quantitative subsidence and uplift history analyses. Recent work by TOPOEUROPE scientists has also elucidated the control exerted by the inherited mechanical weakness of the lithosphere on its subsequent evolution, as expressed by the geological and geophysical record of orogenic belts and sedimentary basins in intraplate domains and the related development of topography. The mechanical properties of the lithosphere depend on its temperature regime and composition (Cloetingh et al., 2003a; Cloetingh et al., 2003b; Andriessen and Garcia Castellanos, 2004; Cloetingh et al., 2004; Cloetingh and Van Wees, 2005). Therefore TOPO-EUROPE will endeavour to fully integrate geothermochronology and material property analyses of the lithosphere with the reconstruction of its past evolution, derived from the sedimentary record. In doing so, TOPO-EUROPE will trespass traditional boundaries between endogene and exogene geology. 


\subsubsection{Linking the sedimentary record to the underlying lithosphere}

Over the last decades basin analysis has been in the forefront of integrating sedimentary and lithosphere components of previously separated fields of geology and geophysics (Fig. 18). Integrating neotectonics, surface processes and lithospheric dynamics in the reconstruction of the paleo-topography of sedimentary basins and their flanking areas is a key objective of TOPO-EUROPE. A fully integrated approach, combining dynamic topography and sedimentary basin dynamics, is also important considering the societal importance of these basins on account of their resource potential. At the same time, most of the human population resides on sedimentary basins, often close to coastal zones and deltas that are vulnerable to geological hazards inherent to the active Earth system.

One of the major tasks of TOPO-EUROPE is to bridge the gap between historic and geological time scales in analyzing lithospheric deformation rates. Major progress has been made in reconstructing the evolution of sedimentary basins on geological time scales, incorporating faulting and sedimentary phenomena. From this, we have considerably increased our insights into the dynamics of the lithosphere for large time slices (millions of years). On the other hand, knowledge on present-day dynamics is rapidly growing thanks to the high spatial resolution in quantification of earthquake hypocenters and focal mechanisms, and vertical motions of the land surface (component 1). Unification, coupling and fully 3-D application of different modelling approaches to present-day observations (components 1 and 2) and the geological record will permit to strengthen the reconstructive and predictive capabilities of process quantification (component 4). Particularly an intrinsically time-integrated approach will enable us to assess in greater detail the importance of the geological memory of lithospheric properties on present-day dynamics. This is one of the key parameters for predicting future vertical motions.

\subsubsection{Dynamics of sedimentary systems and deformational patterns}

The largest water mass outside the ocean resides not in ice caps nor in lakes and rivers but in the pore space of the Earth's crust. By far the largest proportion of this pore space is contained in sedimentary rocks. Owing to their high porosity, sedimentary rocks are the only significant reservoirs for oil, gas and water and the most significant conduits for subsurface pollution. Therefore, predicting the architecture and properties of sedimentary rocks in the subsurface is one of the great challenges of Solid-Earth science. Progress will critically depend on successful integration of remote imaging of the subsurface and forward modelling from first principles of sedimentation, erosion and chemical reactions. Prediction includes both prediction in space ("ahead of the drill") and forecasting system behaviour in time

\section{Methods for studying uplift and erosion}

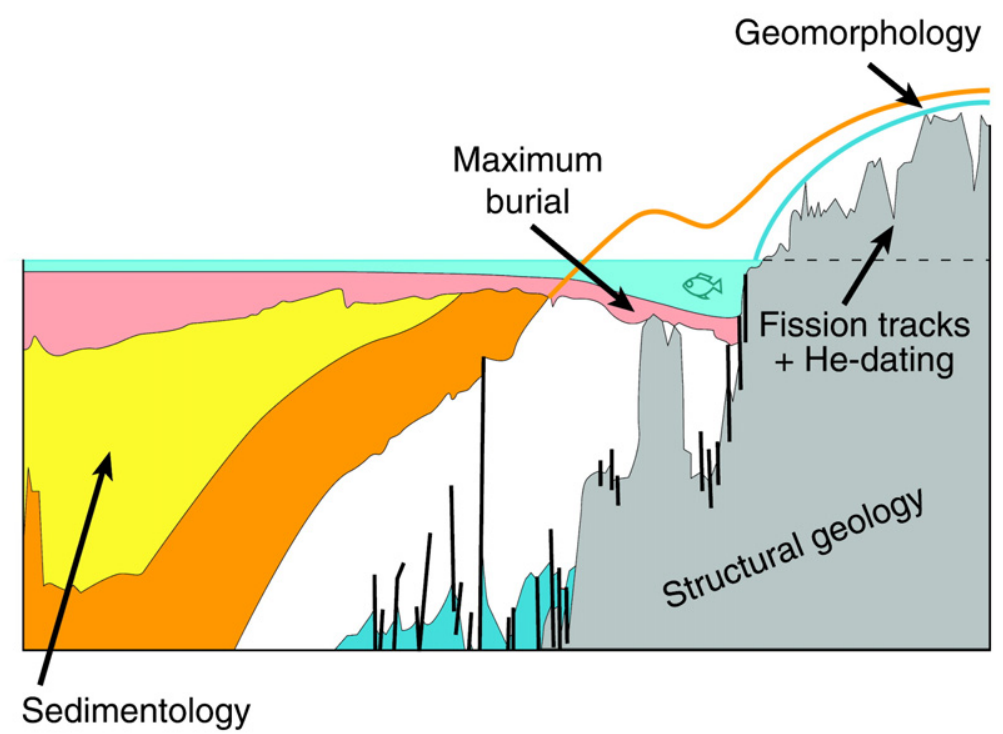

Fig. 18. Role of constraints from structural geology, geochronology, geomorphology and sedimentology in linking the sedimentary record to lithospheric processes (cartoon for coastal Norway by P. Japsen). 
(based on 4-D-monitoring). With its unique blend of geoscientists and engineers, TOPO-EUROPE is particularly well equipped to tackle this problem.

Quantitative analysis of the geometries and facies patterns resulting from erosion and sediment deposition provides a key step in linking the dynamics of hinterland uplift and basin subsidence and the associated mass flux. The prospect of increasingly higher resolution in space and time will provide a much better understanding of the factors controlling topographic evolution on continents and along their margins.

During the last few years it has become increasingly evident that recent deformation has strongly affected the structure and fill of sedimentary basins. Similarly, the long-lasting memory of the lithosphere appears to play a much more important role in basin reactivation than hitherto assumed. Therefore, a better understanding of the 3-D fine structure of the linkage between basin formation and basin deformation is essential for linking lithospheric forcing and upper mantle dynamics to the dynamics of crustal uplift and erosion, and the dynamics of sedimentary systems. In TOPO-EUROPE, structural analysis of the architecture of sedimentary basins, including paleostress assessment, will provide important constraints on the transient nature of intra-plate stress fields.

Reconstruction of the history of sedimentary basins is a prerequisite for identifying transient processes controlling basin (de)formation. TOPO-EUROPE pursues full 3-D reconstructions, including the use of sophisticated 3-D visualization and geometric construction techniques for faulted basin architectures. 3-D back-stripping, including the effects of flexural isostasy and faulting, permits a thorough assessment of sedimentation and faulting rates and changing facies and geometries through time. The established architecture of the preserved sedimentary record serves as key input for the identification and quantification of transient processes.

\subsubsection{Constraints by isotope geology}

Isotope geology uses analytical methods and techniques for geochronology, such as age determinations and definition of process rates, and isotopic tracer studies to analyze transport between various chemical reservoirs. In order to be able to answer questions concerning the chemical evolution of the Solid Earth through time and space, as well as feedback mechanisms between reservoirs contributing to the Solid Earth, it is necessary to identify, record and quantify the underlying processes. An aspect important to the understanding of forces driving these processes is the timing and quantification of mass transfer and chemical fluxes taking place at different scales - from global to mineral lattice.
Analytical techniques in isotope geology have improved considerably, owing to advances in mass-spectrometry and chemistry, and to the use of new techniques such as laser probing. It is now possible to analyze small quantities of material, single grains and spots within a crystal with high precision. Particularly promising techniques are fission track analysis, exposure age dating using noble gas isotopes of ${ }^{21} \mathrm{Ne}$ and ${ }^{3} \mathrm{He}$, Ar-laser probing and U-series. TOPO-EUROPE researchers have in-depth experience in all of these techniques (Sanders et al., 1999; Necea et al., 2005; Ruszkiczay-Rudiger et al., 2005; Juez-Larré and Andriessen, 2006).

Thermochronologic methods provide estimates of regional variations in the timing, duration and rate of uplift and erosion over long-term periods. During the last decade, apatite fission track thermochronology has emerged as a powerful technique to unravel and quantify the denudation history of regionally elevated basement regions, owing to its ability to constrain the low-temperature $\left(<120{ }^{\circ} \mathrm{C}\right)$ cooling history of rock samples (Fig. 19) (Ehlers and Farley, 2003; Reiners and Ehlers, 2005).

\subsubsection{Basement-basin fill interplay and paleo-topography}

Recently a growing awareness has developed that, although denudation is an important aspect of presentday morphology, the development of topography is driven by tectonics controlled by forces operating at depth in the Solid Earth. Moreover, it is realized that tectonic topography is modified by erosion, a process driven by external forces operating at the surface of the Solid Earth. To understand the interrelationship, interdependence and feedback mechanisms between internal and external forcing, lithospheric and surface processes need to be constrained.

Age dating of detrital minerals in sedimentary basins yields information that can be used to infer detailed spatial and temporal denudation patterns in sediment source areas. Such data, together with the volume of sediments contained in basins, provide a powerful tool for estimating in source areas regionally averaged mechanical denudation rates over long time scales. Obviously, there is a clear genetic link between tectonics controlling the geomorphologic evolution of source areas and the subsidence of sedimentary basins. The chronology of denudation inferred from fission track analyses reflects the complex relationship between tectonic reactivation of major structures, development of topography and the associated geomorphologic response, related effects on local denudation rates, and other factors, such as the location of the drainage divide on the uplifted flanks of 

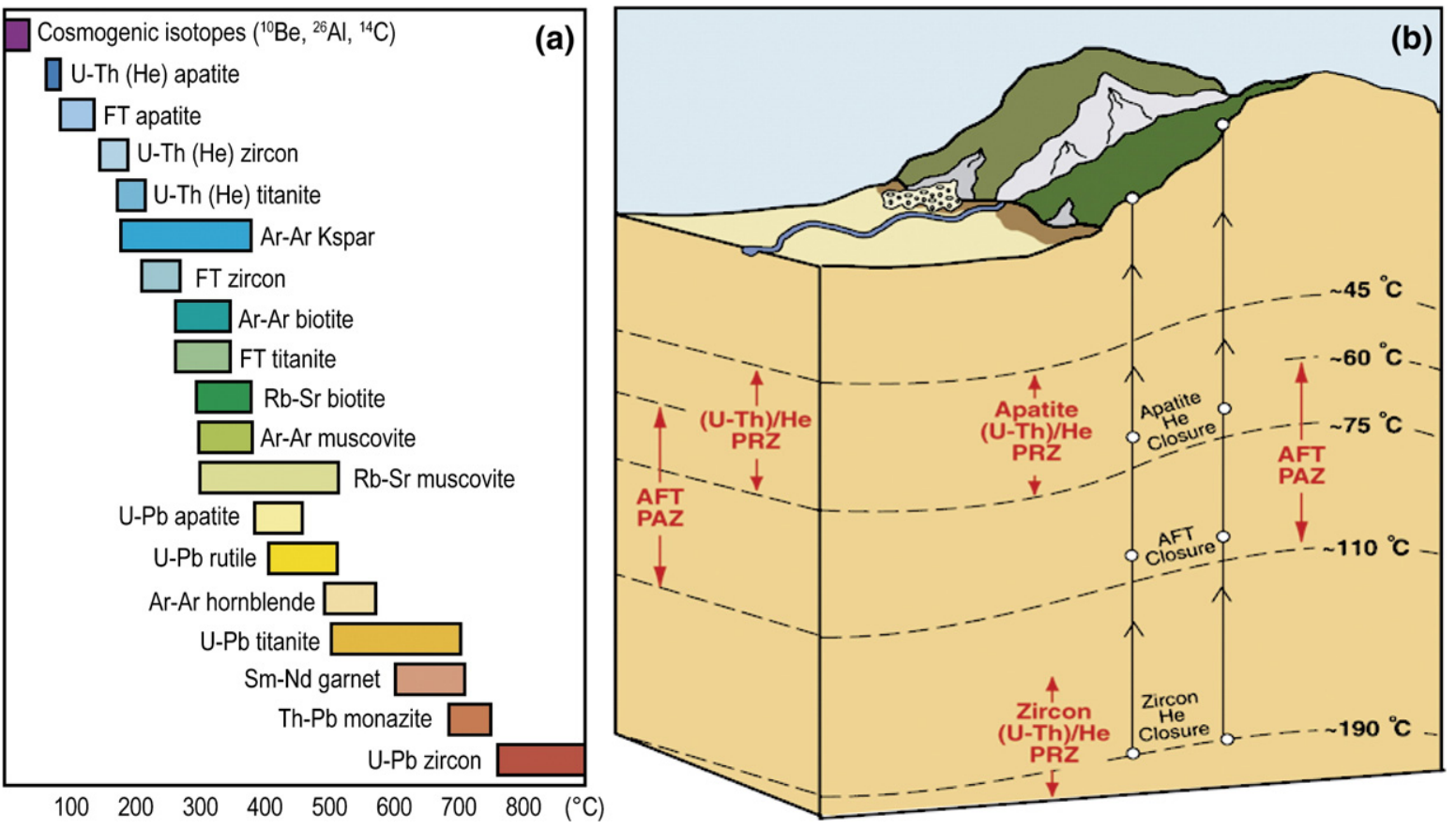

Fig. 19. (a) Temperature range of generally used thermochronometers; (b) Crustal depth profile showing temperature zones of several low-temperature thermochronometers as a result of surface topography and archived as time-temperature records in surface samples (after Ehlers et al., 2001).

sedimentary basins (Bernet and Spiegel, 2004; Reiners and Ehlers, 2005).

\subsubsection{Lithosphere deformation behaviour}

The flow properties of mantle rocks control the thickness and strength of the lithospheric plates, the degree of coupling between moving lithospheric plates and the pattern and rate of asthenospheric convection, and the rate of melt extraction at mid-ocean ridges. To be able to understand the dynamic behaviour of the outer parts of the solid Earth, notably the dynamics of lithospheric extension and associated rifting and sedimentary basin development, a detailed knowledge of the rheology of the upper mantle (30-410 km depth) and between the 410 and 670 transition zones is essential. At present, these flow properties are surprisingly poorly known. Experimental work has yielded constitutive equations describing various types of flow in mantle rocks, but it is not clearly established to what extent the experimentally observed flow mechanisms are relevant for natural crust and mantle conditions. A second problem is that trace amounts of water and melt can cause drastic weakening effects of mantle rocks. Such fluid-related weakening effects are widely recognised as important, for example in controlling the strength of trans-lithospheric faults underlying developing sedimentary basins. However, only limited data exist on such effects, and a quantita- tive, mechanistic understanding suitable for extrapolation to nature is lacking.

These problems can be addressed by means of experimental studies, scanning and transmission electron microscopy (SEM, TEM) and field studies of exposed upper mantle rocks. These approaches will be integrated with the aim of arriving at quantitative, mechanismbased descriptions of mantle rheology suitable for use in modelling the dynamics of the upper mantle and transition zone. Field-based studies involving structural geological and EM work on upper mantle rocks deformed in a variety of geological environments will be used to identify the flow mechanisms actually occurring in the upper mantle. Special attention will be paid to upper mantle rocks showing possible asthenosphere flow structures produced when the rocks contained some fluid or partial melts. Work will also continue on upper mantle shear zone rocks since such zones may play a major role in controlling the lithospheric strength during extension.

\subsubsection{Lithospheric Strength}

Based on knowledge of the thickness and thermal structure of the lithosphere (Fig. 20), strength profiles and effective elastic thicknesses can be calculated (Fig. 21). Over the last decade this has been done for a number of locations in Europe (e.g. Cloetingh and 

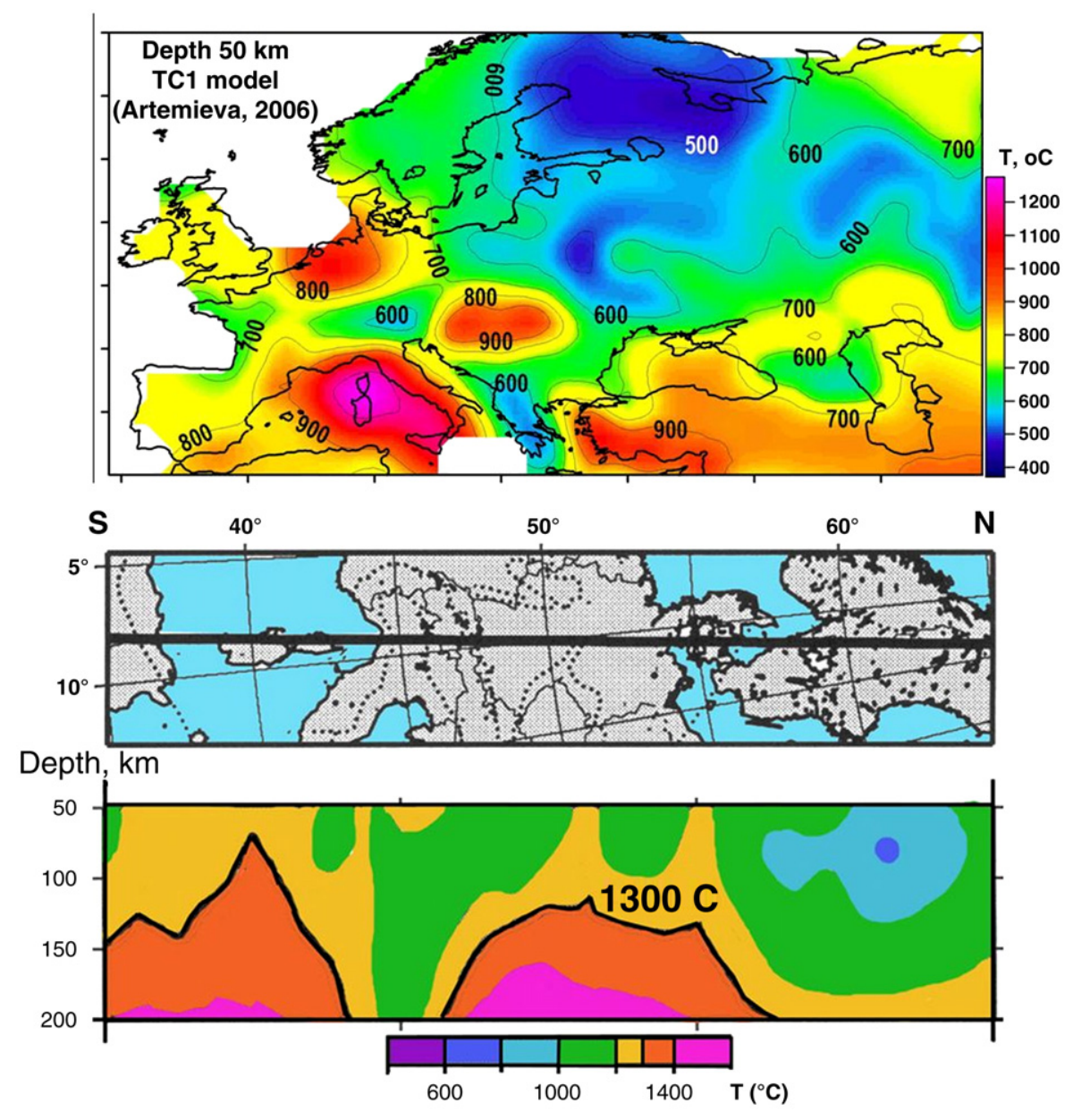

Fig. 20. Temperatures in the lithospheric mantle of Europe. Upper panel: temperature at $50 \mathrm{~km}$ depth constrained by surface heat flow, xenolith data, and global statistics based on tectono-thermal ages (after Artemieva et al., 2006). Lower panel: temperature along a profile extending from North Africa to the Baltic Shield constrained by Vp and Vs seismic velocities based on regional tomography models (after Goes et al., 2000b).

Burov, 1996). Most of these strength profiles and estimates of integrated strength were calculated along available deep seismic crustal cross sections, such as the European Geotraverse (Cloetingh and Banda, 1992) and the TransAlp deep seismic profile (Willingshofer and Cloetingh, 2003). Until recently, lithospheric strength maps have been calculated for restricted areas of Europe only, including the Pannonian Basin-Carpathian region (Lankreijer et al., 1999) and the Baltic Shield (Moisio et al., 2000), but were not yet available on a regional scale for intraplate Europe.

Cloetingh et al. (2005b, 2006b) constructed a 3dimensional strength map for the lithosphere of a large part of Europe. Existing models are based on a 3-D multi-layer composition of the lithosphere, including one upper mantle layer, two to three crustal layers and a sedimentary cover layer (e.g. Hardebol et al., 2003). The seismic tomography data used to infer the temperature structure of the lithosphere below Europe (Goes et al., 2000a; 2000b) has, however, only limited resolution in the mechanically strong part of the lithosphere.

Fig. 22 shows the integrated compressional strength of the entire lithosphere of Western and Central Europe. As evident from this figure, Europe's lithosphere is characterized by major lateral mechanical strength variations, with a pronounced contrast between the strong lithosphere of the Proterozoic East-European Platform east of the Teisseyre-Tornquist line and the relatively weak Phanerozoic lithosphere of Western Europe. A clear strength contrast occurs also at the transition from strong oceanic lithosphere of the Atlantic to the relatively weak continental lithosphere of Western Europe. Within the Alpine foreland, a pronounced northwestsoutheast trending weak zone is evident that coincides 


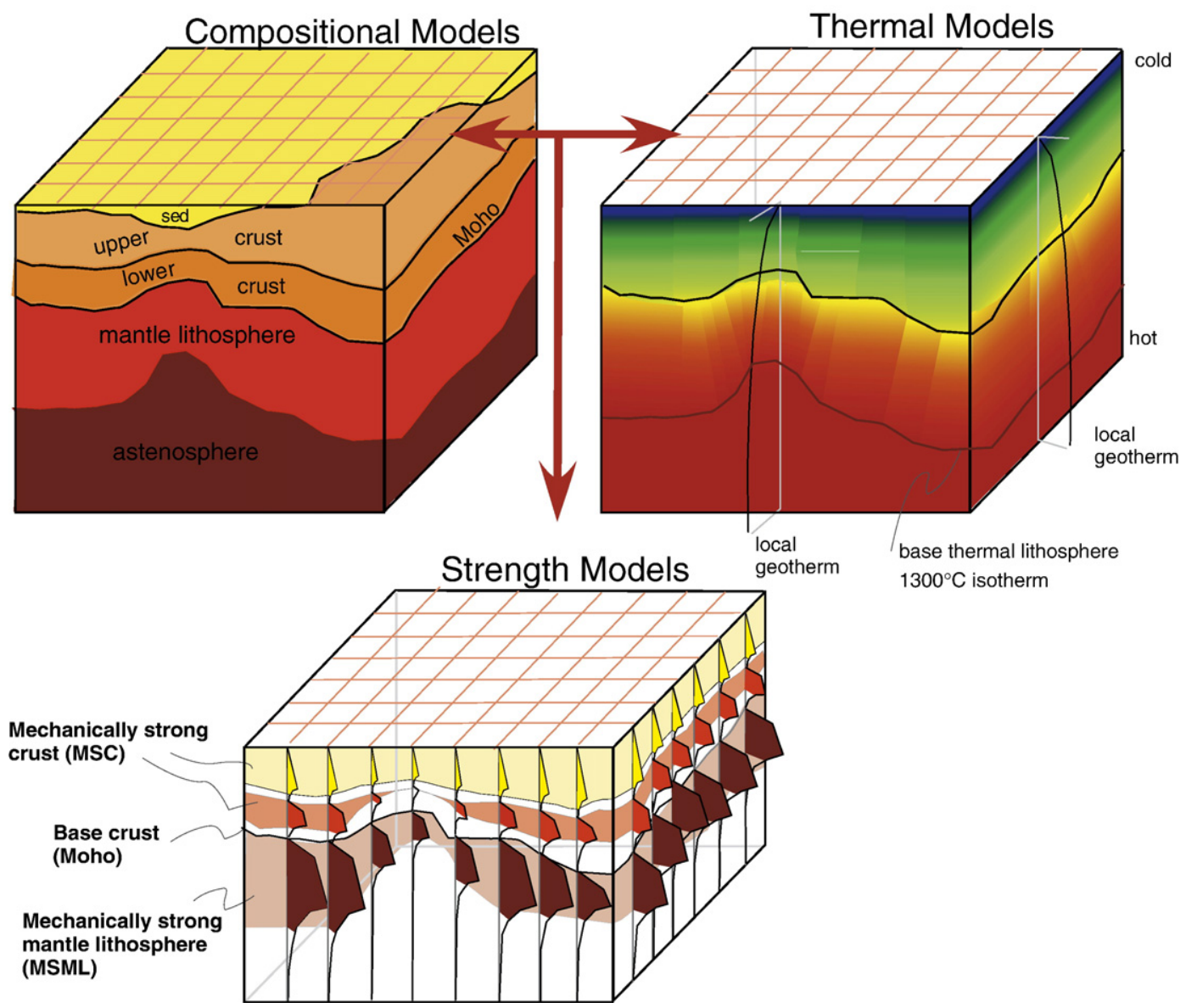

Fig. 21. From crustal thickness (top left) and thermal structure (top right) to lithospheric strength (bottom): conceptual thermal structure and composition of the lithosphere, adopted for the calculation of 3-D strength models (after Cloetingh et al., 2006b).

with the Mesozoic Sole Pit and West Netherlands Basins, the Cenozoic Rhine Rift System and the south-western margin of the Bohemian Massif. Furthermore, a broad zone of weak lithosphere characterizes the MassifCentral and surrounding areas, as well as the Alps. Higherstrength zones are associated with the central parts of the North German Basin, the British Isles and parts of the Armorican and Bohemian Massifs, all of which are characterized by moderate seismicity.

The presence of thickened crust in the area of the Teisseyre-Tornquist suture zone gives rise to a pronounced mechanical weakening of the crustal parts of the lithosphere, whereas the lithospheric mantle retains a moderate strength. Whereas the lithosphere of Fennoscandia is characterized by relatively high strengths, the North Sea rift system corresponds to a zone of weakened lithosphere. A pronounced strength contrast is evident between the strong Adriatic indenter and the weak Pannonian Basin, the Apennines and the Alps.
The lateral strength variations of Europe's intraplate lithosphere are primarily caused by variations in the mechanical strength of the lithospheric mantle (MSML), whereas the contribution from crustal strength variations appears to be more modest (Cloetingh et al., 2005b). The variations in MSML are primarily related to variations in the thermal structure of the lithosphere, reflecting upper mantle thermal perturbations imaged by seismic tomography, with lateral changes in crustal thickness playing a secondary role, apart from Alpine domains that are characterized by deep crustal roots. For instance, the strong lithosphere of the East-European Platform, the Bohemian Massif, the London-Brabant Massif, and the Fennoscandian Shield can be explained by the presence of old, cold lithosphere, whereas the European Cenozoic Rift System coincides with a major axis of weakened lithosphere within the Northwest European Platform. Similarly, weakening of the lithosphere of southern France can be attributed to the 


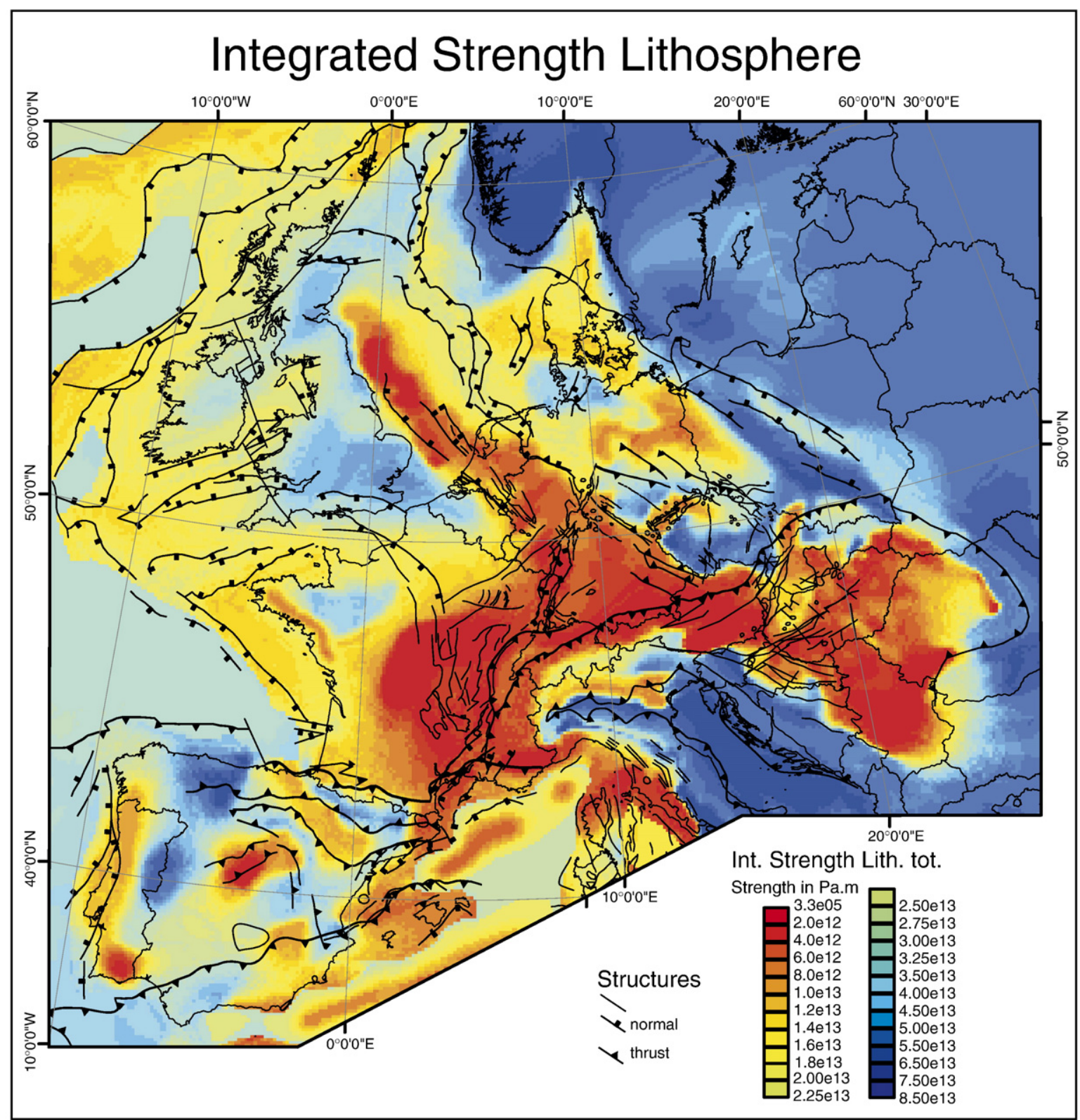

Fig. 22. Integrated strength map for intraplate Europe (after Cloetingh et al., 2005b), showing main structural features (after Ziegler, 1988; Dèzes et al., 2004). Colours represent the integrated compressional strength of the total lithosphere. Adopted composition for upper crust, lower crust and mantle is based on a wet quartzite, diorite and dry olivine composition, respectively. Rheological rock parameters are from Carter and Tsenn (1987). The adopted bulk strain-rate is $10^{-16} / \mathrm{s}$.

presence of a tomographically imaged plume rising up under the Massif Central (Granet et al., 1995; Wilson and Patterson, 2001). Linking mantle flow properties, controlling plate scale deformation patterns, with smaller scale basin deformation and near-surface expression of (neo)tectonics, requires extensive knowledge on crustal rheological properties, and particularly on the mechanical properties of faults. Researchers bundled in TOPO-EUROPE provide extensive expertise and knowledge on this topic.

\subsubsection{Role of the International Continental Scientific Drilling Program (ICDP)}

Scientific Drilling has the unique capacity to provide exact, fundamental and globally significant information on the composition, structure and processes of the 
Earth's crust. The International Continental Scientific Drilling Program (ICDP) coordinates continental scientific drilling efforts addressing research topics of high international priority. ICDP drilling projects are conducted at locations of global geoscientific significance where drilling can provide unprecedented insight into geodynamic processes of essential scientific and socioeconomic relevance.

ICDP addresses such themes as climate dynamics and global environment, impact structures, geobiosphere and early life, volcanic systems and thermal regimes, mantle plumes and rifting, active faulting, collision zones and convergent margins and natural resources. The ICDP cooperates closely with the Integrated Ocean Drilling Program (IODP) as the main scientific goals of both organisations largely overlap. Outstanding examples with a critical need for joint approaches are marinecontinental transects across seismogenic zones, as well as the integrated investigation of marine and continental climate archives.

The GeoForschungsZentrum Potsdam (GFZ), acting as the Executive agency for ICDP, participates in TOPOEUROPE. Moreover, it is also involved in European drilling-related research initiatives. The need for specialized scientific drilling capabilities has led the GFZ to develop an innovative and modular drilling rig and equipment for scientific operations with a penetration capability of up to $5 \mathrm{~km}$. The 'InnovaRig' (Fig. 23) is designed for use within Europe and will be ideal for drilling strategic targets in TOPO-EUROPE natural laboratories. Examples of specific projects and drilling locations for which the rig could be used are: (a) the Sogne Fjord in Central Norway (uplift history and risk assessment of major submarine landslides); (b) the North Anatolian Fault (in-situ stress measurements along the fault to better assess major seismic risk); (c) Campi Flegrei (active volcanism and volcanic risk assessment in Italy); (d) geothermal energy and intraplate volcanic fields.

Lake drilling, a notable strength of European geosciences, will enable to link high-resolution paleoclimatic data to the results of high-resolution tectonic investigations. TOPO-EUROPE researchers plan to study lake and river sediments as recorders of paleoclimate, variations of surface processes and paleotectonics.

In order to advance the understanding of the neotectonic evolution of Europe, a number of specific objectives are envisaged for scientific drilling under the auspices of TOPO-EUROPE, such as tracing environmental (vegetation and fauna, surface processes and paleotectonics) and climatic changes, eruptive volcanic history (e.g. tephra in the record of Monticchio), the

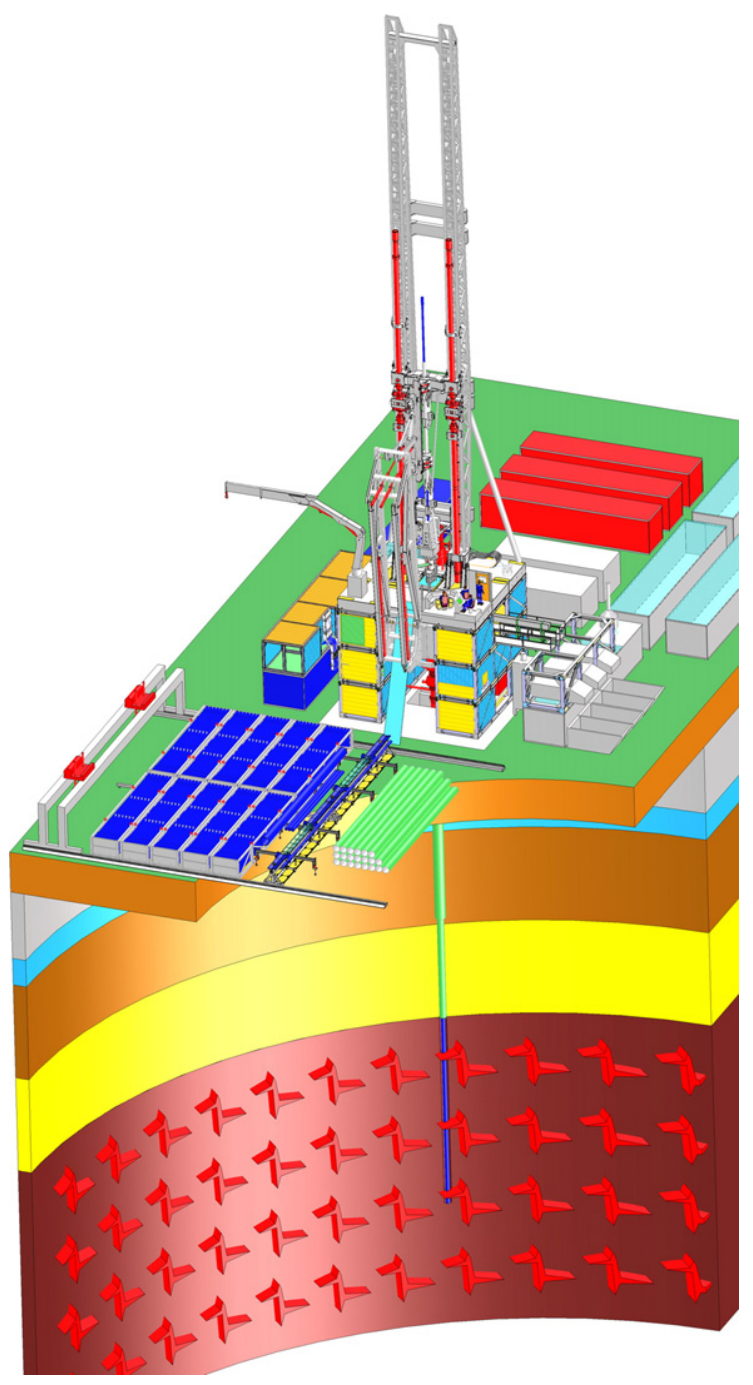

Fig. 23. Deep drilling InnovaRig facility of the GeoForschungsZentrum Potsdam (courtesy GFZ Potsdam).

evolution of the geomagnetic field (e.g. Eifel-Calabrian event), and correlation of the geological time-scale with the history of river terrace deposits and lake records as well as with loess deposits.

\subsection{Component 4 'Process modelling and validation'}

The subject of this component, modelling of SolidEarth processes, is going through the important transition from kinematic to dynamic modelling. This development cannot take place without interaction with (sub)disciplines addressing the Earth's structure and kinematics, or reconstructions of geological processes. In fact, the advances in structure-related research, in 
particular the advent of 3-D seismic velocity models, have set the stage for studies on dynamic processes inside the Earth. In short, structural information (components 1,2) is a prerequisite for modelling Solid-Earth processes. Similarly, information on present-day horizontal and vertical motions (component 1), as well as reconstructed past motions, temperatures or other process characteristics (component 3), is used to formulate and test hypotheses concerning dynamic processes. Inversely, the results of process modelling motivate and guide research in components 1, 2 and 3.

Through the emphasis on process dynamics, it is particularly in this component that the full benefits of coupling of spatial and temporal scales are expected to become apparent. The scale of processes studied ranges from the planetary scale to the small scale relevant to sedimentary processes, the depth scale being reduced accordingly.

In spite of the great successes of the plate tectonic theory in modern Earth sciences, fundamental questions still remain concerning the evolution of continents (or continental lithosphere) and their role in the dynamics of the Earth's surface, lithosphere and mantle. The growth process of continents (on the scale of a differentiating planet), their thickness and their dynamic coupling with the underlying mantle are topics requiring focused attention from a series of subdisciplines (see Artemieva, 2006).

Equally important questions remain to be solved on mechanisms controlling continental tectonics and their effects on vertical motions, dynamic topography, and sedimentary basin formation. Vital in this respect are the dynamics of rifting, subduction and orogeny (mountain building) and their effects on continental platform evolution and ocean-continent boundary processes.

For the quantification of Solid-Earth processes the coupling of internal and external forcing has to be addressed. Starting from the large scale mantle and lithospheric structure and processes, increasingly finer scales of crustal structure and processes, the dynamics of topography and sedimentary basins and their fill need to be analyzed. TOPO-EUROPE concentrates its process modelling efforts on a number of topics, for each of which a brief description and an outline of the proposed research are given below.

\subsubsection{4-D Integrated Approaches}

One of the primary and most innovative objectives of TOPO-EUROPE is to promote 4-D approaches that will lead to integrated interpretations of existing and newly acquired geomorphologic, geologic, geophysical, geodetic, remote sensing and geotechnologic datasets. A major challenge is the incorporation of different temporal and spatial scales in the analyses of Solid-Earth and surface processes. Examination of the role played by climate, erosion and tectonics on landscape evolution should provide key constraints for quantifying feedback mechanisms and teleconnections that link the Solid Earth, active tectonics and surface processes. Monitoring horizontal and vertical motions of the surface and mapping the subsurface, using modern geophysical, geodetic, remote sensing and geotechnical techniques, will provide new constraints on present-day deformation patterns and related topographic changes. Analogue and numerical modelling, based on these new constraints as input parameters, can be used to test integrated interpretations and to provide information on dynamic processes controlling topography development in intraplate settings and adjacent orogens.

\subsubsection{Innovative Modelling of Mantle-to-Lithosphere- to-Surface Processes}

The evolution of surface topography and morphology strongly depends on the interplay of subsurface and surface processes. Erosion unloads growing topography whereas sedimentation accelerates basin subsidence. This is clearly demonstrated by the strong correlation between denudation and tectonic uplift rates in zones of active deformation. During collision, surface processes contribute towards the localization and growth of mountain belts and fault zones, and ensure stable growth of topography (Fig. 24). During crustal extension, synrift erosion contributes towards widening of the rifted basin, so that apparent extension coefficients can increase by a factor of 1.5-2 (Fig. 25). Poly-phase subsidence and other deviations from thermal subsidence models can be also controlled by feedback between surface and subsurface deformation.

A new generation of 3-D and 4-D tectonically realistic models is required for an understanding of dynamic feedbacks between tectonic and surface processes, providing new insights into the evolution of tectonically active systems and related surface topography:

- Morphologically and tectonically consistent collision and exhumation models.

- Basin modelling, synthetic stratigraphy.

- Climate-coupled modelling.

The topographic reaction to surface loading and unloading depends on the mechanical strength of the lithosphere as well as on the strength partitioning between the crust and lithospheric mantle. Consequently testing different rheological profiles in areas where the data on 
(a)

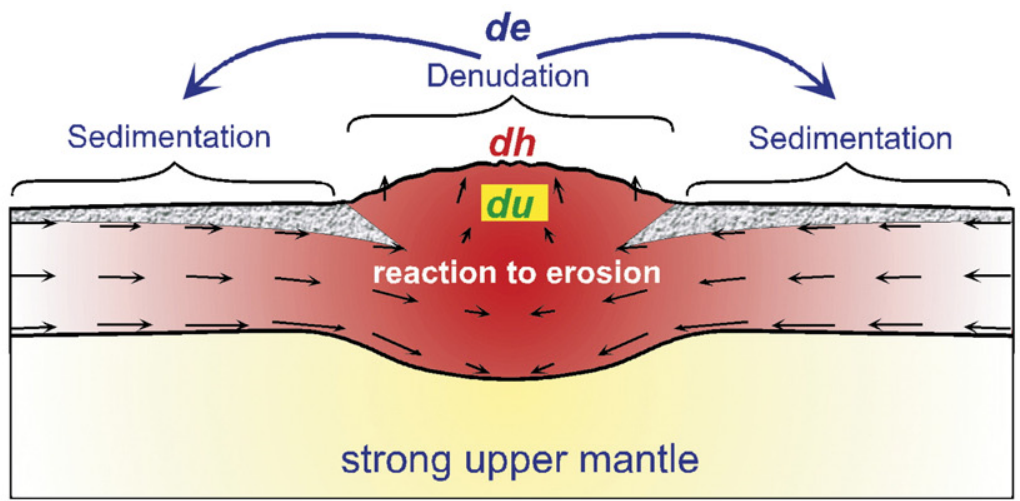

(b)

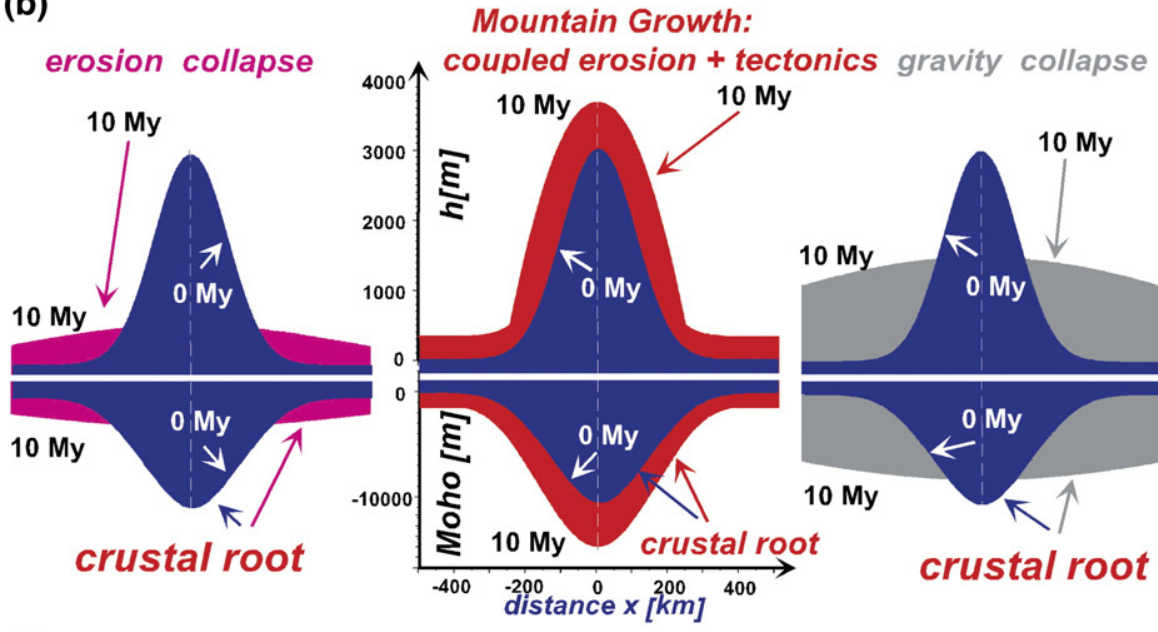

(c)
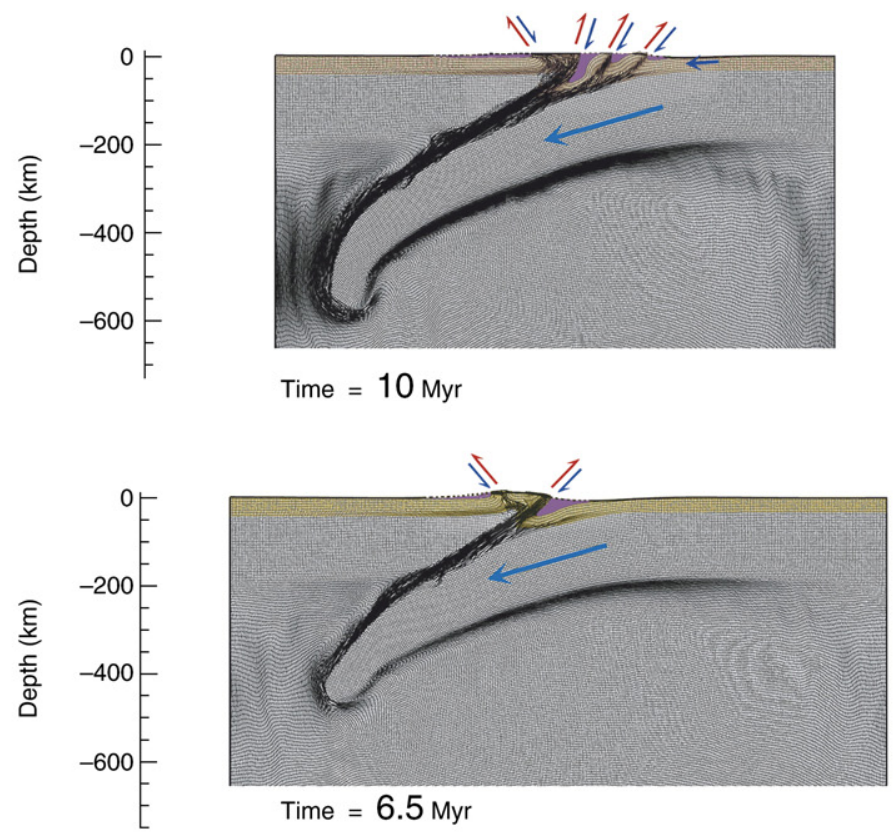

Fig. 24. Orogen evolution and surface processes. (a) Conceptual simplified model of feedback between surface and subsurface processes in orogenic context; (b) Major modes of orogen evolution; (c) Reproduction of evolution of fine tectonic structures in a fully coupled thermo-mechanical model of continental subduction that account for surface processes, elastic-plastic-ductile rheology and deep mantle processes (courtesy of E. Burov). 
(a)

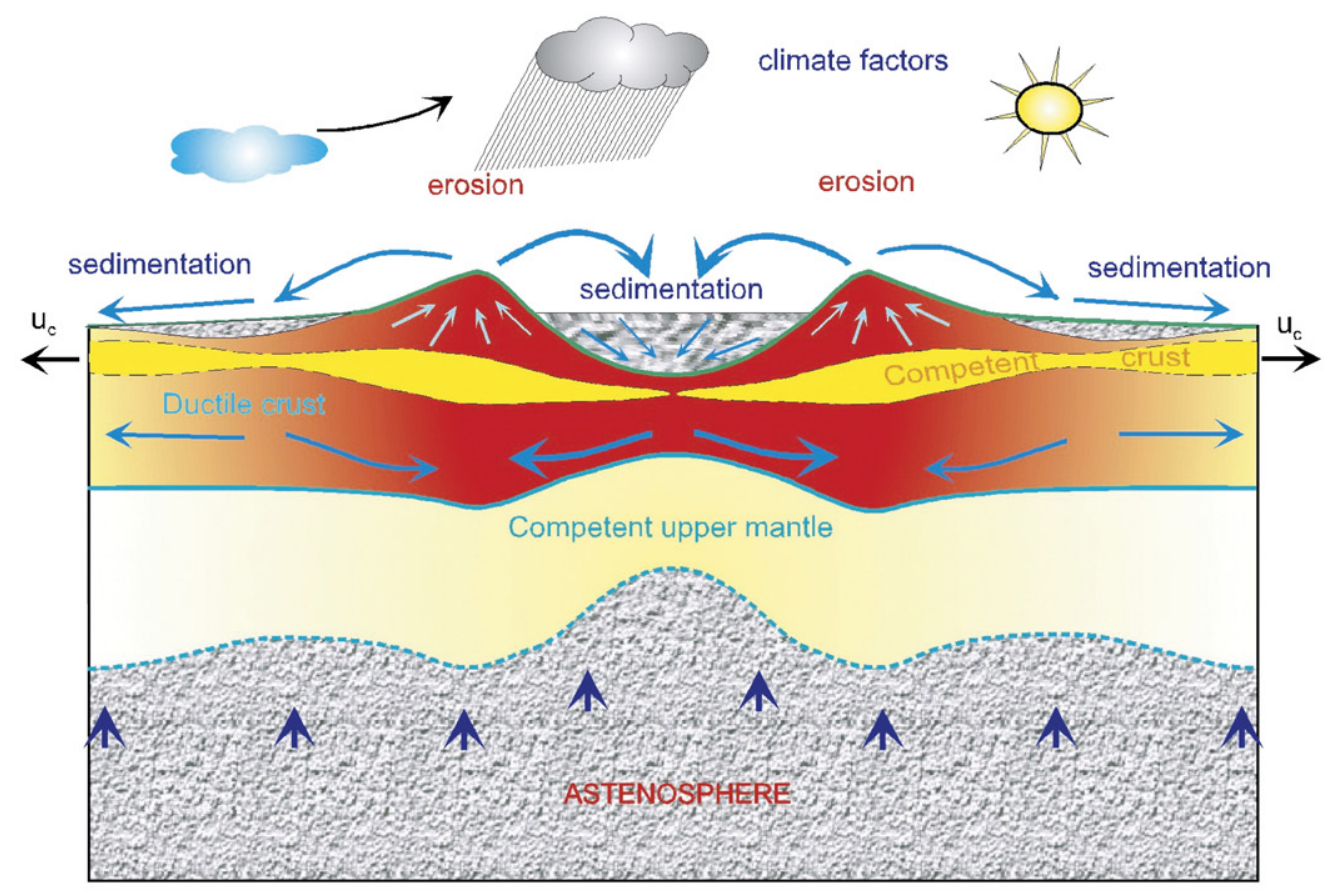

(b)

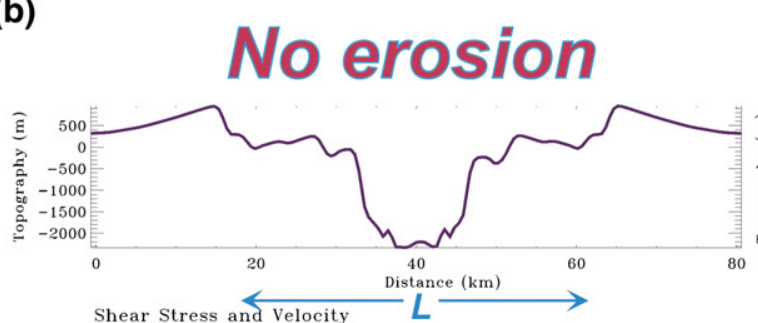

\section{With rapid erosion}
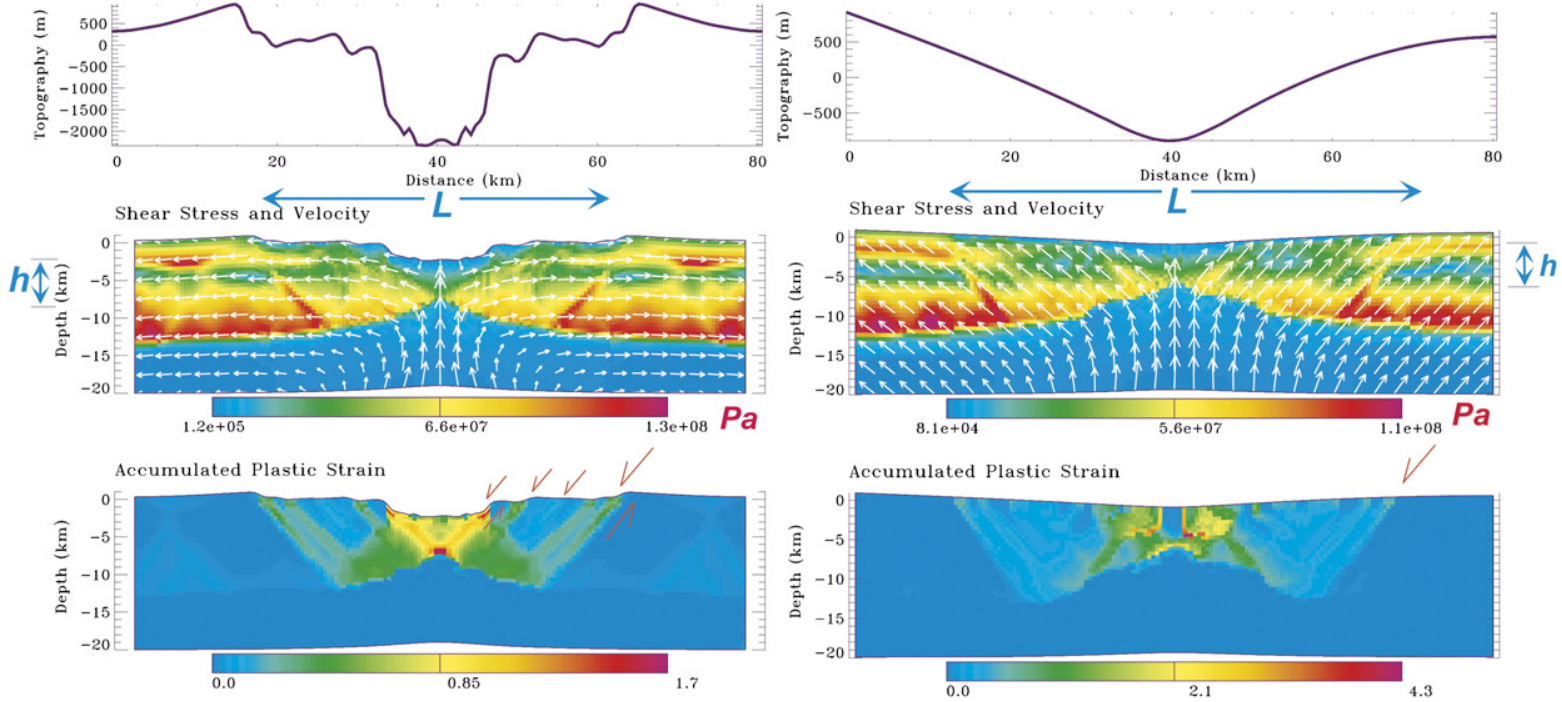

Fig. 25. (a) Syn- and post-rift feedback conceptual model (Burov and Cloetingh, 1997); (b) Numerical model (Burov and Poliakov, 2001) of rift evolution with and without active surface erosion, for the same boundary and initial conditions. Erosion results in much stronger crustal thinning and a wider basin than in the case without erosion.

denudation/sedimentation rates are well constrained may provide new possibilities for constraining the longterm rheology of the lithosphere (e.g. Burov and Watts, 2006).

Reliable information on (de)coupling processes at the crust-mantle and lithosphere-asthenosphere boundaries and at the two principal phase transitions within the deeper mantle (at about 410 and $660 \mathrm{~km}$ depth) will be of fundamental importance for modelling surface topography. The quantification of dynamic depth-to-surface relationships is a major challenge, requiring innovative approaches to 4-D modelling. The principles of available 
conventional fluid-dynamic modelling are robust, but require greatly increased computer power to provide adequate resolution of a convection system characterized by thermal boundary layers, slabs and plumes of complex structure that may evolve rapidly. New approaches need to incorporate yielding rheologies of crustal and mantle materials, integrated modelling of material flow and elastic deformation (also crucial for predicting realistic topography evolution), crustal and lithospheric weakness zones and/or faults. To account for elastic and plastic deformation may actually require modifying available large-scale mantle dynamics models to solve, at least for the lithospheric part, full stress equations with free upper surface boundary conditions instead of flow approximations (Fig. 24c). Mantle models need to be constrained by mantle tomography, geodetic and electromagnetic data. The latest geo-modelling tools are able to consistently treat homogeneous and inhomogeneous deformation with realistic faults, so that the magnitude of uplift, subsidence, fluid flow and other types of deformation (derived from geological markers or GPS, stress in boreholes and earthquakes) can be linked and interpreted quantitatively. The goal of 4-D modelling is to quantify the dynamic evolution of Solid-Earth boundaries and phase transitions and associated surface deformation, and to define the present state of surface deformation, including its space-time gradient (a prerequisite for geoprediction). To achieve this goal, very highresolution at temporal and spatial scales (e.g. 50-100 yr, $5-10 \mathrm{~km})$ is required.

\subsubsection{Synergy between Analogue and Numerical Modelling}

Novel tectonic modelling concepts and their implementation in numerical modelling software provide new opportunities for quantifying the interplay between stresses and rheology during deformation of the lithosphere. Computer simulations will focus on the links between mountain-forming and basin-forming processes, basin geometries and vertical motions in space and time. Furthermore, thermo-mechanical numerical modelling schemes, accounting for the physics of strain localization in the lithosphere and its consequence for poly-phase deformation and associated vertical motions, can be designed and implemented.

Analogue modelling will provide independent validation of numerical models and will be particularly useful in complex settings, such as those with pronounced 3-D geometries (e.g. strike-slip systems and compressional mountain belts). Various scales can be handled: shallow to deep, local to regional with advantages of analogue modelling in terms of complexity and proximity to geological observations and advantage of numerical modelling in terms of physical clarity and higher potential for sensitivity studies and parameter variation (Fig. 26). In analogue experiments, geomechanical boundary conditions and material properties will be dynamically scaled to simulate lithospheric conditions.

With respect to modelling techniques, ever-faster computer systems and ever-larger datasets result in vast improvements in modelling capabilities. A transition to true 4-D modelling has been achieved during the last years. However, modelling approaches to different problems are still developed on an ad-hoc basis.

\section{The natural laboratory concept: from orogen through platform to continental margin}

The TOPO-EUROPE network provides a discussion forum for a multidisciplinary research programme which functions in a feedback mode between advancement of new numerical modelling concepts and their validation by an array of geological and geophysical datasets from a number of natural laboratories in Europe. To this purpose the network concentrates on well documented regions, each of which is optimally suited to address the coupling between tectonic (endogenic) and surface (exogenic) processes and the related effects on topography development and inherent geo-hazards (Fig. 27).

TOPO-EUROPE up-scales the expertise acquired during the EUROPROBE programme through the integration of the above-described components as the fundamental approach to provide conditions for closing the loop between observation, reconstruction and process-oriented modelling. TOPO-EUROPE integrates geology, geophysics, geodesy and geotechnology and provides the frame for intense cross-fertilization between these disciplines. By working together in a concerted effort on common data sets, an optimal dissemination of results will be achieved.

Integration of data sets and data handling is vital to the efficient transmission of findings through the above mentioned chain of components. In TOPO-EUROPE this can be achieved via a number of connected implementation steps centred on three key cells, namely: (1) the creation of new think-tanks for the development and implementation of new conceptual approaches and testing of their viability against geological and geophysical data from selected natural laboratories; (2) the creation of new Earth System teams working jointly on unexplored interfaces between existing research activities; and (3) building of information technology cells to optimize integrated data handling, interdisciplinary modelling and software integration. 


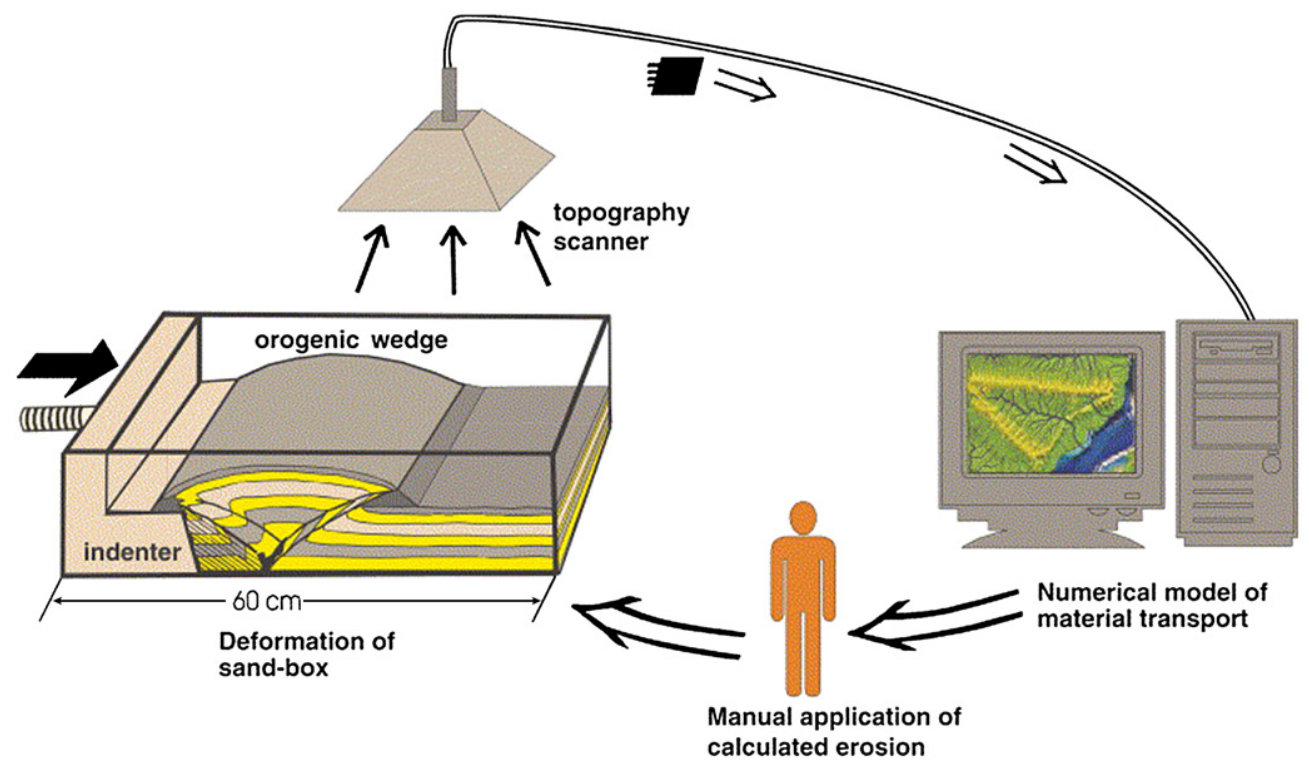

Fig. 26. Schematic diagram showing the added value of a coupled analogue-numerical modelling system (Persson et al., 2004). The analogue modelling facilities are used to simulate upper crustal deformation and its dynamic response to surface erosion and sedimentation predicted by the developed numerical models. The scanner is used to transmit the surface topography of the analogue model to the numerical model. The displayed image shows the drainage system of the Ebro river (NE Spain) (Garcia-Castellanos et al., 2003). Subsequently, the calculated erosion/deposition is manually applied to the analogue model.

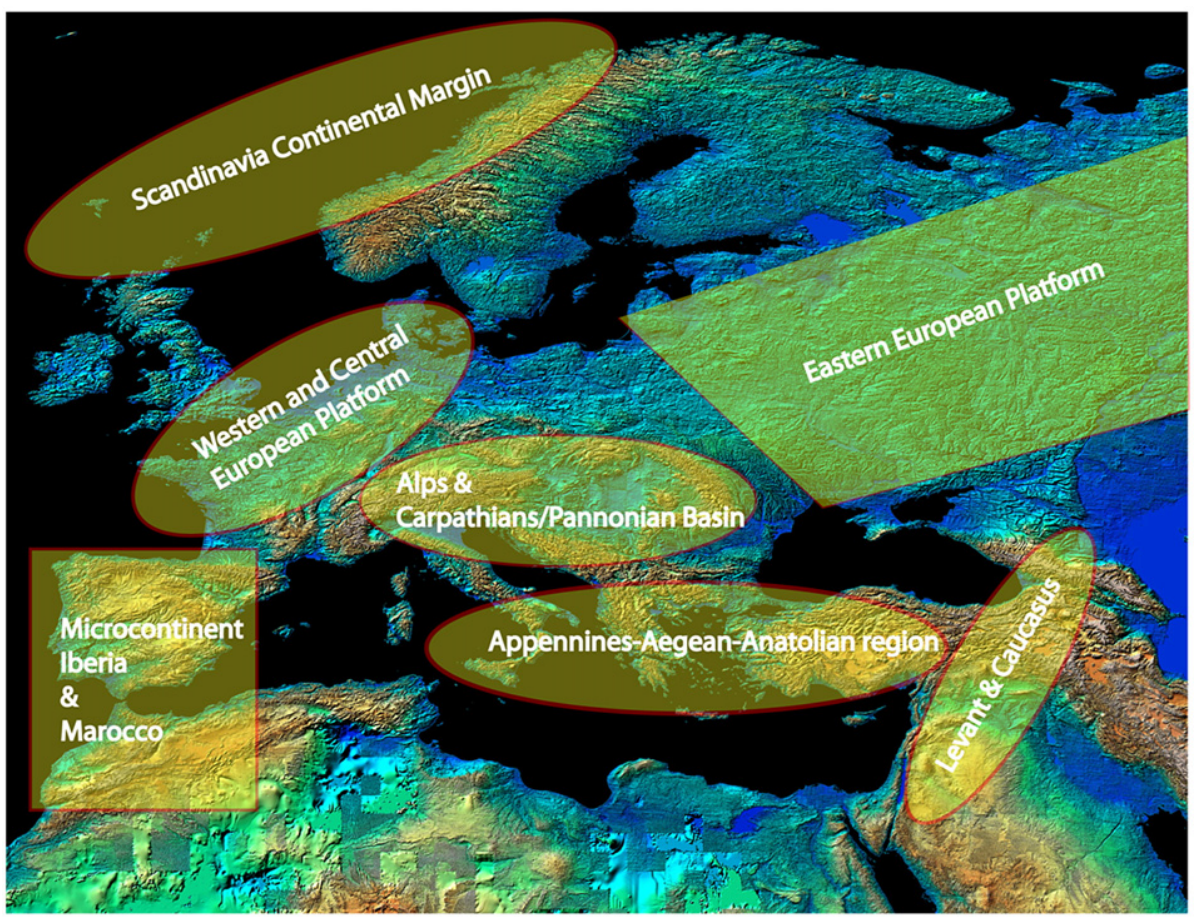

Fig. 27. Location of TOPO-EUROPE natural laboratories discussed in the text. 


\section{Integrated approach to selected natural laboratories and analogues}

In Earth Sciences, analogues are the key to reconstructing the past and predicting the future. The Earth's natural laboratories provide observations on different time slices at a range of scales. An unparalleled opportunity to fill the gaps in our present understanding of the Solid-Earth system is provided by comparison and quantitative analysis of high resolution 4-D data cubes generated by the chain of the 4 integrated TOPOEUROPE components. Such comparisons can be made at different time and space scales.

TOPO-EUROPE operates in an iterative manner with initial models being developed to explain existing data sets and concepts. In parallel, new higher resolution data will be acquired in a number of carefully selected European natural laboratories. The derived numerical models will then be tested and refined on the basis of the new data.

The TOPO-EUROPE integrative research program is centred on critical regional and continental-scale Earth Science problems in carefully selected natural laboratories that cover a wide range of geodynamic settings and geo-hazard provinces, for each of which extensive databases are available. Examples are (Fig. 27):

- The Alps/Carpathians-Pannonian Basin System, where mountain building and the development of deep continental basins has created Europe's weakest crust, prone to major earthquakes, land slides and flooding.

- The West and Central European Platform, where the continent is breaking apart, land is subsiding below sea level and much of Europe's population and infrastructure are concentrated.

- The Aegean-Anatolian and Apennines-Tyrrhenian regions where seismicity, volcanism and mountain building result from the ongoing collision of the European and African-Arabian plates during the final closing stages of an ocean.

- The Iberian Peninsula, where discrimination between deformation induced by plate boundary forces and by deep-seated thermal anomalies is needed.

- The Scandinavian Continental Margin, where continental rupturing resulted in opening of an oceanic basin and the development of ocean-continent boundary zones rich in hydrocarbons.

- The East-European Platform, where key research will target the detailed structure of the upper mantle to constrain ancient tectonic analogues of modern geodynamic processes and to evaluate the effect of deep mantle processes on reworking of the litho- sphere leading to on-going subsidence of its southern margins.

- The Caucasus and the Levant, where the interaction between continental collision and continental extension can be studied in an area with the highest topography of Europe (the Caucasus Mountains) and the lowest continental depression (the Dead Sea).

- Analogues elsewhere in the world, such as the Andes, the western USA and the Middle East.

Together these natural laboratories provide a set of world-class opportunities to probe and quantify the entire range of plate interaction processes affecting topography in the context of presently active geological processes. In these areas we can obtain the highest possible resolution required to discriminate between endogenic and exogenic Earth processes, required to quantify the coupling between Solid-Earth and surface processes. TOPO-EUROPE's natural laboratories discussed below offer unique key study areas for developing a new generation of models explaining ongoing deformation of the lithosphere and its repercussions on continental topography and the human habitat. Other natural laboratories may be selected as the project advances. These will be chosen based on their merits.

\subsection{Within the Orogen: the Alps/Carpathians- Pannonian Basin System}

The Alps/Carpathians-Pannonian Basin System offers the opportunity to analyze and quantify intraplate tectonics and slab mechanics that operate in the aftermath of continental collision on an orogen that is presently characterized by significant neotectonic activity (e.g. Cloetingh et al., 2004). These processes control the 4-D evolution of topography, erosion, mass transfer and sediment accumulation (e.g. Cloetingh et al., 2003a). Of particular importance is the development and validation of a new generation of models for ongoing orogenic activity, as well as the analysis and modelling of neotectonic controls on topography development and landscape forming processes. Dedicated research efforts involve the interpretation of already available data, deployment of analytical facilities, and process-oriented 3-D modelling. Results obtained so far demonstrate the importance of recent crustal deformation (Fig. 28), and particularly of the dramatic differential vertical movements that occurred during the last several million years and that are still ongoing. An important research aspect addresses the mechanics of coupling between crustal shortening and foreland basin development along the Alpine-Carpathian arc and back-arc deformation in the 


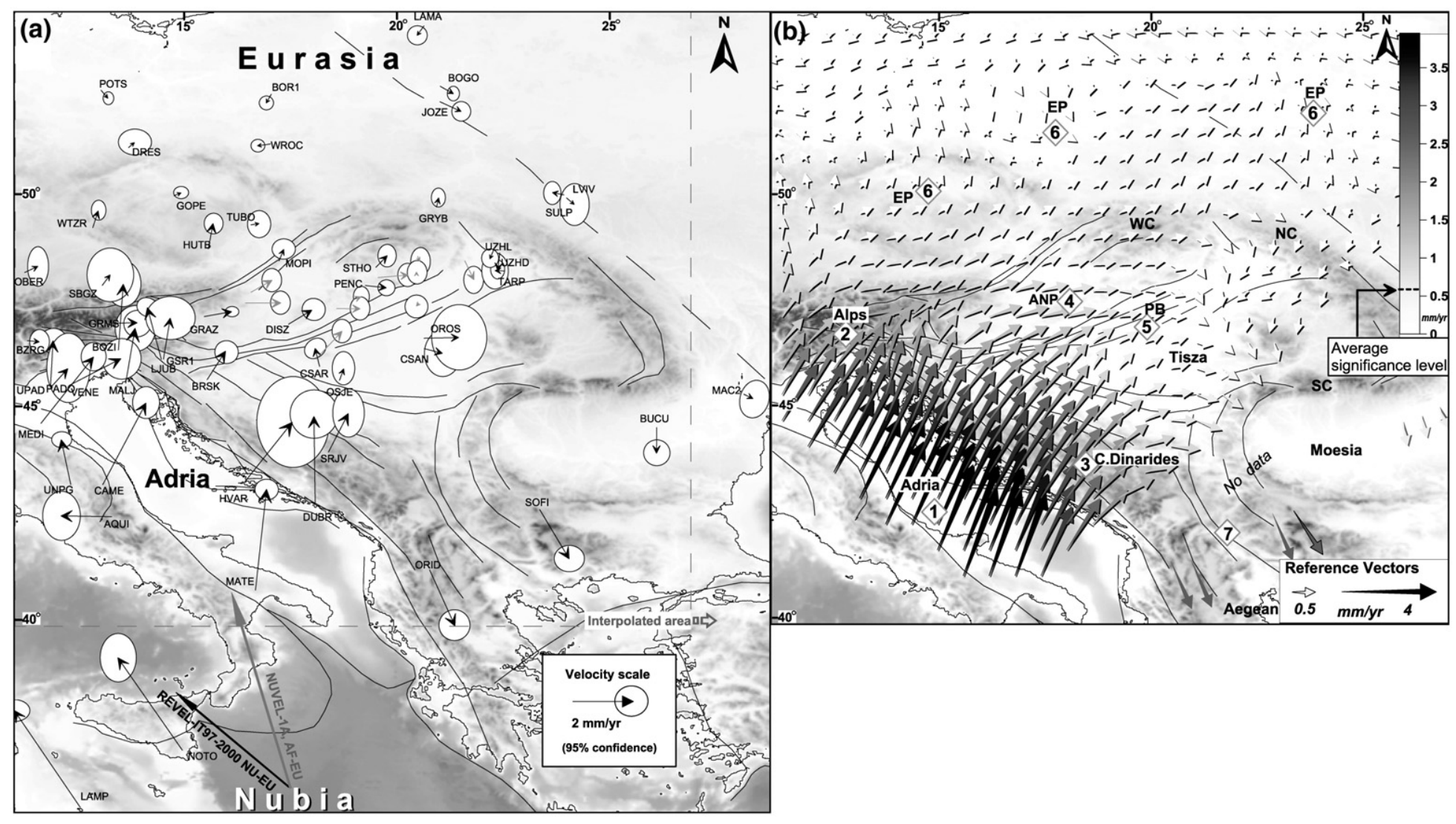

Fig. 28. (a) GPS velocities in respect to Eurasia and (b) interpolated GPS velocity field and tectonic interpretation for the Pannonian-Carpathians-Dinarides domain (after Grenerczy et al., 2005). 
Pannonian Basin (e.g. Horváth and Cloetingh, 1996; Cloetingh et al., 2006a). Moreover, research will focus on the interplay between lithosphere dynamics, active tectonics and the evolution of topography and drainage patterns. Geoprediction in the Alpine/Carpathian-Pannonian Basin System requires a multidisciplinary effort and, therefore, the interaction and collaboration of researchers covering a broad field of expertise. A major challenge to TOPO-EUROPE is to establish reliable links between lithosphere dynamics, neotectonics, topography development, and climatically controlled surface processes through quantitative modelling of an array of datasets, covering different scales and aspects of these phenomena. As the TOPO-EUROPE network focuses on Solid-Earth processes and their interaction, it will take an integrated multi-scale approach, both in time and space, to questions inherent to the Alpine/Carpathian-Pannonian Basin natural laboratory. Research activities will aim at understanding the coupling between endogenic processes that operate at a 3-D lithospheric scale and exogenic processes that are active at or near the Earth's surface.

Specific goals for this natural laboratory will be the reconstruction and modelling of neotectonic and landscape forming processes. The mechanics of coupling between back-arc deformation in the Pannonian Basin, continental collision and foreland basin evolution along the Alpine-Carpathian arc will be investigated. Analysis of the interplay between active tectonics, mantle dynamics, topography evolution, drainage pattern development and natural hazards is of key importance in this natural laboratory. European researchers are in a competitive position in this domain, owing to the recent acquisition of a number of deep seismic profiles (e.g. TRANSALP, NFP-20, CELEBRATION, DACIA-PLAN, Vrancea 1999-2001) covering various sectors of the entire system.

\subsubsection{Neotectonics, climate and surface processes}

The Late Pleistocene and Holocene record of tectonic and climate changes is particularly intriguing in the light of the remarkable coincidence of societal evolution events and historical benchmarks that apparently were driven by environmental changes (e.g. Bada et al., 2005b). Most of the present climate reconstruction studies target isolated parts of the sediment source (mountains) to sink (basins) corridor that is subject to tectonically, as well as climatically induced changes. Correspondingly, the interrelation of these changes is poorly defined, and their mechanisms remain enigmatic (Fig. 29). Therefore, an integrated approach is required to unravel the response of the interacting parts of the complex source-to-sink system to tectonic and climatic changes. In this respect, Late Neogene source-sink systems, well documented for instance in the Carpathians by surface and subsurface data (e.g. Matenco and Bertotti, 2000; Matenco et al., 2003; Tãrãpoancã et al., 2003; Dinu et al., 2005), will be analyzed in terms of their response to tectonics, controlling uplift of orogenic belts, the opening and closing of sea ways and the subsidence of sedimentary basins. These will be linked to climate changes, controlling erosion rates, sediment transport mechanisms and potentially the erosional break-down of tectonically-induced sills, controlling the erosional baselevel in dammed-up sedimentary basins, as for instance at the Iron Gates straddling the South CarpathiansBalkans connection. The thus established past sourcesink analogues, and their modelling, will aid in the understanding of recent changes (Fig. 30). Particularly, at the transition from the Pliocene to the Quaternary an enigmatic massive influx of sediments is observed, the tectonic and climatic signals of which are poorly understood (Necea et al., 2005). However, it is important to determine the neotectonic signal that underlies the Late Pleistocene and Holocene changes in the Alpine/ Carpathian-Pannonian Basin system (e.g. Bertotti et al., 2003; Fodor et al., 2005). Precise dating and highresolution correlations are prerequisites for sound geological constraints on thermo-mechanical modelling of basin geometries (e.g. Sanders et al., 1999). Particularly the recently developed state-of-the-art U-Th or nuclides methodology, combined with step-wise provenance studies, permit accurate dating of the most recent tectonic events that had a high human impact (e.g. Merten et al., 2005). Similarly, isotope geochronology provides an important tool for quantifying the timing and rate of erosion in source areas and sediment transport to actively subsiding basins, particularly during regional crisis events (e.g. Foeken et al., 2003; Ruszkiczay-Rudiger et al., 2005). Moreover, Pliocene-Quaternary climatic events can serve as time markers for unravelling signals that result from major plate tectonic processes that may be expressed by different types of deformation along the orogenic chain.

\subsubsection{Implications for the natural hazards, in particular the Vrancea seismicity}

The societal impact of active tectonics in the SE Carpathians is one of the largest in Europe. Strong earthquakes within the lithospheric slab that gravitationally sinks into the mantle have a recurrence interval of $10 \mathrm{yr}$ for earthquakes with $\mathrm{M}_{\mathrm{w}}>6.5,25 \mathrm{yr}$ for $\mathrm{M}_{\mathrm{w}}>7$ and $50 \mathrm{yr}$ for $\mathrm{M}_{\mathrm{w}}>7.5$ (Oncescu and Trifu, 1987). Within the seismogenic volume $(80 \times 40 \times 120 \mathrm{~km}$, Fig. 31$)$ the five 


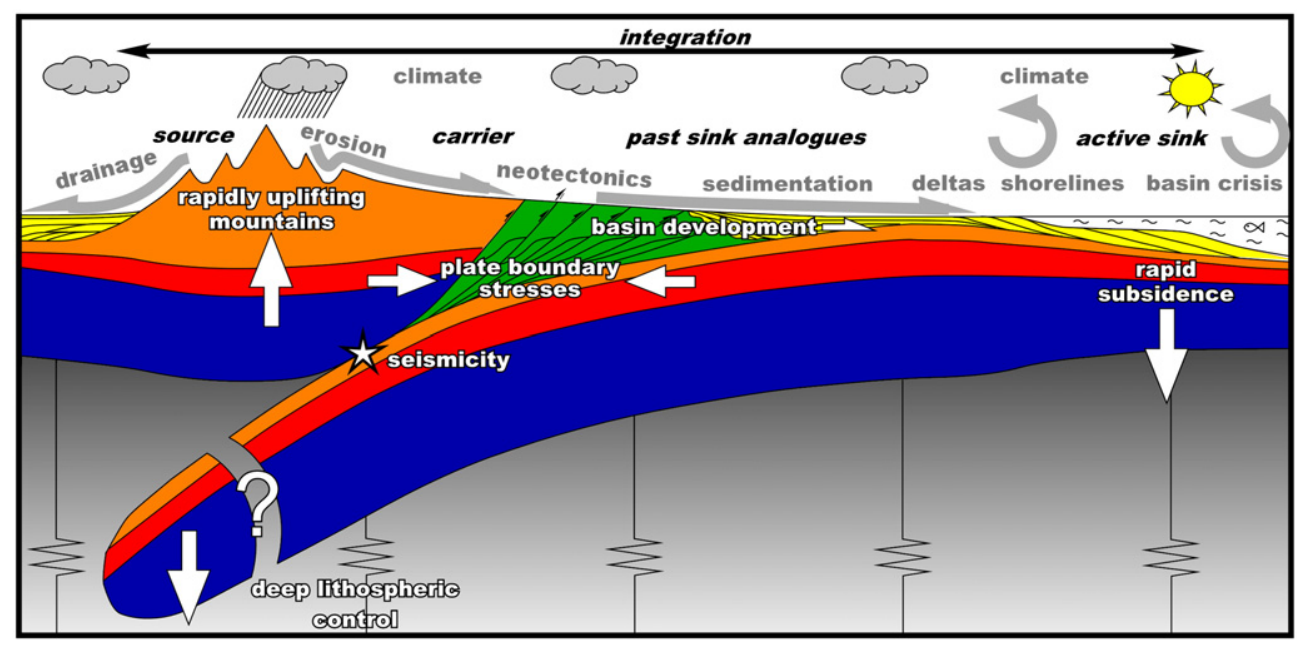

Fig. 29. Schematic Source-to-Sink systematics and coupled orogen-basin evolution in the aftermath of continental collision.

strong earthquakes of the last century (Oncescu and Bonjer, 1997; Bala et al., 2003) exhibit the largest present-day strain concentration in continental Europe of $2 \times 10^{-7} \mathrm{yr}^{-1}$ (Wenzel et al., 1999) and had a significant impact on densely populated areas, such as the city of Bucharest (Sokolov et al., 2004).

In order to better assess seismic hazard in the Vrancea region, processes controlling the stress and strain evolution
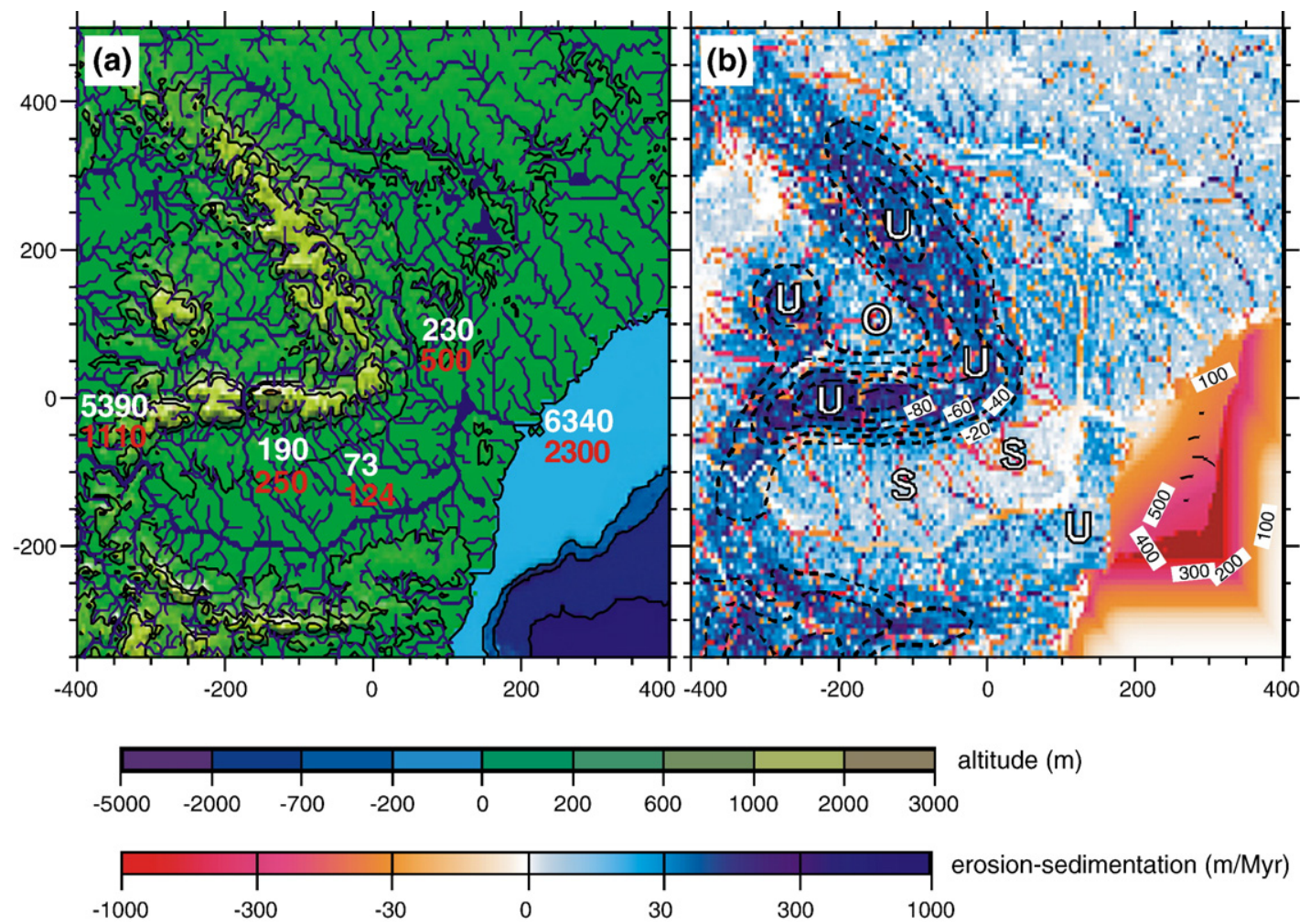

Fig. 30. Numerical model for surface transport in the Romanian Carpathians. (a) Present-day observed topography and predicted drainage network using the historical mean runoff distribution. Numbers indicate water discharge (white, in $\mathrm{m}^{3} / \mathrm{s}$ ) and sediment load (red, in $\mathrm{kg} / \mathrm{s}$ ) at selected locations of the Danube river and its tributaries. River width is plotted proportional to the predicted water discharge. (b) Predicted erosion/deposition (shade) and isostatic vertical velocity of the crust related to the surface mass transport (isolines labeled in $\mathrm{mm} / \mathrm{yr}$; dashed lines correspond to uplift). $\mathrm{U}, \mathrm{S}$ and $\mathrm{O}$ indicate present-day uplift, subsidence and stable topography, respectively, as inferred from geodetic leveling measurements (after Cloetingh et al., 2003a). 


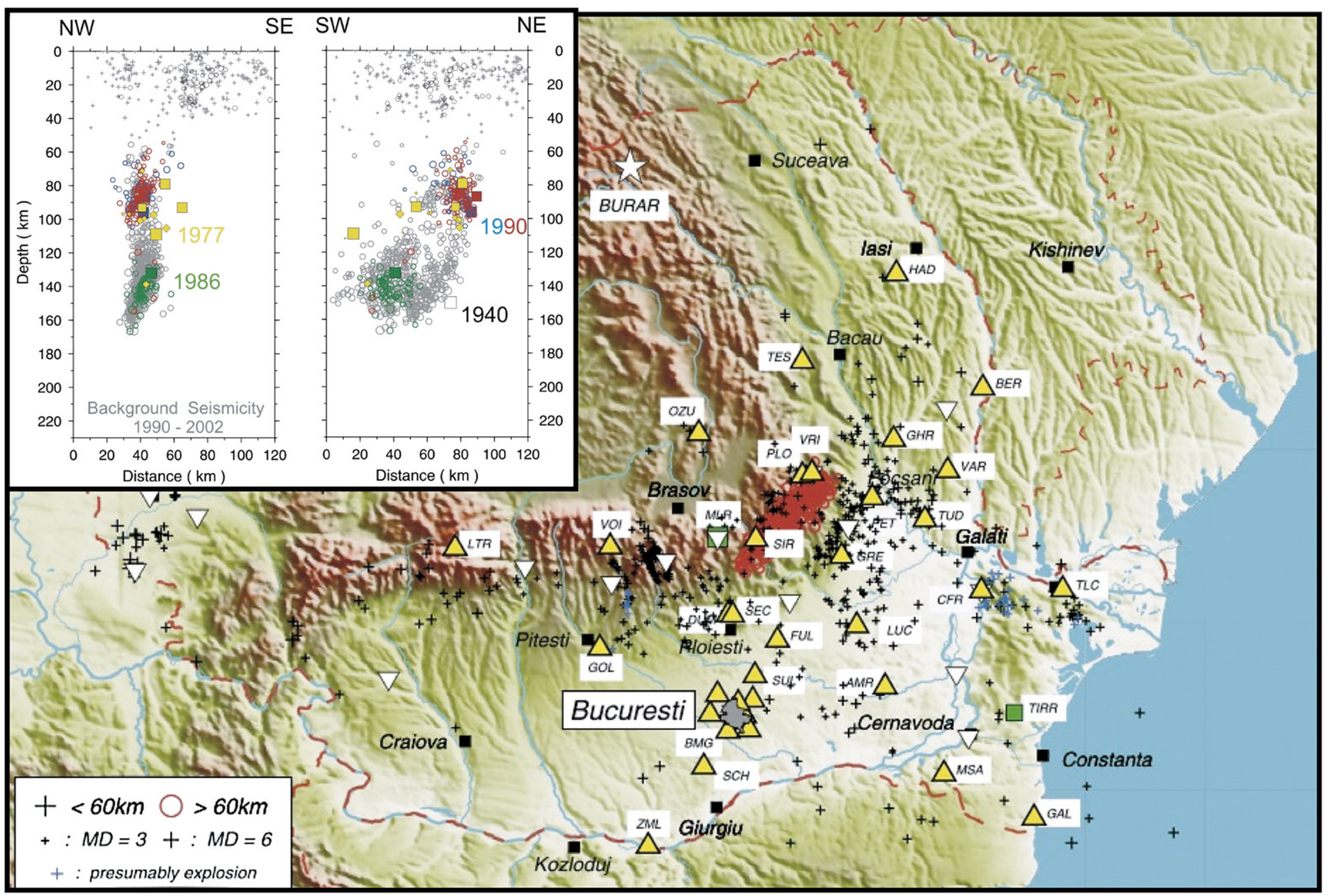

Fig. 31. Background seismicity in the Vrancea region in the period 1990-2002, and $>$ M6.0 earthquakes in the last century. Yellow triangles and green square show seismic stations. Inset shows the intermediate depth earthquakes along NW-SE and SW-NE profiles. Note the spatially limited occurrence of earthquakes in the slab and the seismic gap below the Moho at $\sim 40 \mathrm{~km}$ depth. (Source: Collaborative Research Centre, CRC 461 Strong Earthquakes, University of Karlsruhe). 
need to be understood. Questions of why seismicity is concentrated in a sub-volume of the high-velocity body (Fig. 32), whether there is a pattern, and what is the role of stress diffusion in the mantle around the high-velocity body, are highly relevant to seismic hazard assessment. A key question is whether the sequence of $M>7.0$ earthquakes is random in depth and time, or if there is a causal relationship between them. A simple general hypothesis states that the co-seismic static stress changes, the Coulomb Failure Stress Changes (CFS) control the location of the succeeding earthquake (King et al., 1994). This CFS triggering hypothesis has been tested successfully on the 20th century earthquake sequence along the North Anatolian fault (Stein et al., 1997). However, at greater depth, such as in the seismogenic volume of the Vrancea slab, stress transfer also involves transient processes (Pollitz, 2003).

To clarify whether there is a predictable triggering process through static and transient stress transfer that controls the spatial succession of strong earthquakes in the Vrancea slab, a deterministic 4-D numerical model is required. An independent control of such a model is the estimation of vertical movements with GPS and the geologically estimated subsidence and uplift rates on longer time-scales. These observations are assumed to be the surface expression of geodynamic processes that act at depth and control the stress evolution. Processes

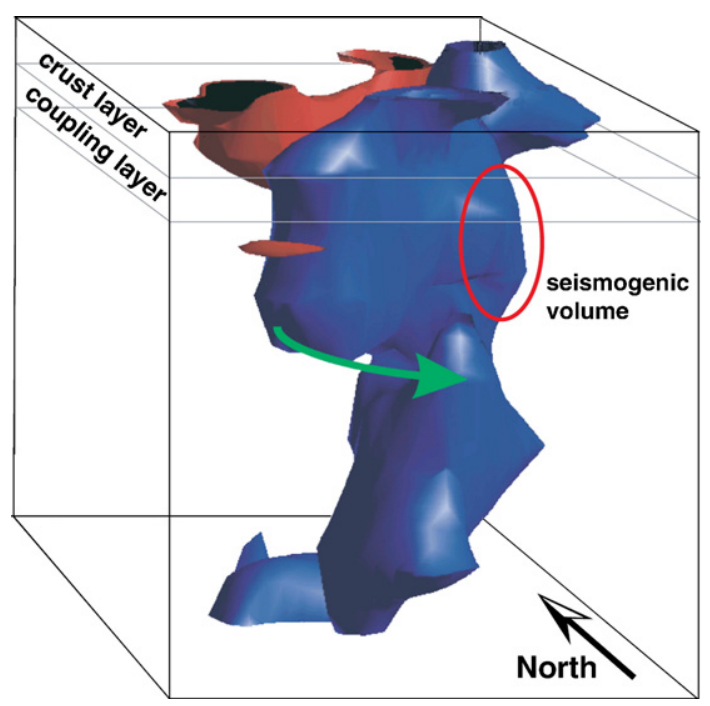

Fig. 32. 3-D image of the high-velocity mantle body beneath the Vrancea area. Blue and red indicate the $+2.5 \%$ and $-2.5 \% \mathrm{Vp}$ tomographic velocity anomaly, respectively (Martin et al., 2006). The red ellipse approximately shows the area of the seismogenic volume, as given in the inset of Fig. 31. The green arrow indicates that the lower part of the slab is probably laterally torn off (after Martin et al., 2006). that play a role in the stress evolution and active tectonics include subduction, re-equilibration of crust and mantle, mass re-distribution (erosion, sedimentation), and post-seismic relaxation.

Several models have already been advanced for the geodynamics and tectonics of the Vrancea region (Bertotti et al., 2003; Cloetingh et al., 2004; Sperner et al., 2004; Dirkzwager et al., in press). Each of these models addressed a specific question on its inherent time scale and delivered fundamental understanding of (a) the processes that contribute to the topography evolution and its changes in time and space or (b) the stress concentrations and state of stress at depth that are responsible for seismic events of intermediate strength.

The next generation of numerical models that address contemporary stress and strain accumulation needs to integrate these different approaches, and to physically link the 3-D structural complexity of the crust with mantle processes as well as surface processes such as erosion and sedimentation and their mechanical response. Such an integrated model approach can for the first time address the feedback between processes that act in the crust and lithospheric mantle with sub-lithospheric mantle processes. In order to set up such an integrated model the necessary algorithms and tools are currently developed within the CRC 461 Strong Earthquakes (Wenzel et al., 1998) of the Karlsruhe University. The importance of such an approach has been revealed by Dirkzwager et al. (in press), where a 3-D semi-analytical discretization method is used to construct a model geometry representing the present-day lithospheric structure of Vrancea, in order to model and ascertain the driving forces behind the vertical GPS field (Pollitz, 1997; Pollitz, 2003). Model results show that the maximum post-seismic deformation due to post-seismic relaxation after the five intermediate strength earthquakes in the Vrancea region between 1940 and 1990 are approximately $2 \mathrm{~mm} / \mathrm{yr}$, and suggest that post-seismic relaxation is contributing to but not driving the observed vertical deformation pattern. The discrepancy between the modelled and observed vertical velocity rates may be due to inaccuracies in the visco-elastic model, the length of GPS monitoring or alternatively, the post-seismic signal may be superimposed on a positive background signal arising from isostatic rebound of the lithosphere after, for example, 'break-off' of the subducted lithospheric slab.

Apart from seismicity, landslides and flooding events that also pose large hazard risks have so far not been assessed in terms of neotectonic activity (Matenco et al., in press). Displacement of the basement along active normal fault systems can cause large scale collapse of 
its poorly consolidated Quaternary cover, giving rise to long linear landslide alignments often threatening large inhabited areas in entire SE Moldavia. Due to active uplift of the external SE Carpathians units and subsidence of their foreland, a largely uncompensated and unstable river network developed (Rãdoane et al., 2003). Whilst braided rivers rapidly incise in the rising Carpathians, meandering systems deposit thick alluvial sediments in the subsiding foreland (Fig. 30). Furthermore, the present-day subsidence axis is used by the drainage collector of the East Carpathians, the Siret River, which by meander shifts and flooding actively deposits alluvial material in the Focsani basin, an area close to sea level (minimum $2.5 \mathrm{~m}$ above MSL; Fig. 33). Active subsidence increases the disequilibrium of the system and associated natural risk, as observed in recent years through increasing flooding damages in the Focsani area (e.g., $\sim 1.5$ bn $€$ of direct damages in 2005). Mitigation of this type of natural risk must take into account the pattern of Quaternary and active tectonics.

\subsubsection{Regional tectonics, basin evolution and modelling}

Dynamic and kinematic modelling studies, constrained by integrated basin analysis, thermochronology and structural field studies in source areas, can shed light on the coupling between crustal shortening in the Carpathian arc and deformation of the Pannonian backarc system of basins. Consequently, TOPO-EUROPE addresses the Miocene and Pliocene tectonic and sedimentary evolution of foreland and back-arc basin in the Pannonian-Carpathians domain and plans to develop past analogues on the basis of which the driving mechanisms of Quaternary deformations can be assessed (e.g. Cloetingh et al., 2003a). From such analogue and thermo-mechanical models (e.g. Garcia-Castellanos et al., 2002; Sokoutis et al., 2005), the pattern and interaction of

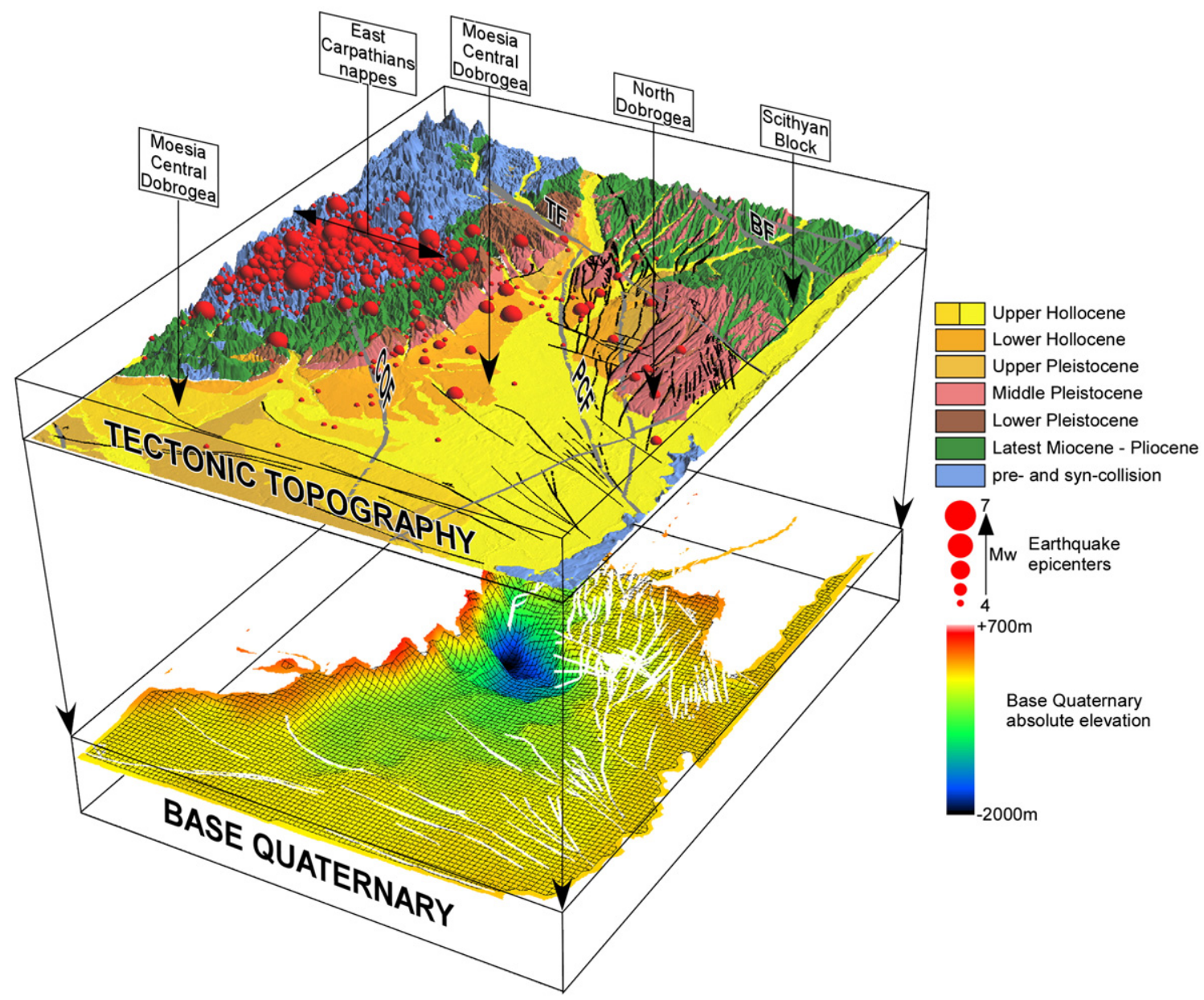

Fig. 33. 3-D geometry of Quaternary deposits and post-orogenic relationship with topography development in the foreland of the SE Carpathians (after Cloetingh et al., 2005a). 
the coupled surface phenomena erosion and sedimentation will be analyzed. The aim is to understand the mechanisms of small-scale changes in the source-sink domain that are caused by large-scale lithospheric processes. A key element in the regional assessment of processes controlling the evolution of the source-sink domains is 4-D tectonic and stratigraphic modelling of the entire Carpathian-Pannonian basin system over large time scales (e.g. Vasiliev et al., 2004; Vasiliev et al., 2005). The objective is to simulate the evolution of these basins, taking into account different tectonic scenarios and the timing of their subsidence and uplift. Such medium scale modelling can be coupled with macroscale thermo-mechanical lithospheric modelling, and micro-scale modelling of the drainage pattern and landscape evolution (Fig. 33).

\subsubsection{Danube river systematics}

The Danube River Basin is one of the highest risk areas of Europe. The environment of this river basin, which itself is subject to significant natural hazards such as earthquakes and flooding, is increasingly stressed owing to human activities. Modernization and intensification of agricultural practices at local, regional and transnational levels, as well as waste disposal, cause soil, water and air pollution, and thus lead to a serious deterioration of environmental conditions, particularly in the active Black Sea sink. Process-level studies are required to improve our understanding of mechanisms that determine the present-day sediment supply to this basin and its ongoing changes. An integrated and strategic management of interdisciplinary research activities is crucial for the sustainable development of regional natural resources. Key areas of the carrier system in the Pannonian-Carpathian domain are the Danube gorges in the South Carpathians (e.g. Clauzon et al., 2005) (Fig. 34), catchment barriers in Transdanubia (Ruszkiczay-Rudiger et al., 2005) (Fig. 35) and the Danube Delta interaction point with the active Black Sea sink (e.g. Ballard et al., 2000; Panin, 2003) (Fig. 36), which is characterized by large lateral wetland variations and mobility in response to active geo-processes (Popescu et al., 2001). In this context, quantitative analysis of the sediment budget and quantification of flooding hazards inherent to a dynamic fluvial system are of greatest importance. This can be resolved by mapping the architecture, facies development and thickness of Pliocene to Quaternary deposits on the basis of available reflection seismic lines, and by carrying out quantitative subsidence analyses, with emphasis on Holocene eustatically induced shoreline variations (e.g. Wong et al., 1994).

\subsubsection{The Danube Delta}

The Danube Delta resulted from the continuous interaction and feedback between offshore dynamics of the Black Sea, the sediment budget of the Danube River, climate changes and human activities in a system that developed during the Holocene (e.g. Panin, 2003) (Fig. 36). Particularly important are ongoing changes in the Danube Delta system, which result both from climatic changes and from slight changes in the neotectonic deformation pattern, controlling opening or closure of connections between sedimentary basins that form part of the same source-sink system (Ungureanu and Stãnicã, 2000). Shallow high-resolution reflection-seismic profiling can resolve the architecture and deformation of late Pleistocene and Holocene river deposits and delta sequences, thus permitting reconstruction of the evolution of the source-sink system during the recent past. River bank structures and their geometry can be correlated with major flooding events. Of particular importance is the study of active coastal processes with emphasis on the analysis and management of delta front areas (Fig. 36).

\subsubsection{Specific targets for the Alps/Carpathians-} Pannonian Basin System

- To better constrain ongoing movements of the Adriatic indenter in order to resolve contrasting elevations between the Alps/Carpathians/Dinarides and the lowlands of the neotectonically active Pannonian Basin System.

- To define a reference geomorphological framework in order to identify where additional age dates are required.

- To increase where possible the absolute ages database in key sectors of the Pannonian-Carpathian system.

- To better discriminate between tectonic and glacial controls on uplift and subsidence.

- To involve the Dinarides countries (Slovenia, Croatia, Serbia, Bulgaria etc) to improve the understanding of deformation transfer from the Dinarides towards the Carpathians.

- To implement a European consortium for the Carpathian Basins Seismological Project and expand it in key areas.

- To define potential key areas for drilling under the ICDP programme.

\subsection{In Front of the Orogen: the West and Central European Platform}

The West and Central European Platform forms the foreland of the Alpine and Pyrenean orogens and provides a natural laboratory for analyzing the response 


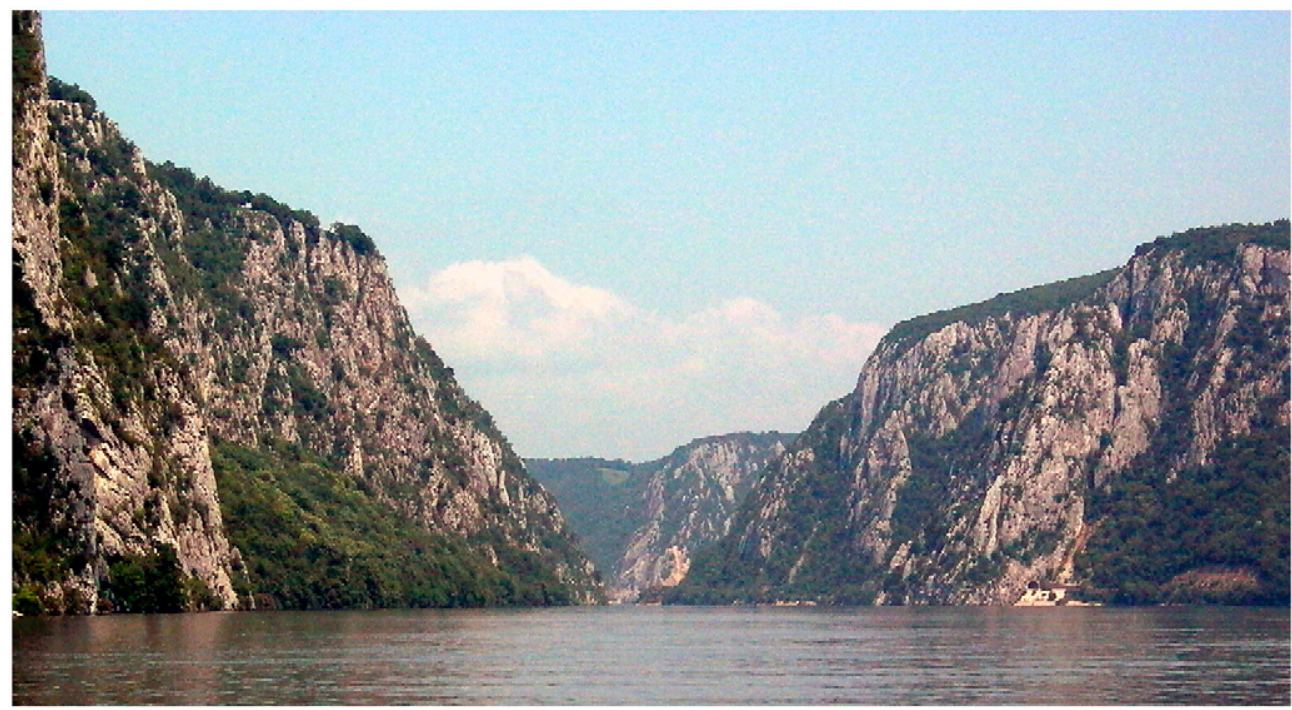

Fig. 34. Iron Gate Danube gorges in the SW Carpathians (Cloetingh et al., 2005a). For scale, note the train tunnel on the right bank of the Danube. A large amount of Quaternary uplift recorded in the flanking mountain chains was accompanied by corresponding river incision.

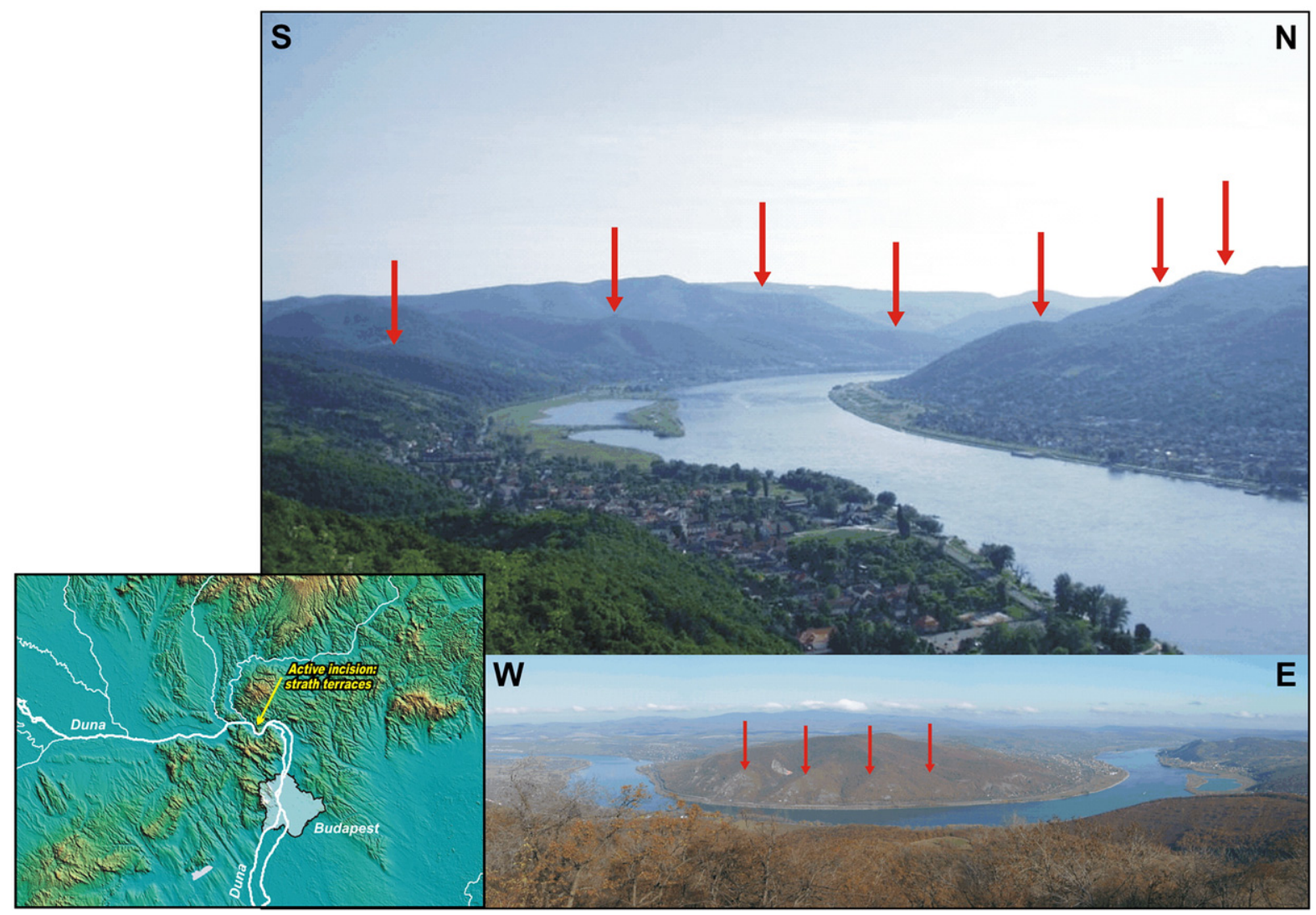

Fig. 35. Ancient Danube terraces at Visegrád, upstream Budapest: ongoing uplift, river incision and erosion. Exposure age of terraces: 0 to 250 Ky, incision rate: $\sim 1.5 \mathrm{~mm} / \mathrm{yr}$, linear incision, no apparent climatic control (after Bada et al., 2005a). 


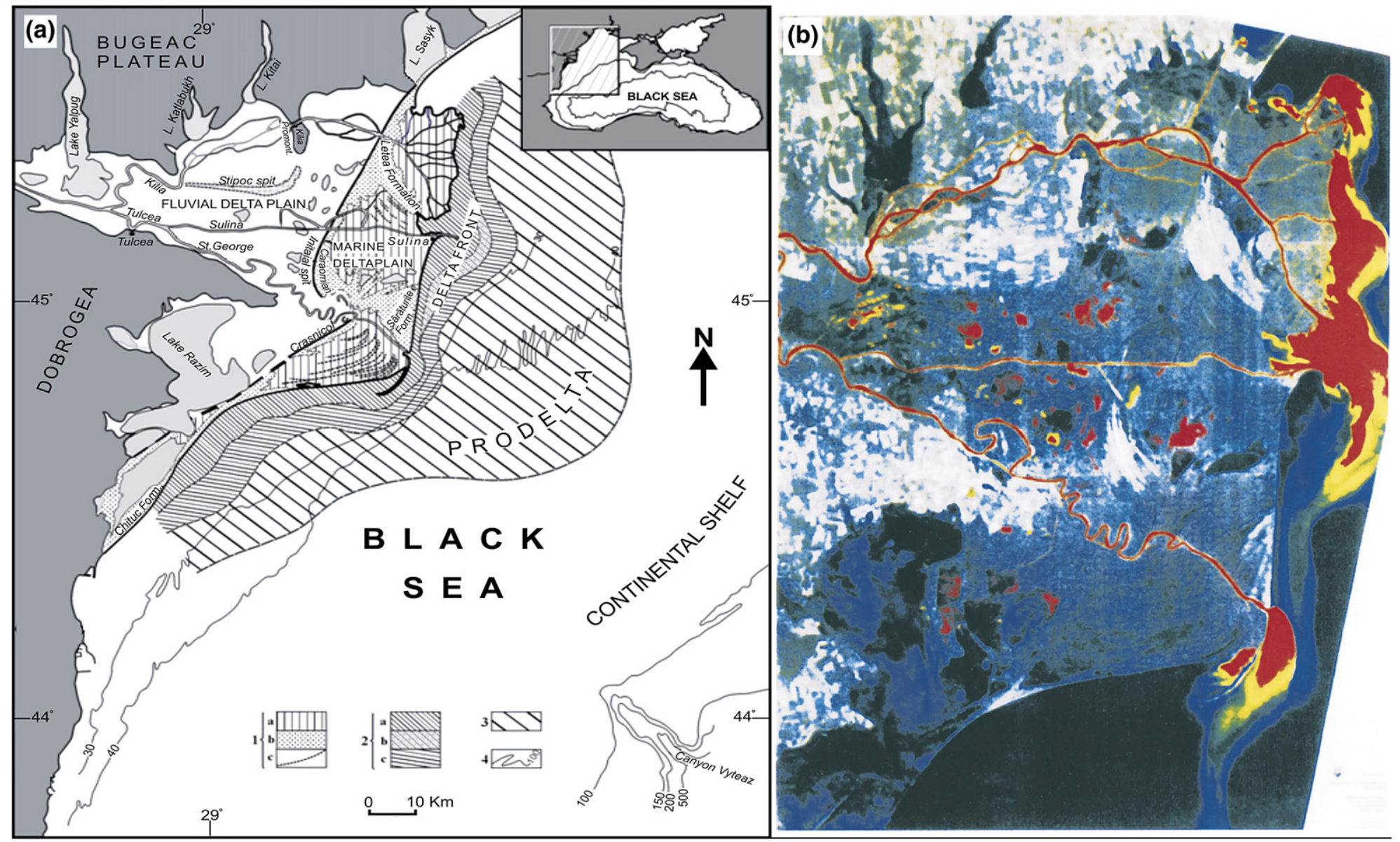

Fig. 36. Left: main morphological and depositional units of the Danube Delta (e.g. Panin, 2003). 1: delta plain; fluvial delta plain (1a); marine delta plain (1b); fossil and modern beach-ridges and littoral accumulative formations built up by juxtaposition of beach ridges (1c); 2: delta-front; delta front platform (2a); relics of the "Sulina Delta" and its delta-front (2b); delta front slope (2c); 3: Danube prodelta; 4: depth contour lines in meters. Right: Satellite image of the Danube Delta, showing suspended sediment supplied by the Danube River (Source: GeoEcoMar Bucharest). 
of an intraplate domain to Alpine collision-related and Atlantic ridge-push forces and to plume-induced thermal perturbation of the sub-lithospheric mantle (Cloetingh and Cornu, 2005b). During the Cenozoic, the lithosphere of the West and Central European Platform has undergone a polyphase evolution, involving the development of the European Cenozoic Rift System (ECRIS), basin inversion, lithospheric folding controlling uplift of the Massif Central-Vosges-Black Forest-Bohemian Massif arch and the Armorican Massif, as well as subsidence of the North Sea Basin, and thermal doming of the Rhenish Massif and the Massif Central (Dèzes et al., 2004). These deformations had severe repercussions on the development of the topography and drainage systems of the Phanerozoic European Platform, particularly during the last $20 \mathrm{My}$ (Fig. 37).

The intraplate domain of the West and Central European Platform is associated with a much higher level of neotectonic activity than hitherto realized (Fig. 38). Seismicity and stress indicator data, combined with geodetic and geomorphologic observations, demonstrate that this platform is presently deforming at strain rates of up to $1 \mathrm{~mm} / \mathrm{yr}$ (Cloetingh et al., 2006b). This has major implications for the assessment of its natural hazards and environmental degradation. The TOPOEUROPE network addresses the relationship between deeper lithospheric processes controlling neotectonics, and surface processes that affect the West and Central

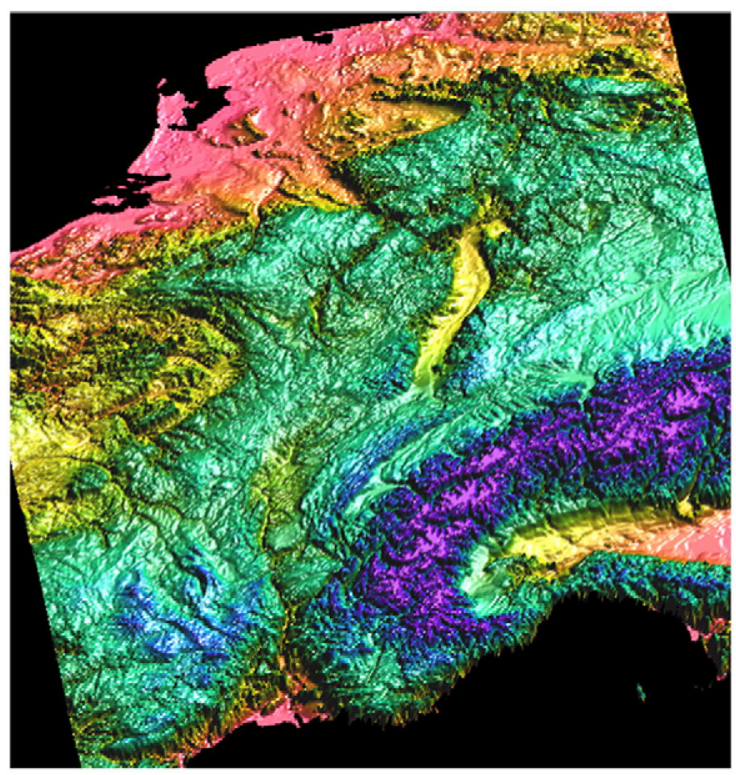

Fig. 37. Digital Elevation Model of the West-European Platform (courtesy EUCOR-URGENT).
European Platform, with special emphasis on tectonically induced topography. The objective is to quantify the contribution of Alpine collisional and Atlantic ridge push stresses, as well as of the loads exerted by mantle-plumes, to the on-going intraplate deformation of the West and Central European Platform and its impact on topography and drainage system evolution and related natural hazards.

\subsubsection{Rationale}

Under the auspices of the World Stress Map project and the Origin of Sedimentary Basins Task Force, both sponsored by International Lithosphere Program (ILP), new databases were developed during the last decade for the stress field and recent crustal-scale vertical motions of the Phanerozoic European Platform. On the basis of these, close links could be established between the stress field, the Neogene to Quaternary intraplate deformation, and the distribution of seismic activity and topography. The present-day stress field of Western and Central Europe (Müller et al., 1997) could be successfully modelled by taking Alpine collisional coupling and Atlantic ridgepush forces into account (Gölke and Coblentz, 1996; Ziegler et al., 2002; Guimerà et al., 2004). Furthermore, acquisition of high-quality tomographic data (Goes et al., 2000a) permitted to image the thermal structure of the sub-lithospheric mantle beneath the West and Central European Platform, revealing that in the area of the European Cenozoic rift system (ECRIS) thermal anomalies occur immediately above the $410 \mathrm{~km}$ discontinuity. These can be interpreted as the heads of mantle plumes from which secondary plumes intermittently welled up (Dèzes et al., 2005), as currently evident beneath the Massif Central (Granet et al., 1995) and the Eifel region of the Rhenish Massif (Ritter et al., 2001).

There is increasing evidence that the West and Central European lithosphere responds to the build-up of intraplate compressional stresses by lithospheric folding (Cloetingh et al., 1999), as evidenced for instance by the Plio-Pleistocene subsidence acceleration of the North Sea Basin and contemporaneous uplift of the Fennoscandian Shield (Cloetingh and Burov, 1996; Van Wees and Cloetingh, 1996). In this context, it is noteworthy that studies on mechanical properties of Europe's lithosphere reveal a direct link between its thermotectonic age and bulk strength, whereas inferences from $\mathrm{P}$ - and S-wave tomography and thermo-mechanical modelling point to pronounced weakening of the lithosphere in the area of the Massif Central and Rhenish Massif owing to high upper mantle temperatures (Cloetingh et al., 2005b). Uplift of the Rhenish Massif by as much as $250 \mathrm{~m}$ during the last $0.8 \mathrm{My}$ (Van Balen 


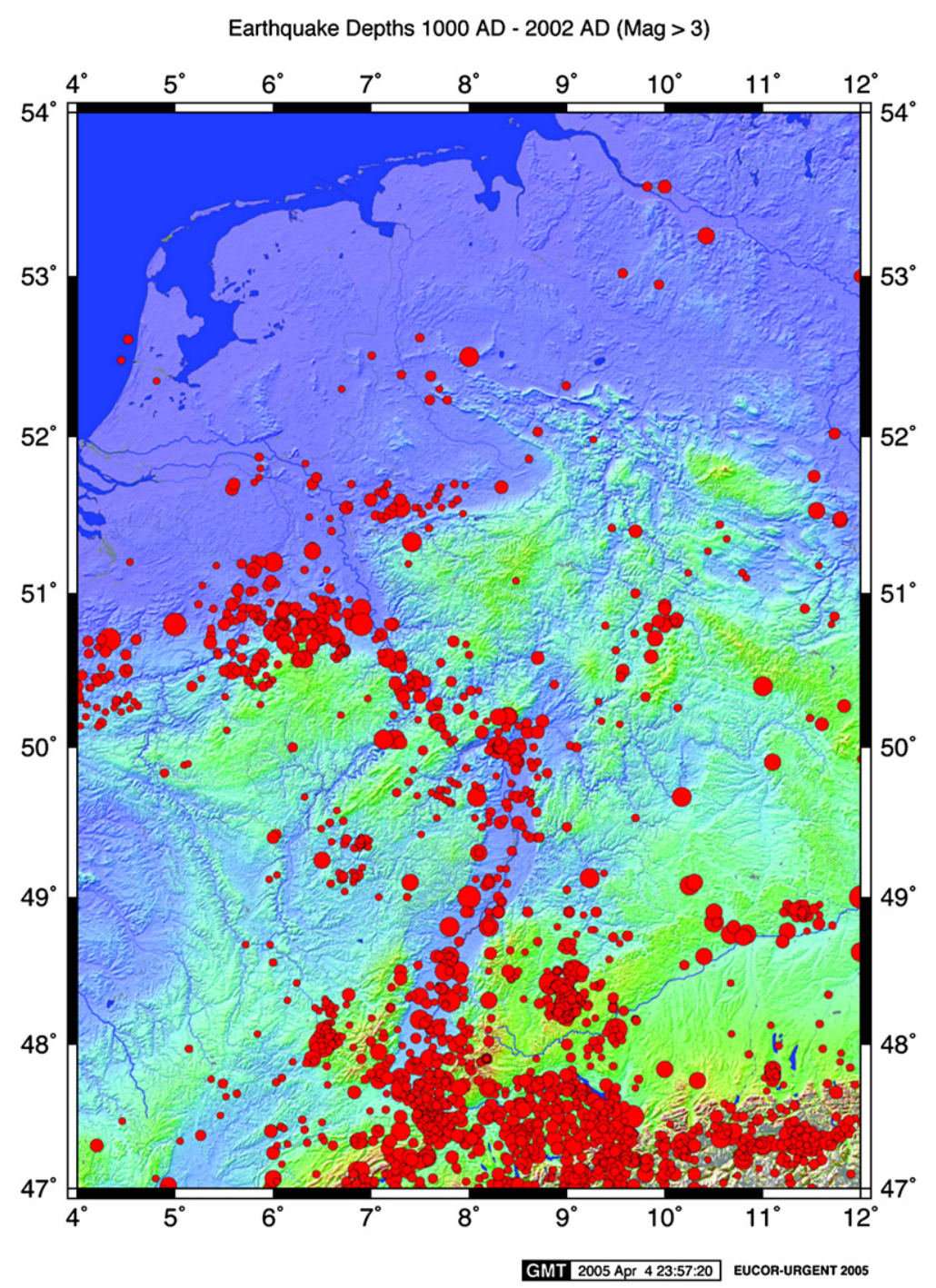

Fig. 38. Seismicity of the Rhine rift system (courtesy EUCOR-URGENT).

et al., 2000; Meyer and Stets, 2002) can be directly attributed to the load of an impinging mantle plume and related thermal thinning of the lithosphere (GarciaCastellanos et al., 2000; Dèzes et al., 2004).

The evolution of ECRIS and the progressive uplift of the Massif Central, the Vosges Black Forest Arch and the Rhenish and Bohemian Massifs during the last 20 My had severe repercussions on the development of the drainage system on the West and Central European Platform (Sissingh, 2006; Ziegler and Dèzes, 2007-this volume). As parts of this drainage system are prone to repeated catastrophic flooding, as seen for instance in Northern Germany and Poland, it is highly susceptible to neotectonic deformations.
Assessment of crustal and lithospheric controls on the neotectonic deformation of the North-European Alpine foreland was the focus of the European ENTEC program that integrated geological, geophysical, geodetic, geomorphologic, and geotechnological approaches (Cloetingh and Cornu, 2005a). Results of this pioneering program show that monitoring of the subsurface by $3-\mathrm{D}$ seismics, combined with satellite-based geodetic monitoring of horizontal and vertical crustal motions, permits to extend the record of neotectonic activity and related topography development into the domain of 100,000 to a few million years, thus building up a large database for validation of process modelling. This approach will be further refined by TOPO-EUROPE. Within the West and 
Central European Platform natural laboratory, TOPOEUROPE will addresses four specific areas and their inherent neotectonic phenomena. These are:

- Neotectonics of the Rhine Graben system.

- Vulnerability of the Rhine-Meuse delta system.

- Seismicity and neotectonic deformation of the Armorican Massif.

- Neotectonic uplift of the Bohemian Massif.

\subsubsection{The Rhine Graben system}

The Rhine Graben system forms an integral part of ECRIS, development of which commenced in the late Middle Eocene in response to the build-up of collisionrelated compressional stresses in the foreland of the Alps and Pyrenees (Ziegler and Dèzes, 2007-this volume). At the transition from the Oligocene to the Miocene, the stress field controlling the evolution of ECRIS changed owing to the consolidation of the Pyrenees (Dèzes et al., 2004). Under the present N- to NW-directed compressional stress regime of the European Platform (Müller et al., 1997) the Rhine Graben system is tectonically active (Fig. 39) and the locus of increased seismic hazards, as evidenced by the great Basel ML 6.2 earthquake of October 18th, 1356.

In the area of the Rhine Graben system, the trajectories of the Miocene and present stress field are very similar (Schumacher, 2002). Yet, the stress level apparently increased between 3 and $2.5 \mathrm{Ma}$ (Dèzes et al., 2004). This is compatible with a subsidence acceleration of the Roer Valley Graben around 2.5 Ma (Zijerveld et al., 1992; Geluk et al., 1994; Michon et al., 2003). Moreover, the paleo-Aare river that had flowed from 4.2 Ma onward westwards along the thrust front of the Jura Mountains into the Bresse Graben (Sundgau gravels) and drained into the Mediterranean Sea, was deflected around 2.9 Ma into the Upper Rhine Graben, thus draining into the North Sea (Müller et al., 2002; Giamboni et al., 2004). This may be attributed to a slowdown of up-warping of the Vosges-Black Forest Arch, a lithospheric fold that was uplifted from mid-Burdigalian (18 My) times onward, and the related resumption of tensional subsidence of the southern parts of the Upper Rhine Graben (Dèzes et al., 2004; Ziegler and Dèzes, 2007-this volume). Geodetic data show for the Black Forest a pattern of slow uplift of horst and slow subsidence of graben structures at rates rarely exceeding $0.25 \mathrm{~mm} / \mathrm{yr}$ (Müller et al., 2002). In the area of the Rhenish Massif, volcanic activity shifted during the Pliocene and Quaternary towards the Eifel area (Lippolt, 1983), for which geomorphologic data indicate from 0.8 Ma onward accelerating uplift rates (Van Balen et al.,
2000; Meyer and Stets, 2002) that at present attain rates of up to $1.2 \mathrm{~mm} / \mathrm{yr}$ (Mälzer et al., 1983).

High-resolution reflection-seismic data, recorded on the river Rhine, and back-stripped well data indicate that the northern parts of the Upper Rhine Graben subsided continuously during Miocene to Quaternary times with some faults extending upward through Quaternary deposits. A minor, base-Quaternary erosional unconformity, evident in the northernmost parts of the Upper Rhine Graben, presumably developed in conjunction with uplift of the Rhenish Massif. This unconformity disappears southward towards the Heidelberg depocentre. Further southward, late Miocene and Pliocene fluvial and lacustrine sediments progressively overstep the intra-Burdigalian unconformity that had developed in conjunction with the doming of the Vosges-Black Forest arch. In the southern parts of the Upper Rhine Graben, where sedimentation resumed only during the late Pliocene and Quaternary, numerous syn-sedimentary extensional faults and local positive flower-structures (Strasbourg transfer zone) were active during its PlioQuaternary subsidence.

In the Roer Valley Graben, Alpine detrital components occur for the first time at the Plio-Quaternary transition (2.6 Ma; Boenigk, 2002; Heumann and Litt, 2002), whilst the timing of the first occurrence of Alpine components in the Upper Rhine Graben is still poorly constrained and may range between 2.9 and $2.6 \mathrm{Ma}$. Correspondingly, it is uncertain whether during the Late Pliocene (2.9-2.6 Ma) the sedimentary load of the river Aare was effectively trapped in the Upper Rhine Graben. During this time, sediment supply to the Upper Rhine Graben may have been in balance with the development of accommodation space in response to its extensional subsidence and tectonic controls on its erosional base level (uplift of the Rhenish Massif). During the Late Pliocene, the Upper Rhine Graben was presumably drained by a northward flowing, low-energy river (Bingen-Koblenz Rhine) that linked up with the higher energy Moselle River that crossed the Rhenish Massif and debouched into the Roer Valley Graben where the Kieseloolite sands and gravels were deposited (Brunnacker and Boenigk, 1983; Klett et al., 2002; Sissingh, 2003). With the end-Pliocene capture of the Alpine Rhine by the Aare drainage system, sediment supply to the Upper Rhine Graben apparently exceeded its subsidence rate and the energy and sediment load of the Bingen-Koblenz Rhine increased, thus facilitating the transport of Alpine components across the Rhenish Massif into the Roer Valley Graben. During the Quaternary, the erosional base level in the continuously subsiding Upper Rhine Graben was controlled by the 


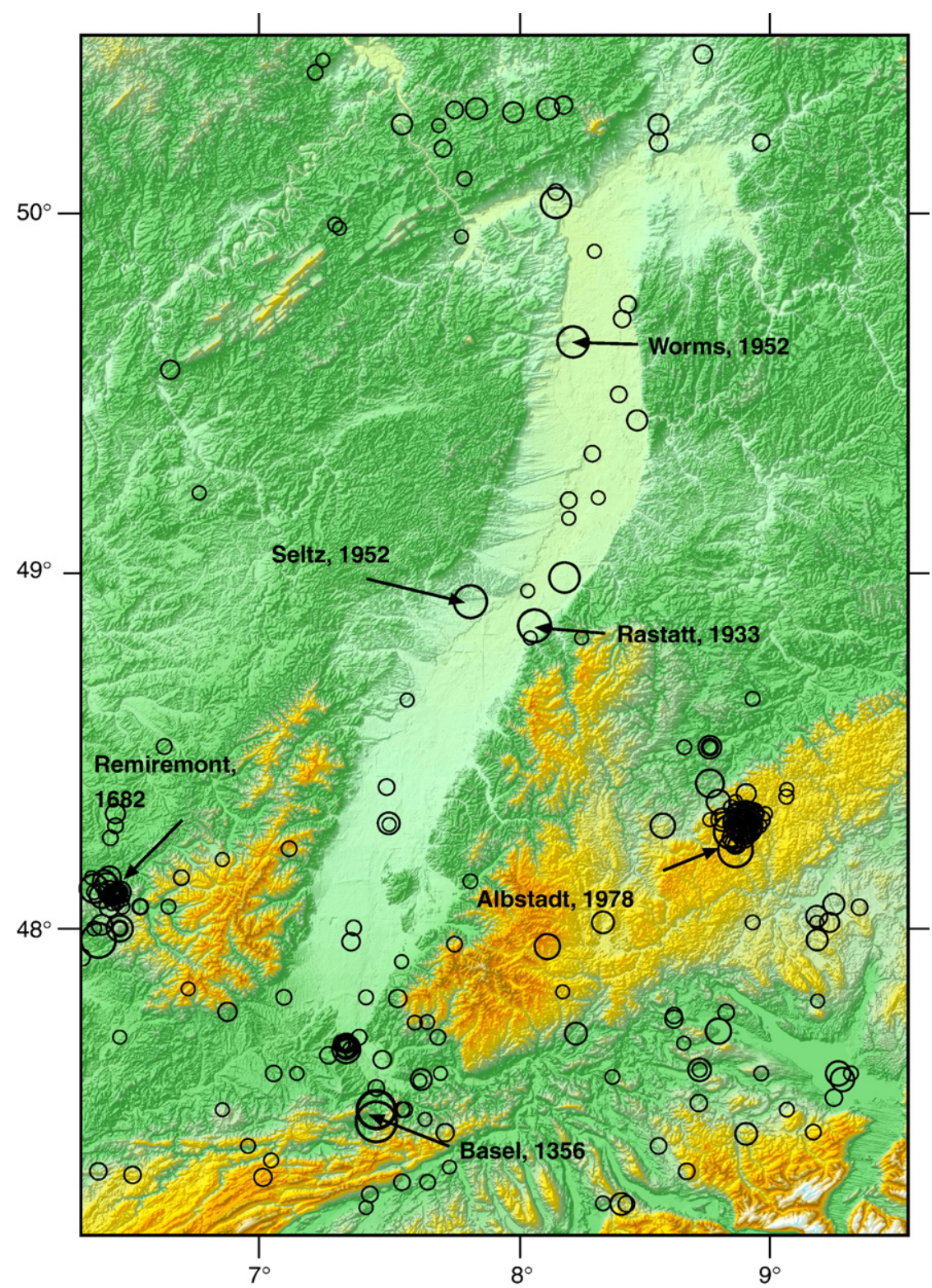

Fig. 39. Seismicity in the Upper Rhine Graben area: Instrumental seismicity ML 3-5 (1952-2002) and historical events ML 5-6.2 (859-1948). Data source: Leydecker (2003).

balance between the uplift rate of the Rhenish Massif and the incision rate of the river Rhine. Presently the erosional base level of the Upper Rhine Graben is located $80 \mathrm{~m}$ above MSL at Bingen where the Rhine canyon starts to cut across the Rhenish Massif.

In the southern parts of the Upper Rhine Graben, PlioQuaternary tectonic activity is documented by folding of the Pliocene Sundgau gravels along the Jura Mountains thrust front (Giamboni et al., 2004), by faults extending through Quaternary deposits of the graben fill, and by the seismicity of the area. In this context it is noteworthy that earthquakes occur almost down to the Moho but are absent below it. Earthquake focal mechanisms indicate deformation of the upper crust by strike-slip to reverse faulting whilst the lower crust is subjected to extension (Plenefisch and Bonjer, 1997; Deichmann et al., 2000). Transpressional deformation of the upper crust can be attributed to collision-related stresses that are transmitted from the Alps above an incipient mid-crustal detachment level. By contrast, lower crustal extension may be related to folding of the mantle-lithosphere, controlling uplift of the Vosges-Black Forest Arch (Dèzes et al., 2004). The 
effects of Cenozoic rifting are still evident in the lower crust, as visualized by relative $\mathrm{P}$-wave velocity images (Lopes Cardozo and Granet, 2003; Lopes Cardozo et al., 2005; Lopes Cardozo and Granet, 2005).

Moderate Pliocene and Quaternary extension across the Bresse and Upper Rhine Grabens presumably gave rise to sinistral movements along the seismically still active Burgundy transfer zone that links them. Geodetic data indicate horizontal displacement rates across the Upper Rhine Graben of $0.8 \mathrm{~mm} / \mathrm{yr}$ (Rozsa et al., 2005) and for the French Jura Mountains shortening rates of $1 \mathrm{~mm} / \mathrm{yr}$ (Walpersdorf et al., 2006) to perhaps as much as $3 \mathrm{~mm} / \mathrm{yr}$ (Jouanne et al., 1995). From about $4 \mathrm{Ma}$ onward, compressional deformation of the Jura Mountains was no longer exclusively thin skinned, but involved also the basement, as indicated by intra-crustal earthquakes (Roure et al., 1994; Becker, 2000).

In the framework of the EUCOR-URGENT (Upper Rhine Graben: Evolution and Neotectonics) and TOPOEUROPE projects, ongoing studies address (i) management of water resources hosted in the Pliocene and Quaternary aquifers of the Upper Rhine Graben that are endangered by pollution owing to intensive agricultural activities (EU-INTERREG III Project MoNit) and (ii) earthquake microzonation of the greater Basel area, the city of Mulhouse, and the Fessenheim nuclear power plant (EU-INTERREG III Project Microzonation). Regarding the evolution of the Alps-Rhine-North Sea source-sink system, the interrelation between the Quaternary uplift of the Rhenish Massif and sediment accumulation in the Upper Rhine Graben is addressed on the basis of geomorphologic studies and high-resolution river seismic data. In this context, a $400 \mathrm{~m}$ deep core-hole is currently being drilled in the Quaternary Heidelberg depocentre, with the objective to analyse the Quaternary climate record and its repercussions on sediment transport. Fission-track studies, addressing the uplift and denudation history of the Vosges-Black Forest Arch and its thermal regime, continue to be pursued and will be supported by river-gradient analyses. The neotectonics of the Rhine-Bresse Transfer Zone and their effect on the evolution of the drainage systems is currently being analyzed with special attention on the reactivation of Permo-Carboniferous crustal weakness zone and related seismotectonics. GPS measuring campaigns, involving stations covering the entire Rhine rift zone, are repeated at intervals.

TOPO-EUROPE plans to model the Rhine catchments from source (Alps) to sink (Atlantic Ocean, North Sea Basin), as a function of climate and tectonics. Important parameters to be addressed are the sediment production, transfer and storage rates. Understanding the time lags between sediment production events caused by for example climate changes, tectonic events, or river captures, and the resulting sedimentation events in the basins are of prime importance for interpreting the stratigraphic record. Secondly, the relative importance of (temporal) sediment storage in glacial and rifted basins along the course of the Rhine (Upper and Lower Rhine Graben) is at present unknown. Important constraints for this study have been put forward by cosmogenic isotope studies and morphological research.

Active Tectonics in the Upper Rhine Graben (URG)

Rifting of the URG started in the late Middle Eocene, approximately contemporaneously with an important phase of the Alpine orogeny. Changes in the stress regime during the evolution of the graben have resulted in different subsidence and uplift phases (e.g. Illies, 1975; Ziegler, 1992; Sissingh, 1998; Schumacher, 2002; Dèzes et al., 2004). The large thickness variations of Pliocene and Quaternary sediments in the graben imply syndepositional tectonic movements and suggest an average subsidence rate for the Quaternary of $0.1-0.2 \mathrm{~mm} / \mathrm{yr}$. Precision levelling across major faults in the northern URG shows contemporary movements of $0.4-1 \mathrm{~mm} / \mathrm{yr}$. The most obvious topographic feature of the graben is the significant height difference between the graben shoulders and the alluvial plain of the river Rhine (up to $\sim 1000 \mathrm{~m}$ ), corresponding to a clear morphological signature of the border faults. This suggests that the latter were tectonically active during the Quaternary, as evidenced also by high-resolution seismic lines recorded on the river Rhine and its tributaries.

Although several authors have addressed the recent tectonics of the URG, Quaternary tectonic activity has only locally been documented in its northern part where trenches were opened across its western border fault (WBF) to investigate evidence of surface deformation in young sediments (Peters et al., 2005). The investigated segment of the WBF is associated with a $20-\mathrm{km}$-long and 50-100-m-high linear scarp (Fig. 40). Integration of shallow geophysics and paleo-seismological and structural analyses of trench walls permitted to identify and characterize near-surface deformation structures along the WBF, at the base of the southern end of the scarp. The results of 3 trenches point to extensional faulting producing a consistent, conjugate set of $015^{\circ}$-striking faults, parallelling the WBF, with maximum vertical displacements in the order of $0.5 \mathrm{~m}$ (Fig. 41). Thermoluminescence dating of the deformed sediments shows that the paleo-seismic displacement occurred between 19 and $8 \mathrm{ka}$ and may have been caused by a single seismic event with a moment magnitude of 6.5. It is important to note that creep movements cannot be entirely excluded. 

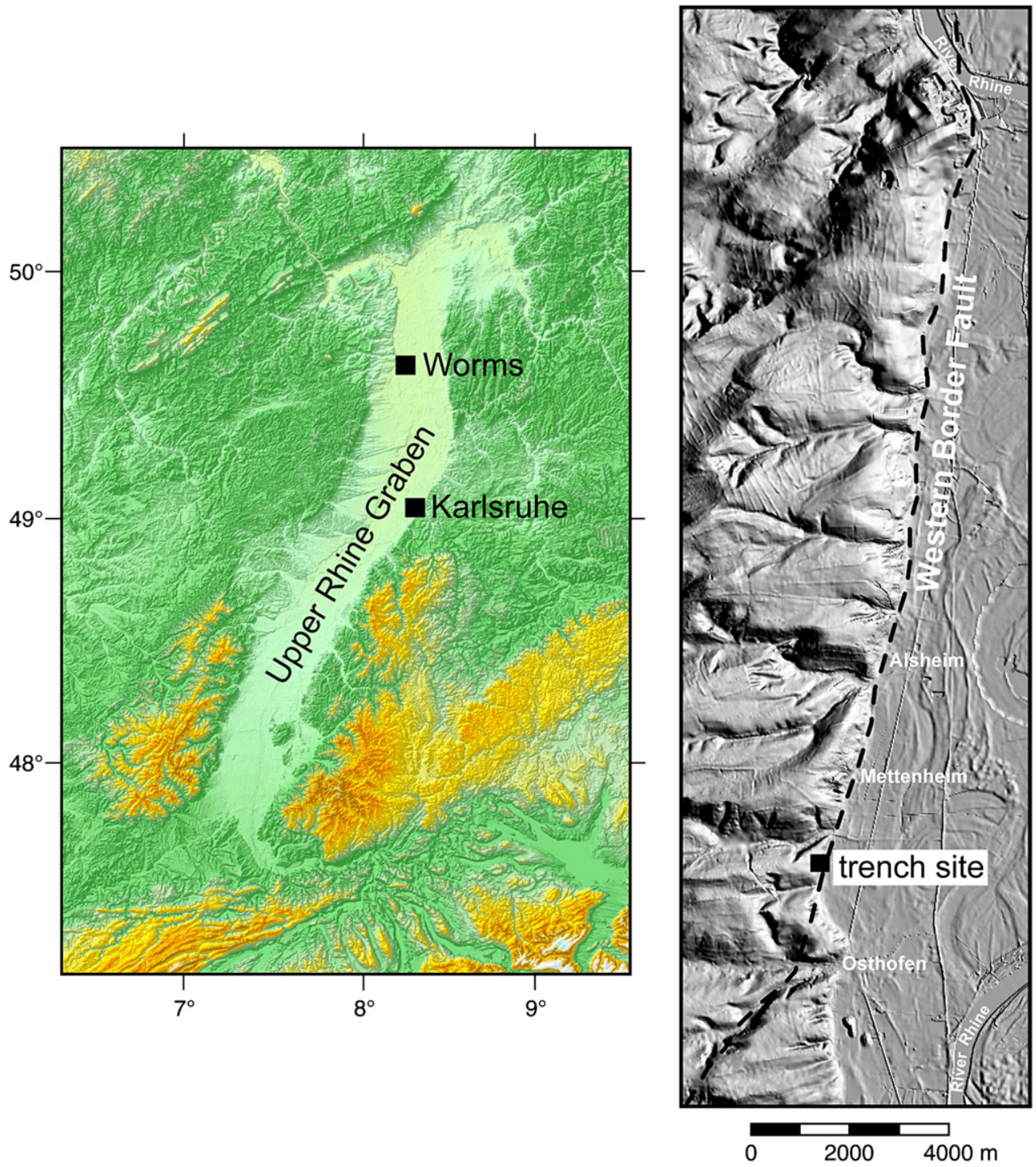

Fig. 40. Location of trench studies in the Upper Rhine Graben along its Western Border Fault (WBF). Right panel: shaded relief map, surface trace of the WBF (dashed white line) as mapped by morphology (after Peters et al., 2005).

Reconstruction of the sequence of events at the trench site speaks for local-scale interplay between tectonic activity on the WBF and fluvial erosional processes. This suggests a mixed origin of the $20 \mathrm{~km}$ long WBF scarp, involving regional uplift, localized tectonic activity on the WBF and fluvial dynamics of the River Rhine.

Analyses of river terraces showed that the northern part of the URG is affected by the uplift of the Rhenish Massif, although the timing of uplift may slightly differ. This uplift also affected stream gradients and valley cross-sections (Peters and Van Balen, 2007b-this volume). The present-day morphology of the drainage system shows clear-cut evidence for active tectonic control, with the possibility of locating individual faults by terrace analysis (Peters and Van Balen, 2007a).

TOPO-EUROPE research will focus on fault activity documented in the Quaternary and Holocene deposits in the axial part of the graben (Haimberger et al., 2005), using river-seismic data, core holes and geomorphology for paleo-tectonic and paleo-geographic reconstructions, to analyze tectonic imprints. Horizontal and vertical movements inferred from geodesy (InSAR) will be integrated with the geologic/geomorphic record. The Heidelberger Loch research well, which is currently being drilled, will yield detailed chrono- and lithostratigraphic information on Quaternary and Late Pliocene sediments. 

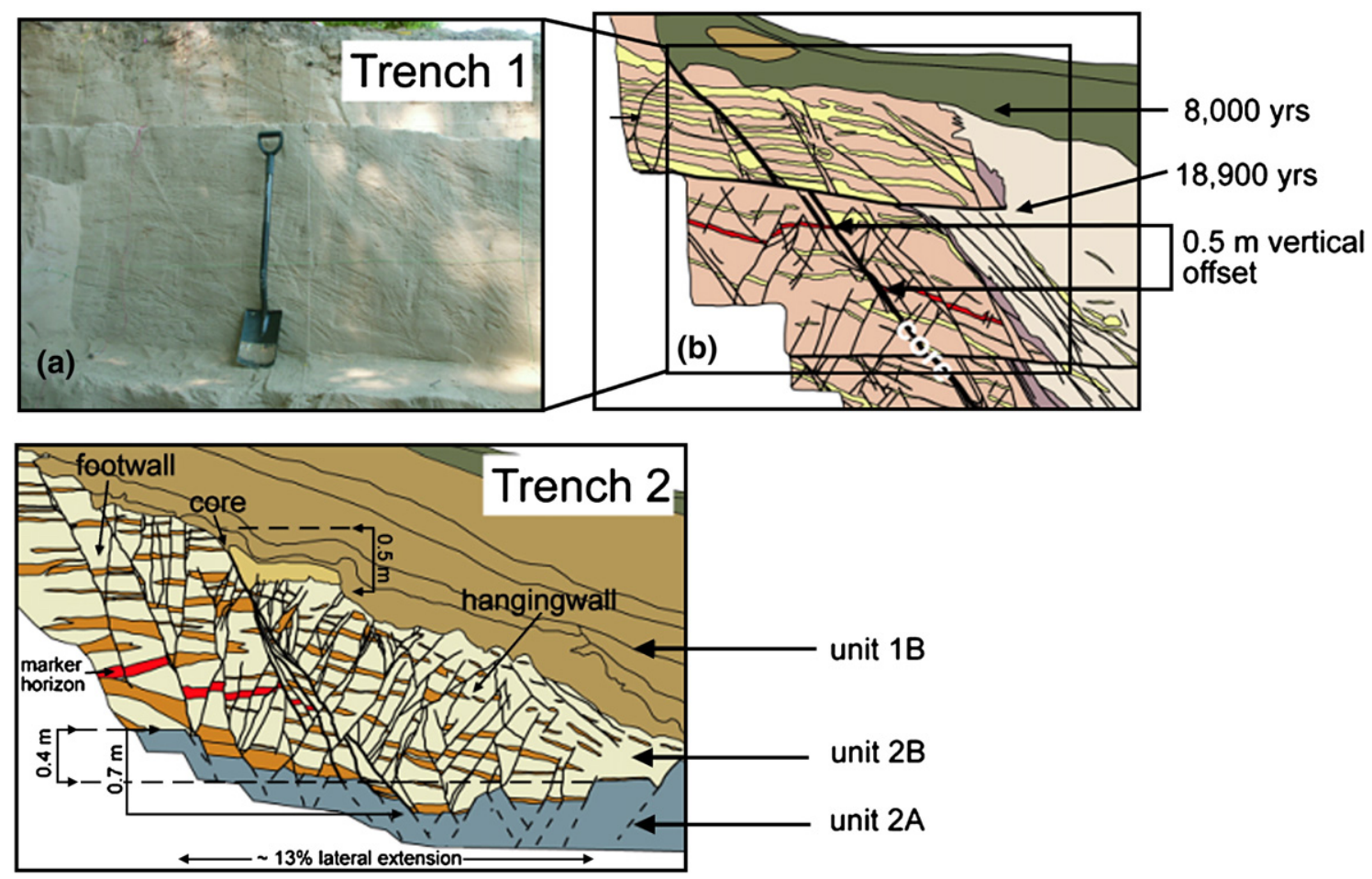

Fig. 41. (a) Photograph of Trench 1; (b) Interpretation of Trench 1; (c) Interpretation of Trench 2. The fault zone has a basal vertical displacement of $0.7 \mathrm{~m}$ and at the top of unit $1 \mathrm{~B}$ a net displacement of $0.4 \mathrm{~m}$. Unit $2 \mathrm{~B}$ is offset by a minimum of $0.5 \mathrm{~m}$. Due to lateral variations, the red marker horizon cannot be correlated across the main fault and its strands (fault core, thick black lines). For location see Fig. 40 (modified after Peters et al., 2005).

\section{The Rhine-Meuse delta system}

The densely populated coastal lowlands of the RhineMeuse delta system, located at the northern end of the ECRIS (Fig. 42), are highly vulnerable to flooding owing to land subsidence and rising sea levels. Moreover, the neotectonically active Roer Valley graben is characterized by increased seismic hazards, as evidenced by the ML 5.8 Roermond earthquake of April 13th 1992 (Van Eck and Davenport, 1994).

Neotectonic deformation of the Netherlands involves gentle uplift of its SE and slow subsidence of its NW coastal parts (Fig. 43; Van Balen et al., 2005). Seismic activity reflects reactivation of fault systems outlining the Lower Rhine-Roer Valley graben system. Continued subsidence of this rift, combined with uplift of the Rhenish Massif and Ardennes (Fig. 44), strongly influenced the Neogene and Quaternary evolution of the Rhine-Meuse river system and its delta (Dirkzwager et al., 2000).

During the last decade NEESDI (Netherlands Environmental Earth System Dynamics Initiative) investigated the interplay between tectonic subsidence and faulting, compaction and sea level changes that affect the Rhine-Meuse delta system. Integration of high-resolution reflection-seismics, 3-D seismic data analysis and geomechanical modelling resulted in the development of a new generation of delta models and concepts for tectonic controls on river evolution on subsiding coastal plains (Cloetingh, 2000).

Integrated analysis of crustal-scale cross sections, and their comparison with isopach maps of Tertiary and Quaternary sequences, demonstrate that faults already active during the Mesozoic exert a strong control on recent differential vertical motions in the Roer Valley Graben and in coastal areas (Fig. 43). Results of 3D gravity back-stripping show a clear correlation between positive residual gravity anomalies and the main structural trends of the Lower Rhine-Roer Valley Graben system. Geomorphologic studies indicate that during Miocene-Quaternary times tectonic uplift of the Ardennes amounted to as much as $600 \mathrm{~m}$ whilst the Roer Valley Graben subsided by several $100 \mathrm{~m}$ (Van Balen et al., 2000; 2005). During this time span, much of the sedimentary load of the river Meuse was deposited in the Roer Valley Graben (Fig. 45). In the coastal zone of the Netherlands, development of Weichselian-Holocene terrace systems can be related to climatic processes and the level of sediment supply from the uplifting Ardennes (Van Balen et al., 2000). In the Ardennes, river incision rates reached a maximum during the last $0.75-0.3 \mathrm{Myr}$, 


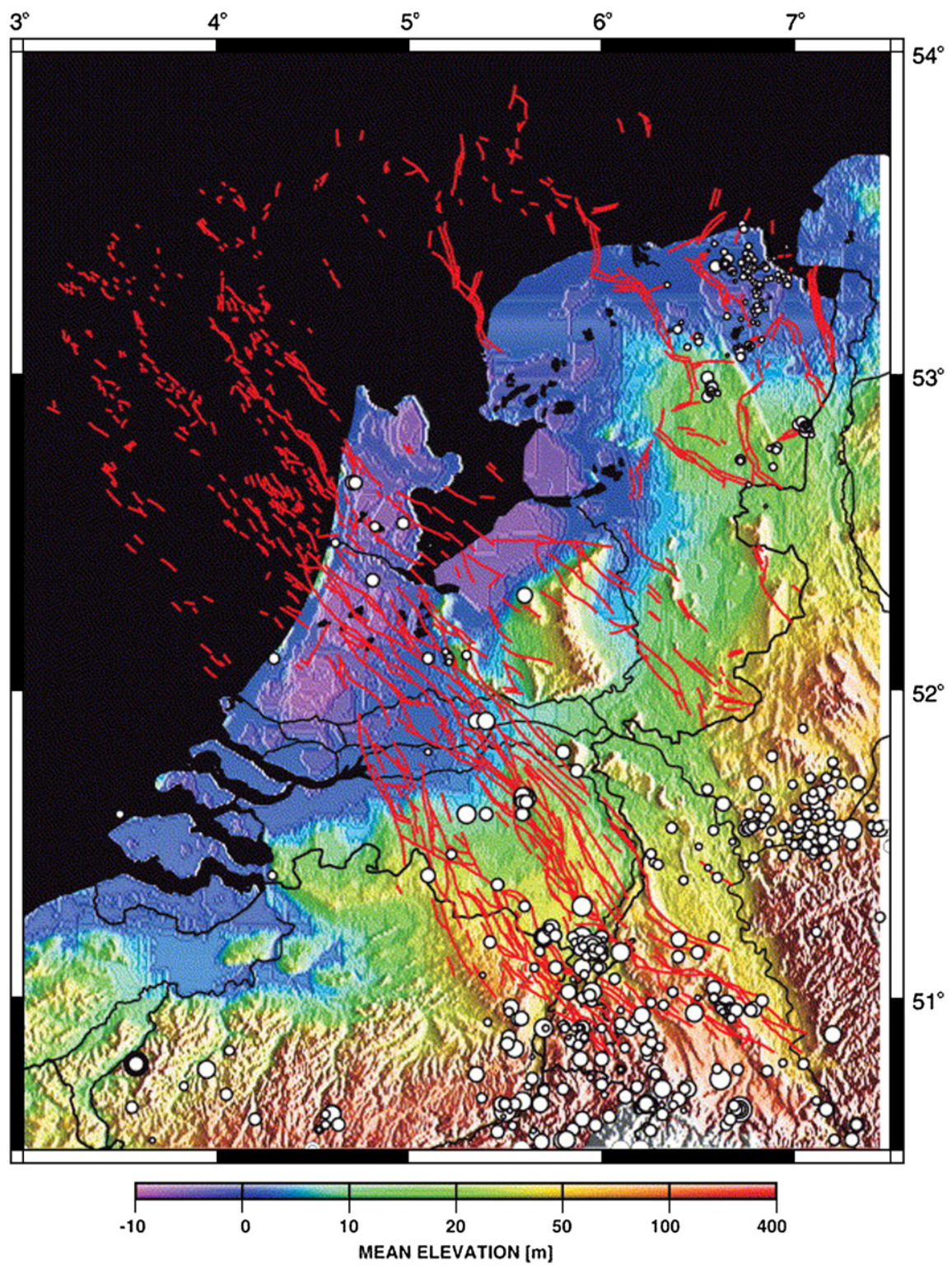

Fig. 42. Colour-coded relief map of the Netherlands and surroundings (data from GTOPO30). Red lines: faults affecting the Base Tertiary, White dots: earthquake epicenters (data from the ORFEUS data centre) (after Cloetingh et al., 2006b).

reflecting their uplift by some $250 \mathrm{~m}$ (Meyer and Stets, 1998; Van Balen et al., 2000).

In the Roer Valley Graben, neotectonic fault patterns were defined by geomorphologic studies, supported by industrial seismic data and the results of trenching. Modelling studies, focusing on the contribution of climate changes to terrace formation, indicate a complex relationship between fluvial incision and aggradation that mainly results from changes in river discharge and sediment flux, controlled by the coupling of precipitation and vegetation with climate. Preservation of terraces results from tectonic uplift. The longitudinal profile of the river Meuse evolved in response to the combined effects of Quaternary tectonic uplift of the Ardennes, sea level and climate changes, and related changes in the sedimentary load composition of the river Meuse (Van Balen et al., 2000).

Subsidence of the Dutch coastal area, quantified by precision levelling, is largely controlled by compaction of Neogene deltaic series with neotectonics playing an overprinting role. During sediment compaction, lateral fluid flow in shallow and deeper aquifers plays an 

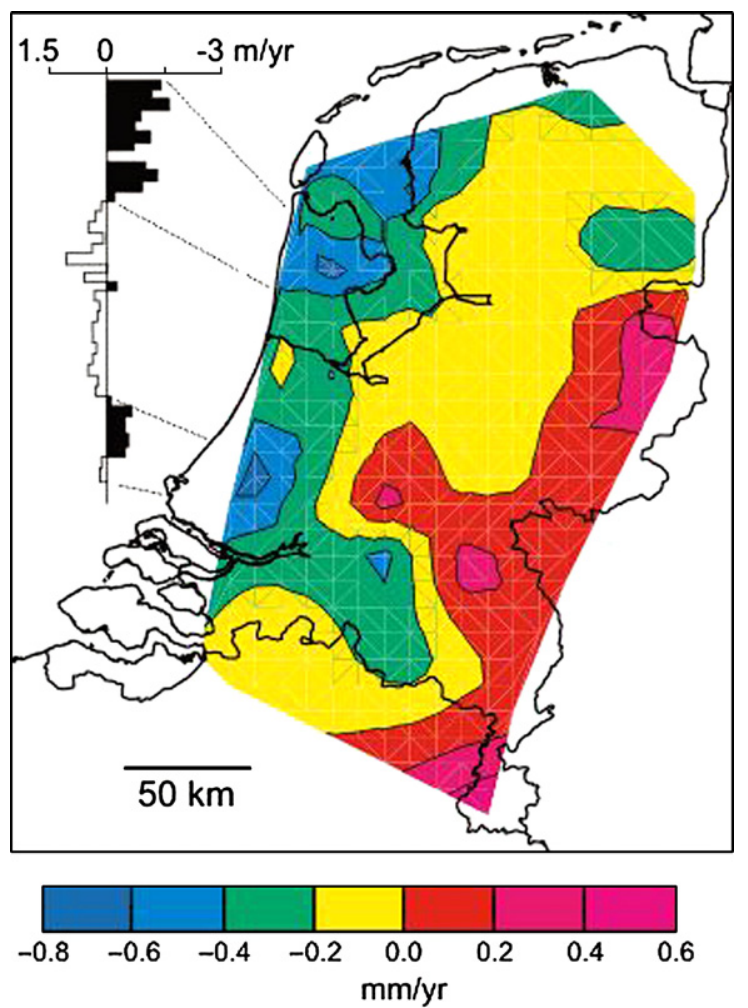

Fig. 43. Present-day tectonic vertical motions correlated to coastal transgression/regression rates (after Van Balen et al., 2005).

important role (Kooi, 2000). Coastal regression and transgression patterns are strongly influenced by these subsidence patterns (Fig. 45; Van Balen et al., 2005).
The Rhine-Meuse delta system provides an ideal laboratory for analyzing the effects of natural perturbations of the Earth system on the human environment, owing to the availability of a high-quality database and intense studies by academic and industrial researchers and government organizations. The vulnerability of this delta system to eustatically rising sea levels and a subsidence-controlled relative sea level rise takes priority in developing strategies for optimizing the use and management of the environment. The stability of coastal zones, the dynamics of river systems, and the management and protection of non-contaminated groundwater resources are of greatest societal relevance.

In view of this, TOPO-EUROPE plans to probe the interplay of neotectonics, sea level and climate changes in the lowlands of the Rhine-Meuse delta system. Quantification of the role of neotectonics and their interplay with regional subsidence/uplift and climate changes are of fundamental importance. The magnitude of vertical crustal movements in the Netherlands during the last 2.6 My is illustrated by the thickness of Quaternary sediments that attains values of up to $500 \mathrm{~m}$ in onshore areas, increasing to $1000 \mathrm{~m}$ offshore in the North Sea Central Graben. Precision levelling shows a systematic difference between the eastern parts of the Netherlands, which are being uplifted, and its western parts that subside (Fig. 43). The overall pattern suggests tilting of the entire country that is consistent with accelerated Pliocene-Quaternary tectonic subsidence of the North Sea Basin and uplift of the Rhenish MassifArdennes. At the same time, important contributions

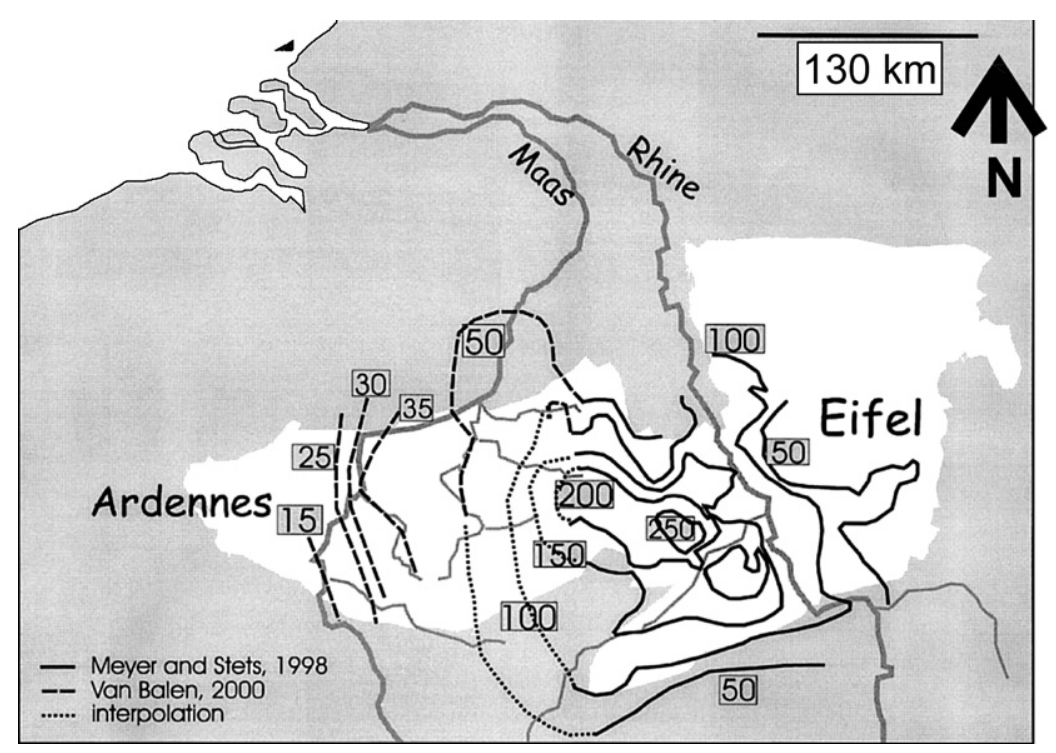

Fig. 44. Pattern and magnitude of early Middle Pleistocene to Recent uplift of the Ardennes and Rhenish Massif (after Van Balen et al., 2000). 

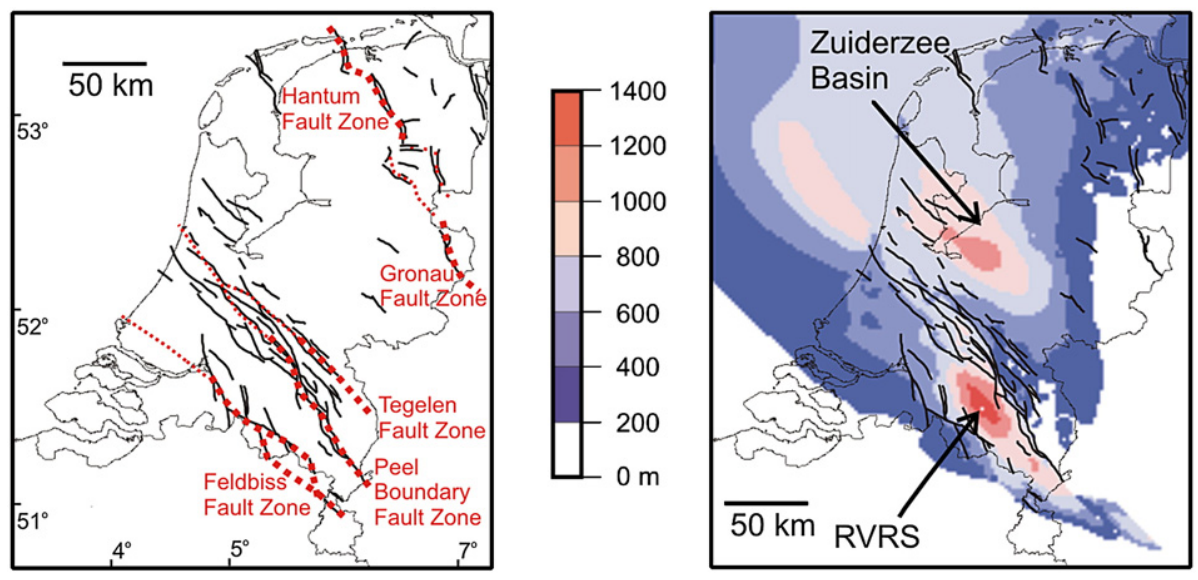

Fig. 45. Isopach map of Neogene sediments in the Netherlands, showing fault zones active during the Neogene (after Van Balen et al., 2005).

from compaction-driven subsidence and glacio-isostasic uplift are evident.

Separating the effects of neotectonics from those of eustasy and climate remains a formidable task (Cloetingh, 2000) that requires an improved and more detailed chronostratigraphic subdivision of Plio-Quaternary deposits. Moreover, it is vital to access the shallow parts of industrial 3-D seismic data sets and to analyze them with state-of-the-art seismic processing and interpretation techniques in terms of reconstructing the architecture and evolution of the Rhine-Meuse delta. High-resolution river reflection-seismic, a rapidly developing and very important research tool in the study of neotectonics, images fault control on the course of the river Meuse (Fig. 46). Furthermore, trenching permitted to identify fault activity in the Roer Valley Graben that occurred during the last $40 \mathrm{Ky}$. Detailed reconstruction of river systems in the Roer Valley Graben and in northward adjacent areas has provided evidence for neotectonics affecting fluvial systems and river gradients. A systematic study of the Holocene evolution of the RhineMeuse delta system has documented tectonic control on river avulsion (Fig. 46) (Berendsen and Stouthamer, 2002; Cohen et al., 2002). Integration of shallow seismic and borehole data with the results of paleo-seismicity studies will be further pursued, aiming at defining the recurrence time of major earthquakes.

TOPO-EUROPE will extend the geological record by integrating the high-resolution seismic data recorded on rivers into the neotectonic dataset. Secondly, highprecision levelling data (InSAR) and high-precision digital elevation models (AHN) will be used, in combination with the seismic catalogue, to characterize the recent tectonic activity. In a third step, the Middle to Late Pleistocene evolution of the landscape will be addressed by forward modelling of the geomorphology as a function of sediment supply (fluvial and eolean), climate changes, tectonics, and anthropogenic activity. In this, the full 3-D geometry of the faults and their displacement rates and slip directions will be taken into account. Special attention will be paid to modelling the effect of faulting on the Rhine and Meuse rivers.

\subsubsection{Seismicity and neotectonic deformation of the Armorican Massif}

There is increasing evidence that the lithosphere of the North-Alpine foreland responds to the build-up of intraplate compressional stresses by long-wavelength folding that is controlled by the strong part of the lithospheric mantle. On-going lithospheric folding in a low strain-rate regime is thought to control uplift patterns, river incision and the location of drainage divides in the area of the Armorican Massif. This Massif is characterized by a SE-NW-trending belt of increased seismic activity, reflecting reactivation of the Paleozoic Armorican shear zones.

Repeated precision levelling surveys indicate that the western and south-western parts of Brittany, forming the NW branch of the Armorican Massif, are currently being uplifted at rates of up to $1 \mathrm{~mm} / \mathrm{yr}$ (Lenôtre et al., 1999). Geomorphologic studies indicate that this uplift pattern controls the magnitude of fluvial incision, the location of drainage divides and repeated river captures. Moreover, Pleistocene deposits are locally folded and faulted (Bonnet et al., 1998; Bonnet et al., 2000; Brault et al., 2001). As the spatial pattern and timing of uplift inferred from river incision cannot be explained by glacio-eustatic sea level fluctuations, the underlying vertical crustal motions must be attributed to deformation of the lithosphere under the present-day NW-SE 


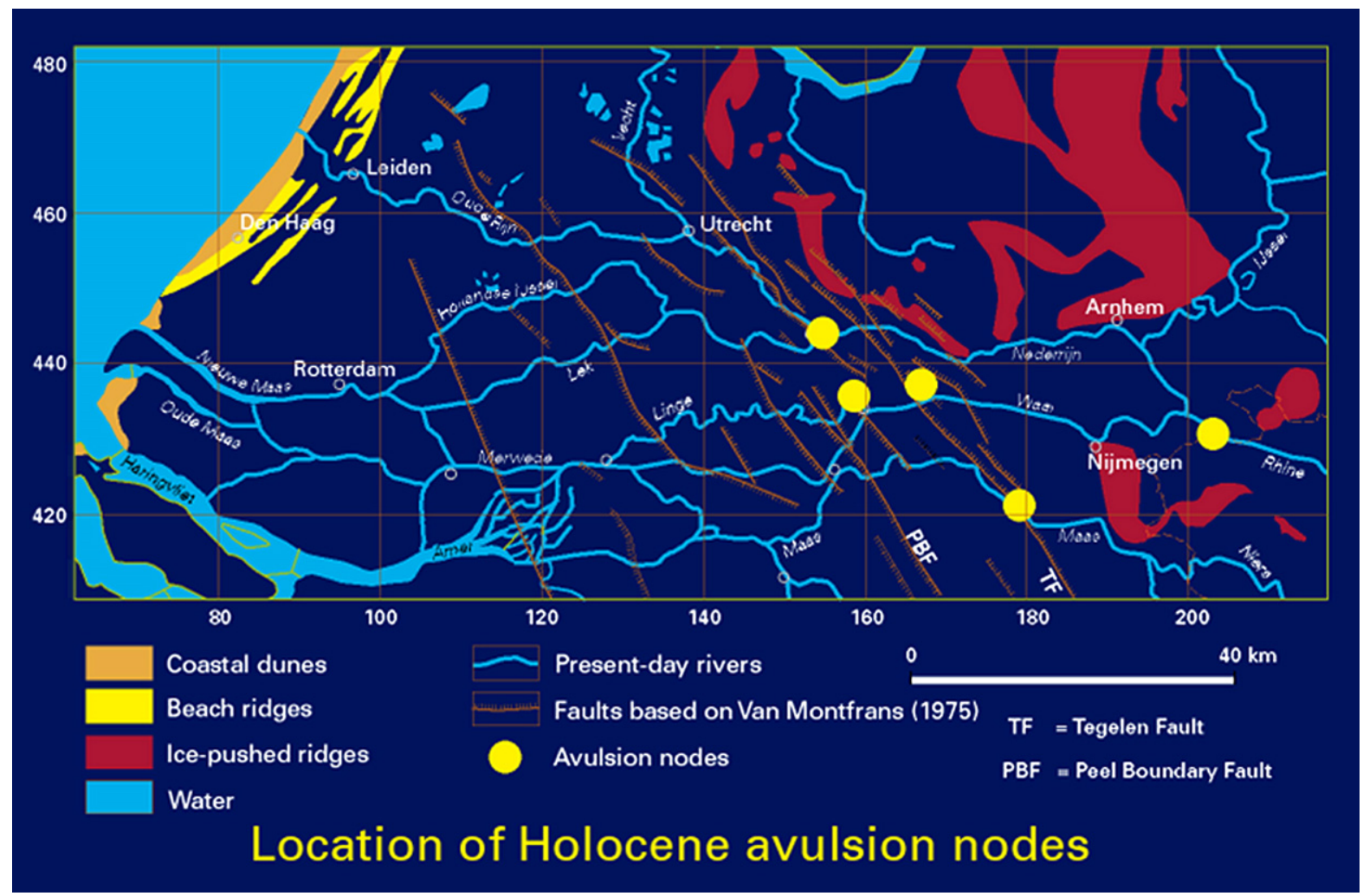

Fig. 46. Location of Holocene avulsion nodes in the Rhine-Meuse delta. Avulsion nodes are mainly located on the fault bounding the Peel Block (modified after Berendsen and Stouthamer, 2002).

directed compressional stress field (Müller et al., 1997). This is compatible with the occurrence of a broad belt of increased seismic activity that extends from the Massif Central to the western tip of the Armorican Massif (Fig. 2), reflecting reactivation of the Paleozoic Armorican shear zones. Although there is geological and geodetic evidence for local fault reactivation, the wavelength of about $250 \mathrm{~km}$ for the observed broad uplift points to a lithospheric mantle control on the ongoing deformation.

TOPO-EUROPE research will focus on quantifying the neotectonic deformation rates of the Armorican Massif by applying astronomical dating technologies to terrace systems, repeated precision levelling and SAR and InSAR measurements. Furthermore, geodetic data will be modelled that suggest that under the present NWdirected compressional stress field, reactivation of the Armorican shear zones is caused by the clockwise rotation of Northern France with respect to Southern France and Central Europe as a consequence of transtensional opening of the Rhine Graben system under the present NW-directed compressional stress field (Fig. 5; Cloetingh and Cornu, 2005b; Tesauro et al., 2005). It will be of special interest to assess when post-Mesozoic deforma- tion of the Armorican Massif commenced and how it relates to the evolution of ECRIS and the inversion of the Western Approaches and Channel Basins and upwarping of the Weald-Arois Axis (Ziegler et al., 2002; Dèzes et al., 2004; Ziegler and Dèzes, 2007-this volume).

\subsubsection{The Bohemian Massif}

Starting in the Late Turonian and culminating during the Paleocene, basement blocks forming the Bohemian Massif were upthrusted in response to the build-up of pre- and syn-collisional intraplate stresses originating at the front of the evolving Alpine-Carpathian Orogen (Malkovsky, 1987; Ziegler, 1990; Ziegler and Dèzes, 2007-this volume). Subsequently, the Bohemian Massif was subjected to profound weathering and erosion, resulting in the development of a regional peneplain on which only locally thin late Eocene-early Oligocene fluvial and lacustrine clastics were deposited, whilst its southern flank was overstepped by late Eocene and Oligocene marine series of the evolving AlpineCarpathian flexural foreland basin (Ziegler, 1990).

During Early Oligocene to Early Miocene times volcanic activity preceded the main subsidence phase of the Eger Graben (Malkovsky, 1987). During the latest 
Oligocene to Burdigalian, when volcanic activity gradually abated, a northerly-directed drainage system developed on the Bohemian Massif and up to $500 \mathrm{~m}$ of lacustrine and fluvial clastics accumulated under a mildly tensional setting in the Eger volcano-tectonic zone (Malkovsky, 1975; Malkovsky, 1979). After sedimentation in the Eger Graben had ended around $18 \mathrm{Ma}$, extension intensified and the northern parts of the Bohemian Massif, including the Eger Graben were uplifted and subjected to erosion during the Middle and Late Miocene, presumably in response to lithospheric folding. During the early Middle Miocene, marine transgressions advanced from the Alpine-Carpathian foreland basin along valleys into the southern and eastern parts of the Bohemian Massif, indicating that they were located close to sea level, and that the intra-Bohemian watershed had shifted northward (Malkovsky, 1979; Suk, 1984). During the late Middle Miocene, compressional reactivation of the Bohemian Massif fault systems commenced and persisted into the Quaternary, causing disruption of the pre-existing peneplain, and by uplift of its marginal fault blocks the gradual development of its present physiographic relief that peaks at $1452 \mathrm{~m}$ above MSL. In the process of this, Middle Miocene marine deposits were locally uplifted to $600 \mathrm{~m}$ above MSL.

During the Late Miocene and Pliocene volcanic activity resumed in the Eger Graben area that, after deposition of Pliocene fluvial clastics, was affected by uplift and minor extension (Malkovsky, 1979).

Pliocene and Quaternary uplift of the Bohemian Massif exerted a strong control on the development and deep incision of its present-day mainly north-directed drainage system that, as compared to its middle Miocene drainage system, entailed an important south-eastward shift of the watershed between the Danube and North German-Polish drainage systems (Ziegler and Dèzes, 2007-this volume).

End-Paleocene relaxation of compressional intraplate stresses controlling deformation of the Bohemian Massif can be related to post-collisional mechanical decoupling of the foreland and the Alpine-Carpathian orogenic wedge owing to sediment subduction. Mid-Miocene to recent uplift of the Bohemian Massif is attributed to a renewed build-up of intraplate compressional stresses, inducing lithospheric buckling and later transpressional reactivation of pre-existing crustal discontinuities in response to the onset of northward subduction of Adriatic lithosphere beneath the European foreland (Ziegler et al., 2002; Schmid et al., 2004).

Close dating of terrace systems, supported by geodetic data will help to constrain the rate of neotectonic and ongoing topographic uplift of the Bohemian Massif that had severe repercussions on the evolution of the Central European drainage system, which is prone to repeated catastrophic flooding.

TOPO-EUROPE will address Late Miocene to Quaternary uplift, deformation and denudation history of the Bohemian Massif and related magmatic activity and analyze it in terms of controlling mechanisms. Astronomical dating of terrace systems, supported by geodetic data and seismotectonic analyses are required to constrain the pattern, dynamics and rates of PlioceneQuaternary and ongoing uplift and topography development of the Bohemian Massif and their repercussions on the development of the Central European drainage system.

\subsubsection{Specific targets for the West and Central European Platform}

- Transgressions and regressions during Oligocene and later times.

- Integration of geodetic and geomorphologic groups of Western and Central Europe in an effort to improve constraints on present-day vertical and lateral motions (precise levelling-GPS-InSAR-Gallileo).

- (Neo)Tectonic controls on the evolution of topography and river systems; improved correlation and dating of river terraces; paleogeographic maps retracing the evolution of the drainage system during the last $20 \mathrm{My}$.

- Assessment of dynamic processes controlling uplift of Variscan Massifs and subsidence of sedimentary basins, including their neotectonic deformation.

- Correlation between deep erosional zones (glacial tunnel valleys in Northern Germany) and neotectonic activity.

- Fault reactivation and lithospheric folding; mantle tomography; receiver functions from existing data; lithosphere-asthenosphere boundary mapping.

- Mapping and timing of erosion; reconstruction of the eroded mass in Europe.

- High-resolution river seismic.

- Paleo-seismologic studies and seismic hazards (Rhine Graben system).

- Volcanism in West and Central Europe: baby-plumes; volcanism as time marker.

\subsection{Within the Africa-Europe Collision Zone: the Apennines-Aegean-Anatolian Region}

The Apennines-Aegean-Anatolian region offers a natural laboratory for analyzing dynamic processes that control ongoing deformation of the lithosphere under 
syn-orogenic conditions at strain rates of up to $3 \mathrm{~cm} / \mathrm{yr}$ (Jiménez-Munt et al., 2003). The Aegean regions, as well as northern and southeastern Anatolia are seismically very active and therefore exposed to very high earthquake hazards (Erdik et al., 1999; Giardini et al., 2003). In these areas major mountainous areas as well as submarine topography developed during Neogene to Quaternary times. Geohazards, apart from destructive earthquakes (e.g. Izmit Mw 7.4 of 1999.08.17; Fig. 47), include flooding due to land subsidence, landslides, volcanism and tsunamis (e.g. Santorini 1658 BC).

The central Mediterranean region is a crucial site for analyzing the ongoing surface response to deep mantle evolution. Recent (middle Pleistocene and onward) rapid uplift of the Apennines-Calabrian orogenic belt is most probably dynamically related to mantle circulation induced by the subducting slab and its ongoing deformation. As in the Aegean and Anatolia, tectonic activity in the Apennines-Calabrian belt and in Sicily gives rise to natural hazards (including for megacities), such as landslides, destructive earthquakes, explosive volcanism (Vesuvius and Phlegrean fields) and tsunamis.

\subsubsection{Rationale}

The Aegean region and Anatolia are underlain by orogenically destabilized continental lithosphere (Papanikolaou et al., 2004; Stephenson et al., 2004). Along the Hellenic and Cyprus arc-trench system oceanic lithosphere of the Eastern Mediterranean, representing the last remnant of the Neotethys, is presently subducted northward beneath the Aegean and Anatolian regions. By contrast, East-Anatolia is located in the collision zone between the Arabian craton and the Taurides (Okay and Tüysüz, 1999).

The present-day Hellenic arc-trench system was activated during the latest Miocene (Papanikolaou et al., 2004) after the consumption of the external Hellenic block that formed part of the Apulia plate. The Erathostenes seamount collided during the Messinian with the Cyprus arc-trench system that was activated during the early Miocene (Robertson, 2000; Stephenson et al., 2004). Arabia collided during the Senonian with the intra-oceanic Semail arc-trench system. The remnant Semail Ocean was closed during the Eocene-Oligocene, resulting in collision of Arabia with the amalgamated Taurides elements (Yilmaz, 1993; Gilmour and Mäkel, 1996; Robertson, 2000; Stampfli and Borel, 2004; Agard et al., 2005). In the eastern Taurides crustal shortening persisted during the Miocene (Yilmaz, 1993; Gilmour and Mäkel, 1996; Ziegler et al., 2002) whilst in the eastern Pontides (Transcaucasus) and Caucasus major crustal shortening ended prior to the late Miocene
(Yilmaz et al., 2000b; Nikishin et al., 2001). Possibly owing slab break-off, orogenic over-thickening of the lithosphere in the domain of the eastern Pontides and Taurides and continued convergence of the Arabian craton with Eurasia, the dextral North Anatolian Fault Zone (NAFZ) was activated during middle to late Miocene times (Burchfiel et al., 2000; Yilmaz et al., 2000b; Nikishin et al., 2001) whereas the sinistral East Anatolian Fault Zone (EAFZ) was activated during the latest Miocene (Robertson, 2000). This facilitated westward escape of the rigid Anatolian block. During the late Miocene the sinistral Levant (Dead Sea) transform fault system was activated (Mart et al., 2005). With this, the Arabian indenter became decoupled from the African plate of which the continental Sinai-Levant and the oceanic East-Mediterranean domains form part.

Geodetic data indicate that Arabia currently moves northward at rates of 20-24 mm/yr whereas the African plate converges with Europe in a counter clock-wise mode at rates increasing from $3.3 \mathrm{~mm} / \mathrm{yr}$ in the West to $10 \mathrm{~mm} / \mathrm{yr}$ near Arabia (Le Pichon et al., 1995; McClusky et al., 2000). On the other hand, the entire AnatolianAegean region moves in a counter clockwise rotational mode W- and SSW-ward at rates of $20 \mathrm{~mm} / \mathrm{yr}$ in central Anatolia, increasing to $30 \mathrm{~mm} / \mathrm{yr}$ near the Hellenic trench (Figs. 6,48) (Jiménez-Munt et al., 2003).

At present the Aegean-West-Anatolian region is subjected to SSW-directed extension whilst the Hellenic arc is affected by arc-parallel extension (Hatzfeld, 1999) and frontal accretion persists along the Hellenic-Cyprus arc-trench system. Seismic tomography images a continuous, deep-reaching subduction slab that extends from the Ionian Islands via Crete to Rhodes, and dips beneath the North-Aegean region, penetrating the $410 \mathrm{~km}$ and $660 \mathrm{~km}$ discontinuities (Fig. 11). A separate subduction slab appears to be associated with the western part of the Cyprus arc while there is clear evidence for a detached slab beneath eastern Anatolia (Faccenna et al., 2005). On the other hand, the subduction slab of the Dinarides was apparently detached from the lithosphere, although at depth it may still be connected with the Hellenic slab (Wortel and Spakman, 2000). The Dinaridic subduction slab was apparently detached from the lithosphere at the Eocene-Oligocene transition, as evidenced by a widespread high-K calc-alkaline and shoshonitic magmatism (Pamic et al., 2002). The question arises whether the weight of the Dinaridic and/or the Anatolian slab causes propagation of slabdetachment and contributes to the progressive sinking of the Hellenic slab into the deep mantle (Wortel and Spakman, 2000; Faccenna et al., 2005), thus facilitating the rapid SSW advance of the Hellenic arc-trench system 


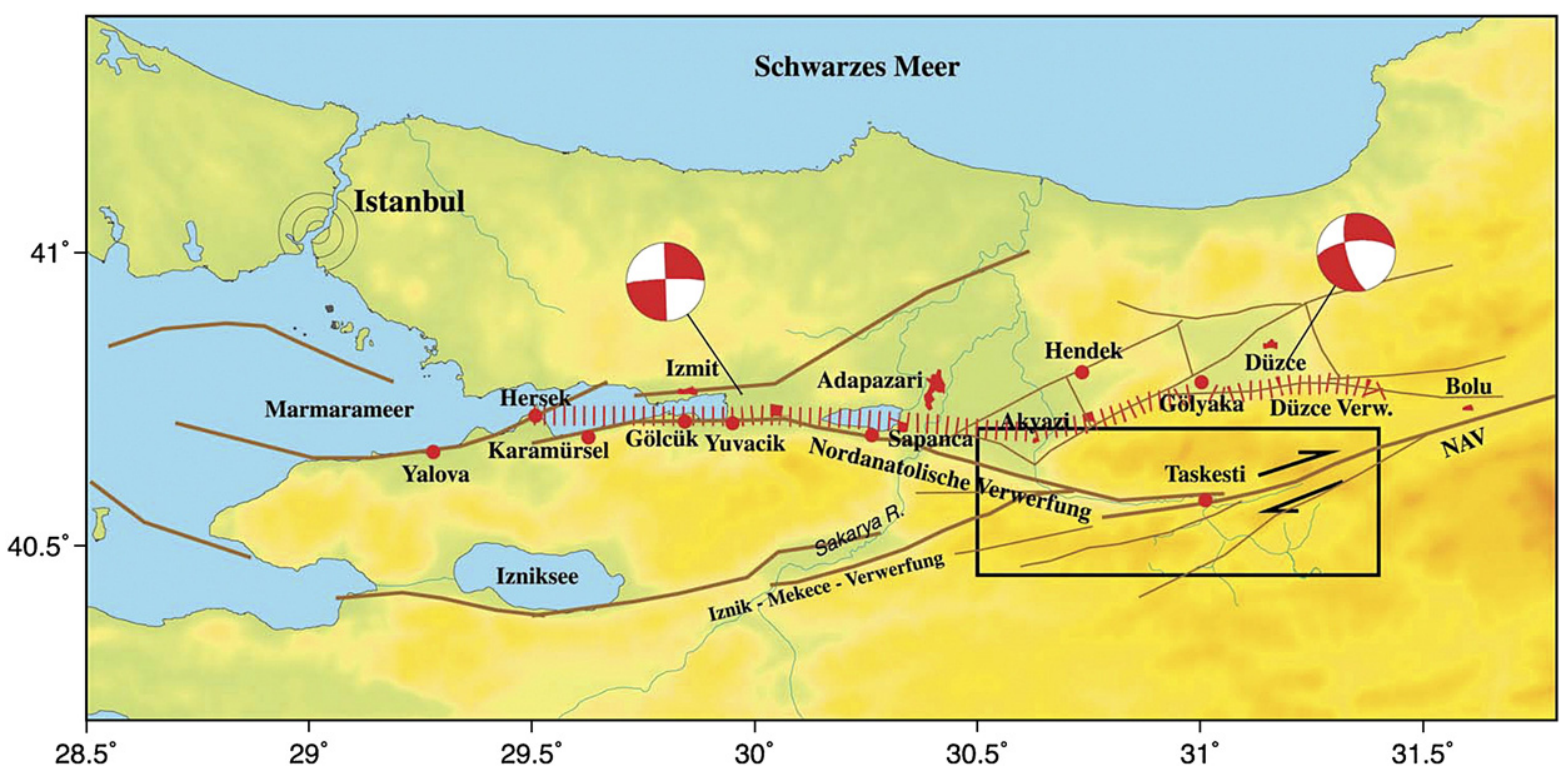

Fig. 47. Fault system in the Istanbul-Izmit area, showing epicentre distribution of about 2000 aftershocks of the Mw. 7.4 Izmit earthquake, 17 August 1999 (courtesy GFZ-Potsdam).

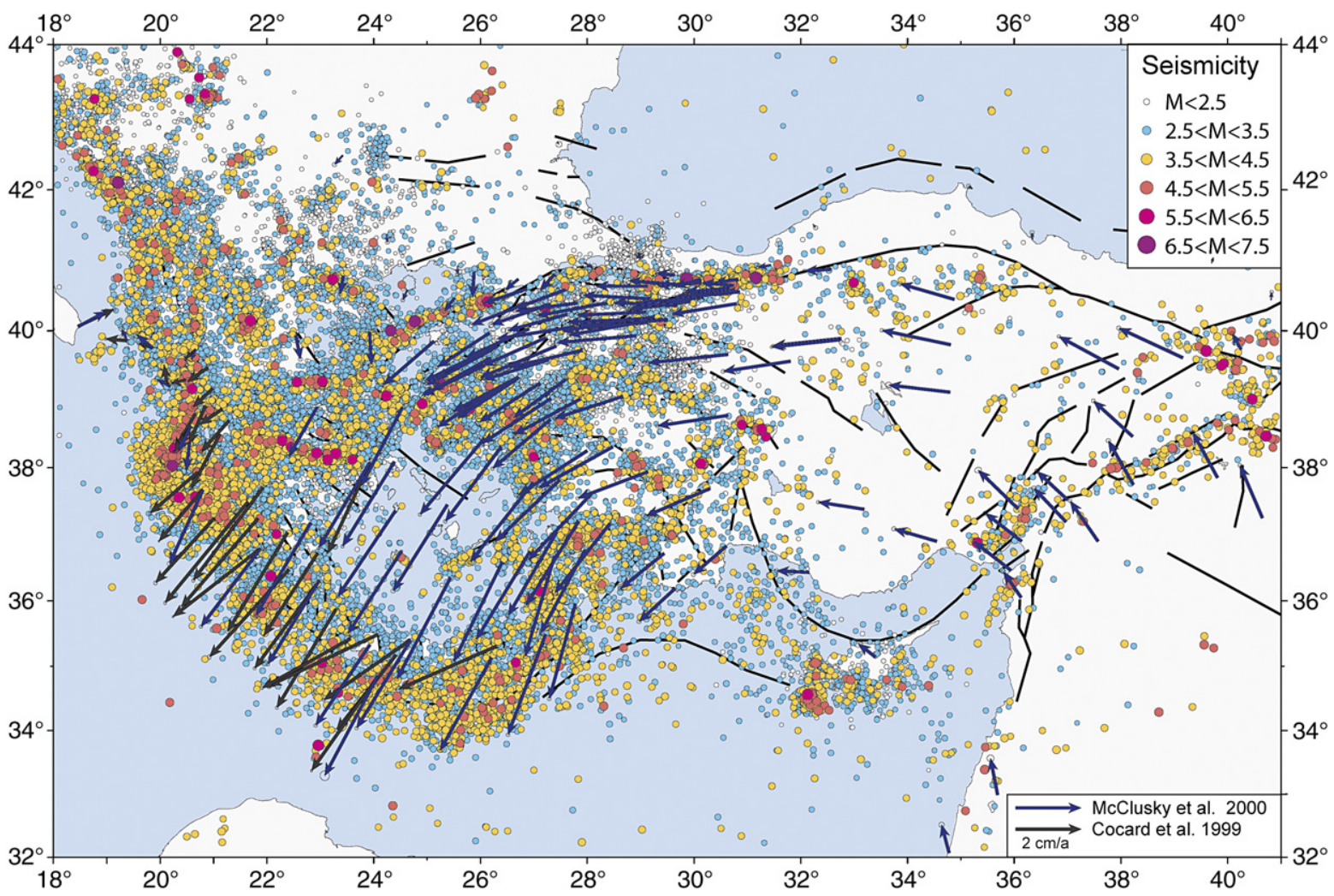

Fig. 48. Seismicity of the Aegean-Anatolian area (after NEIC catalogue) with superimposed observed GPS velocities relative to a fixed Eurasia plate shown by black arrows (after Cocard et al., 1999; McClusky et al., 2000). Black lines: active faults. 
and the associated extension in its Aegean and WestAnatolian back-arc domain.

In the northern parts of the Aegean region, back-arc extension commenced during the Late Eocene, and in time progressed southward while stacking of nappes derived from the External Hellenic platform continued along the convergent front (Jolivet and Patriat, 1999; Papanikolaou et al., 2004). Tensional subsidence of the Thrace Basin commenced during the Late Eocene (Turgut et al., 1991), whereas the North Aegean and Marmara troughs, which are closely associated with the NAFZ, began to subside during the late Burdigalian (17 Ma; Lybéris, 1984; Georgakopoulos et al., 1995; Görür et al., 2000). Subsequently, back-arc extensional tectonics propagated southward into the central and southern Aegean domains, reaching the latter during the Tortonian (10 Ma; Papanikolaou et al., 2004).

Westward movement of the Anatolian block probably commenced around $17 \mathrm{Ma}$ and was followed by a $40^{\circ}$ clockwise rotation of the West-Aegean domain between 15-13 and $8 \mathrm{Ma}$ (Van Hinsbergen et al., 2005b) that was accompanied by increased subduction rates along the South Aegean arc (Jolivet and Patriat, 1999). By latest Miocene-earliest Pliocene times $( \pm 5 \mathrm{Ma})$, the present-day Hellenic arc-trench system was activated (Papanikolaou et al., 2004), implying that subduction of the oceanic East-Mediterranean Neotethyan lithosphere commenced. At the same time the essentially thinskinned External Hellenic nappe stack, forming part of the Hellenic orogenic wedge, became inactive. With this, the Aegean-West-Anatolian back-arc domain was subjected to a new extensional phase that overprinted all earlier formed grabens (Papanikolaou et al., 2004), and that was accompanied by a further $10^{\circ}$ clockwise rotation of the West-Aegean domain during the last $4 \mathrm{My}$ (Van Hinsbergen et al., 2005b).

At the Miocene-Pliocene transition subduction prograded from the Pindos-Cylades zone to the southern margin of the External Hellenic block, presumably owing to subduction resistance of the latter (Papanikolaou et al., 2004), In the process of this, compressional stresses were exerted onto the African passive margin, causing inversion of the Jabal al Akhdar Basin in northern Libya (El-Havat and Shelmani, 1993; Ziegler et al., 1998; Papanikolaou et al., 2004). The configuration of the tomographically imaged deep-reaching Hellenic subduction slab (Wortel and Spakman, 2000; Faccenna et al., 2003) suggests that subduction progradation did not involve detachment of earlier formed slabs but that these form now the middle and lower parts of the present-day deep-reaching slab (Papanikolaou et al., 2004; Van Hinsbergen et al., 2005b).
West-Anatolia was affected by E-W extension during Early-Middle Miocene times whilst the thrust front of West-Taurides Lycian nappes continued to advance southward. Following their emplacement on the Antalya Basin, $\mathrm{N}-\mathrm{S}$ extension affected West-Anatolia during the Late Miocene. After a remission at the Miocene-Pliocene transition, N-S extension resumed and persisted to the Present. The observed $\mathrm{N}-\mathrm{S}$ extension is presumably closely related to westward escape of Anatolia that may have commenced already during the Middle Miocene and accelerated during Late Miocene-Pliocene times (Yilmaz et al., 2000b).

Roll-back and steepening of the Hellenic subduction slab (Spakman and Wortel, 2004) has been proposed as the controlling mechanism for extension of the AegeanWest-Anatolian region (Le Pichon and Angelier, 1979; McKenzie and Yilmaz, 1991). However, as the Hellenic slab is anchored in the deep mantle beneath the North Aegean domain (Wortel and Spakman, 2000), such a mechanism cannot be implied. Conversely, numerical modelling of geodetic and seismologic data suggests that slab-pull forces exerted on the African lower plate and trench-suction forces exerted onto the Aegean upper plate by the gravitationally sinking Hellenic slab, combined with lateral escape of Anatolia in response to the impact of the Arabian indenter, are the primary driving mechanisms controlling the Pliocene-Quaternary evolution of the Aegean-West-Anatolian region (Heidbach and Drewes, 2003). Africa-Europe convergence and possible slab tearing are thought to play secondary roles (Jiménez-Munt et al., 2003).

In the Central Mediterranean, southeast- and eastward roll-back of the subducting slab underlies the opening of back-arc basins such as the LigurianProvencal, the Algerian and the Tyrrhenian basin (Faccenna et al., 2001a; Spakman and Wortel, 2004). At present, traces of this large subduction system are seismologically recognised only beneath the Calabrian arc. In Calabria, the Wadati-Benioff plane and tomographic images allow to define a narrow subducting slab (less than $300 \mathrm{~km}$ wide) that dips at high-angle toward the northwest and presently undergoes in-plane compression (Selvaggi and Chiarabba, 1995). While there is general agreement on the key role played by subduction processes in the evolution of the Mediterranean domain (Malinverno and Ryan, 1986; Patacca et al., 1990; Doglioni et al., 2001; Faccenna et al., 2004), the recent tectonic activity of the slab as well as the causes for its present-day narrow shape are uncertain. The Calabrian subduction zone has retreated during the last 10 My by about 300-400 km (Malinverno and Ryan, 1986; Patacca et al., 1990). In the course of this rapid retreat, 
the subducting slab was progressively deformed and its width reduced to its present configuration. Such a mechanism is characteristic for orogenic arcs in the Alpine-Mediterranean domain, such as the Gibraltar and the Carpathian arcs (Royden, 1993; Lonergan and White, 1997; Wortel and Spakman, 2000; Faccenna et al., 2004; Faccenna et al., 2005). High-resolution tomographic analyses have recently stimulated studies on deformation processes affecting the central Mediterranean subduction slab (Carminati et al., 1998; Wortel and Spakman, 2000; Gvirtzman and Nur, 2001; Faccenna et al., 2004; Faccenna et al., 2005). Geochemical data on volcanic rocks and tomographic images suggest that progressive narrowing of the active subduction front is related to the opening of a slabwindow at deep levels, as evident in the southern Apennines and in the Sicily Channel. As a result, the Calabrian slab was progressively separated from the adjacent continental lithosphere whilst north-westward subduction of Ionian oceanic lithosphere continued. Geochemical data show that mantle material originally located beneath this slab moved upward through subduction windows. This suggests the existence of complex 3-D mantle flows, which are poorly constrained. The development of toroidal flows at the edges of the slab could in fact have caused a temperature increase, both in the orogenic arc and in the subducting slab, thus causing thermal erosion (Kincaid and Griffiths, 2003; Davaille and Lees, 2004; Funiciello et al., 2004) and accelerated roll-back of the slab (Dvorkin et al., 1993), giving rise to dynamic uplift of the orogenic belt. Geodetic data (Hollenstein et al., 2003; D’Agostino and Selvaggi, 2004) have recently shown that extensional tectonics in the Tyrrhenian Basin is presently quiescent and that in Calabria the present-day convergence rate is only a few millimetres per year, whereas it amounted to at least $3-4 \mathrm{~cm} / \mathrm{yr}$ during the Pliocene. Moreover, seismological data show that none of the recent earthquakes are related to on-going subduction processes, several aspects of which are still unclear. Most importantly, it is still unclear whether subduction beneath the Calabrian-Apennine region is still active and what process controls wholesale uplift of the Italian peninsula.

\subsubsection{Program scope and objectives}

Although major research efforts have hitherto been devoted to the understanding of the evolution, neotectonics and hazard assessment of the Apennines-AegeanAnatolian region, many concepts developed so far need to be critically reassessed and validated by a multidisciplinary approach, involving integration of all available data and acquisition of new data, as well as data-interactive modelling, both of the analogue and numerical type. In this respect, the cornerstones of the TOPO-EUROPE program include the application of state-of-the-art and the development of advanced data acquisition methodologies in the fields of space geodesy, thermochronology/geochronology (astronomical time scales), paleomagnetism, seismology, lithosphere and mantle tomography and geological field studies, including paleostress analyses, combined with experimental rock deformation studies. Previous investigations by TOPO-EUROPE research groups in the Apennines-Aegean-Anatolian region provide a strong starting point for this new endeavour. Specific research objectives are presented below.

\subsubsection{Evolution of East-Mediterranean subduction zones, Arabia-Eurasian collision and related magmatism}

During Cretaceous and Tertiary times, evolution of the Aegean-Anatolian orogenic system was controlled by northward subduction of a system of oceanic basins and intervening ribbon-shaped continental fragments, flanking the Neotethys Ocean to the North (Okay and Tüysüz, 1999; Stampfli et al., 2001; Papanikolaou et al., 2004; Van Hinsbergen et al., 2005b). Starting in MidCretaceous times, subduction of Neotethys commenced in the eastern Taurides sector and was completed during the Eocene, resulting in collision of Arabia with the Taurides orogenic wedge. In the western Taurides sector, subduction of Neotethys commenced during the Late Cretaceous and continues at present. In the Hellenides sector, subduction of Neotethys oceanic lithosphere commenced only at the Mio-Pliocene transition and continues at present (Makris and Yegorova, 2006). The Aegean-Taurides system represents a classical accretionary orogen that has progressed in its eastern parts to a continent-to-continent collisional setting whereas its western parts have remained in an ocean-continent collisional setting up to the present.

The subducting slab beneath the Aegean region, as imaged by seismic tomography, extends to a depth of about $1500 \mathrm{~km}$ and has a length of some $2400 \mathrm{~km}$, reflecting the dimension of post-Jurassic lithospheric shortening (Bijwaard et al., 1998; Wortel and Spakman, 2000). The presence of this slab, which consists of alternating segments of oceanic lithosphere and continental lower crust and lithospheric mantle, indicates that no slab detachment has occurred in the Aegean region (Faccenna et al., 2003; Van Hinsbergen et al., 2005b). Seismic tomography indicates that also the Cyprus arc is associated with a deep-reaching subduction slab. However, the Hellenic and the Cyprus slabs appear to be separated by a vertical tear that extends from Rhodes into western Anatolia (De Boorder et al., 1998; Wortel and 
Spakman, 2000; Faccenna et al., 2006). Development of this slab-tear presumably facilitated the rapid SSW propagation of the Hellenic arc, involving sinistral shear along its SE flank that is marked by the Strabo and Pliny trenches (Ten Veen et al., 2005). Latest Miocene activation of the sinistral EAFZ apparently caused a disruption of the Cyprus arc subduction slab, its Pliocene detachment from the lithosphere and the extrusion of alkali basalts in SE Anatolia (Yurtmen et al., 2000). Similarly, the mid-Miocene and Pliocene magmatism of eastern Anatolia (Arger et al., 2000) is presumably related to detachment of the Neotethys slab within the subducted margin of the continental Arabia lithosphere and the subsequent activation to the NAFZ and EAFZ. This is compatible with tomographic data that show at depths of $600 \mathrm{~km}$ a foundered subduction slab that is separated from the lithosphere (De Boorder et al., 1998; Wortel and Spakman, 2000; Faccenna et al., 2006).

Slab detachment (or alternatively lithospheric delamination) can be held responsible for changes in the chemical signature of arc volcanism and an increase in heat flow, contributing to weakening of the lithosphere and its post-orogenic collapse (De Boorder et al., 1998).

TOPO-EUROPE intends to refine available tomographic images of the lithospheric and mantle structure of the Aegean-Anatolian region and to prepare a sequence of cross-sections and depth slices. Furthermore, the age and geochemical/isotopic signature of volcanics will be reviewed in terms of potential changes from subductionrelated to slab detachment-related magma generation and of the timing of such changes. These data will serve as input for the modelling of first-order processes that governed the evolution of the Aegean-Anatolian area, with emphasis on its Neogene and Quaternary deformation. Special attention will be directed towards establishing a link between "deep" driving processes and the "shallow" geological response, aimed at predicting the near-surface response of the evolving system that can be compared with and tested against independent geological, geophysical and geodetic data. Of special interest is the assessment and modelling of processes that controlled the PlioceneQuaternary rapid SSW advance of the Hellenic arc-trench system and the associated extension in the Aegean region. Did subduction resistance of the Erathostenes seamount impede southward advancement of the Cyprus arc? What is the mass balance between Plio-Quaternary compressional shortening in East Anatolia, lateral escape of Anatolia and expansion of the Aegean area?

\subsubsection{Extensional processes and block rotation}

The Aegean-West-Anatolian region, characterized by a system of horsts and grabens, is one of the most rapidly deforming regions of the world. The NAFZ forms roughly the northern boundary of the deforming zone, the EAFZ its south-eastern boundary, whereas its southern and south-western boundaries are more diffuse and reach as far south as Crete and the Rhodes depression, and to the Hellenic and Pliny-Strabo trenches. The driving mechanism of this extensional regime is seen in the westward extrusion of Anatolia in response to persisting Arabia-Eurasia convergence, and in continuing subduction of the East-Mediterranean oceanic lithosphere, involving rapid SSW-ward propagation of the Hellenic arc.

TOPO-EUROPE aims at integrating detailed studies that have already been carried out on many of the extensional basins in the Aegean and West-Anatolian regions (e.g. Bozkurt et al., 2000), particularly in their onshore parts, as well as the results of studies on the development of extensional core complexes (e.g. Jolivet and Patriat, 1999; Lips et al., 1999). Results of these studies, complemented by data from offshore basins, will be compiled in an effort to define on a regional basis and in time and space the onset, progress and direction of crustal extension and activity along associated shear systems. Where required, supplementary field studies will be carried out.

It is of particular interest that West-Anatolia provides evidence for an Early-Middle Miocene phase of E-W extension that was followed by Late Miocene and younger pulses of $\mathrm{N}-\mathrm{S}$ extension, resulting in the superposition of interfering graben and horst structures. This suggests that a fundamental reorientation of the stress field and a corresponding change in the extensional driving mechanism had occurred (Yilmaz et al., 2000b). Whether an analogous sequence of events controlled the evolution of grabens in the offshore parts of the Aegean and the onshore parts of Greece needs to be assessed. Where available, access to industrial seismic and well data will be sought. Furthermore, paleo-stress analyses could contribute towards the recognition and definition of stress field changes.

Paleomagnetic studies carried out in the Western Aegean area, defining the timing and magnitude of major block rotations (Van Hinsbergen et al., 2005b), need to be extended into the Anatolian domain. It should be attempted to develop a step-wise palinspastic restoration of the Aegean-Anatolian region during its Oligocene to recent evolution.

Numerical and analogue modelling of the extensional history of the Aegean-Anatolian region, as developed during the planned compilation effort, will draw heavily on the results of lithospheric and mantle tomography, structural analyses and cross-sections, the distribution 
and focal depth and mechanisms of earthquakes and geodetic data.

\subsubsection{Opening and closing of marine gateways}

Tectonically controlled opening and closing of marine gateways, combined with climatic and glacioeustatic sea-level changes, have played an important role in the Neogene and Quaternary history of the Mediterranean and Black Sea area, with the most dramatic event being the Messinian salinity crisis that spanned approximately 5.96-5.33 Ma. Isolation of the Mediterranean Basin from the world oceans, commencing in the late Tortonian under a relatively low humidity climate resulted during the Messinian in an evaporationinduced rapid drawdown of its sea level by as much as 2 km (Buttler et al., 1999; Flecker and Ellam, 1999; Andersen et al., 2001; Krijgsman et al., 2002; Mart et al., 2004). Mechanisms contributing to the isolation of the Mediterranean Basin include a glacio-eustatic sea level fall but mainly the gradual closure of marine gateways connecting it with the Atlantic Ocean via the Betic and Rif foreland basins and with the Indian Ocean via the Taurus (Bitlis)-Zagros foreland basin (Ziegler, 1988).

As the mechanisms by which, and the exact time when, these marine gateways were closed are still poorly constrained, this is a research objective of TOPOEUROPE (e.g. Middle-Late Miocene permanent silting up of Taurus-Zagros foreland basin combined with its compressional deformation prior to early Pliocene activation of the Kara Su rift (Bahroudi and Koyi, 2004; Mart et al., 2005)). The Messinian sea level drawdown (7.24-5.33 Ma) and ensuing erosion in exposed areas had a major unloading effect, whereas the accumulation of up to $2 \mathrm{~km}$ thick salts and clastics in remnant deepwater basins had a counteracting loading effect on the Mediterranean lithosphere. The isostatic response of the lithosphere to Messinian loading and unloading needs to be quantified in order to assess its contribution to the amplitude of the Messinian unconformity. Similarly, the end-Messinian water-loading effects ought to be taken into consideration. In this context, it is of interest to note that during the (Late?) Messinian a marine connection was opened between the Black Sea and the Aegean via the Marmara Trough (Mart et al., 2004). However, this connection was interrupted during the early Pliocene (Görür et al., 2000) when open marine communications between the Mediterranean Basin and the Atlantic were re-opened, owing to breakdown of the Gibraltar arc (Ziegler, 1988).

The objectives of the proposed TOPO-EUROPE studies are to improve the understanding of the cause- and-effects and the relative contribution of geodynamic processes and climatic changes to the Messinian salinity crisis, as well as to changes in the interconnection of the Mediterranean and Black Sea, which in the latter caused around $5600 \mathrm{BC}$ flooding of large stretches of inhabited lands, triggering major migrations (Ryan and Pitman, 1999).

\subsubsection{Neotectonics and post-seismic deformation in Anatolia}

Recent studies, combining GPS measurements of post-seismic displacements with numerical modelling, indicate that near-linear viscous relaxation processes operate on and around the NAFZ. Similar phenomena have been observed on and around the San Andreas Fault. This viscous relaxation behaviour is likely to play an important role in the frequency and location of future seismicity on the NAFZ and related fault systems. However, these processes are not yet understood in terms of deformation mechanisms and rheological models describing the post-seismic response of fault cores, adjacent damage zones and surrounding crustal material need to be developed.

Experimental work provides evidence for linear viscous creep of fault rocks and intact crustal material under mid-crustal conditions. TOPO-EUROPE plans to combine experimental work on the rheology of fault zones with observations and numerical modelling in an attempt to gain a quantitative understanding of the postseismic relaxation phenomena that are recorded by the available Anatolian GPS database. The objective is to develop a physically based understanding of post-seismic deformation and stress relaxation phenomena that may be applied in the assessment of seismic hazards inherent to the NAFZ, and that may contribute at a fundamental level to the understanding of seismic cycles.

\subsubsection{Uplift of the Calabria-Apennine orogenic belt}

The Neogene evolution of the Central Mediterranean was dominated by progressive roll-back of the subducting Alpine Tethys slab, which induced the opening of the Liguro-Provencal (30-16.5 Ma) and Tyrrhenian (12 Ma to present-day) back-arc basins. During the last $10 \mathrm{My}$, the subducting slab was progressively deformed and disrupted resulting in the opening of slab windows. These are tomographically imaged beneath the Sicily Channel and the Apennines (Fig. 49). This process led to a reduction of the active subduction zone to a width of less than $300 \mathrm{~km}$ and to the formation of the Calabrian arc, and probably had a bearing on the thermal regime, volcanism and slab kinematics of the latter. Although the Calabrian subduction zone has been studied by 
(a)

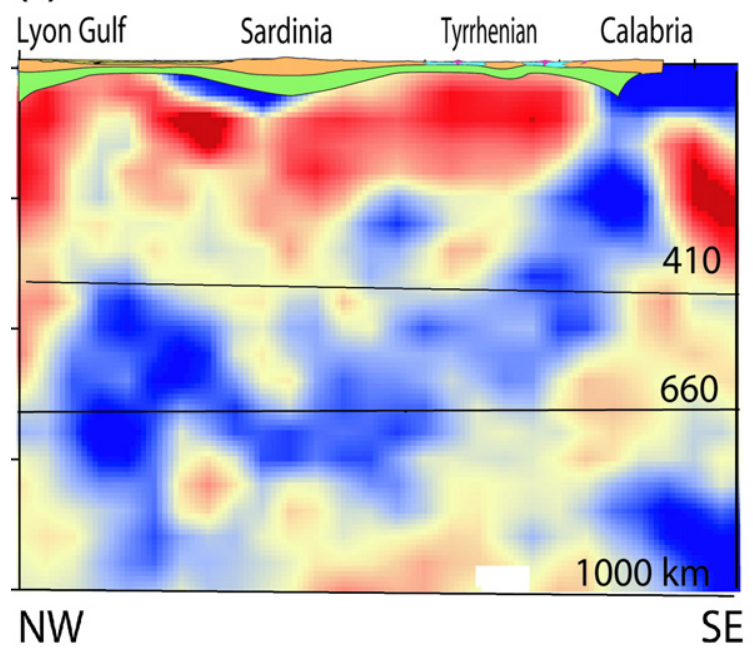

(b)

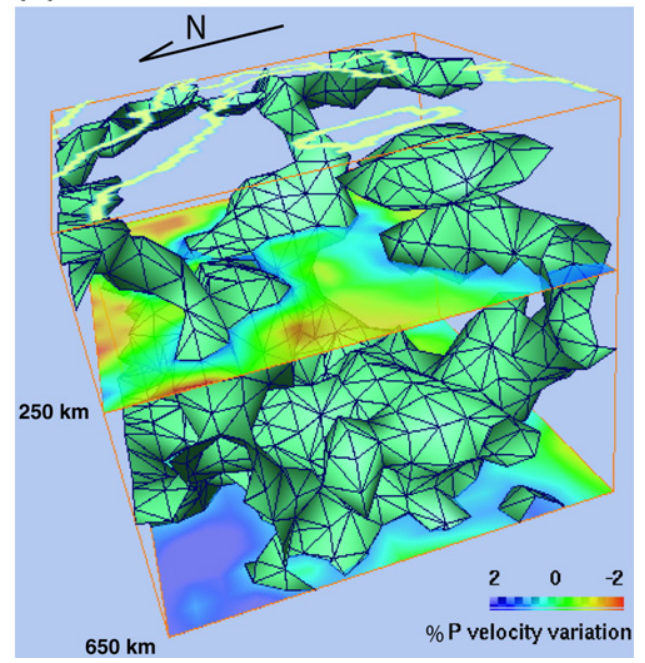

Fig. 49. (a) NE-SE-striking tomographic cross-section from the Gulf of Lyon (left) across Calabria into the Ionian Sea (right) and (b) threedimensional image of the upper mantle beneath Italy and the Tyrrhenian Sea (after tomographic model PM0.5 of Piromallo and Morelli, 2003). The cross-section in panel a shows in blue the $1000 \mathrm{~km}$ long Calabrian slab that penetrates the $410 \mathrm{~km}$ discontinuity and flattens out above the $660-\mathrm{km}$ discontinuity. The 3-D model in panel $\mathrm{b}$ shows the reduced width of the Calabrian slab. The green isosurface encloses the volume characterized by velocity anomalies larger than $+0.8 \%$ relative to average mantle velocities. The layers at 250 and $650 \mathrm{~km}$ depth are shown in coloured transparency; blue: regions of higher than average velocity (cold material); red: areas of lower than average velocity (hot material) (after Faccenna et al., 2005).

geological, seismological, and geochemical methods, several aspects are still unclear. These include the shallow geometry of the subduction zone, the cause and the mechanism of the Calabrian uplift, the temporal and spatial relationships between orogenic and anorogenic volcanism, and the question of whether subduction and accretion processes are still active.

TOPO-EUROPE aims at assessing a number of key issues by integrating different approaches, including seismology, geochemistry, reflection seismics, radiometric dating, geomorphology, fluid dynamics, and thermo-mechanical modelling:

(i) Active status of the Calabrian subduction process: Paleomagnetic data show that evolution of the Calabrian orogenic arc ended during the midPleistocene (Gattacceca and Speranza, 2002; Mattei et al., 2004). Geodetic data (Fig. 50) show a convergence rate of only a few millimetres per year for this region (Hollenstein et al., 2003; D'Agostino and Selvaggi, 2004). In the tectonic framework of the Calabrian arc, the present deep seismicity along the Wadati-Benioff plane may possibly be related to progressing slab break-off rather than to active subduction. To shed light on this process, a re-analysis of the deep and shallow stress regimes of the subducting slab is required. Combined with the analyses of the large amount of available reflection-seismic profiles, this can shed light on the tectonic style and structural geometries of the underplating/accretion process.

(ii) Shallow geometry of the subducting slab: At depths shallower than about $50-70 \mathrm{~km}$, the geometry of the subducting slab is poorly known. Reflection-seismic data show a $15^{\circ}$ dipping reflector beneath the Calabrian orogenic wedge that is interpreted as the Moho and that can be traced over a distance of about $60 \mathrm{~km}$ (Cernobori et al., 1996). In contrast, at deeper levels, the geometry of the slab is constrained by the WadatiBenioff plane (Selvaggi and Chiarabba, 1995). Tomographic analyses will shed light on the shallow geometry of the subducting slab.

(iii) Origin of the Calabrian and Apennines uplift: Marked uplift of the Calabrian-Apennines commenced probably during mid-Pleistocene. The wavelength of this uplift (Fig. 51) suggests that it is controlled by sub-lithospheric processes, analogous to those proposed for the remainder of the Apennines (Bordoni and Valensise, 1998). Several 2-D models have been advanced to explain this process, such as friction decrease along the subduction surface (Giunchi et al., 1996) or slab break-off (Westaway, 1993). To solve this problem it is necessary to: (i) analyze and date the oldest and less manifest evidence for uplift; (ii) verify the 


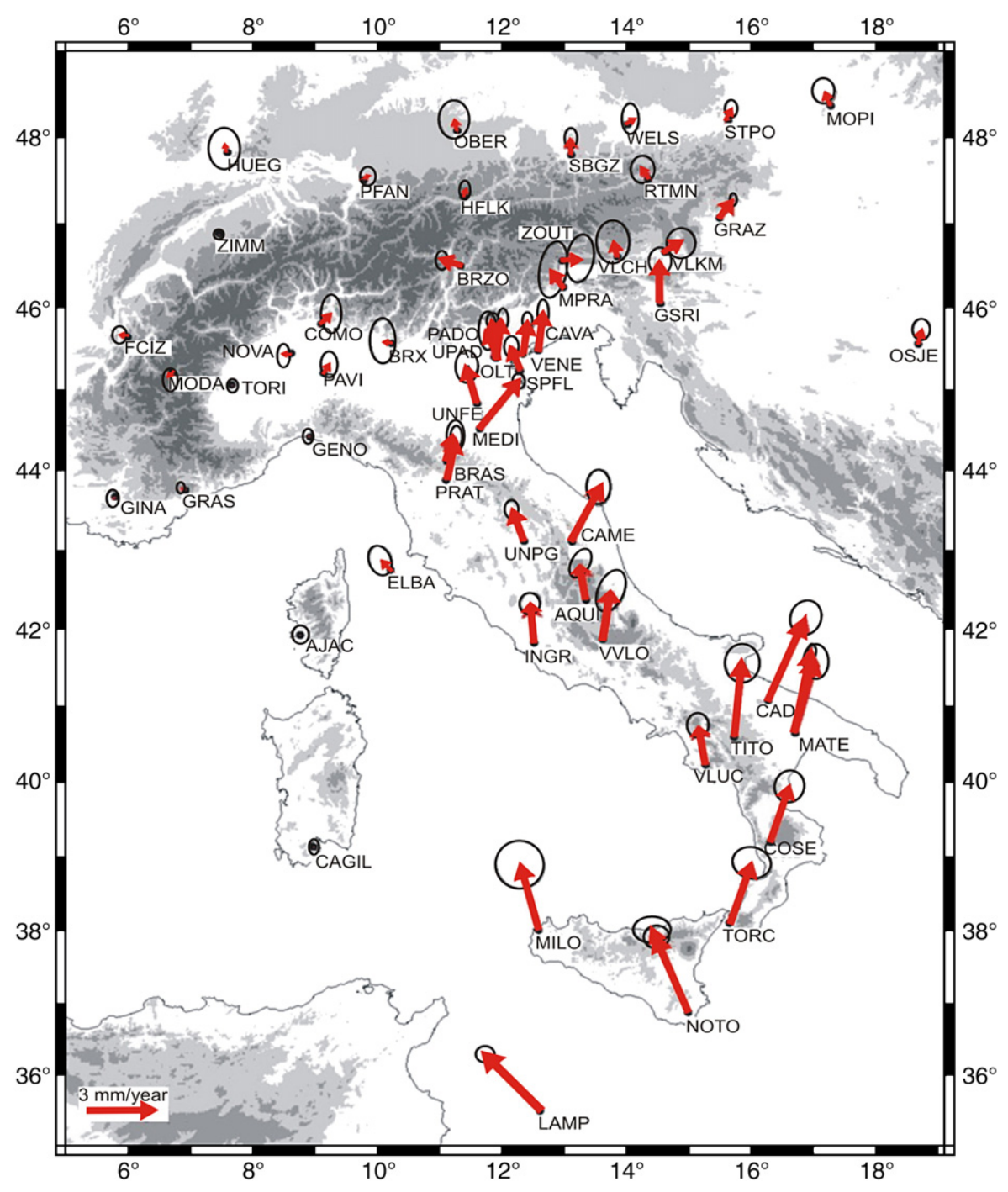

Fig. 50. GPS vectors for permanent GPS stations in Italy in the EurAsia fixed reference frame (D'Agostino and Selvaggi, 2004). Differential motions between Sicily (reflecting the motion of Nubia) and the rest of the Italian Peninsula are accommodated in northeast Sicily, notably at the Messina site of large earthquakes (e.g. 23.12.1908).

continuity and integrity of the subducting slab at shallow levels; (iii) develop models for 3-D simulations of the above-mentioned processes.

(iv) Spatial and temporal evolution of mantle sources of volcanism in the southern Tyrrhenian Sea: In the southern Tyrrhenian Sea, orogenic and anorogenic (OIB) volcanic rocks were emplaced contemporaneously. Although these volcanic rocks have been variably interpreted, there is general agreement that the OIB volcanism is related to mantle flow around the edges of the subducted slab or through slab windows (Doglioni et al., 2001; Trua et al., 2003; Faccenna et al., 2004; Faccenna et al., 2005). To further the understanding of this issue, it is necessary to assess the geochemical and isotopic characterization of the pre-orogenic mantle and to define the contribution of subducted sediments, as well as the spatial and temporal relationship between orogenic and anorogenic magmatism in some key areas where this is still poorly constrained.

(v) Reconstruction of the mantle flows induced by the subduction process: The simulation of narrow subducting slabs $(<300 \mathrm{~km})$ is complex because 2-D return flow models of mantle flow are unable to simulate this. Narrow slabs are characterized by 


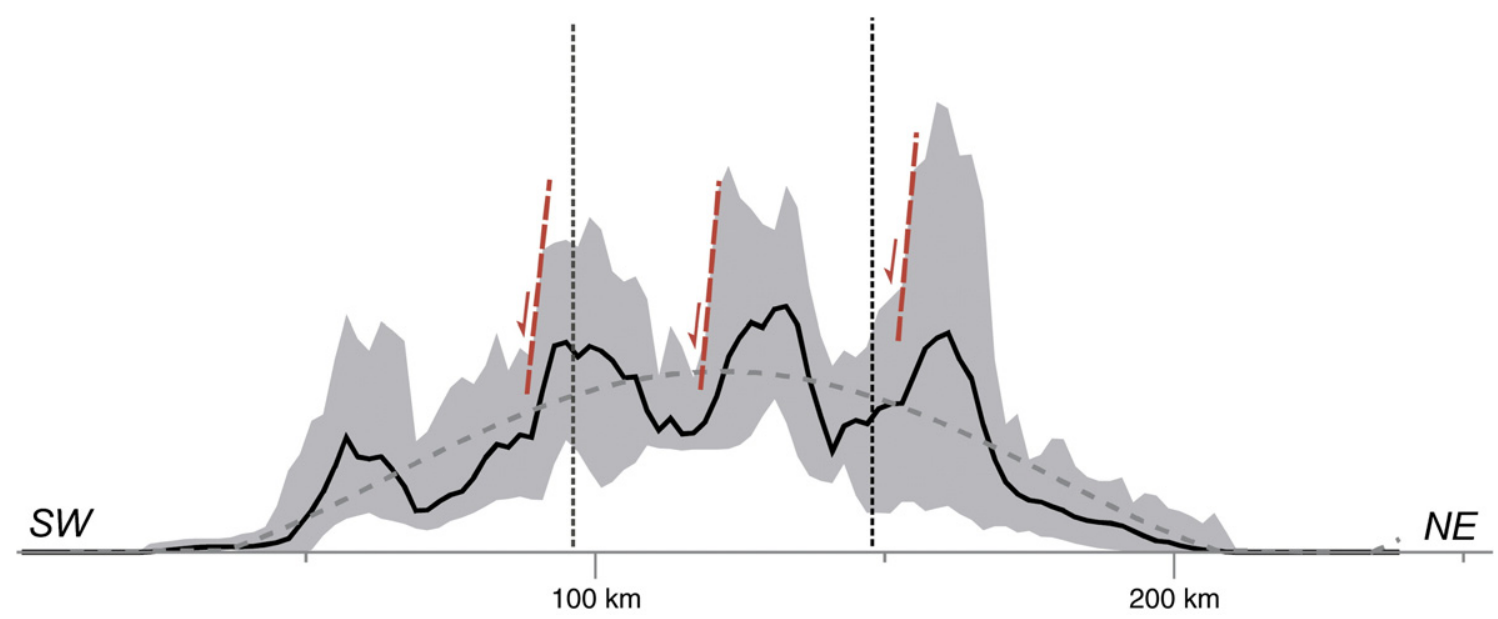

Fig. 51. SW-NE-oriented topographic swath profile across the Central Apennines. Elevation points from the 40 km-wide swaths are projected into the profile and maximum, minimum and mean elevations are calculated for $2 \mathrm{~km}$ intervals. Thick dashed line is obtained by fitting a 4 th order polynomial fit to the mean elevation. Highest peak is around 3000 meter. Two wavelengths of topography are evident. The long-wavelength topography may be attributed to dynamical mantle support whereas the shorter wavelength topography may be related to elastic flexure in response to normal faulting (modified after Bartolini et al., 2003).

intense mantle flow around their edges (Dvorkin et al., 1993; Funiciello et al., 2004). This process is also invoked to explain some characteristics of the southern Tyrrhenian and Mt Etna magmatic provinces (Gvirtzman and Nur, 1999; Doglioni et al., 2001; Marani and Trua, 2002). The SKS anisotropy of the mantle beneath Calabria suggest toroidal mantle flow around the edges of the subducting slab (Civello and Margheriti, 2004). Mantle material upwelling from below the slab and flowing towards the orogenic arc may have generated local decompression (Kincaid and Griffiths, 2003), temperature increase (Davaille and Lees, 2004), modification of mantle composition (Marani and Trua, 2002), slab erosion, and acceleration of slab roll-back (Dvorkin et al., 1993). These processes will be analyzed by seismological methods (particularly by considering mantle anisotropy), by geochemical and volcanologic methods applied in areas where both orogenic and anorogenic volcanic rocks occur, and by modelling methods aimed at quantitatively determining these processes in the central Mediterranean (Fig. 52).

\subsubsection{Specific targets for the Africa-Europe Collision} Zone: The Apennines-Aegean-Anatolian Region

- To develop an integrated network of scientists addressing Tyrrhenian-Apennine and Aegean-Anatolian systems (including Greece and Turkey).

- To connect with ICDP \& IODP projects which are working or planning activities in this region. Specific targets for ICDP include active volcanism in the Phlegrean fields and stress and seismic hazard on the North Anatolian Fault.

- Understanding and quantitative measurements of earthquake cycles on major fault systems.

- Hazard investigation of key locations in the Mediterranean area, such as Messina Strait, Hellenic arc, Lisbon.

- Lithosphere-asthenosphere mapping and high resolution mantle tomography, combined with 4-D modelling of lithospheric scale and coupled mantlesurface processes.

- Improved dating capacity, improved control and work power, development of new dating technologies (to be coordinated on a European scale).

- Improved geodetic constraints on on-going deformation and improved geomorphologic constraints on neotectonics.

- Investigate landscape response times to changes in orientation and magnitude of stress fields.

- Paleotopographic studies to assess the uplift history of mountain belts.

\subsection{In Front of the Africa-Europe Collision Zone: the Iberian Microcontinent}

The Iberian microcontinent is rimmed to the North by the Pyrenean-Cantabrian and to the South by the BeticBalearic orogen, both of which form an integral part of the Alpine-Mediterranean orogenic system (Cavazza et al., 2004). During their Cenozoic evolution, the 


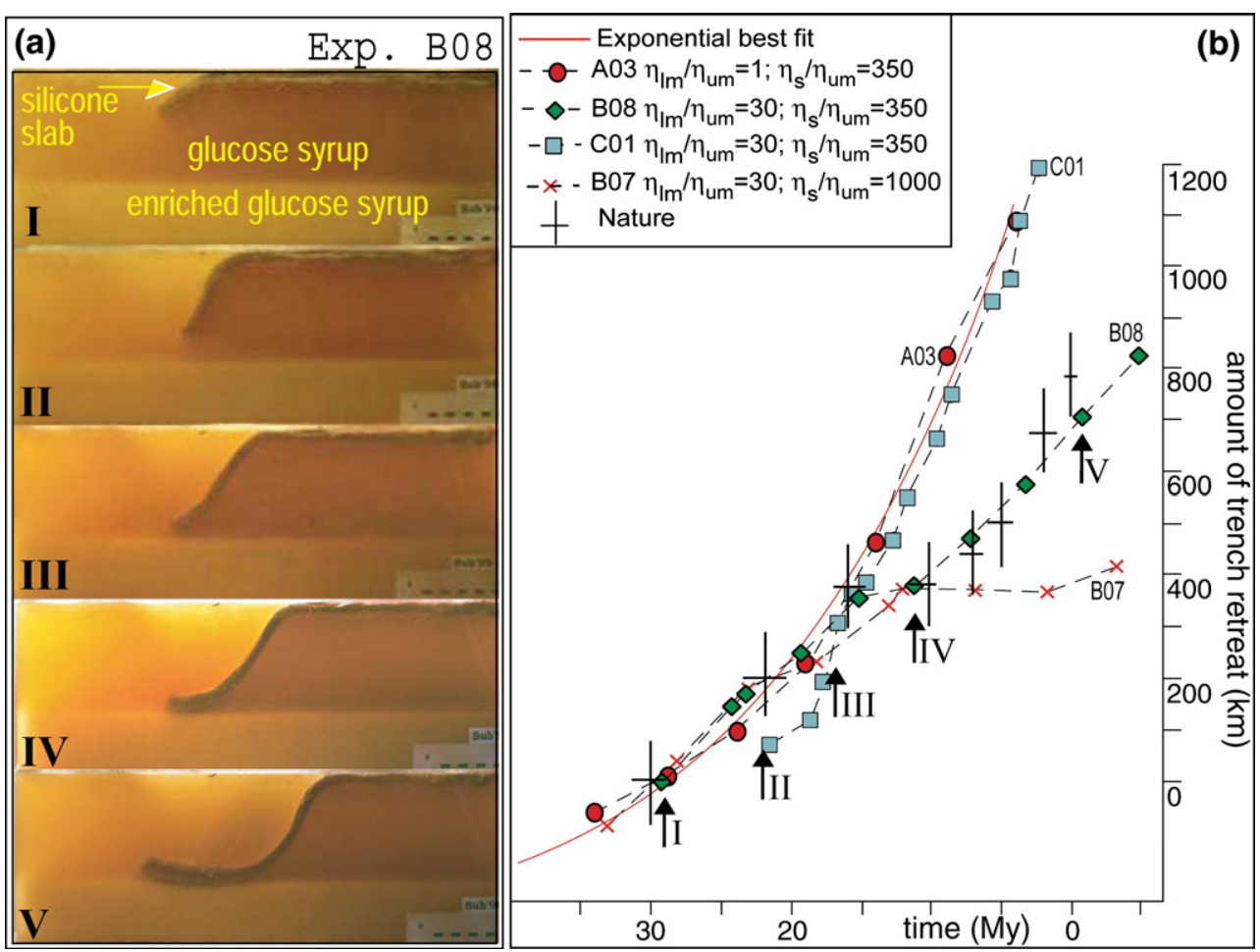

Fig. 52. (a) Five stages in the evolution of the B08 subduction system analogue model that is contained in a rectangular plexiglas tank ( $34 \mathrm{~cm}$ high, $58 \mathrm{~cm}$ long, 14-30 cm wide) and illuminated from the side. A silicone plate is used to simulate the long-term viscous behaviour of the subducting lithospheric slab whilst different glucose syrups are used to simulate the upper and lower mantle. Viscosity ratios for the slab/upper mantle and the lower/upper mantle are 350 and 30, respectively. Note that during stages IV and V the slab flattens out at the upper/lower mantle boundary. (b) Diagram comparing the geological timing of trench migration in the Central Mediterranean during the last 40 My (crosses) with the results of different analogue models (A03, B08, B07, C01). The curve for model B08 (green diamonds in panel b, and shown in panel a), which involved a nonhomogeneous mantle, fits best with natural observations and differs significantly from the best-fitting exponential curve of model A03, which simulates gravity-driven subduction into a homogeneous mantle.

cratonic part of Iberia was subjected to intense intraplate compression, as well as to extensional forces controlling opening of the oceanic Algero-Provençal Basin. Under the present NW to N-directed stress field the Pyrenees and Betic Cordillera, the Central System and the Mediterranean and Atlantic seaboards of Iberia are seismically active (Fig. 53; Jiménez et al., 1999; Andeweg, 2002; Cloetingh et al., 2005b).

Presently, Iberia is located in an area of low-velocity ( 2 to $4 \mathrm{~mm} / \mathrm{yr}$ ) NW-SE-directed convergence of the African and Eurasian plates (Argus et al., 1989) with the Azores-Gibraltar fracture zone forming the boundary between them since the Early Miocene when Iberia had joined the Eurasian plate (Fig. 53) (Srivastava et al., 1990). The Cenozoic paleogeographic and tectonic evolution of Iberia is related to closing of the AlpineTethys and the Pyrenean rift during the Alpine Orogeny, involving relative movements between the Iberian microcontinent and the Eurasian and African plates and their mechanical coupling (Vegas, 1985; Savostin et al.,
1986; Ziegler, 1988; Dewey et al., 1989; Andeweg, 2002; Jabaloy et al., 2002). The neotectonic deformation of Iberia is governed by a combination of collisionrelated and Atlantic ridge-push forces (Fig. 54) and can be elucidated by taking its Late Cretaceous to Paleogene (Srivastava et al., 1990; Roest and Srivastava, 1991) and Neogene (Mazzoli and Helman, 1994) tectonic history into consideration.

Iberia is a natural laboratory for analyzing the response of continental lithosphere to plate-boundary forces and thermal loads. Combined structural, thermogeochronological and modelling studies on lithospheric and surface processes have revealed that regional deformation of the lithosphere and the decoupled crust controlled the development of Iberia's topography, drainage pattern and sedimentary basins (Cloetingh et al., 2002).

TOPO-EUROPE, and specifically TOPO-IBERIA research will focus on the crustal and lithospheric configuration of Iberia and the structure of its sub- 

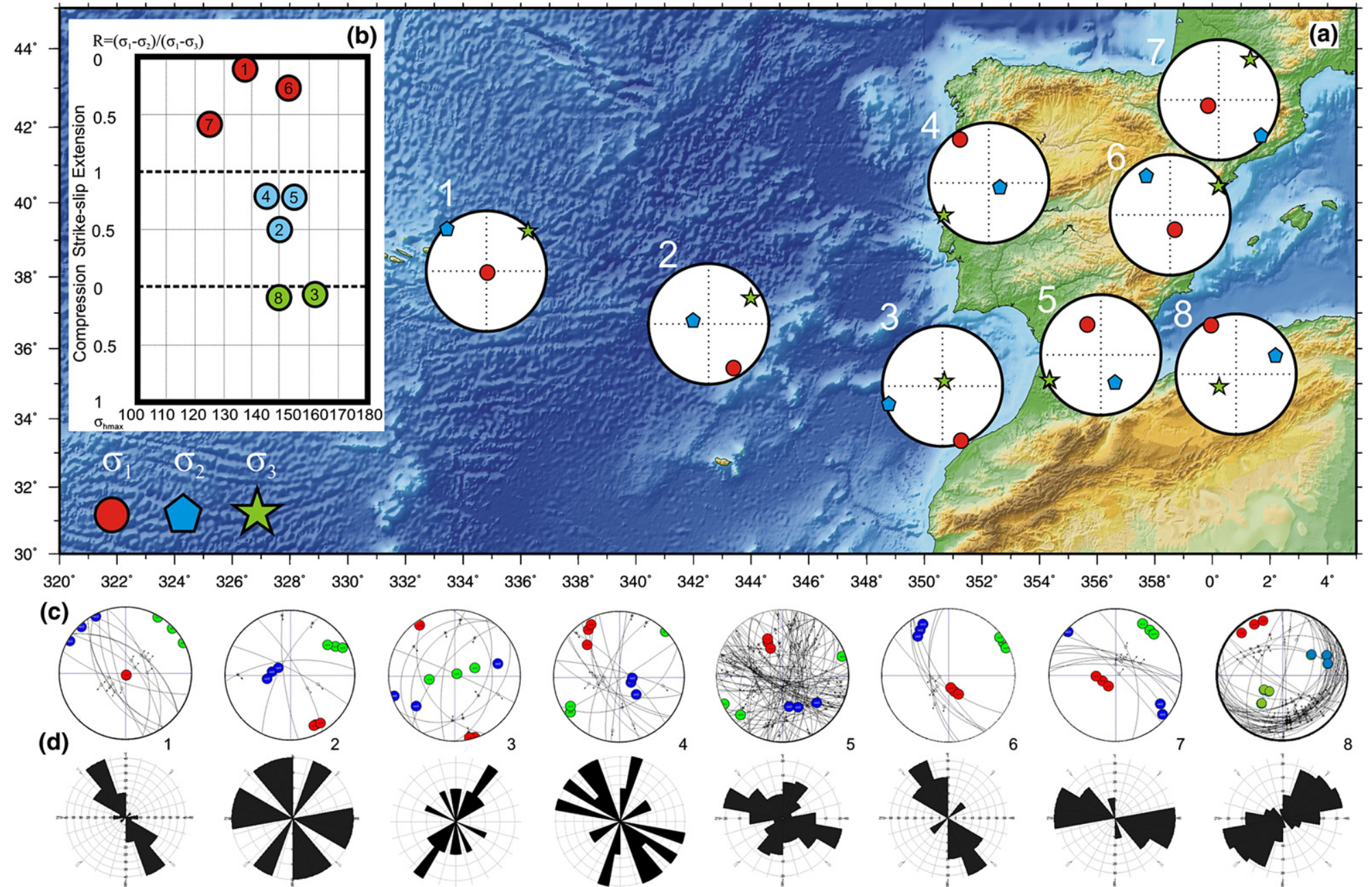

Fig. 53. Map showing topography of Iberia and adjacent areas and bathymetry of the Atlantic and Western Mediterranean together with the distribution and magnitude of earthquakes during 1980-1996 and main stress directions. Seismic activity is mainly concentrated on active and former plate boundaries (after Jiménez et al., 1999; Andeweg, 2002; Cloetingh et al., 2005b). 


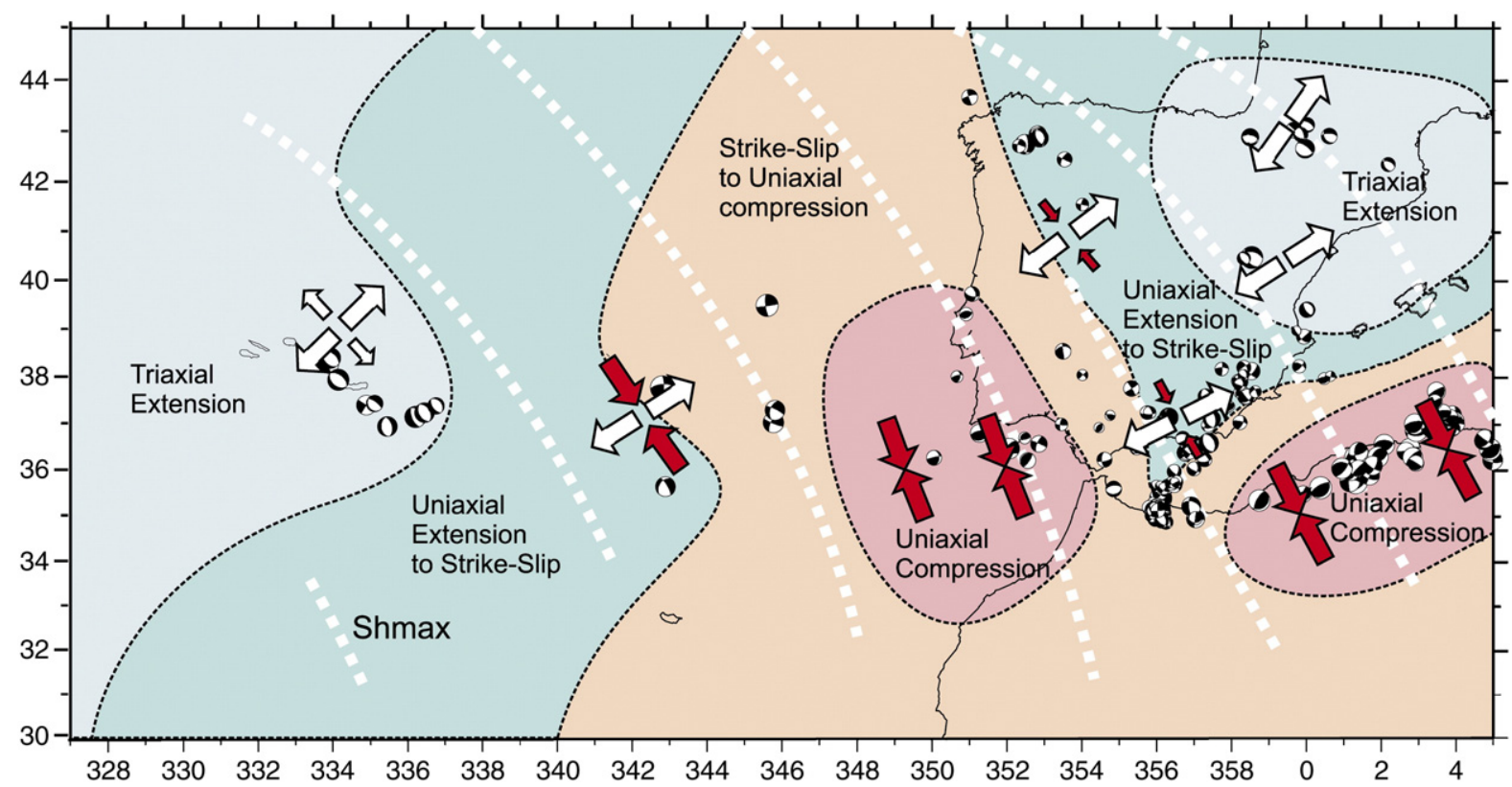

Fig. 54. Orientation of principal stresses and principal stress difference ratio in Iberia and surrounding areas, determined by inversion of focal mechanisms of earthquakes. With a predominantly $\mathrm{NW}-\mathrm{SE}$-oriented $\mathrm{Sh}_{\max }$, strike-slip and extensional stresses prevail in most of the Iberian Peninsula, whereas in the south uniaxial compressional stresses dominate (De Vicente et al., 2006).

lithospheric mantle in order to discriminate between deformations induced by various types of plate boundary forces and by deep-seated thermal anomalies related to mantle plumes and the detachment of the AlpineTethys subduction slab. The objective is to assess processes controlling the neotectonic deformation of Iberia, the resulting development of topography and the effects of erosion, sedimentation and climate on the latter. To this end a new generation of predictive dynamic models will be developed for Iberia's neotectonic deformation and topographic evolution.

\subsubsection{Background}

The lithosphere of cratonic Iberia was consolidated during the Variscan orogeny. During the Mesozoic break-up of Pangea, the Iberian microcontinent became step-wise isolated in response to opening of the oceanic Alpine-Tethys (Middle Jurassic), North Atlantic (Early Cretaceous) and Bay of Biscay (Mid-Cretaceous) basins (Ziegler, 1988; Stampfli et al., 2002; Stampfli and Borel, 2004). With the Late Cretaceous onset of AfricaEurope convergence (Rosenbaum et al., 2002), subduction of the Alpine-Tethys beneath the Iberian microcontinent commenced during the Campanian ( $\pm 80 \mathrm{Ma})$, as indicated by the age of the oldest high-pressure metamorphic rocks (Zeck, 1999; Faccenna et al., 2001b). At the same time closure of the Pyrenean rift started, involving northward subduction of continental Iberian lithosphere beneath Europe and southward subduction of the oceanic Bay of Biscay beneath Iberia (e.g. Ziegler, 1988). During Campanian to Late Eocene times Iberia was at least partly coupled to the African plate with the African-Eurasian plate boundary coinciding with the Cantabrian-Pyrenean orogen. Evolution of the latter (Munoz, 1992; Vergéz and Garcia-Senez, 2001) was accompanied by a gentle clockwise rotation of Iberia (Rosenbaum et al., 2002), involving initially tensional and later strike-slip reactivation of fault systems along its Atlantic margin. The CampanianMaastrichtian alkali basalt magmatism of southern Portugal (Tavares Martins, 1999) can be related to the activation of the NE Atlantic mantle plume (Hoernle et al., 1995).

During the Late Eocene-Early Miocene Iberia acted as an independent micro-plate with Africa-Eurasia convergence being increasingly compensated by activity along the Betic-Balearic arc-trench system. Upon Early Miocene consolidation of the Cantabrian-Pyrenean Orogen, Iberia became welded to the Eurasian plate with Africa-Europe convergence being fully taken up at the Betic-Balearic arc-trench system. At the same time the convergence direction of Africa with Europe changed from NNE during the Late Oligocene-Burdigalian to NNW during the Langhian-early Tortonian and 
from late Tortonian onward to NW (De Vicente et al., 2004).

During the Late Cretaceous the eastern parts of the Iberian microcontinent were covered by an extensive carbonate platform, reflecting that they were located near sea level (Stampfli et al., 2001). During the Late Eocene and Oligocene evolution of the Cantabrian-Pyrenean and the Betic-Balearic orogens, the Iberian microcontinent was subjected to repeated pulses of intraplate compression, causing inversion of the Mesozoic extensional Catalan Coast Ranges and the Iberian Chain basins (Salas et al., 2001; Guimerà et al., 2004) and Oligocene-Early Miocene upthrusting of the Central System basement block that had not been affected by Mesozoic extension (De Vicente et al., 1996; Gomez-Ortiz et al., 2005). This resulted in the development of major topography, tectonic silling of the flexural Ebro foreland basin and subsidence of the Tagus Basin (Andeweg, 2002).

Roll-back of the northwest-dipping Alpine-Tethys slab started during the Late Oligocene, causing development of the Gulf of Lions-Valencia Trough rift system by back-arc extension that culminated in late Aquitanian (21.5 Ma) separation of Corsica-Sardinia from Iberia and the opening of the oceanic LiguriaProvençal Basin. At the same time the Kabylia-Alboran block was separated from the Balearic promontory, resulting in the opening of the oceanic Algerian Basin, In the evolving Betic-Balearic orogen, crustal shortening persisted until late Mid-Miocene times (Rocca, 2001). During the Late Miocene, the Valencia Trough was tensionally mildly reactivated. Compressional stresses build up again during the Plio-Pleistocene, as evidenced by a subsidence acceleration of the LiguriaProvençal-Valencia Basin (Rocca, 2001).

Seismic tomography (Fig. 55) indicates that the Alpine-Tethys slab is still attached to the African lithosphere in the area of the Rif fold belt but that opening of a slab window had commenced in the Maghrebian domain and in time progressed westward (Spakman and Wortel, 2004), as evidenced by late Middle Miocene to Pliocene slab detachment-related magmatic activity (Wilson and Bianchini, 1999). The Tortonian and younger alkaline magmatism (10-0.1 Ma) along the Iberian Mediterranean margin (e.g. Calatrava, Colombretes, Olot-Gerona-La Selva) appears to be plume-related (Wilson and Bianchini, 1999; Rocca, 2001). Tomographically imaged upper asthenospheric low velocity anomalies beneath NE Iberia and southern France can be interpreted as a plume head that has spread out above the $410 \mathrm{~km}$ discontinuity (Fig. 55). As these anomalies appear to extend under large parts of Iberia (Sibuet et al., 2004; Spakman and Wortel, 2004), they may be related to the NE Atlantic plume that rises up from the deep mantle (Hoernle et al., 1995).

In the Pyrenean and Betic collision zones subduction processes apparently ceased at End-Oligocene and MidMiocene times, respectively. Subsequent convergence of Africa with Iberia and Europe at rates of 3.3-5 mm $\mathrm{yr}^{-1}$ (Jiménez-Munt et al., 2003), combined with Atlantic ridge push forces, is held responsible for the seismicity and neotectonic deformation of Iberia, with the latter exerting a strong control on its topography (Cloetingh et al., 2005b).

\subsubsection{Program scope and objectives}

Although major research efforts have already been devoted to the understanding of the evolution, neotectonics and hazard assessment of the Iberian micro-continent, concepts developed so far need to be critically reassessed and validated by a multidisciplinary approach, involving integration of all available and acquisition of new data, as well as data-interactive modelling, both of the analogue and numerical type. In this respect, the cornerstones of the TOPO-EUROPE program include the application of stateof-the-art and the development of advanced data acquisition methodologies in the fields of space geodesy, thermochronology/geochronology (astronomical time scales), paleostresses, sedimentary record, seismology, lithosphere and mantle tomography and geomorphology studies. Previous investigations by TOPO-EUROPE research groups in Iberia provide a strong starting point for this new endeavour (Cloetingh et al., 2005b).

\subsubsection{Constraints on vertical motions}

Large parts of Iberia are presently elevated to 750-1000 m, with mountain chains reaching heights of up to $1500 \mathrm{~m}$ in areas that were affected by Late Eocene to Early Miocene compression. Apatite fission-track (AFT) studies carried out on the Mediterranean and Atlantic margins of Iberia (Stapel et al., 1996), on the Central System (De Bruijne and Andriessen, 2000; De Bruijne and Andriessen, 2002), as well as on the Betics (Zeck et al., 1992) and the Pyrenees (Fitzgerald et al., 1999), provided evidence for a rapid post-Miocene cooling phase (uplift and erosion). For the Central System these data show that Late Eocene to Early Oligocene compressional uplift was followed by significant Middle Miocene (15 My) cooling and subsequently by a pronounced cooling acceleration starting in the Early Pliocene (5 My; De Bruijne and Andriessen, 2000). From the Sierra Guadarrama, which forms the eastern part of the Central System, a rock column of $6 \mathrm{~km}$ was eroded during Pliocene and Quaternary times (De Bruijne and Andriessen, 2000; Ter Voorde et al., 2004). 

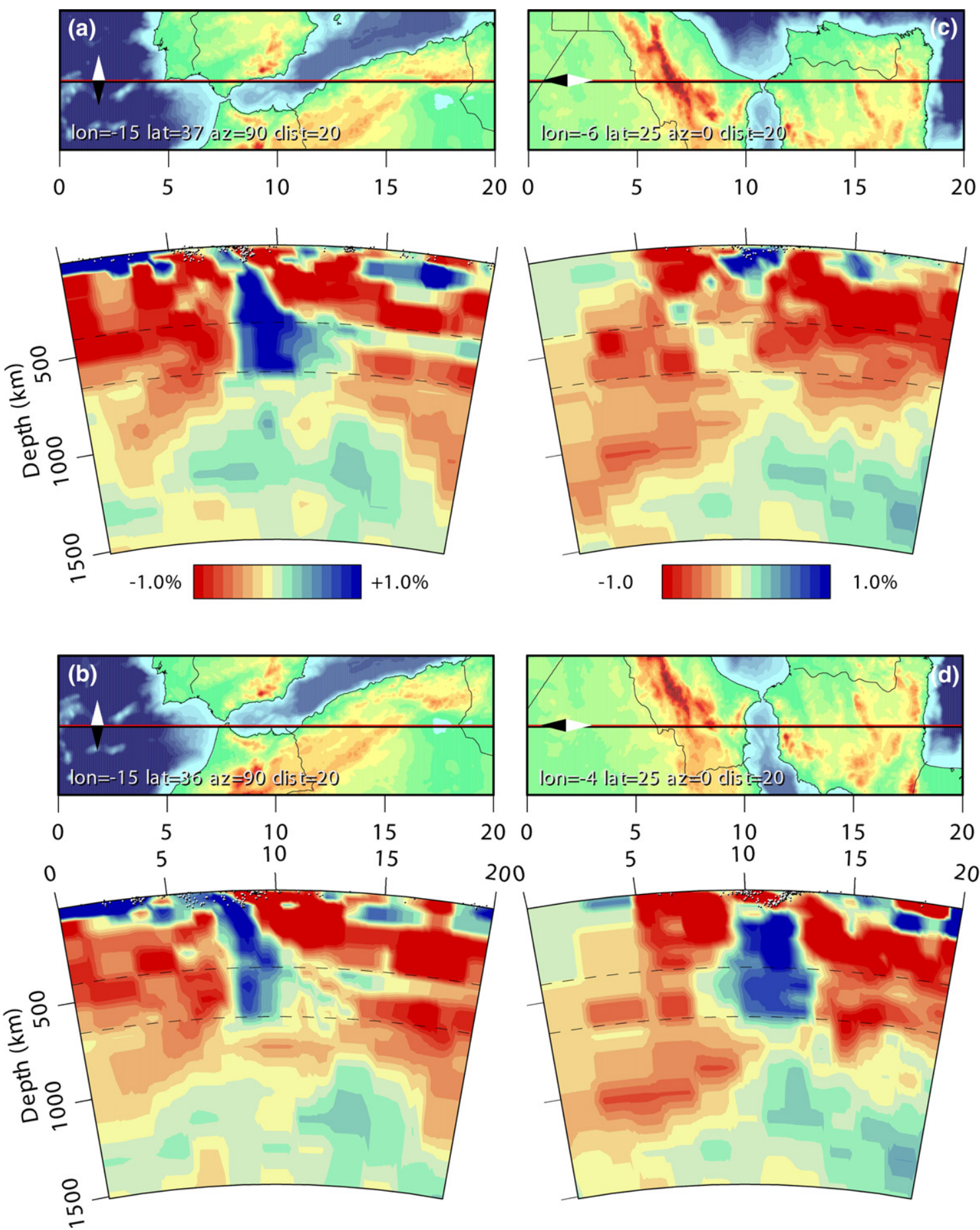

Fig. 55. E-W and N-S P-wave mantle tomography cross sections through the Gibraltar Strait and the Iberian Peninsula, respectively. Colours indicate seismic wave speed anomalies as percentage deviations from average mantle velocities given by a depth-dependent reference model. Horizontal axis in degrees along great circle segments defining the location of the cross-sections (straight lines on maps) (After Spakman and Wortel, 2004). 
Preliminary data indicate that during Pliocene and Quaternary times the Atlantic sea board of Portugal was uplifted by some $1000 \mathrm{~m}$, the Betic Cordillera by up to $1200 \mathrm{~m}$ and the Pyrenees by some $500 \mathrm{~m}$ (Cloetingh and Cornu, 2005b). Moreover, numerous paleo-seismic features occur in the Tagus Basin (De Vicente et al., 2007this volume).

TOPO-EUROPE plans to assess the neotectonic uplift/subsidence pattern of entire Iberia by combining geomorphologic studies and geodetic data with additional AFT studies. In order to quantify the seismic hazard potential of the Iberia area, combined paleoseismic and modelling studies are required.

\subsubsection{Interplay between surface transport and vertical motions}

Erosional unroofing of elevated areas causes isostatic uplift, while sedimentation in topographic lows causes flexural subsidence. Numerical modelling of the evolution of drainage networks (Garcia-Castellanos et al., 2003) shows that surface transport processes can effectively enhance tectonically induced large-scale continental topography. Despite the intrinsic non-linear nature of drainage networks, already moderate vertical movements appear to be able to organize drainage patterns in relatively flat areas where drainage is not yet well organized and incised (Garcia-Castellanos et al., 2002).

During the Late Eocene to Early Miocene compressional deformation of continental Iberia, erosion products derived from the rising structural highs were deposited in adjacent topographic lows, such as the Duero, Almazan, Ebro, Guadiana, Guadalquivir and Tagus basins. In most of these basins sedimentation persisted during the Miocene with expanding lacustrine facies (Calvo et al., 1995), but terminated at the transition to the Pliocene (Andeweg, 2002) when it gave way to erosion. This is compatible with the results of fission track studies that indicate for Central Iberia a Plio-Pleistocene phase of uplift and erosion rather than a Miocene uplift phase followed by erosion (Ter Voorde et al., 2004). The sedimentary record of the Atlantic and Mediterranean shelf basins provides information on the timing of development of the modern drainage system. For instance, development of the river Ebro, that cuts through the Catalan Coast Ranges and deeply incises into the Ebro Basin, is dated as late Tortonian by the development of its Castellon delta (Gaspar-Escribano et al., 2003). TOPO-EUROPE intends to carry out similar studies on the deltas of other major Iberian rivers, using available industrial reflection-seismic and well data, in order to constrain the timing of their activation. Moreover, the effects of erosional unroofing of continental Iberia and load-induced subsidence of it continental shelves will be modelled. These models will also be applied to the major Iberian sedimentary basins, as their tecto-sedimentary record permits to develop a correlation between the different deformation events and provides constraints for numerical and analogue models.

\subsubsection{Present-day stress regime and topography}

Much of Iberia is dominated by a NW-SE-directed compressional stress field that had come into evidence during the Middle and Late Miocene (Fig. 54a) (Galindo-Zaldivar et al., 1993; De Vicente et al., 1996; Ribeiro et al., 1996; CSN, 1998; Andeweg, 2002; De Vicente et al., 2006). In the NE part of the Peninsula, along the Pyrenean domain, the Ebro Basin and the Valencia Trough, the trajectories of maximum horizontal compressional stresses are deflected into a N-S direction (De Vicente et al., 1996; Jurado and Müller, 1997; Schindler et al., 1998; Goula et al., 1999; De Vicente et al., 2006). Zones of active extension occur in the Iberian Chain and the Valencia Trough.

In the Betic foreland, earthquake focal mechanisms suggest possible reactivation of NW-SE-striking normal faults and WNW-ESE-trending right-lateral and SSE-NNW-trending left lateral strike-slip faults. Whilst in the easternmost parts focal mechanisms suggest activation of normal faults, strike-slip focal mechanisms become increasingly frequent going westward.

This is compatible with the NW-SE maximum horizontal compressional stress field of the southern parts of the Iberian Peninsula, the Alboran Sea and the Rif of Morocco (Fig. 54). In Algeria, the most common focal mechanisms indicate NW-SE compression, while in the Gulf of Cadiz and Gorringe, stress solutions are indicative for a strike-slip regime and NW-SE-directed compression.

The regional stress field of Iberia reflects a combination of forces related to collisional coupling of Africa, Iberia and Europe, and Atlantic ridge-push (Andeweg, 2002). NW-ward movement of Africa at rates of $3.3-5 \mathrm{~mm} \mathrm{yr}^{-1}$ is apparently compensated by crustal deformation in the seismically active Maghrebian, Betic and Pyrenean zones, as well as by deformation of cratonic Iberia. Moreover, first results of GPS surveys point toward a consistent NW-directed horizontal displacement of Iberia at rates of some $5 \mathrm{~mm} / \mathrm{yr}$ (Fernandes et al., 2000).

The topography of cratonic Iberia is characterized by a succession of roughly NE-SW-trending highs and lows that strike normal to the present-day stress trajectories 
and parallel similar trending Bouguer gravity anomalies (Cloetingh et al., 2002). The magnitude of PlioPleistocene vertical motions and results of precision levelling suggest that processes controlling topography development are still on-going and exert a first-order control on the present surface topography of Iberia. Observed Bouguer gravity anomalies reflect long-wavelength depth variations of intra-lithospheric density interfaces, such as the crust-mantle boundary (Cloetingh and Burov, 1996), and thus mirror deformation of the entire lithosphere. This raises the question whether the observed Plio-Quaternary vertical motions are related to lithospheric folding (Andeweg and Cloetingh, 2001) or whether they are related to upper mantle thermal perturbations evidenced by mantle tomography (Fig. 55; Sibuet et al., 2004; Spakman and Wortel, 2004).

In order to assess whether the average high elevation of Iberia results from stress-induced lithospheric folding and/or potential large-scale asthenospheric thermal anomalies, giving rise to a gravity signal with a wavelength of over $500 \mathrm{~km}$, TOPO-EUROPE intends to image the structure of the lithosphere and the mantle beneath entire Iberia and its surrounding areas by detailed seismic tomography and magnetotelluric profiling (Figs. 56 and 57). Results will permit to assess and model dynamic processes controlling the neotectonic deformation of Iberia, the resulting topography and its repercussions on drainage systems. Furthermore seismotectonic and paleo-seismic studies will aim at identifying active fault zones and at a refinement of available seismic hazard maps.

\subsubsection{Specific targets for the front of the Africa-Europe} collision zone: microcontinent Iberia

- Kinematics of intracontinental Iberia, in particular timing of deformation.

- Analogue and numerical modelling of intraplate stress transfer.

- Analysis of the different geomorphic systems of Iberia.

- Detailed AFT studies on main thrusts.

- Construction of a realistic and quantitative neotectonic map of continental Iberia.

- Crustal and lithospheric configuration of Iberia and structure of its sub-lithospheric mantle.

- Discrimination between deformations induced by plate boundary forces and deep-seated thermal anomalies related to mantle plumes and detachment and roll-back of the Alpine-Tethys subduction slab.

- Development of a new generation of dynamic models for Iberia's neotectonic deformation, topographic evolution and seismic hazards.
3.5. Far-field studies: continental margin topography of Scandinavia and Greenland

\subsubsection{Motivation and objectives}

The principal scientific objectives of TOPO-EUROPE research on the Scandinavian and Greenland passive margins are to advance the understanding of crustal, lithospheric and mantle processes that controlled the post-rift uplift of their onshore parts and subsidence of their shelves, as well as to unravel geological and climatic controls on the long-term evolution of their topography. Unlike the rifted passive margins of e.g. the Central Atlantic, those of the Arctic-North Atlantic are characterized by considerable topography that developed during their post-rift stage. As such, they present a natural target for integrated geological and geophysical research on late-stage continental margin topography development and related geohazards, including tsunamis triggered by rock-falls in fjords and submarine landslides on continental shelves:

- The available wealth of geological and geophysical data provides close constraints on the evolution of crustal and lithospheric structures and related vertical motions and permits testing of hypotheses on the development of continental margin topography.

- Extensive data sets available for many sedimentary basins provide a detailed record of vertical motions during continental break-up and the subsequent passive margin evolution.

- Combined onshore/offshore studies indicate that preexisting (Caledonian to Early Carboniferous) fault systems were reactivated as normal faults during the post-rift phase, particularly along the Norwegian margin, influencing (local) vertical motions.

- Vertical lithospheric motion during the syn- and postrift evolution of the Arctic-North Atlantic basins and their borderlands had a bearing on the opening and closure of the Arctic seaway, causing long-term natural climate changes.

- Major petroleum provinces associated with the Arctic-North Atlantic passive margins and their borderlands were affected by late-stage vertical motions.

- Fission track analyses document post-rift denudation and uplift of onshore Scandinavia.

\subsubsection{Quantifying the Uplift of Scandinavia in space and time}

Development of the Norwegian passive margin was preceded by 280 My of intermittent rifting that culminated at the Paleocene-Eocene transition in crustal 


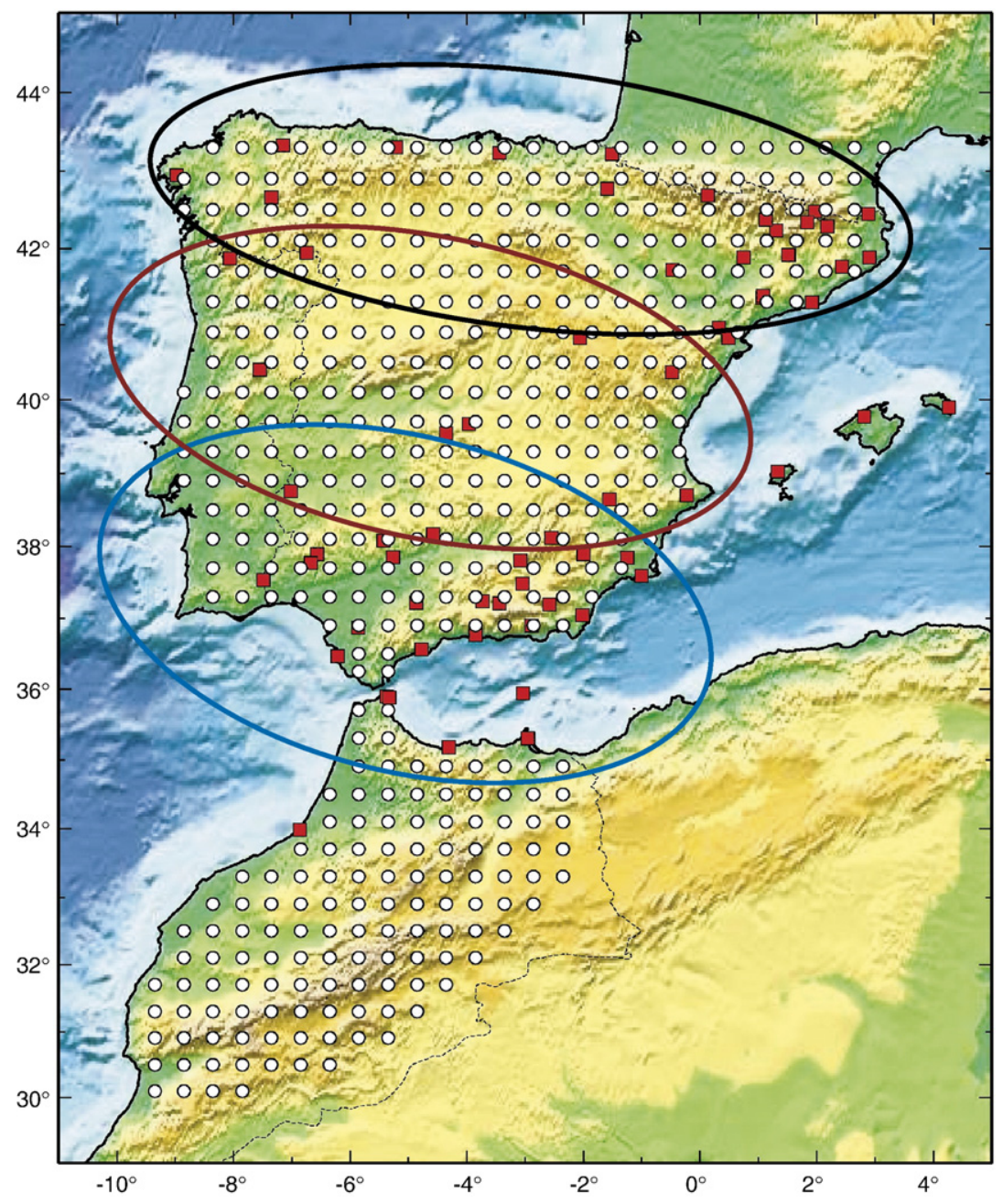

Fig. 56. International research initiative PICASSO, 50x50 km grid covering Iberia and northwestern Africa. Red squares indicate the operational broadband seismic stations of the Spanish permanent network. Ellipsoides indicate deployments that would be required to cover the three thematic areas of Iber-Array: South (blue); Centre (red), North (black) (Courtesy PICASSO).

separation between Scandinavia and Greenland and the onset of sea-floor spreading (Ziegler, 1988). The present-day landscape of Scandinavia's Atlantic border is characterized by elevated margins with associated escarpments, and an overall topography that gradually diminishes towards the continental interior. In western Fennoscandia, a deeply incised topographic escarpment runs close to and parallel with parts of the Norwegian coast, separating the uplifted western Scandinavian landmass from deep offshore sedimentary basins. In southcentral Norway, an uplifted sub-Cambrian peneplain is evident that reaches elevations of more than 1000 metres. To the east, in central Sweden and Finland, this subCambrian peneplain lies very close to sea level, suggesting that very little vertical motion has occurred in these areas since the late Proterozoic. Thus, a flexural profile appears to characterize onshore Fennoscandia (Redfield et al., 2005). Offshore Mid-Norway, the extremely deep Møre and Vøring basins present megascale sags that developed in response to thermal subsidence and sedimentation after the Jurassic-Cretaceous rift phase that preceded crustal separation. In the hinge that developed between the uplifting landmass and the subsiding post-rift basins, inherited Paleozoic fault complexes appear to have been reactivated from the Late Cretaceous onwards, probably affecting the shape and distribution of topographic highs and lows. Offshore, the deep crustal geometry of the Møre and Vøring basins appear to be controlled by major extensional detachment faults that partly re-activate structures stemming from the 


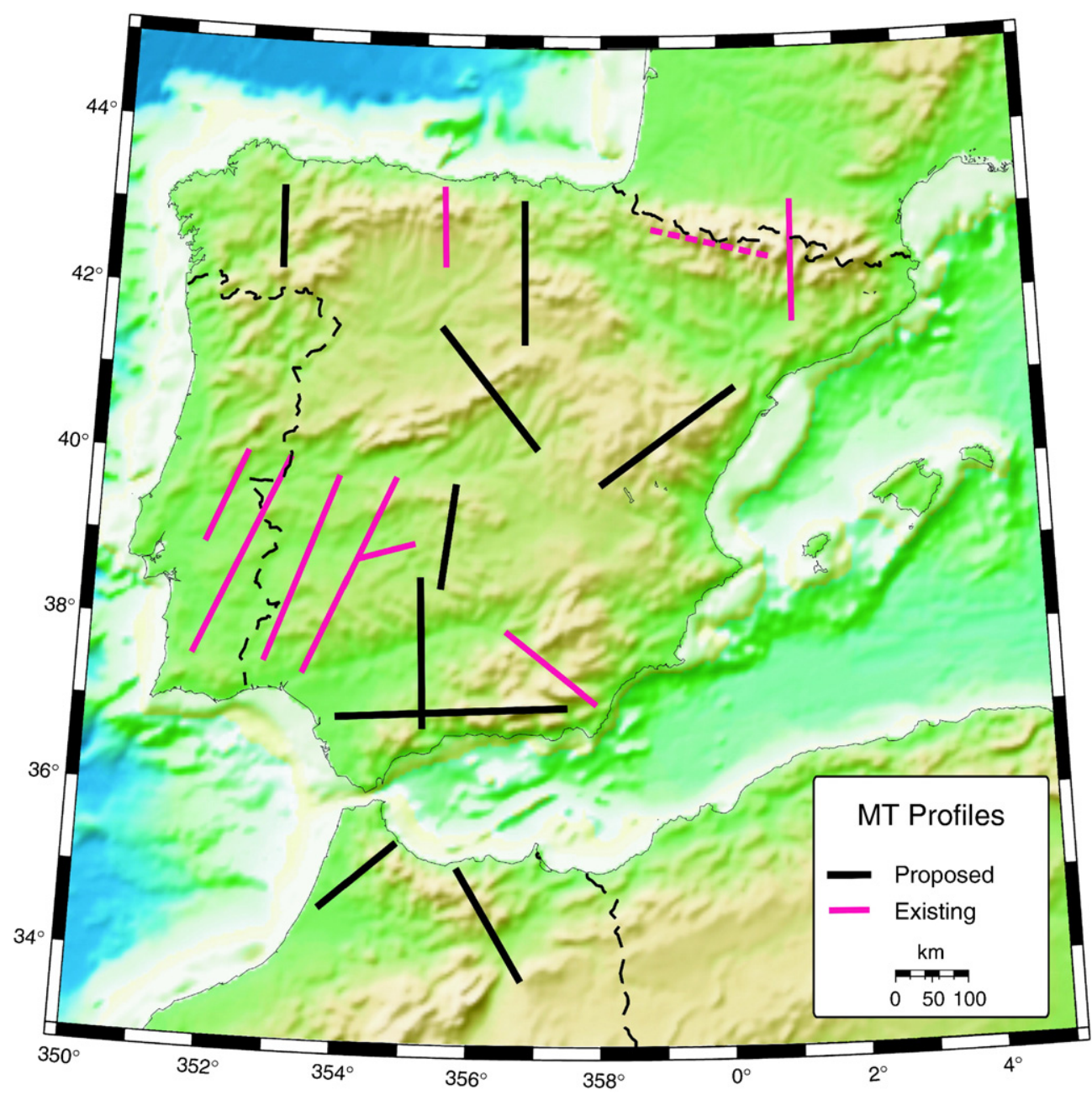

Fig. 57. Existing magnetotelluric profiles in Iberia (red lines), and profiles to be acquired under the proposed TOPO-Iberia Project (black lines) (Courtesy TOPO-IBERIA).

late- and post-orogenic collapse of the Caledonides (Gabrielsen et al., 2005; Ebbing et al., 2006).

The topography of western Scandinavian borderlands is characterized by surfaces that reflect important stages in their uplift and erosion. The most clear is the so-called palaeic surface that occurs over large areas of southern Norway at elevations of $800-1000 \mathrm{~m}$. Topographically higher (and tentatively older) surfaces have been proposed. An intriguing challenge lies in understanding of mechanisms that controlled the development, uplift and incision of these surfaces that probably formed during the Late Mesozoic, Cenozoic and Quaternary (LidmarBergstrom and Naslund, 2002). A critical component of this challenge is the exact dating of the development of these surfaces (Hendriks and Andriessen, 2002).

To unravel the dominant mechanisms responsible for the present-day Scandinavian topography and its past evolution, TOPO-EUROPE participants will examine the interaction between tectonics and landscape evolution, placing quantitative constraints on the timing of processes that control denudation and morphological development. To study these phenomena, new highresolution data on denudation rates will be required. Local-versus regional-scale effects will be assessed and compared to the post-break-up landform evolution of the conjugate Norwegian and East Greenland (de) glaciated margins (Tsikalas et al., 2005). Available apatite fission track (AFT) data (Fig. 58) document a broad, regional-scale pattern of post-rift denudation and uplift (Rohrman et al., 1995; Cederbom, 2001; Hendriks and Andriessen, 2002; Rohrman et al., 2002; Huigen and Andriessen, 2004; Murrell and Andriessen, 2004; Redfield et al., 2004; Hendriks and Redfield, 2005). However, there is a lack of data on denudation rates at 


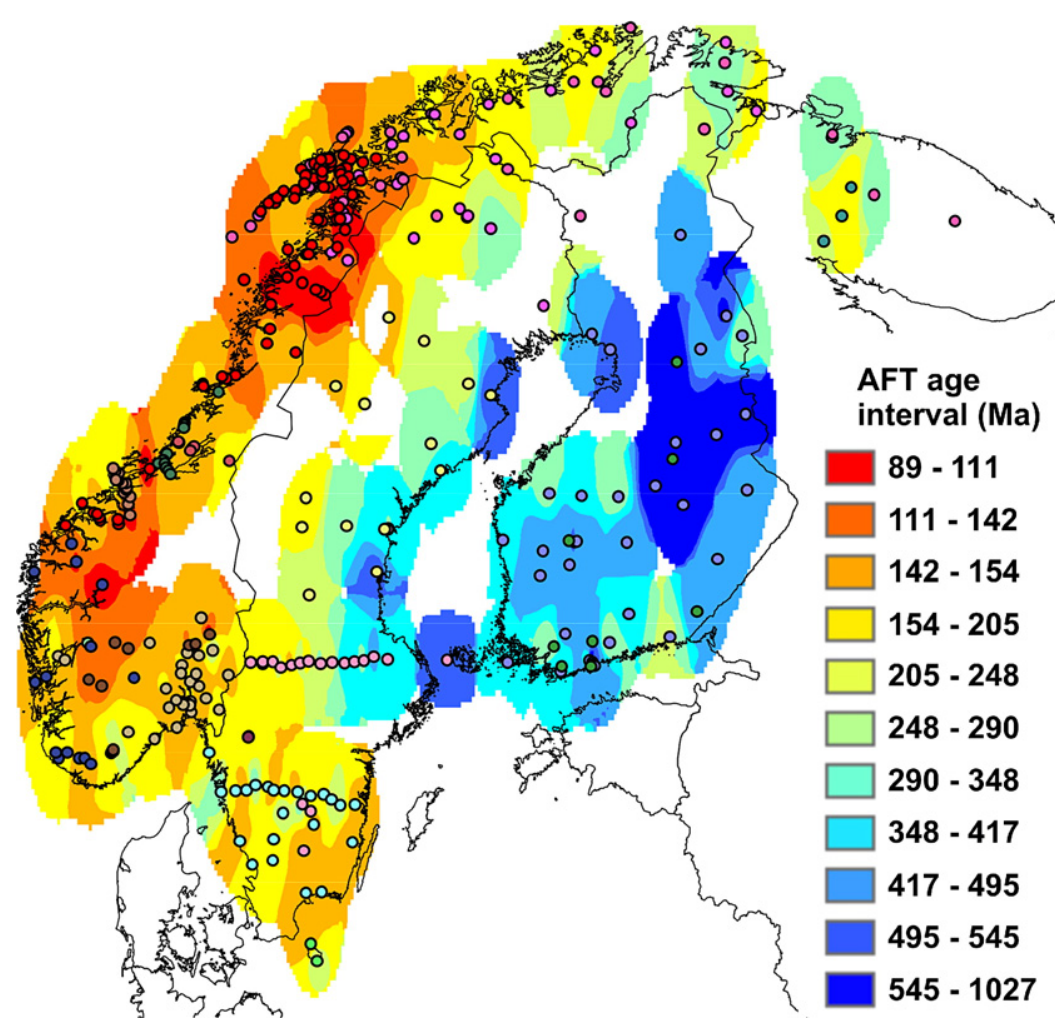

Fig. 58. Regional map of Fennoscandia showing contoured AFT ages (after Hendriks et al., 2004). Selection criteria for samples included in this compilation are: elevations up to 500 above MSL, ages obtained with the External Detector Method and from chlorine-rich apatites are excluded. The AFT ages represent slow cooling and therefore do not directly correspond to geological events of the respective age. However, the pattern of ages highlighted by this compilation suggests a rift shoulder origin for the ancestral Scandes Mountains. Note that areas with a very low sampling density remain blank. This compilation is based on the work of many people, including a large number of PhD students from the Vrije Universiteit Amsterdam that were supervised by P.A.M. Andriessen.

the finer resolution scale required for constraining numerical models for surface and deeper lithospheric or even asthenospheric processes. Therefore, TOPO-EUROPE will combine low temperature $\left(<70{ }^{\circ} \mathrm{C}\right)$ apatite (U-Th)/He analyses with higher temperature $\left(120-60^{\circ} \mathrm{C}\right)$ AFT thermochronology to place as fine a resolution as possible on patterns and timing of denudation. Data will be collected along profiles that are carefully laid-out together with structural geologists to distinguish between tectonic juxtaposition and erosion-related denudation. The advantage of this approach is that a distinction can be made between regional- and local-scale exhumation patterns vs. regional- or local-scale patterns of post-rift tectonics (Redfield et al., 2005).

TOPO-EUROPE will thus focus on problems such as (a) quantification of timing and amount of uplift and denudation, (b) finer resolutions of denudation patterns stemming from syn-rift or post-rift structuring of the margin, and (c) comparing the post-break-up landform evolution of conjugate margins.

\subsubsection{Effects of lithospheric and sub-lithospheric processes on topography development}

The Norwegian margin has been extensively explored for petroleum during the past three decades, rendering it probably the world's best-documented volcanic passive margin. Information obtained from seismic reflection/ refraction surveys, potential field studies and tomographic inversions coupled with the results of related studies (e.g. ESF EUROCORES EUROMARGINS) that focused on the deep-crustal architecture offshore MidNorway and East-Greenland make Scandinavia's margin an excellent natural laboratory to evaluate the effects of deep lithospheric and sub-lithospheric processes on its syn- and post-rift evolution.

Processes controlling both dynamic and isostatic topography development played an important role in the evolving North-Atlantic margins. To enhance their understanding, onshore and offshore field studies and numerical modelling will be carried out. The structural configuration of offshore basins and their internal 
sedimentary architecture will be regionally mapped based on the available dense grid of mainly 2-D industrial multi-channel reflection-seismic lines, supplemented by deep seismic reflection/refraction and potential field data, plus 3-D seismic data where available. Complementary onshore studies will encompass in-depth structural field work in close conjunction with geochronologic and geomorphologic studies to 'set the stage' and place results in a coordinated, well-constrained, tectonically integrated framework. This will be supported by a regional 3-D interpretation based on seismic tomography, potential field data and heat flow measurements (Olesen et al., 2005).

Particular emphasis will be given to the construction of a set of comparative, lithospheric-scale regional transects across the Norwegian and Greenland margins, from far offshore to well inshore (Mosar, 2003; Gernigon et al., 2006). Numerical methods will be applied to determine the present-day structure of the lithosphere from a wealth of geophysical data (Pascal, 2006). Stepwise palinspastic restoration of these transects, incorporating sediment decompaction and corrections for water depths and data on uplift and denudation, will permit to assess the extensional strain distribution and rates in time and space, as well as subsidence and uplift patterns.

Of particular interest is the computation of dynamic topography due to large-scale mantle density anomalies and flow, using codes developed by Steinberger (2007). For very long wavelengths of $>3000 \mathrm{~km}$, a reasonably good match, both in the pattern and amplitude, can be obtained in the Arctic-North Atlantic/Scandinavian region between computed and observation-based present-day dynamic topography (Fig. 59; Steinberger, 2007). The effect of varying modelling assumptions (mantle density anomalies, viscosity structure, plate motions etc.) on the computed dynamic topography will be investigated in an effort to define in which range of models a good fit with observations can be achieved. For successful models the advection of mantle density heterogeneities will be modelled backward in time (Steinberger and O'Connell, 1997), together with the resulting change in dynamic topography. Although such a procedure cannot recover the past mantle density structure in regions where diffusion was the main heat transport mechanism (i.e., the lithosphere), computations will be meaningful for assessing how the change of density anomalies and flow in the sub-lithospheric mantle has contributed to topography changes through time.

Surface topography induced by the Iceland plume will be quantified. With large-scale flow models, the position of the Iceland plume through time will be recomputed, as in Steinberger (2000). Based on the
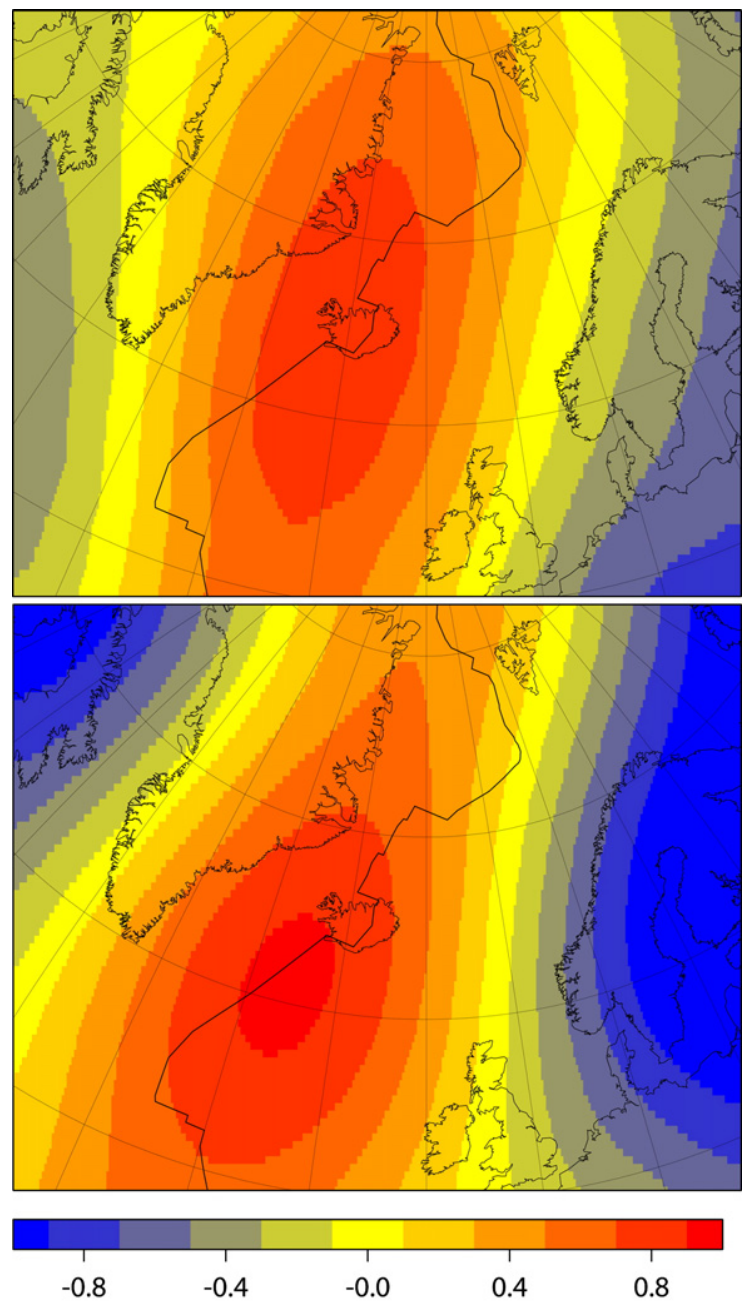

dynamic / residual topography $[\mathrm{km}]$

Fig. 59. Upper panel: computed dynamic topography due to density anomalies and flow in the mantle; density anomaly based on tomographic model S20RTS (Ritsema and Van Heijst, 2000). Lower panel: residual topography obtained by subtracting topography due to variations in crustal thickness and density (crust2.0, online at http:// mahi.ucsd.edu/Gabi/rem.html) and ocean floor age (Mueller et al., 2005) from actual topography. Expansion up to spherical harmonic degree 12 (after Steinberger, 2007).

computed location of the Iceland plume and the midAtlantic ridge through time, and on buoyancy flux and models of plume-ridge and plume-lithosphere interaction (Mihalffy et al., in press), topography changes will be estimated and compared to observations. This modelling study will explicitly address the questions during what time interval the Iceland plume has been entrained by the Atlantic spreading ridge, and how it may have contributed to the late-stage uplift of Scandinavia. Modelling will use input from, and results will 
be compared with detailed mantle tomography to be acquired.

Topography is composed of a signal from the mantle, as described above, and contributions from lithosphere isostasy and local crustal processes that are not yet in equilibrium. The surface deflection that can be caused by deep mantle loads is a function of the strength of the lithosphere. Crustal-to lithospheric-scale finite element models will be combined with mantle flow models to constrain the evolution of surface topography. Lithosphere models have a high resolution and sophisticated (visco-elasto-plastic) rheology (Buiter et al., 2004) and can thus 'filter' the dynamic topography obtained from mantle flow models. Finite element models will be used to test if and how inherited structures are reactivated during the evolution of the margin. Vertical surface motions will be quantified for the localization of rifting on (Caledonian) compressional structures, reactivation of normal faults in extension, and reactivation of normal faults in contraction (Buiter and Pfiffner, 2003; Panien et al., 2006). The interaction between lithospheric flexure and sedimentation and erosion will be examined with numerical flexural models to assess the contribution of long-wavelength isostatic processes to the Scandinavian surface topography. In order to test mechanical concepts and assist the interpretation of geological and geophysical data, analogue modelling will be performed in close connection with numerical modelling. Experiments will examine the development of transfer zones which separate domains of contrasting normal fault polarities, and experiments will be carried out to evaluate the role of inherited structures in localizing subsequent deformation.

\subsubsection{Climate controls on topography}

As the topography and morphology of mountainous terranes result from the interaction of tectonic, climatic and erosional processes, it is necessary to study mountain-building through a system-oriented approach that takes fluvial and glacial processes explicitly into account. The Scandinavian mountain range has been extensively glaciated during the Quaternary period (Shackleton et al., 1984; Mangerud et al., 1996) with possible onset of local and regional glaciations already during the Middle Miocene (Fronval and Jansen, 1996; O'Connel et al., 1996). From then on, the elevated terrain of the Scandes Mountains acted as nucleation centre for the North European glaciations. Glaciers resided in the Scandinavian mountains for at least $65 \%$ of Pleistocene time (Porter, 1989; Fredin, 2002). Hence, the glacial imprint on the Scandinavian topography and landscape is profound (Fig. 60). During interglacial periods, mass movements and fluvial processes are thought to have played a major role. In spite of extensive glaciations, the Scandinavian mountains also bear significant imprint from geomorphologic processes predating the Quaternary glaciations, such as weathering remnants, incised fluvial valleys and uplifted highland plateaus akin to a mature landscape. Moreover, the Quaternary glacially sculpted valleys often follow preexisting fluvial drainage systems (Fig. 60).

Offshore Mid-Norway a thick and extensive sequence of Quaternary sediments (Naust Formation) was deposited during the last ca. 2.7 My (Eidvin et al., 1998; Fig. 61). This sequence has a formidable potential for constraining terrestrial Quaternary erosion both in time and space. The Naust Formation was mainly deposited west of the 'deltaic sands' of the Middle Miocene-Early Pliocene Molo Formation, which subcrops parallel to the coast. This subcrop appears to represent an important hinge line between subsidence to the west and uplift to the east. The timing of the Neogene uplift and subsidence phases is still uncertain. Instability of these prograding Pliocene and younger clastic wedges has given rise to the development of several, presumably earthquake-triggered large submarine slide during Late Pleistocene and Holocene times that partly were associated with major tsunamis (Fig. 61; Bondevik et al., 2005; Evans et al., 2005).

Evidence for Late Neogene exhumation of southern Norway is provided by the subcrop pattern of Cenozoic and Mesozoic sediments beneath Quaternary deposits in the marginal parts of the North Sea Basin (Fig. 18). The thickness of sediments removed at this base Quaternary unconformity can be estimated from Chalk sonic velocities and amounts to some $1000 \mathrm{~m}$ where the Chalk is truncated (Japsen, 1998; 2000; Fig. 62).

During the last $0.4-0.5 \mathrm{Ma}$ (deposition of Naust sequences $\mathrm{S}$ and $\mathrm{T}$ ) several extensive ice sheets extended seaward to the shelf break (Rise et al., 2005), while for Naust U time 3-D seismic data indicate that glaciers extended onto the shelf. The progradation of sedimentary wedges was considerable during Naust $\mathrm{N}$ and A times (oldest; Fig. 61), although depositional processes are poorly understood. Ice rafted debris are found in samples from exploration wells, and grooves from icebergs are observed on some 3-D seismic surfaces. The age of Naust $\mathrm{U}, \mathrm{A}$ and $\mathrm{N}$ sequences is uncertain, and the limited chronostratigraphic data available provide conflicting results. Therefore, there is a need for better constraints on the timing and depositional mode of these sequences to improve the understanding of terrestrial erosion and relief generation (c.f. Riis, 1996). 


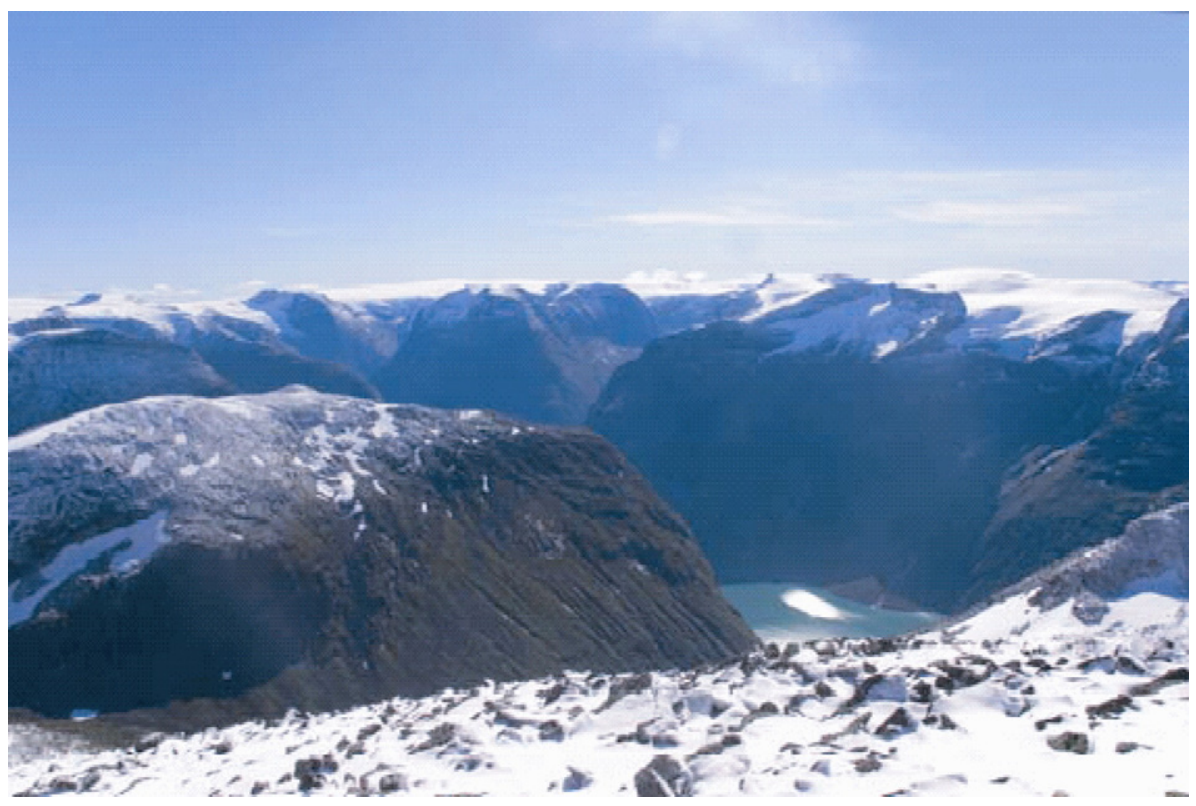

Fig. 60. Glacial valleys are deeply incised into the uplifted old paleic surface(s), exhibiting a distinct Gipfelflur. Relief in this picture, including bathymetry of the fjord, exceeds $2 \mathrm{~km}$ (Courtesy P. Japsen).

\subsubsection{West Greenland: Late Neogene uplift along a rifted margin 50 My after rifting}

In Scandinavia, the timing and extent of uplift movements are difficult to determine because the uplifted area consists almost exclusively of ancient metamorphic rocks. In West Greenland however, the preserved Mesozoic-Cenozoic sedimentary and volcanic record renders this a key area for studying the uplift of passive continental margins and thus may provide a model for the Cenozoic development of the NW European margin. In West Greenland, the $2 \mathrm{~km}$ high mountains on Nuussuaq and Disko expose a Cretaceous-Eocene sedimentary and volcanic sequence that reveals two phases of extension and rift formation during the Early Cretaceous (Chalmers and Pulvertaft, 2001) and latest Maastrichtian-early Paleocene (Chalmers et al., 1999; Fig. 63). These mountains also contain a detailed record of an uplift episode that occurred during the mid-Paleocene, probably a response to impingement of the Iceland plume on the lithosphere (Dam et al., 1998), immediately prior to rapid $\mathrm{km}$-scale subsidence and deposition of Late Paleocene and Eocene sediments and volcanic rocks in the Nuussuaq Basin (Japsen et al., 2005). Subsidence and infilling of this basin was paralleled by sea-floor spreading in the Labrador Sea (Chalmers et al., 1999; Chalmers and Pulvertaft, 2001). Neogene uplift (Japsen et al., 2005; Bonow et al., 2006a) has brought Paleocene marine sediments to $1200 \mathrm{~m}$ above MSL (Piasecki et al., 1992) whilst in present-day offshore areas time equiva- lent deposits were buried below $3 \mathrm{~km}$ of sediments. Farther south, the rift is located offshore, parallel to the coast (Chalmers and Pulvertaft, 2001) whilst the mountainous hinterland is composed of Precambrian basement.

Remnants of a high plateau have been identified on Nuussuaq and Disko and in the highlands south of Disko Bugt (Fig. 64; Bonow et al., 2006a; 2006b). Bonow et al. (2006a) interpreted the plateau on Nuussuaq and Disko as an erosional surface, mainly formed by a fluvial system that was graded close to base level, and that was subsequently uplifted to its present elevation. It extends over $150 \mathrm{~km}$ east-west, has a low relative relief, is broken along faults, is tilted westwards in the west and eastwards in the east, and has a maximum elevation of c. $2 \mathrm{~km}$ in central Nuussuaq and Disko. This erosional surface cuts across Precambrian basement rocks and PaleoceneEocene lavas, constraining its age as being substantially younger than the last rifting event of the Nuussuaq Basin, which occurred during the Late Maastrichtian and Danian.

In the highlands south of Disko Bugt, a similar plateau can be traced to almost $2 \mathrm{~km}$ above MSL (Bonow et al., 2006b). Its surface is tilted towards Disko Bugt, where it cuts off a more steeply inclined etch surface that occurs at lower elevation and has a distinct hilly relief. This hilly relief emerges as an inclined surface from the Cretaceous sediments in Disko Bugt (Bonow, 2005) and is interpreted as a stripped Late Mesozoic etch surface. 

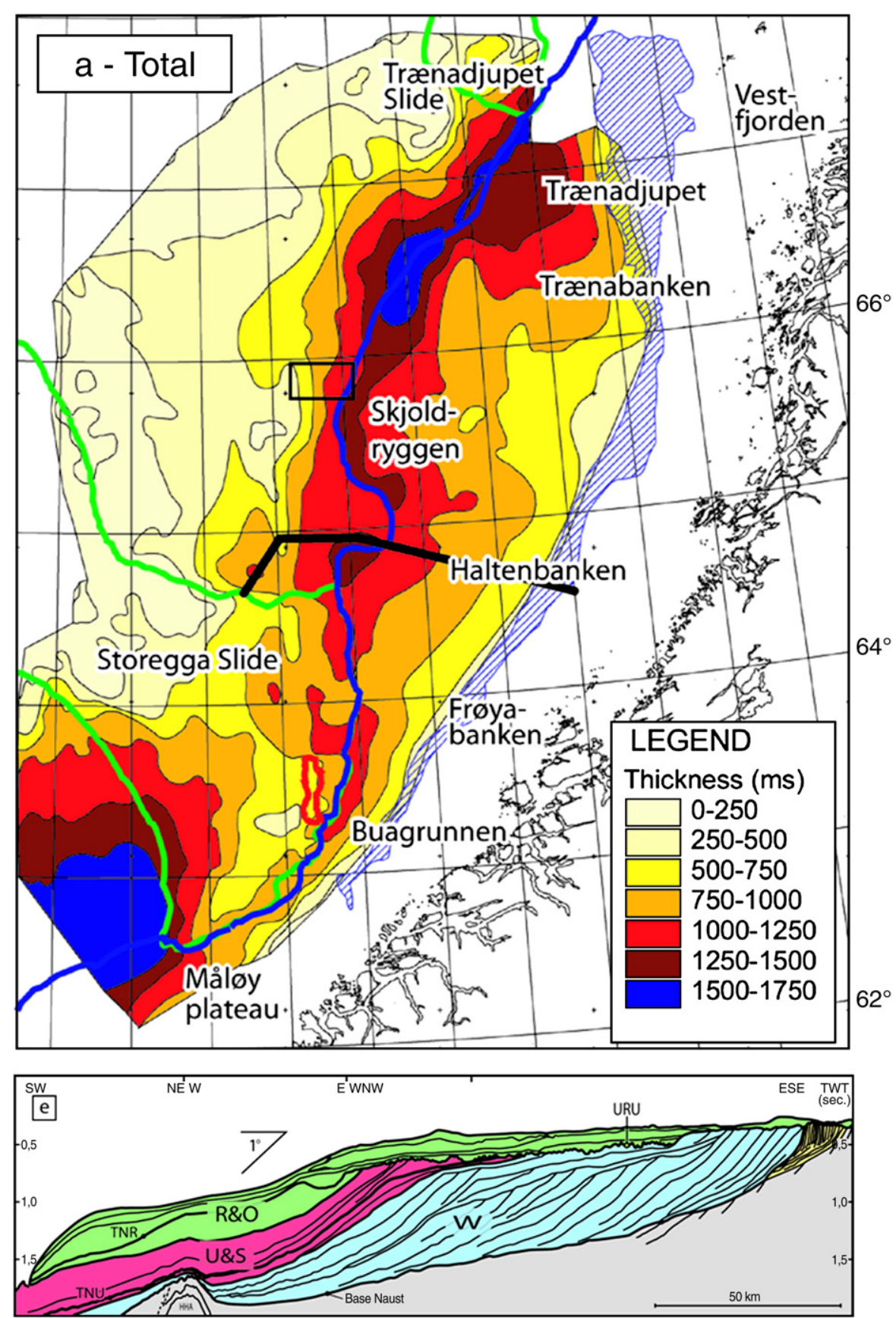

Fig. 61. Isopach map of late Pliocene/Pleistocene clastic wedges prograding onto the Mid-Norway Shelf (top panel) and representative seismostratigraphic cross-section (bottom panel) (after Rise et al., 2005).

This surface is cut off towards the south by a less inclined planation surface that thus must be younger and consequently of Cenozoic age.

Borehole samples down to $3 \mathrm{~km}$ depth are available from the Gro-3 well on Nuussuaq (Fig. 65). Apatite fission-track analysis (AFT) data and vitrinite-reflectance data reveal that these samples cooled from maximum paleotemperatures between 40 and $30 \mathrm{Ma}$ followed by two further cooling episodes beginning during 11-10 Ma and 7-2 Ma (Japsen et al., 2005). When the first cooling episode began, the samples from the Gro-3 borehole were buried 1500-2000 m deeper than at present, with the paleogeothermal gradient being $40-48^{\circ} \mathrm{C} / \mathrm{km}$. 


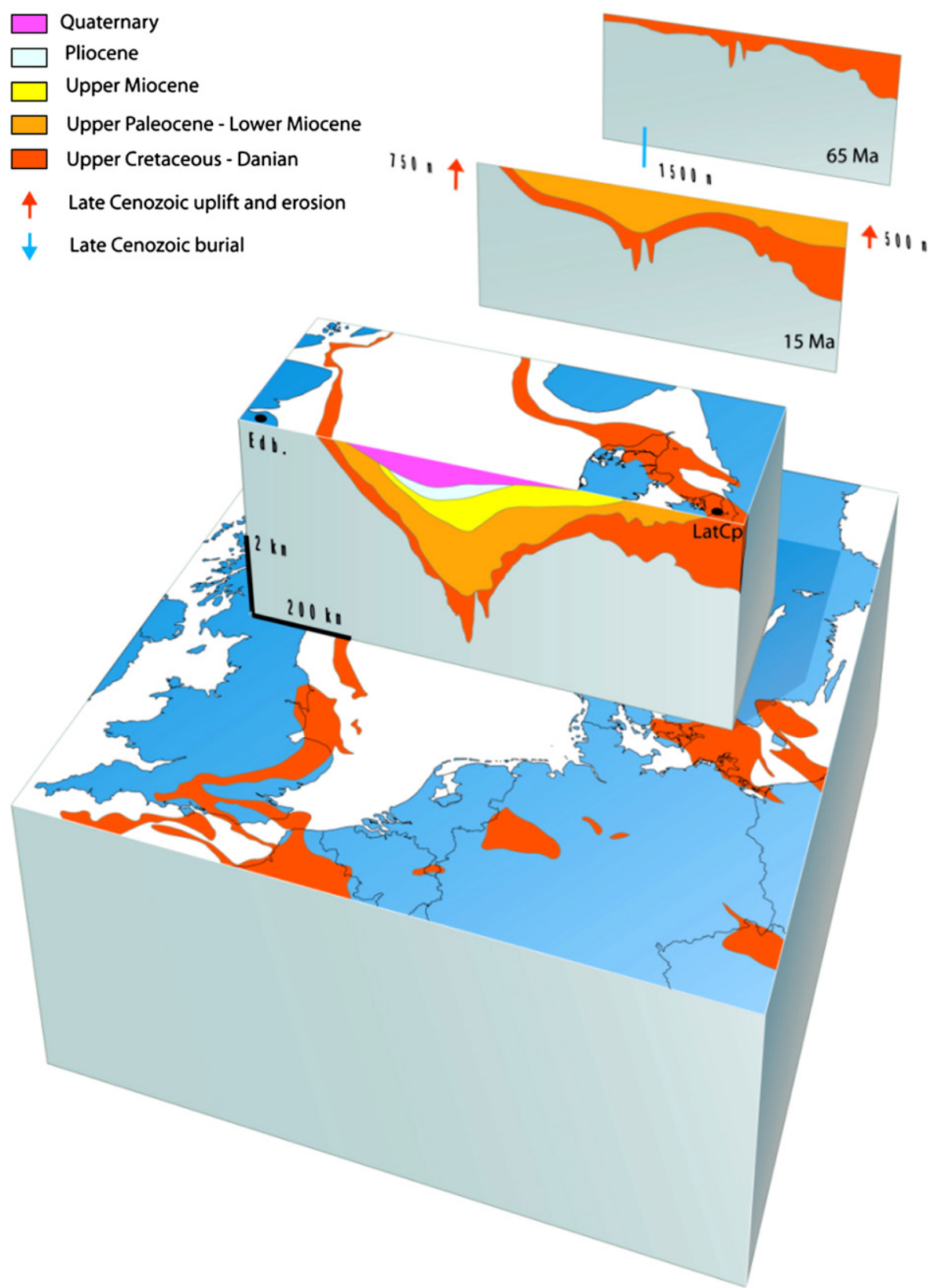

Late Cenozoic vertical movements of the North Sea Basin

Fig. 62. Late Cenozoic vertical movements in the North Sea area along a cross-section extending from Edinburgh (Edb) to Copenhagen (Cp). The Late Cretaceous-Danian Chalk Group was deposited in an epicontinental sea that covered most of NW Europe (65 Ma). In the North Sea the Chalk was buried beneath thick Paleogene and early Neogene sediments that extended beyond their present erosional limit (15 Ma). In the course of the Late Neogene the western and eastern margins of the North Sea Basin were uplifted and exhumed whilst the basin centre continued to subside. Along the basin margins Neogene and older sediments (including the Chalk) are truncated by the base-Quaternary unconformity (0 Ma). Comparison of observed Chalk interval velocities with a normal Chalk velocity-depth trend permits to estimate the thickness of eroded sediments (modified after Japsen, 1998; Japsen and Bidstrup, 1999; Japsen, 2000).

Bonow et al. (2006a) suggested that development of the erosion surface on Nuussuaq and Disko was triggered by an uplift and erosion event starting between 40 and $30 \mathrm{Ma}$. This erosional surface was fully developed prior to an uplift event starting between 11 and $10 \mathrm{Ma}$, which caused the incision of valleys. This generation of valleys graded to the new base level and formed a lower erosion surface, at the most $1 \mathrm{~km}$ below the summit erosion 

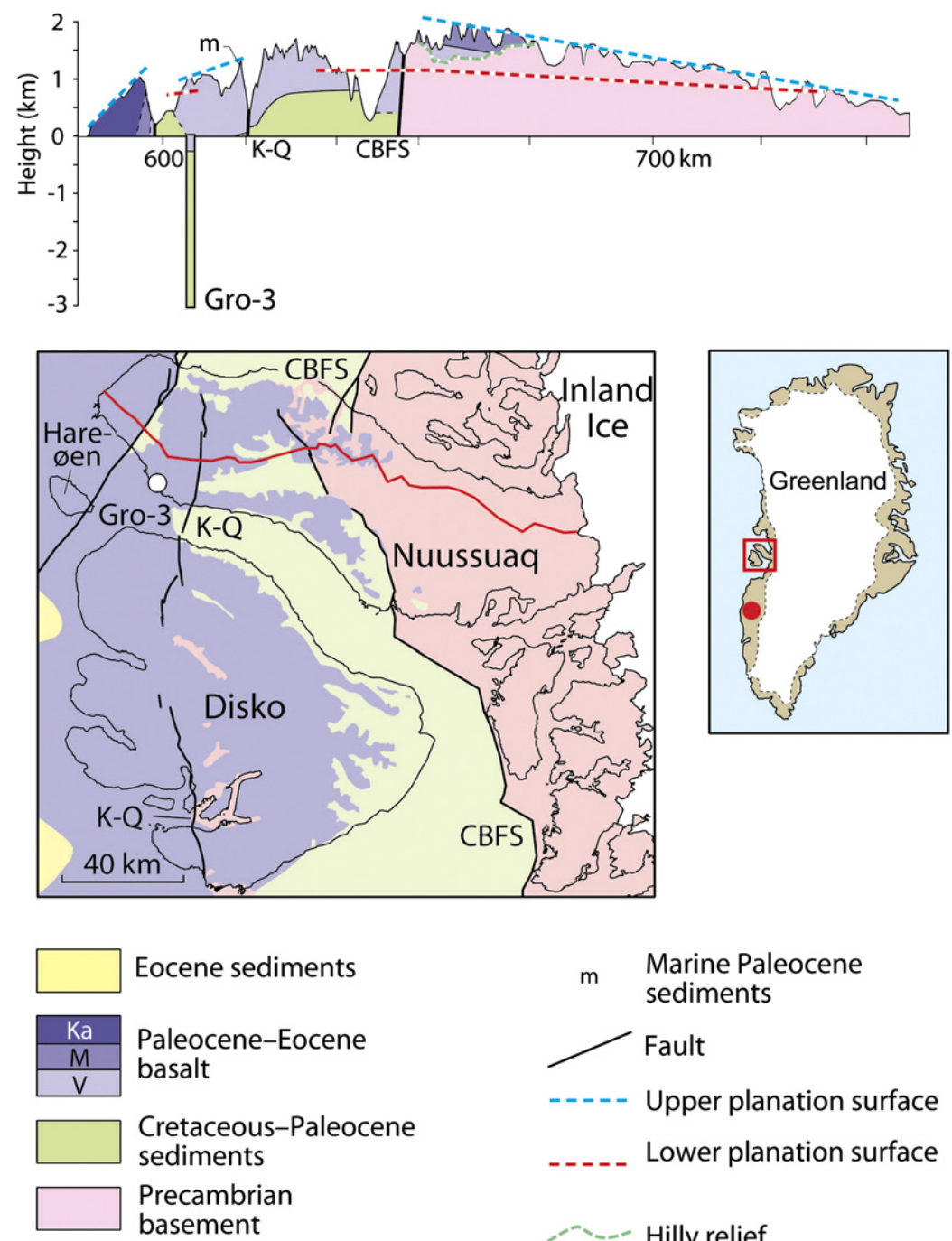

Eocene sediments

Paleocene-Eocene basalt

Cretaceous-Paleocene

sediments

Precambrian

basement m Marine Paleocene sediments

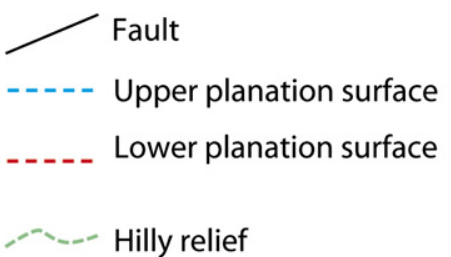

Fig. 63. Geological map of Nuussuaq-Disko area, Western Greenland. For location see red rectangle on inset map. Cross-section through Nuussuaq with projected stratigraphy of the Gro-3 well, showing position of planation surfaces. Post-Paleocene uplift by at least $1200 \mathrm{~m}$ is evident from the occurrence of marine Paleocene sediments at this elevation (Piasecki et al., 1992). Uplift of the planation surfaces probably occurred during the Late Neogene (Japsen et al., 2006). Basalts: V: Vaigat Formation (c. 61 Ma; Storey et al., 1998), M: Maligât Formation (c. 60 Ma; Storey et al., 1998) and Ka: Kanisut Member (c. 53 Ma; Storey et al., 1998). Eocene sediments: T: Talerua Member (c. 39 Ma; Schmidt et al., 2005) K-Q: KuugannguaqQunnilik fault. CBFS: Cretaceous Boundary Fault System (c. $65 \mathrm{Ma}$ ) (modified after Japsen et al., 2006).

surface, and thus indicates the magnitude of uplift. Formation of this valley generation was shortly interrupted by a third uplift event also with a magnitude of $1 \mathrm{~km}$, lifting the landscape to near its present position. The subsequent erosion was probably both of a fluvial and glacial nature. Correlation with the fission-track record suggests that this uplift event started between 7 and $2 \mathrm{Ma}$.

The present-day high mountains of West Greenland were thus not uplifted during the Paleogene, but are erosional remnants of an Oligocene-Miocene planation surface that was offset by reactivated faults, resulting in megablocks that were tilted and uplifted to their present- day elevation during two late Neogene phases (Japsen et al., 2006) These late Neogene uplift phases postdate rifting by about 50 million years, and sea-floor spreading west of Greenland by about 30 million years.

\subsubsection{Specific targets for far-field studies: the} Scandinavia continental margin topography

Deep Earth processes:

- What is the relationship between syn-rift crustal thinning and post-rift vertical movements? This 


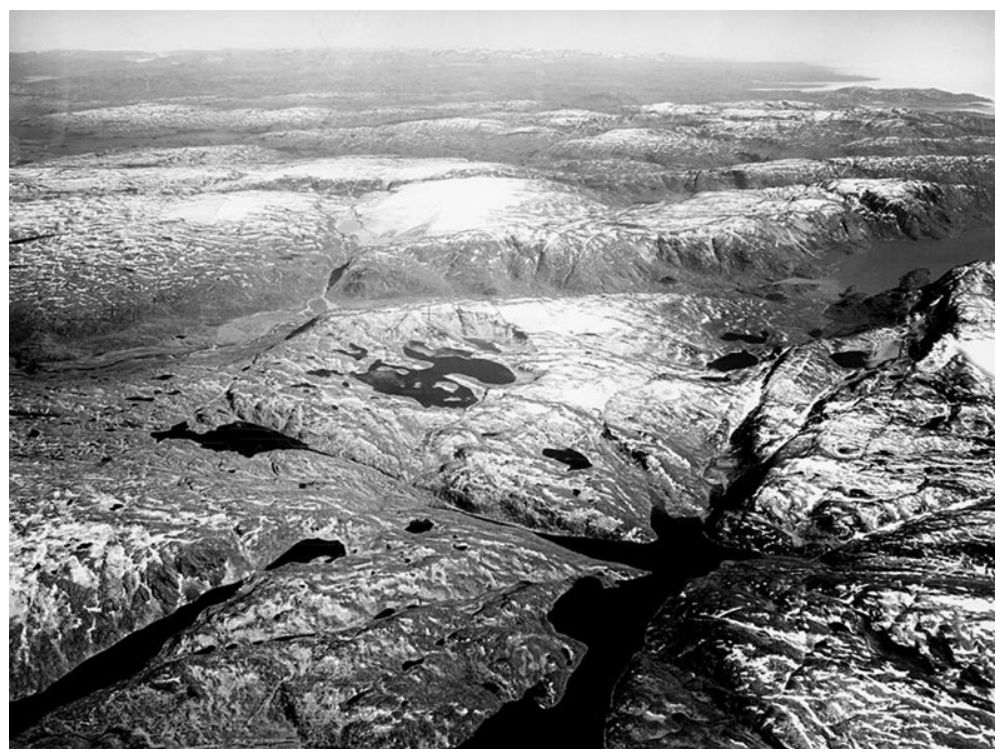

Fig. 64. Photograph showing a plateau that is being upheld by Precambrian basement and that has been elevated to about 1 km above M.S.L. For location see red spot in inset map in Fig. 63. A similar erosion surface cuts across the Paleocene-Eocene basalts on Disko and Nuussuaq (Fig. 63). This surface was formed by erosion during Oligocene-Miocene times and was uplifted during two Late Neogene episodes (Japsen et al., 2006).

appears to be much better understood in sedimentary basins (thermal subsidence, post-rift sedimentary load) than in the uplifted onshore areas (multiple models).

- What are the roles played by flexure of the lithosphere in response to its erosional unloading and sedimentary loading, 'dynamic impingement' of mantle plumes and/or mantle upwelling, and intraplate compressional stresses on long wavelength uplift? Detailed tomographic images of sub-lithospheric mantle beneath the Norwegian margin and Scandes mountains are required to constrain structural and material contrasts.

- What is the relationship between inherited structures and post-rift vertical movements? Do contractional movements occur and are they localized on inherited structures?

- Does active faulting contribute to uplift and subsidence during the post-rift phase?

- What is the relationship between faulting and postrift sediment transport patterns?

- What is the role played by magmatism during rifting and margin evolution?

- What is the relative contribution of mantle and crustal processes to topography development?

Surface processes:

- What is the relationship between (tectonic) uplift, palaeic surfaces and landscape types? What are their ages?
- How do erosion and uplift interact?

- What are the mechanisms of relief development through fluvial and glacial erosion?

(a)

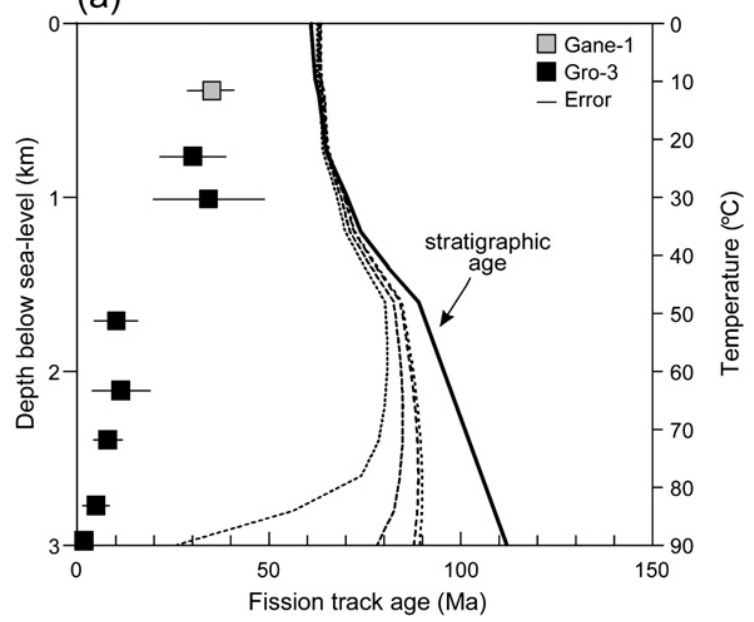

Fig. 65. Fission-track ages from Gro-3 and Gane-1 boreholes plotted against depth. Continuous line: variation of stratigraphic age with depth. Dashed lines: predicted patterns of fission-track age from the Default Thermal History based on the preserved sedimentary section for apatites containing $0.0-0.1,0.4-0.5,0.9-1.0$ and $1.5-1.6 \mathrm{wt} . \% \mathrm{Cl}$. The Default Thermal History is obtained by combining the burial history derived from the preserved sedimentary section with the present-day geothermal gradient. The fission-track ages decrease with depth and are much less than the values predicted from the Default Thermal History. This shows that the sampled sedimentary units have been much hotter in the past (after Japsen et al., 2005). 
- What are the ages, configuration and origin of the paleic surfaces?

- What is the configuration and development of the pre-Quaternary fluvial landscape?

- How does fluvial and glacial transport and deposition of erosion products to offshore areas occur?

\section{Tasks in landform evolution}

- Mapping and dating of terrestrial pre-Quaternary landforms and sediments to reconstruct the pre-glacial landscape.

- Mapping and dating of offshore erosion surfaces.

- Offshore 3-D seismic interpretation to constrain transport and depositional processes and patterns.

- Chronological control and volume calculations of offshore sediments in an effort to establish a material balance between onshore erosion and offshore deposition.

- Determination of age, genesis, uplift and lateral movement of the different paleic surfaces.

- Quantification of landform evolution and sediment fluxes to constrain Neogene uplift.

- Modelling of fluvial incision in response to uplift and climate change during pre-Quaternary landscape evolution.

- Modelling of glacial landscape development, including sub-glacial erosion on how glaciers exploit preexisting topography.

\subsection{East-European Platform}

\subsubsection{Background}

The East-European Platform (EEP) provides a unique natural laboratory to study the links between the sedimentary record, the crust and mantle structure, and the tectonic evolution of continental lithosphere over a time span of ca. 3 Gy. Past analogues are keys for understanding modern geodynamic processes. 4-D models of the lithospheric structure based on integration of already available data, deployment of seismic and magnetotelluric networks, and process-orientated modelling will provide the database for ancient analogues of modern tectonic processes and for validation of process modelling in the TOPO-EUROPE target areas of Phanerozoic Europe.

Three Archean continents (Baltia, Sarmatia, and Volga-Uralia) form the basement of the EEP. These are separated by roughly linear, several thousand kilometres long, trans-cratonic sutures zones. These zones, consisting of a tectonic mixture of high-grade metamorphic, volcanic, and sedimentary rocks, are interpreted as paleo-collision zones. Most of the EEP crust underwent intense tectonic reworking during the Paleoproterozoic. However, as most of Volga-Uralia is covered by a thick sedimentary cover (typically 2 to $3 \mathrm{~km}$, with ca. $4 \mathrm{~km}$ in the Proterozoic trans-cratonic sutures zones, and as much as $25 \mathrm{~km}$ of sediments in the Peri-Caspian Basin), the paleotectonic evolution of the north-western part of the EEP (Baltia, Sarmatia) is better known. Baltia is characterized by Archean granulate-gneiss and greenstone terranes, surrounded by Paleoproterozoic mobile belts with high-grade metamorphic rocks. Largely Paleoproterozoic in age, Baltia is separated from Sarmatia by WSW-ENE-trending continental arcs that were accreted during Paleoproterozoic large-scale tectonic collisions (e.g. Bogdanova et al., 2006). Further south, within the Sarmatian paleocontinent, the orientation of the paleoterranes becomes largely $\mathrm{N}-\mathrm{S}$. This part of the EEP, which consists of a collage of Archean lowgrade and high-grade metamorphic terranes, includes the oldest rocks of the European continent that are also among the oldest ones on the planet (ca. 3.6 Ga).

Studies on the evolution of the East-European Craton have shown that processes occurring along its margin exerted a strong control on the development of its internal parts (e.g. Poprawa et al., 1999; Nikishin et al., 2001). It can be argued that this linkage is one of the major factors controlling the neotectonic and related surface processes of the EEP. But it is also clear that intracratonic heterogeneities are of primary importance. For example, the response of the intracratonic lithosphere to tectonic forces applied to its margins is strongly influenced by its rheological structure. This 'crustal memory' is a basic concept that explains the neotectonic reactivation of ancient tectonic features, thus linking processes that took place $1-2$ billion years ago during crustal accretionary phases with present-day processes.

The lithosphere of the EEP is essentially strong and, though the intensity of ongoing tectonic processes is rather low, neotectonic activity has a significant impact on the recent relief and surface processes. Because relief is dominantly low, even small changes in vertical motions of the crust may lead to significant changes of the surface system. A recent example is the shallowing of the harbours in the Scandinavian part of the Baltic Sea due to on-going crustal uplift while the lowlands along the southern shores of the Baltic Sea are subject to progressive flooding.

Much of the Phanerozoic tectonic activity within the EEP is reflected in the thickness of its sedimentary cover, which increases eastwards from 1-3 in the central part of the EEP to $4-7 \mathrm{~km}$ along the Urals. Rapid 
subsidence of the eastern part of the EEP during the Paleozoic was, at least partly, related to the development of the Uralian Orogen. Late Paleozoic peri- and intracratonic rifting on the southern parts of the EEP led to the development of the Pripyat-Dniepr-Donets rift, which contains more than $20 \mathrm{~km}$ of Devonian and younger sediments in its deepest parts and which cuts across the Archean-Paleoproterozoic terranes of Sarmatia into the Ukrainian Shield and the Voronezh Massif (e.g. Stephenson et al., 2001). Rifting may have been driven by Late Devonian mantle plume activity (Stephenson et al., 2006), which may have caused a substantial thermo-mechanical and compositional reworking of the cratonic lithosphere (Fig. 66). Paleozoic subsidence of the contiguous Peri-Caspian Basin, which contains one of the thickest known sedimentary sequences $(25+\mathrm{km})$ and has a huge hydrocarbon potential, could be related to similar lithospheric processes, but large-scale mechanisms to explain the subsidence of the entire southern part of the EEP have not yet been thoroughly examined (cf. Saintot et al., 2006; Stephenson et al., 2006).

\subsubsection{Ancient analogues of modern tectonic processes}

The EEP provides a natural laboratory to study the effects of different tectonic processes on the structure of the crust and lithospheric mantle. Tectonic structures in the crust and sedimentary cover include Archean terranes, Paleoproterozoic mobile belts, island arcs and continental arcs, Proterozoic and Paleozoic continental rifts, and regions of Phanerozoic salt tectonics. Their study can provide ancient analogues for modern tectonic processes in the younger parts of Europe and a database for validation of process modelling. The cratonic lithosphere of the EEP permits to examine not only thermomechanical effects on topography evolution but also the effects of compositional changes in the lithospheric mantle.

The deep structure of the EEP lithosphere is poorly known. Available data are limited (mainly) to borehole studies, gravity, and seismic reflection/refraction profiles, which commonly do not infer lithosphere properties deeper than 10-20 km below the Moho at most (Artemieva, 2006). Similarly, existing regional electromagnetic studies are limited to models of crustal conductivity. Even these existing data are sparse for the central part of the EEP, which remains a large geophysical "white spot". Due to the small number of seismic stations, continent-scale seismic tomography models have insufficient resolution for the eastern parts of the EEP. Specific goals for this far-field natural observatory will include integration of already available data, deployment of a seismic and MT network, and 3-D process-oriented modelling for tectonic evolution of different parts of the EEP.

\subsubsection{Subsidence history of the EEP}

The occurrence of a thick sedimentary cover over most of the platform is not common for old cratons. The effect of different tectonic processes on the topography of the EEP is reflected in its $>1$ Gy long sedimentary record. A general lack of deep geophysical data has prevented, until now, a thorough examination of the role of different tectonic processes in the development of the depressed topography of much of the EEP. These processes include, but are not limited to, collision and suturing of continental blocks, intracratonic rifting, and orogeny and subduction at the craton margins.

Although it has been often asserted that development of the Pripyat-Dniepr-Donets rift was caused by a Late Devonian mantle plume, lithosphere scale tectonic modelling of such a process, including the near breakup of the Sarmatian and Archean terranes into the Ukrainian Shield and the Voronezh Massif has never been performed. 4-D modelling, requiring acquisition of new geophysical data on the lithospheric structure of the region, could establish thermo-mechanical links between the postulated mantle plume, the opening and closure of Tethyan oceanic domains, and the regional tectonic evolution of the southern parts of the EEP, including the subsidence of the Peri-Caspian Basin (much of which is at present close to or below sea level). Meandering rivers on the EEP, which enhance the deposition of sediments, may lead to further platform subsidence, especially in the Volga delta.

The Baltic Basin is an area of anomalous subsidence within the EEP (e.g. Sliaupa et al., 2006), where it can be demonstrated that lithospheric rheology likely plays an important role in controlling Neogene-Quaternary vertical movements (Fig. 67). The Baltic Sea depression is actually confined to the weakest lithosphere, which has an elastic effective thickness (EET) of just $22-25 \mathrm{~km}$ increasing to $40-60 \mathrm{~km}$ at the basin periphery (Fig. 67). This may explain the shape of its present-day geometry that might be inherited from the Paleozoic Baltic Basin. Yet, the origin of the Baltic Sea depression is still uncertain with an alternative hypothesis proposing that the Baltic Sea is an erosional feature. Although this area remains a key area for understanding the development of neotectonic depressions on cratonic platforms, much basic information required for its consistent rheological modelling is not yet available. Nevertheless, the new large-scale passive seismic experiment PASSEQ (Grad et al., 2006) will yield 


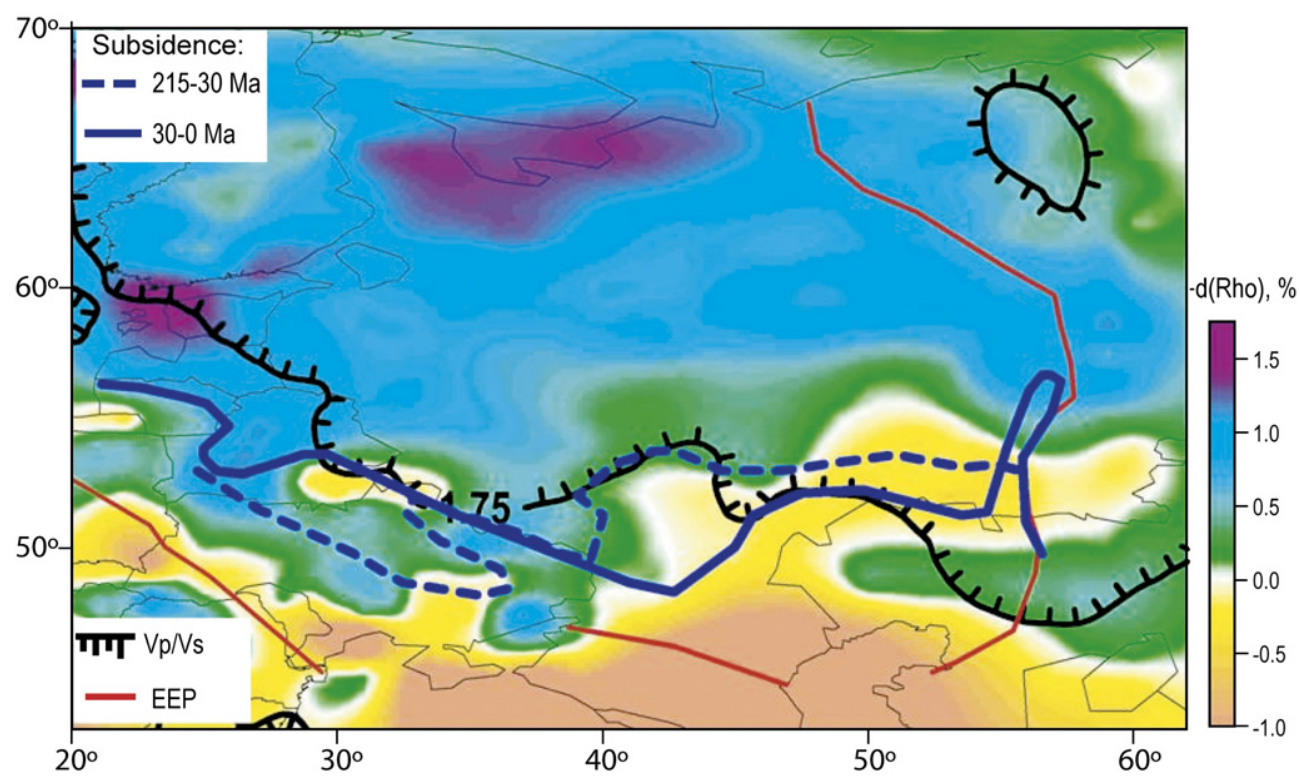

Fig. 66. Topography of the East European Platform (EEP) based on ETOPO2 data. Red lines: boundaries of the EEP. Blue lines: north-eastern boundary of areas subsiding during the Mesozoic-Cenozoic (dashed line) and of areas of on-going subsidence (solid line). Black lines: north-eastern boundaries of compositional changes in the subcrustal lithosphere (solid barbed - based on Vp/Vs ratio at $150 \mathrm{~km}$ depth; dashed - derived from temperature-corrected buoyancy) (after Artemieva, 2003; Artemieva et al., 2006). Note that regions of Mesozoic-Cenozoic subsidence correlate with the compositional boundaries of the cratonic lithosphere.

important new information on the structure of its lithosphere. Yet, as controls on the sub-lithospheric mantle structure of the Baltic Basin are insufficient to constrain subsidence models in the context of large-scale regional processes, acquisition of corresponding data relies on the EUROARRAY component of TOPO-EUROPE.

Process-orientated modelling based on the subsidence history of the basin combined with modern geophysical data is required to elucidate the role of different tectonic processes, including Proterozoic rifting and associated rapakivi-anorthosite magmatism, involving thermo-mechanical and probably compositional reworking of the lithosphere, Late Neoproterozoic rifting and passive margin development, followed by the Early Paleozoic Caledonian collision and foreland basin development.

Quaternary glacial processes largely shaped the relief of the northern half of the EEP. There is a strong interaction between glacial and geodynamic processes. Advancement and retreat by several kilometres thick ice sheets induced considerable isostatic movements of the lithosphere and also apparently activated and de-activated tectonic structures, particularly faults. Although isostatic processes are well studied in Scandinavia, related vertical movements of adjacent platform areas have received little attention. Recent very detailed studies on Baltic Sea terraces in Lithuania permitted to date precisely when post-glacial isostatic rebound ended and tectonic deformations controlled by far-field stresses started to prevail. A co-operative study involving all circum-Baltic countries could provide regional-scale reconstructions of these phenomena. Available data suggest that neotectonically uplifted areas played a greater role in glacial sedimentation than subsiding areas and that this duality considerably affected the present-day relief.

Data on the structure of the lithosphere are important for assessing the isostatic response of the EEP to deglaciation and what role isostatic rebound plays in the development of platform topography. Continentalscale studies demonstrate that borehole data can provide a unique record on Pliocene and Quaternary climate fluctuations and related glaciations and inter-glacial stages (Kukkonen and Joeleht, 2003; Lindner et al., 2006); however, detailed regional models for the entire EEP are still missing.

\subsubsection{Present-day stress regime and hazards}

For most of the EEP the Neogene-Quaternary stress field is constructed mainly on the basis of mesostructures and topo-lineaments (e.g. Sim et al., 1995). These data reveal the impact of collision-related stresses on the southern margin of the platform in the domain of the Great Caucasus, in which shortening rates amount to some $14 \mathrm{~mm} / \mathrm{yr}$, giving rise to uplift rates of $8 \mathrm{~mm} / \mathrm{yr}$ (e.g. Nikishin et al., 2001; Kopp, 2005). On the EEP, E- 

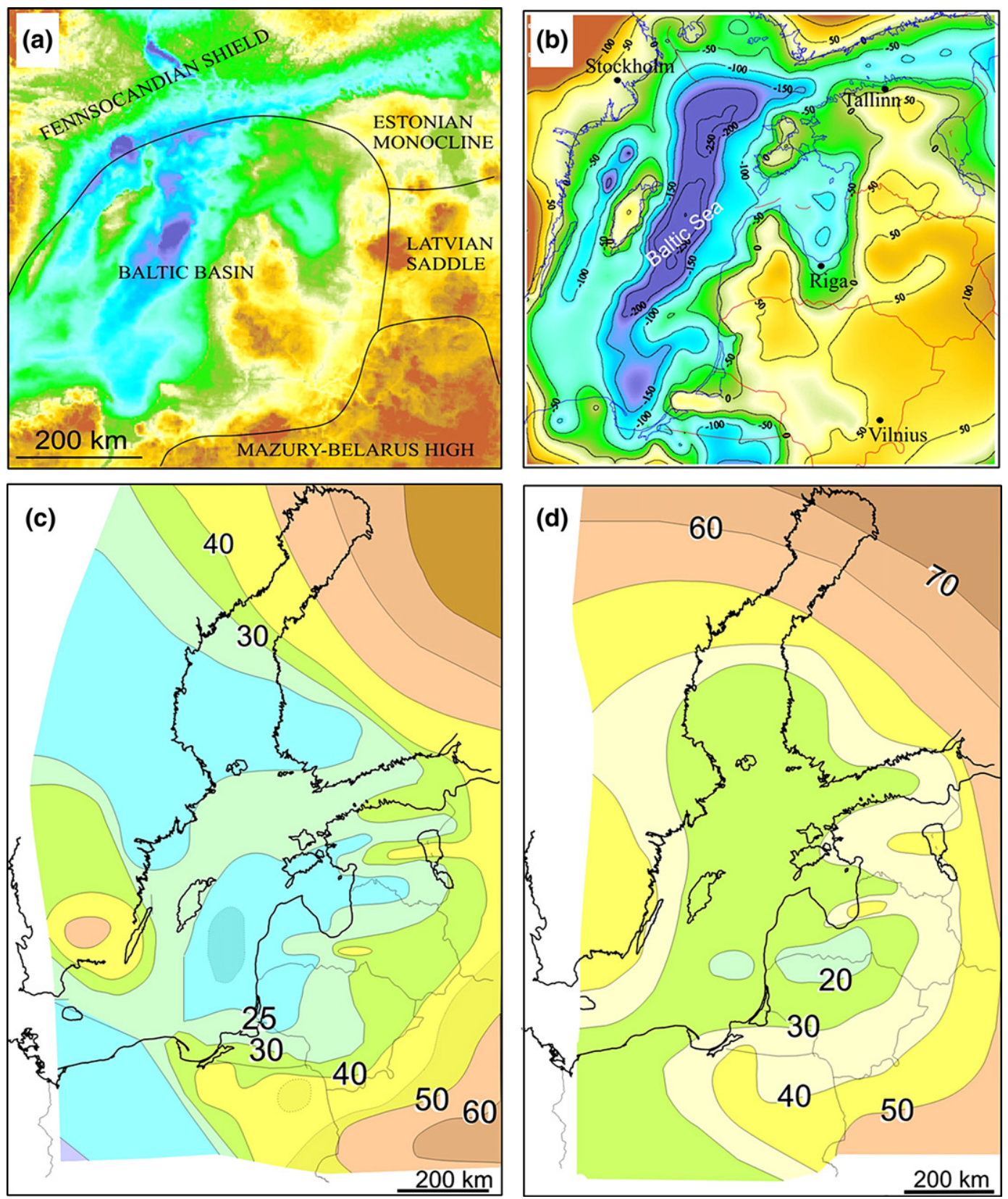

Fig. 67. (a) digital relief model of the Baltic region; (b) map of approximated depths of the Sub-Quaternary surface; (c) effective elastic thickness of the lithosphere (km); (d) depth of Effective Middle Surface of the lithosphere (km) (after Sliaupa and Ershov, 2000).

W-trending neotectonic structures are affected by horizontal compression (e.g. Zhiguli uplift), whereas N-Sstriking features appear to be tensionally reactivated (e.g. Orsha-Don depression).

There are only scarce instrumental data on the recent and present stress regime of the EEP, and these are mainly for its north-western part (World Stress Map, 2003). Available data suggest two stress provinces for the Baltic region. Borehole FMI and break-out data, earthquake focal mechanisms, and GPS measurements indicate that the western half of the Baltic Basin is characterized by a NW-SE orientated maximum horizontal compressional stress, similar to the Fennoscandian Shield, whereas N-S and NNE-SSW compression is indicated for eastern Lithuania, Poland, and the southern Baltic Sea (Jarosinski, 1994; Sliaupa et al., 2004). These stress provinces are 
thought to relate to North-Atlantic ridge-push and Alpine collision, respectively.

Though the tectonic activity of the EEP and related surface processes are of low intensity and are often neglected as the source of potential natural hazards, they nevertheless have to be considered in some cases, such as seismic risk assessment of nuclear power plants or repositories of nuclear wastes. Significantly, repeated GPS measurements in the vicinity of the Ignalina Nuclear Power Plant (eastern Lithuania) have revealed that inherited tectonic zones are characterized by high horizontal strain rates (Zakarevicius et al., 2005). A rather dense GPS network was established in Estonia, Latvia, and Lithuania in early 1990s. A second cycle of measurements of country-scale GPS networks will provide crucial data for the understanding of on-going tectonic processes in the cratonic basement of these areas.

Assessment of the risk potential of cratonic areas remains a most difficult task, as recently highlighted by the Kaliningrad earthquakes of 21 September 2004 $(\mathrm{ML}=4.3$ and 5.0). It should be noted that the maximum seismic risk potential of the Baltic region was assessed Io $=5$ at the time of construction of the Ignalina plant and was later reassessed to $M L=4.6$, which is less than that of the Kaliningrad earthquakes, for which the stress release was calculated as $32 \mathrm{MPa}$ and $40 \mathrm{MPa}$. The GPS data around the Ignalina plant indicate that stress accumulation in some areas may be on the order of $10^{-1} \mathrm{MPa} / \mathrm{a}$ (Zakarevicius et al., 2005). Accordingly, the recurrence period of strong earthquakes along large-scale (inherited) fault zones could be some hundreds of years. Reassessment of the seismic potential and related risk is urgently required for the EEP.

Another group of significant hazards caused by tectonic activity is related to coastal processes. The short and long-term prognosis of uplift and subsidence trends and related coastal processes, many of which have considerable socio-economic impact, is in progress (e.g. Sliaupa et al., 2004).

\subsubsection{Intraplate seismicity: the New Madrid Seismic Zone analogue}

There are no modern or historically known strong seismic events within the EEP. However, other cratons (e.g. central USA, central and western India) provide evidence for catastrophic intraplate earthquakes. Although still a subject of debates, the magnitude of 1811-1812 earthquakes in the New Madrid Seismic Zone (NMSZ) in central USA was estimated to exceed 7.0. The estimated recurrence interval exceeds $1000 \mathrm{yr}$ for magnitude 7 and 10000 yr for magnitude 8 earthquakes (Newman et al., 1999), explaining the absence of a historical record in many stable areas. An analogue study on other regions of intraplate seismicity, and the NMSZ, in particular, is important to assess the risk of destructive earthquakes within the EEP, which may have a catastrophic societal impact in highly populated and industrial areas.

\subsubsection{Specific targets/issues to be addressed on the East European Platform}

- Structure and composition of the lithosphere of the EEP.

- The role of different tectonic processes in reworking/ modification of the cratonic lithosphere as reflected in its sedimentation record.

- Ancient analogues of modern tectonic processes.

- Thermo-mechanical and compositional reworking of the Archean-Paleoproterozoic lithosphere, particularly pertaining to the subsidence of the Baltic Basin, Devonian rifting related to closure of Paleo-Tethys, and mantle plume impingement on the lithosphere of the EEP.

- Stress regimes at the margins of the EEP, in particular the TESZ and the Caucasus.

- Stress regime in the interior of the EEP (with the New Madrid Seismic Zone as a possible analogue).

\subsection{The Caucasus and Levant: Continental Collision and Contrasting Foreland Deformation}

\subsubsection{Background}

The Greater Caucasus and the Levant domains are located in the northern and southern forelands of the Pontides-Lesser Caucasus-Elborz and the TauridesZagros orogenic systems, respectively. Together these mark the collision zone of the Arabian and African plates with the Eurasian plate that contains a complex array of Paleotethyan and Neotethyan sutures (Stampfli and Borel, 2004). Neogene crustal and lithospheric over-thickening in this collision zone gave rise to the Middle to Late Miocene activation of the NAFZ (Burchfiel et al., 2000; Yilmaz et al., 2000a) and the latest Miocene activation of the EAFZ (Robertson, 2000) and the onset of westward extrusion of Anatolia. During the Late Miocene the sinistral Dead Sea transform fault was activated (Mart et al., 2005), compensating for differential northward movements between the African and Arabian plates, amounting at present to 10 and $20-24 \mathrm{~mm} / \mathrm{yr}$, respectively (Jiménez-Munt et al., 2003). As westward extrusion of Anatolia apparently did not fully compensate for the Arabia-Eurasia convergence, compressional stresses building up in the Eurasian foreland of the Lesser Caucasus caused inversion of the Mesozoic Greater 
Caucasus Trough (Nikishin et al., 2001), a process that commenced in the Early Tertiary and that is presently still ongoing.

Whilst Mount Elbrus of the Greater Caucasus peaks at $5642 \mathrm{~m}$ above MSL, the surface of the transtensionally subsiding Dead Sea is located at $417 \mathrm{~m}$ below MSL. The Caucasus and Levant natural laboratories address the syn-collisional deformation of foreland areas characterized by contrasting high-level neotectonic activity, namely intraplate mountain building in the Caucasus domain involving a rift-related weakened Late Paleozoic crust, and in the Levant domain wrench-rift dominated deformation of a foreland that consists of old continental cratonic and the Neotethyan oceanic lithosphere of the eastern Mediterranean.

\subsubsection{Large scale neotectonics of the Caucasus and surrounding areas}

The Greater Caucasus, located at the cross-road of Europe, Asia and Arabia, is Europe's highest mountain range (Khain, 1975; Adamia et al., 1977; Gamkrelidze and Gamkrelidze, 1977; Adamia et al., 1981; Khain, 1997). At its eastern termination, in Azerbaijan, the Greater Caucasus plunges into the Caspian Sea where it forms the Apsheron Sill. The Caspian Sea is one of the world's major oil provinces, and an area of geostrategic and geopolitical importance. The sediments that host the oil reservoirs in the Southern Caspian Sea were deposited in a very deep basin $(>20 \mathrm{~km})$. The provenance/source of these sediments is the Greater Caucasus from where erosion products were carried by large rivers such as the Volga, Samur and Kura into the Caspian Basin. Similarly, the Black Sea represents a major sediment sink at the western termination of the Greater Caucasus.

The continued growth of the Greater Caucasus since the Early Tertiary and the important subsidence of the South Caspian Basin is crucial to the understanding of erosion and sedimentation processes in this area (Polino et al., 1996). The Greater Caucasus is not only Europe's highest mountain range, but also the fastest growing one. This growth is due to the convergence of the Arabian plate with the Eurasian plate at rates of $22-24 \mathrm{~mm} / \mathrm{yr}$, leading to continued earthquake activity and growth of the mountain range (Zonenshain et al., 1990; Priestley et al., 1994; Nilforoushan et al., 2003; Allen et al., 2004).

As tectonic activity is expressed in the morphology, the Greater Caucasus is a unique natural laboratory to investigate links between lithospheric, tectonic, and surface processes. The present topography is also the surface we live on and any dramatic changes or ruptures in this surface are likely to cause important economic damage and possible loss of human life. Slope insta- bilities associated with heavy rainfall regularly causes landslides and other mass wastage processes, resulting in major changes in landscape. Active crustal shortening across the Greater Caucasus and the resulting uplift are associated with constant seismicity. Igneous activity unrelated to the Lesser Caucasus volcanic arc, is manifest in the border area between Georgia and Russia, with Mount Elbrus being the most outstanding example.

The Greater Caucasus developed in response to the final closure and inversion of a Mesozoic back-arc basin that had undergone repeated phases of extension and compression during Triassic to Cretaceous times in response to activity along Tethyan subduction systems located south of the Pontides and the Lesser Caucasus. The Caucasus orogeny commenced during the Late Eocene and persisted until the present. The southern margin of the Greater Caucasus Trough is partly preserved in the western Greater Caucasus near the Black Sea in Georgia (Banks et al., 1997), but is unknown to the east near the Caspian Sea in Azerbaijan. This margin was flanked to the south by the subduction-related volcanic arc of the Lesser Caucasus that had been active since the Early Jurassic (Philip et al., 1989; Ershov et al., 1999; Mikhailov et al., 1999; Nikishin et al., 2001; Brunet et al., 2003; Ershov et al., 2003; Nikishin et al., 2003). The main topographic relief of the Greater Caucasus began to develop during the Middle Miocene and younger tectonic phases. The transition from subsidence of the Greater Caucasus Trough to its inversion and the resulting rise of the mountain chain is documented by the sedimentary record of basins flanking it to the north (Indol-Kuban and Terek-Caspian depressions) and to the south (Rioni and Kura basins) (Ershov et al., 2003). This record needs to be further explored in terms of the gradual rise of the Greater Caucasus mountain range. Although important amounts of sediments were deposited during the Late Eocene and Oligocene in the Caspian Sea-Black Sea Paratethys realm, it remains unclear whether already at these times the Greater Caucasus had formed a major topographic feature or barrier, or whether it formed lowlands prior to its rapid Mid-Miocene uplift (Popov et al., 2004). How is dynamic topography linked to tectonic and surface processes during the Tertiary to recent development of the Greater Caucasus Orogen? What lithospheric processes were involved in the development of the crustal roots that support the present-day topography?

\subsubsection{Tectonic Geomorphology and differential vertical motions}

The Greater Caucasus is a typical doubly verging mountain-belt with two external fold-and-thrust belts. In its eastern part the pro-wedge front is located to the 
South and overrides the Kura Basin, whereas the retrowedge front is located to the North and overrides the Terek-Caspian Basin (Sobornov, 1994; Sobornov, 1996; Ulminshek, 2001). Tectonic structures, such as fault-related folds, thrusts, imbrications, klippen, relay structures, and late transverse structures, such as the large "anti-Caucasian" strike-slip faults, are typical for shallow level fold-and-thrust belt deformations (Gamkrelidze and Rubinstein, 1974; Gamkrelidze and Gamkrelidze, 1977; Kopp and Shcherba, 1985; Dotduyev, 1986; Gamkrelidze and Beridze, 1991; Sholpo, 1993; Ulminshek, 2001). This is corroborated by studies showing that the general metamorphism and internal deformation are weak; schistosity is weak and is only developed in the central parts of the mountain range. Results from apatite fission track studies on basement rocks in Georgia (Kral and Gurbanov, 1996) confirm the prevailing low grade metamorphism in the central part of the orogen. Folds and thrusts generally trend NW-SE to WNW-ESE in the Eastern Great Caucasus, schistosity is axial surface parallel and fold vergence is related to the transport direction. Syn-sedimentary paleotectonic structures of both extensional and compressional (inversion) origin are overprinted by syn-orogenic tectonics.

The evolution of especially the eastern part of the Greater Caucasus is linked to the evolution of the South Caspian Basin. Although it is widely accepted that this basin was initiated by Mesozoic back-arc extension related to the subduction of the Tethys plate to the south, most of the subsidence presently observed occurred during the Tertiary. An additional set of mechanisms must be invoked to explain the younger, greatly accelerated Pliocene-Quaternary phase of subsidence that occurred in a compressional setting, contemporaneous with the subsidence of Caucasus-related foreland basins and the uplift and erosion of the Caucasus Orogen. This phase of rapid subsidence of the South Caspian Basin coincided with the onset of tectonic loading of the crust, in the South by the Elborz orogenic belt and in the North by the Apsheron Sill in the prolongation of the Greater Caucasus. There remains a controversy regarding the timing of the opening of the South Caspian Basin and regarding the presence of one or two different sub-basins (Ershov et al., 1999).

The present-day topography of the Caucasus-East Anatolian area reflects the distribution and arrangement of megatectonic features (Fig. 68). Active and dormant mountain fronts shape the topography along the southern margin of the Greater Caucasus and permit to establish the chronology of major tectonic events. In Azerbaijan, the active thrust front coincides with the Karamarian anticline that involves Quaternary sediments of the Kura Basin. This anticline is related to an active blind thrust, with classic wind and water gaps pointing to its lateral growth. This active southern thrust front extends into the foothills of the Lesser Caucasus in western Azerbaijan. Gentle SSW-directed folding and thrusting produces topographic "bumps" in large alluvial fans, as well as tilting of terraces. So far, only few studies have directly addressed the tectonic geomorphology of the Greater Caucasus such as a study of the Alazani Basin on the southern slope of the Great Caucasus in Georgia (Triep et al., 1995), or relate to larger areas as the Kura Basin or the Caspian Sea. Studies on river deltas are further indicators for an active mountain belt. The occurrence of terrace systems documents continued river incision presumably owing to uplift of the mountain range. On the northern slopes of the Eastern Greater Caucasus this uplift gave rise to the development of important cliffs that are upheld by Quaternary material. Connecting these erosional "events" to the terrace systems along the Caspian Sea opens the prospect of quantifying uplift vs. subsidence.

Uplift of the highest summits in the central and northern parts of the Greater Caucasus is highlighted by the occurrence of marine Plio-Pleistocene sediments at elevations in excess of $2500 \mathrm{~m}$ above MSL. In the northern part of the mountain belt deposits of the river Samur are deeply $(>400 \mathrm{~m})$ incised by its present tributaries. Rivers entrench and cannibalize their own deposits, starting in the Early Tertiary, and thus mirror the active tectonic growth and dynamic evolution of topography. Terraces are found along the Caspian Sea (Brod, 1962; Shirinov, 1973; Shirinov, 1975), with the highest, some 230,000-yr-old terraces being located at about $300 \mathrm{~m}$ above MSL. Terraces younger than $1.8 \mathrm{Ma}$ occur up to an elevation of some $475 \mathrm{~m}$ in the mountain valleys, but many more terraces are present up to altitudes of $2000 \mathrm{~m}$ and above.

Neotectonic analyses on the larger Caucasus area include studies on crustal deformation, GPS measurements, earthquakes and plate tectonics (McClusky et al., 2000; Vernant et al., 2004a). These investigate the geodynamics and the large-scale structure of the lithosphere in the larger Caucasus-Caspian-Iran area. Regional compression is $\mathrm{N}-\mathrm{S}$-directed, with an average deformation of $14 \mathrm{~mm} / \mathrm{yr}$ across the eastern part of the Greater Caucasus and uplift rates of the order of $8 \mathrm{~mm} / \mathrm{yr}$. This is in agreement with studies on paleostresses derived from recent brittle faults that cut the whole mountain range and control the development of prominent morphological features such as deep gorges and mountain crests (Fig. 69). 


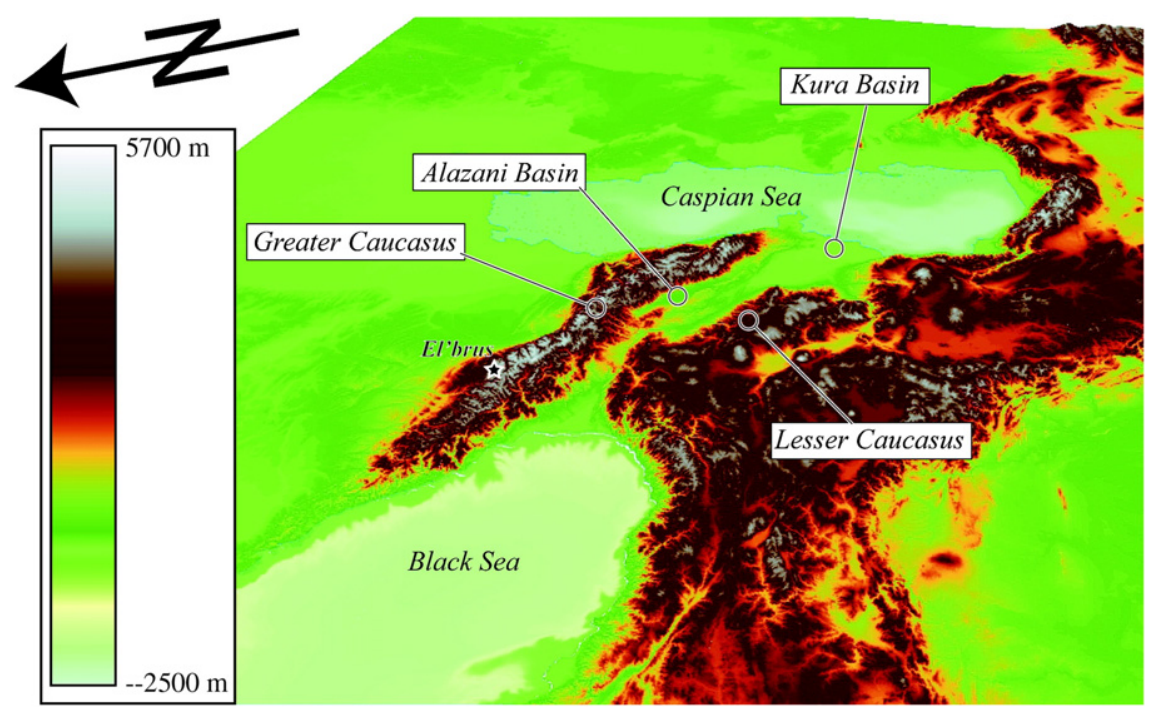

Fig. 68. Digital elevation model for the Arabian-Eurasian collision zone. The geomorphology of the Greater Caucasus reflects the NW-SE trends of its major structural units.

\subsubsection{The Levant and the Eastern Mediterranean: crustal structure and physiography}

In the Levant and Eastern Mediterranean area the accretion of a number of small crustal units is expressed in the physiography and neotectonic activity of the region (Fig. 70).

The Levant-Eastern-Mediterranean area underwent a long and complex evolution, involving different geological processes and repeated changes in its megatectonic setting, starting with the Early Paleozoic Pan-African Orogeny, followed by the Mesozoic break-up of Gondwana and opening of the Neotethys, its Late Mesozoic and Cenozoic partial closure and ultimately the Neogene separation of Arabia from Africa. Today the area includes a number of active plate boundaries that have repercussions on its deformation style and physiographic configuration (e.g. Cyprus arc, Dead Sea transform, Red Sea spreading axis).

Geophysical data, including seismic refraction and reflection profiles, gravity and magnetic measurements, seismicity, topographic and bathymetric maps, suggest that the eastern Mediterranean region can be divided into distinct crustal units which differ in their thickness and internal layering, such as the onshore Negev, JudeaSamaria, Galilee-Lebanon and Jordan blocks and the offshore Levant Basin, Eratosthenes Seamount, Florence Rise, Hecateus Seamount and Cyprus (Fig. 70). Differentiation of the onshore crustal domains probably dates back to Pan-African continental accretion processes. Analysis of the regional geology shows that this crustal differentiation is manifested in the structural style and deformation pattern of the upper few kilometres of the sedimentary section. The differences between the crustal units are also clearly exhibited in the seismicity and topography of the Levant and the bathymetry of the eastern Mediterranean (Fig. 71). Interestingly, the physiography of this region has played a strong role in the distribution and development of plants and birds and the dispersal of humans between Europe, Africa and Asia.

The topography of the region developed through several uplift phases that correlate with uplift phases of southern Europe. This suggests that similar mechanisms are responsible for the uplift of both regions.

\subsubsection{Objectives and future work}

The main objectives of TOPO-EUROPE research in the Greater Caucasus natural laboratory, which is unique world wide, are to understand the relationship between tectonics, basin/margin evolution and surface processes, and to establish the chronology of major tectonic events and related changes in topography and geomorphology. Structures and processes active today will be compared with structures revealing paleo-interactions at a passive/ active plate boundary.

Detailed fieldwork with special attention to tectonic geomorphology, combined with remote sensing, will permit to establish a new framework for assessing the Cenozoic tectonic history and dynamic processes controlling its evolution.

Tectonic topography is important in the aftermath of continental collision and continued convergence. Indeed, 

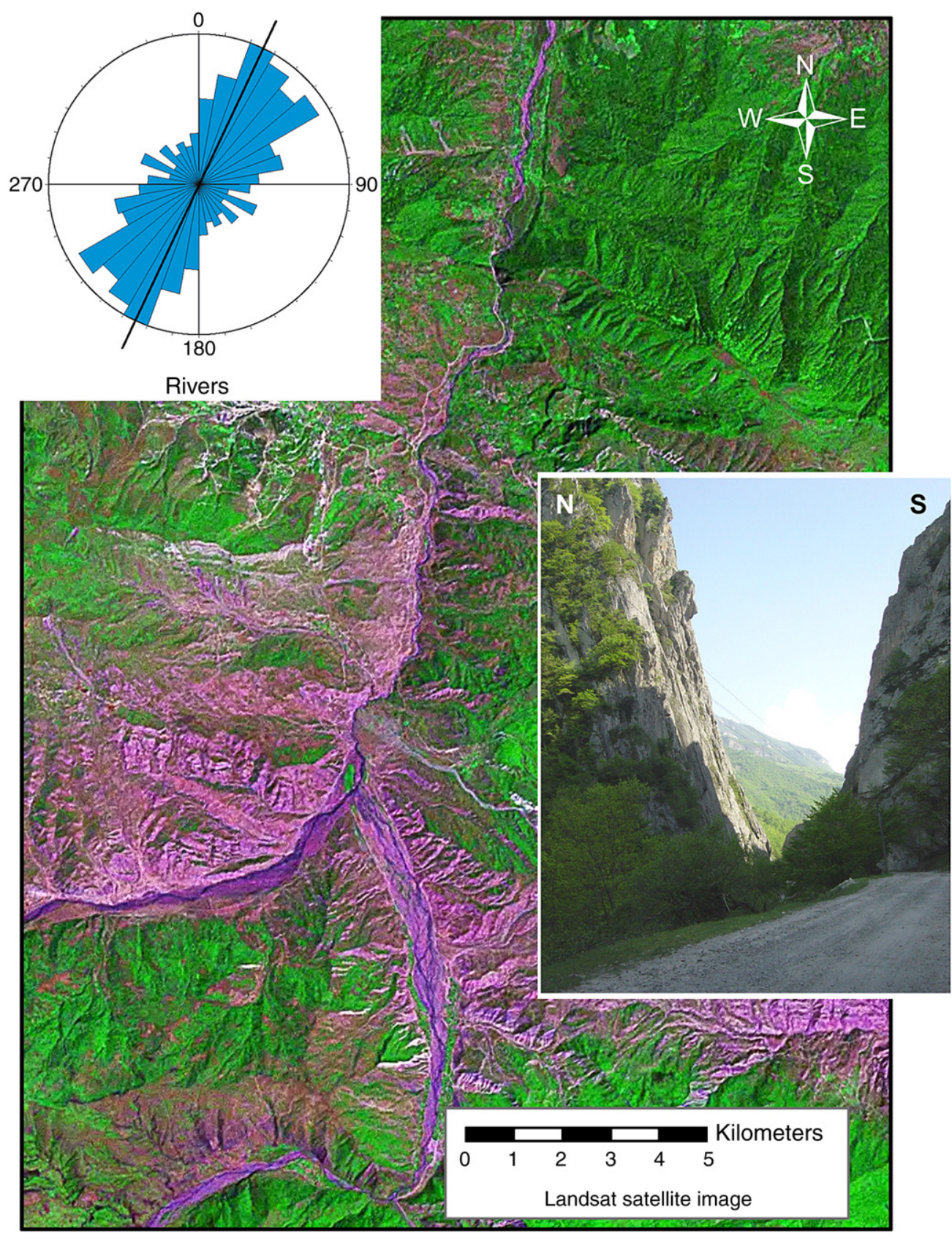

Fig. 69. Landsat image of Tanga Alti valley, northern Greater Caucasus, Azerbaijan. Inset middle right: view of the gorge at its northern exit. This gorge is carved into Jurassic and Cretaceous platform carbonates and follows the trend of a major Anti-Caucasian strike-slip fault. Inset upper left: rose diagram of orientations of major rivers in the Eastern Greater Caucasus of Azerbaijan. The main orientation of anti-Caucasian faults cross-cutting the entire fold-and-thrust belt is NNE-SSW.

processes operating during the Neogene and Quaternary are understood to have been most influential in generating the present-day topography. The controls on rates of river incision into bedrock (including cannibalizing their own deposits) are largely dictated by relationships between climate, lithology, tectonics, and topography. To understand dynamic topography in the Greater Caucasus it is crucial to be able to discriminate and quantify the different uplift events and the related uplift/erosion rates. How does the source-sink system evolve through time? 


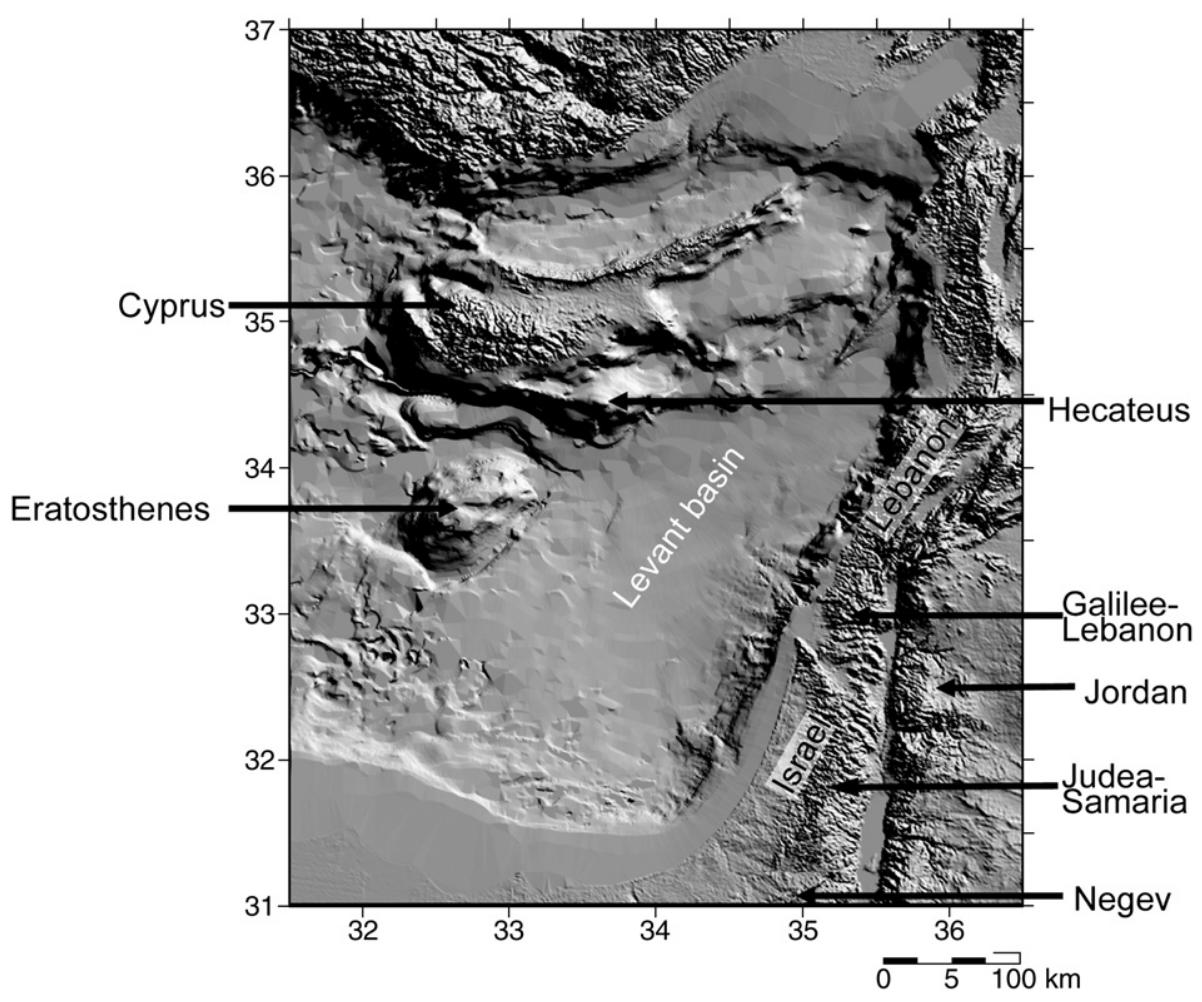

Fig. 70. Distribution of terranes with distinct crustal structure in the eastern Mediterranean and surrounding areas (Ben-Avraham and Ginzburg, 1990; Ben-Avraham et al., 2002; DTM: Hall, 2003).

A pilot study on the Greater Caucasus will be initiated to investigate its uplift history and the interaction of tectonic and surface processes, using modern techniques such as apatite fission track and cosmogenic nuclides. The study will address actively incised terraces, indicative for important post-depositional uplift (in excess of several hundreds of meters). Age dating of these terraces will permit to quantify the magnitude and rates of uplift. Key areas for sampling will be selected based on remote sensing investigations and exploratory fieldwork to locate suitable outcrops.

Numerical simulations and analogue modelling are unique tools to evaluate the relationship between tectonic and surface processes and to compare results with observations on the interaction of erosion and thrusting.

Future work in the Levant and the adjacent Eastern Mediterranean area will concentrate on detailed studies addressing the timing of uplift and the development of topography, and comparisons with similar phenomena that occurred in Europe. Scientists from various fields, such as geophysics, field geology and geochemistry, coming from the Middle East and Europe, will be involved in these studies.
3.7.6. Specific targets/issues of interest to TOPOEUROPE on the Caucasus and Levant

- Establishing a chronology of tectonic geomorphology in the Greater Caucasus.

- Quantifying uplift/erosion rates and mass transfer in source-sink systems.

- Numerical and analogue modelling of coupled deep Earth-surface processes in the Greater Caucasus.

- Quantifying the dynamics of Arabia-Europe interactions by means of mantle tomography.

- Quantifying the timing of formation of differential topography in the Levant and adjacent Eastern Mediterranean area.

- High-resolution lake drilling for quantifying the interplay of tectonics and climate.

\subsection{The Andean Analogue: insights from active mountain building processes}

To this date, the question of why and how the Andean plateau-type orogen formed with crustal thickening at the leading edge of western South America remains one of the hotly debated issues in geodynamics. During the Cenozoic, the Altiplano and Puna plateaux of the Central 


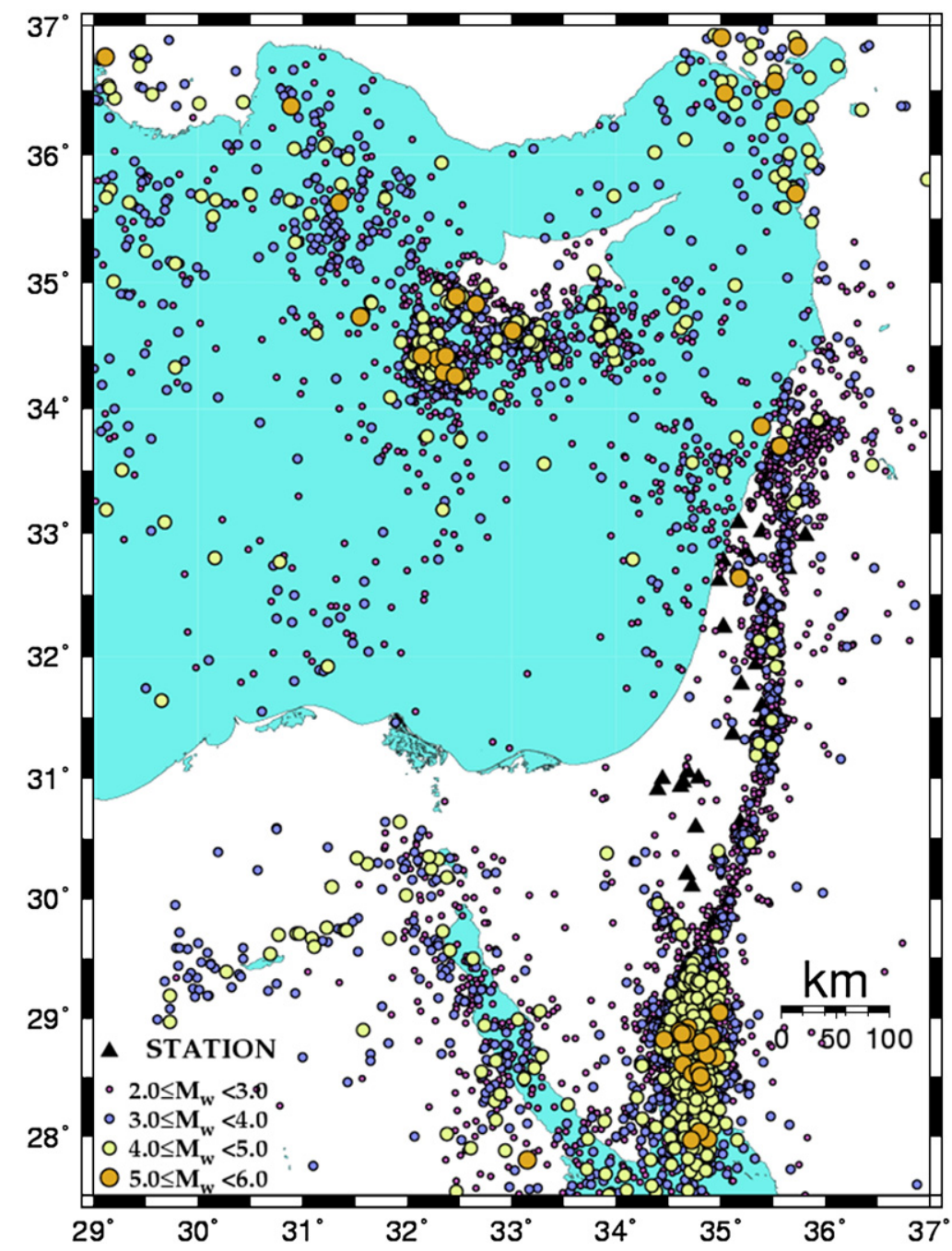

Fig. 71. Distribution of earthquakes in the Levant and eastern Mediterranean area (1983-2003). Note the correlation between crustal unit boundaries and earthquake distribution (Geophysical Institute of Israel).

Andes (average elevation some $4 \mathrm{~km}$, with an extent of $400 \times 2000 \mathrm{~km}$ ) developed during continuous subduction of the oceanic Nazca plate in a convergent continental margin setting - a situation that is unique along the $60,000 \mathrm{~km}$ of convergent margins around the globe. The key challenge is to understand why this plateau developed only along the central portion of the South American leading edge, as well as why and how this feature developed only during the Cenozoic, although the cycle of Andean subduction had been ongoing since at least the Jurassic. Moreover, it would appear that this style of orogeny has only rarely occurred during the Earth's history, another example probably being the Cretaceous North American Laramides (Fig. 72).

Deep geophysical data across the Central Andes between $20^{\circ} \mathrm{S}$ and $24^{\circ} \mathrm{S}$ (ANCORP-Working Group,
2003) (ANCORP'96 and associated geophysical studies) indicate the widespread presence of partial melts or metamorphic fluids at mid-crustal level under the plateau between its bounding Cordilleras. From structural balancing studies, these fluids or melts are associated with decoupling of upper crustal shortening and lower crustal thickening. Based on similar indications from the distribution of magmatism it has been argued that upper plate weakening resulting from widespread heating and partial melting may have been the key to widespread shortening behind the volcanic arc (Isacks, 1988; Allmendinger et al., 1997). In addition, changes in plate convergence are generally considered to have been responsible for tuning the changes in the upper plate system. While the available wealth of geophysical data would seem to lend support to the role of melts and 


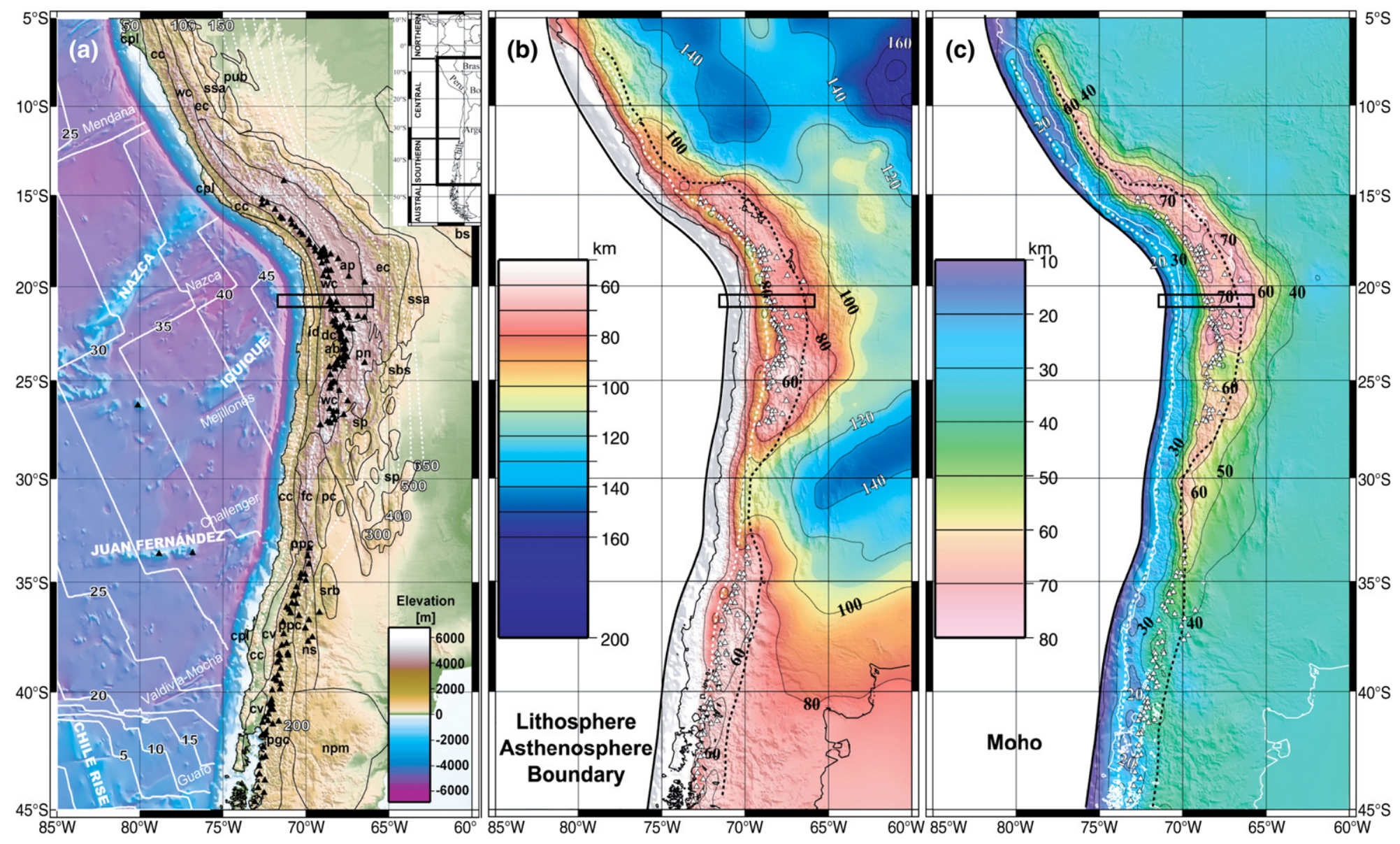

Fig. 72. Geophysical framework of the Central Andes: (a) surface topography; (b) depth to lithosphere-asthenosphere boundary; (c) depth to continental Moho discontinuity (after Tassara, 2005). Black rectangles show location of the transect given in Fig. 73. 
fluids in upper plate orogeny, the sensitivity of the observed elastic, thermal, and conductivity properties to fluids may overemphasize their role (Fig. 73).

Another feature unique to the Central Andes is the complete preservation of syn-tectonic volcanics and sediments throughout the orogen and at its margins allowing spatial and temporal reconstruction of the deformation and uplift history (see Elger et al., 2005; Oncken et al., 2006 for details). Accordingly, analysis shows that the difference between the upper plate velocity and the oceanic slab roll-back velocity is crucial in determining the amount and rate of shortening and surface uplift as well as their lateral variability at the leading edge of the upper plate. This first order control is tuned by factors affecting the strength balance between the South American upper plate lithosphere and its interface with the subducting Nazca lower plate. These include variations in trenchward sediment flux affecting plate interface coupling and slab roll-back. Ultimately, the location of the Central Andes in the global southern hemisphere arid belt plays a key role by allowing the rise and lateral spread of a high plateau (e.g. Lamb and Davis, 2003; Elger et al., 2005; Oncken et al., 2006). The combination of these parameters was highly uncommon during the Phanerozoic, leading to very few plateau style orogens at convergent margins, such as the Cenozoic Central Andes in South America or the Laramide North American Cordillera. This combination was never realized in Europe in its entirety, but some elements are apparent, as for example during the Variscan Orogeny.

Although the Andes and the Alps, as a typical representative of a young European orogen, are extremely diverse in terms of size, internal architecture, completion of a Wilson cycle, etc., their direct comparison indicates substantial differences (e.g. Schmid et al., 1996). Early Alpine deformation, including subsequent collision, was essentially focused on the fore-arc domain of the Adriatic plate (although no real arc was present with exception of the Colli Euganei). The Alps have virtually grown by continuous material addition through mainly basal accretion to the former fore-arc system where all topography evolution was focused. In contrast, nearly all of the Andean deformation and uplift has been confined to the back-arc domain (or the arc domain in the south). Only very little deformation has affected the South American fore-arc during Cenozoic plateau building with very diverse styles from southern Peru to southern Chile. Mechanisms responsible for these features are gradually emerging from various ongoing research initiatives and may provide clues for understanding the pre-collisional evolution of South European convergent plate margins. The obvious key is the kinematic response of the fore-arc to the above variations resulting from trench fill evolution and the ratio between upper plate motion and slab/hinge roll-back. These affect fore-arc material addition or destruction leading to tectonic accretion or subduction erosion with resultant vertical motions of the fore-arc system as well as to various internal kinematics (c.f. Heuret and Lallemand, 2005). Spatial and temporal variability of these processes at the South American margin indicates the very delicate, partly self-controlled balance of the interaction of several of the above processes. All of these observations underscore the role of the Cenozoic climatic evolution of the Andean margin and the influence of its $\mathrm{N}-\mathrm{S}$ extent through various climate zones (Fig. 74).

Recent observations of the kinematic behaviour on very short time scales from satellite-based techniques (GPS, INSAR), seismology, and neotectonics show that strain accumulation is partly related to the style of seismicity. At convergent plate margins the extent and degree of seismic coupling play a major role in force transmission, as well as in the mechanisms generating great intraplate earthquakes. Despite the key role of the coupling zone for plate tectonics, the processes that shape it and its relation to surface deformation are poorly understood. Based on observations of transients at various time scales, fore-arc systems may tend to be close to self-organized criticality, reacting in a complex mode with highly complex kinematics from surface to depth in different stages of the seismic cycle. These kinematic variations and the related transients are poorly understood but probably a future key to understanding strain accumulation in the brittle crust. Hence, in the present day Andean fore-arc as well as in the South European fore-arc systems we may be facing a complex system of coupled processes responsible for deformation and surface response that primarily include the interaction of the climatically controlled trench fill evolution, the upper plate structural heterogeneity and various transients related to the seismic cycle as well as to changes in accretion mode. These may - in conjunction with other aspects - ultimately be the cause for differences between the fore-arc orogens of South European plate margins and the Andean back-arc orogen.

\subsection{Analogue studies in the western USA and the Middle East}

The questions to be addressed by the TOPOEUROPE Initiative will benefit from ongoing research activities in other broadly deforming, but semi-arid 

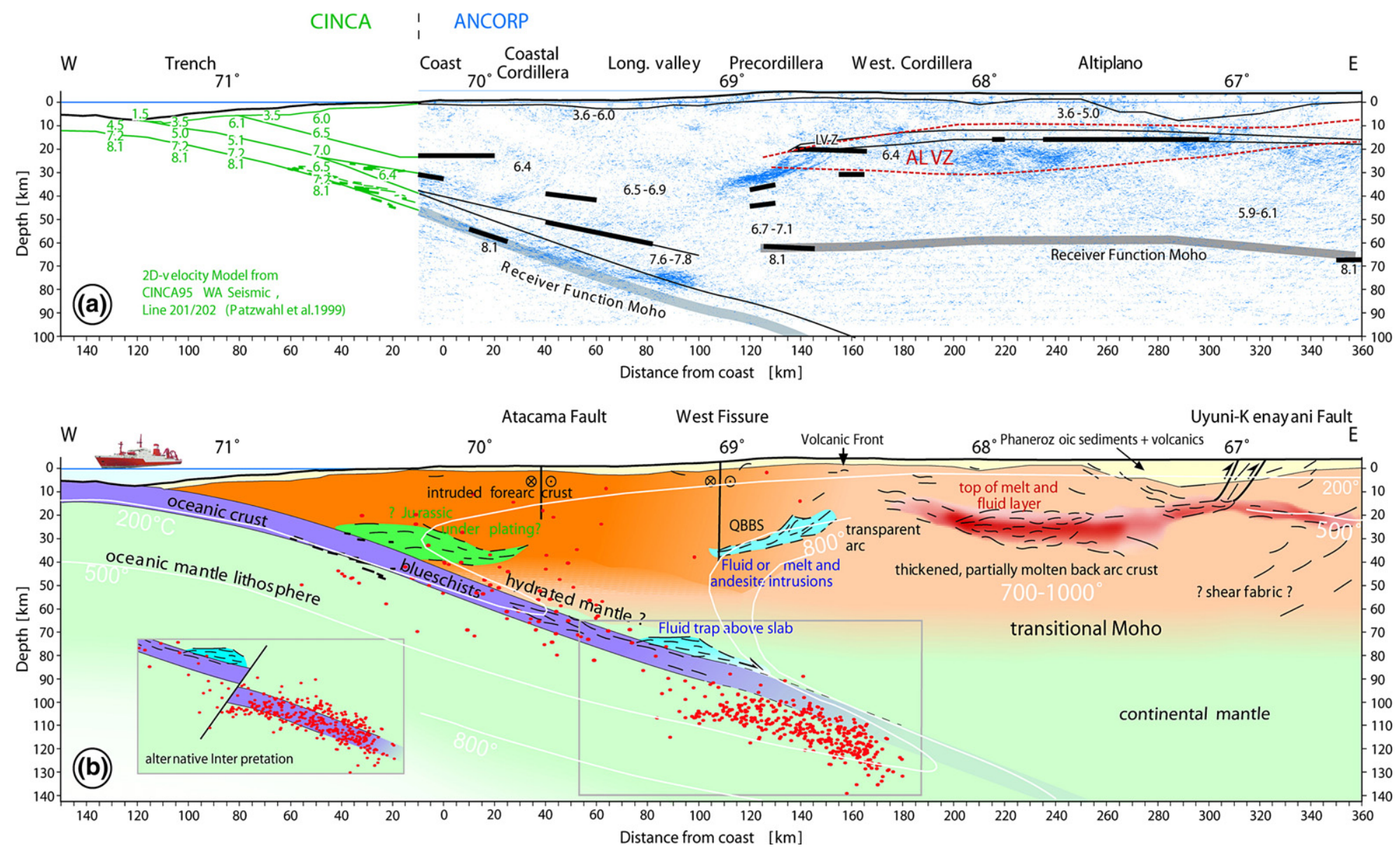

Fig. 73. Geophysical transect through the Central Andes (for location see Fig. 72). (a) Automatic line drawing of depth migrated ANCORP reflection data, including onshore wide angle and receiver function results (Yuan et al., 2000), merged with results of the offshore CINCA experiment and its onshore recording (Patzwahl et al., 1999). Thick black lines denote reflector elements. Reflector elements from below the western and eastern Andean plateau margins after Wigger et al. (1994). The grey line at $65-75 \mathrm{~km}$ below the Andean plateau represents the Moho discontinuity as inferred from receiver function data (Yuan et al., 2000). (b) Suggested interpretation of seismic observations including an alternative interpretation of the relation between slab geometry and seismicity Isotherms after Springer (1999) are only included for the fore-arc domain due to unconstrained convective heat transfer below the Andean plateau (after ANCORP-Working Group, 2003). 


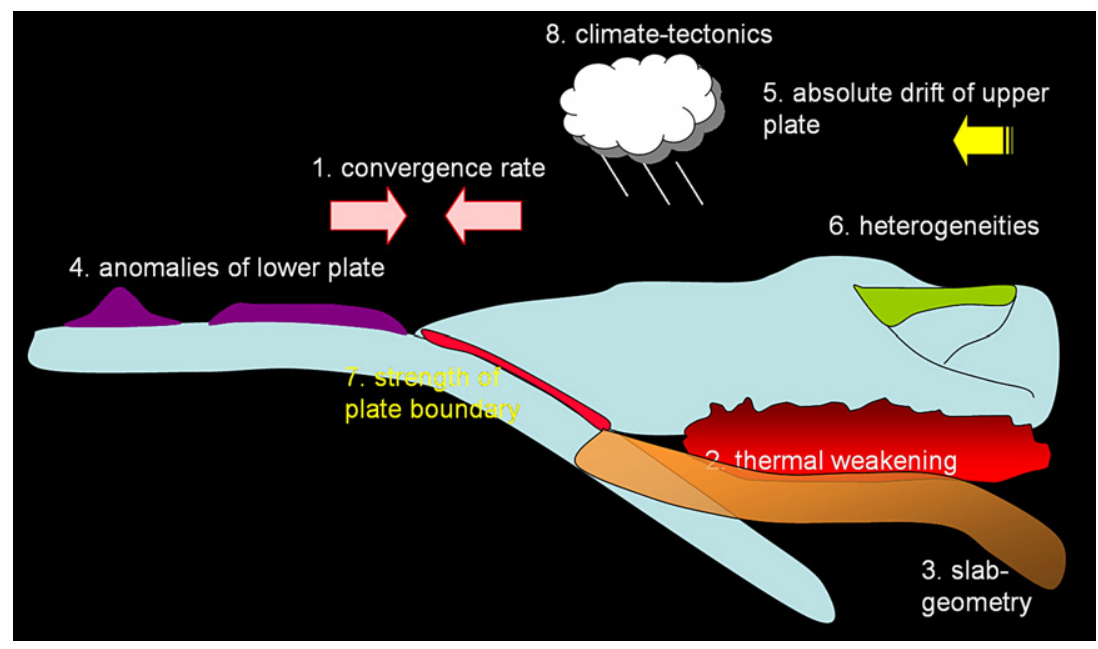

Fig. 74. Cartoon showing main factors affecting the development of orogens at convergent ocean-continent plate margins (Courtesy O. Oncken).

intra-continental regions such as the Basin-and-Range Province (USA) or the Eurasian-Arabian plate boundary region across Iran. In order to model the 4-D evolution of topography in response to internal and external Earth processes it is essential to know the signal intensity, duration, and the time since when a particular process has been active at a particular location. Such parameters are especially important in regions with large transient gradients in topography or complex fault system geometries. Of particular interest for modelling of the underlying dynamic process also is the rate at which such signals propagate in time and space. A related concern is whether it will be possible to close the observational gap between processes operating at historic time scales and those operating at geologic time scales.

Much progress towards solving these questions has recently been made along the Pacific-North American plate boundary region, western USA. The Basin-andRange Province is one of the best-monitored examples of an active, diffusely deforming intraplate region, and its location in a semi-arid climate grants excellent exposure and preservation of climatic and tectonic proxy records. Measurements with $>50$ GPS stations (BARGEN, e.g. Bennett et al., 2003), which have been recording continuously since 1996, have confirmed that about $1 \mathrm{~cm} / \mathrm{yr}$ or about one third of the contemporary strain accumulation across the plate boundary occurs up to $1000 \mathrm{~km}$ from the San Andreas transform system. On a historic time scale only a small number of faults have experienced large ground-rupturing seismic events, whereas on intermediate time scales (10s to 100 s of ky) nearly all faults have been active. Some of the faults, such as the Wasatch fault, exhibit a spectral deformation character with order of magnitude variations in measurable fault slip parameters on annual, millennial, and million-year time scales. First order variations in fault slip rates are attributed to changes in tectonic boundary conditions and occur on the million-year time scale (Fig. 75, Table 1). Second order variations are likely related to fault system dynamics and occur on time scales of thousands of years. Third order variations provide key information on the time scale of the seismic cycle. For several other faults (e.g. Owens Valley fault, Crescent Valley fault, and Garlock fault; Peltzer et al., 2001; Friedrich et al., 2004), paleo-seismic data in conjunction with space-geodetic data yield fluctuations in contemporary strain on time scales significantly shorter than the seismic cycle. On one hand, this behaviour implies that measurements of deformational parameters with just a single method over a short time window are insufficient to capture short-, intermediate- and long-term processes. On the other hand, this implies that it is possible to detect real variability in a process-related parameter if timeseries are measured over sufficiently long intervals, and at three neighbouring frequencies. This approach will be adopted at the TOPO-EUROPE focus sites whenever possible.

Variations in fault interaction also occur on a range of spatial scales, particularly expressed in terms of alternating slip rates on neighbouring fault systems. For example, on a scale of several hundred kilometres the slip-rate histories of the San Andreas and San Jacinto faults in California have co-varied over the past $5 \mathrm{My}$ (Bennett et al., 2004). On a scale of a few hundred kilometres, variation of fault activity also appears to covary, as has been observed in the Los Angeles BasinMojave Desert regions (e.g. Rockwell et al., 2000). On 


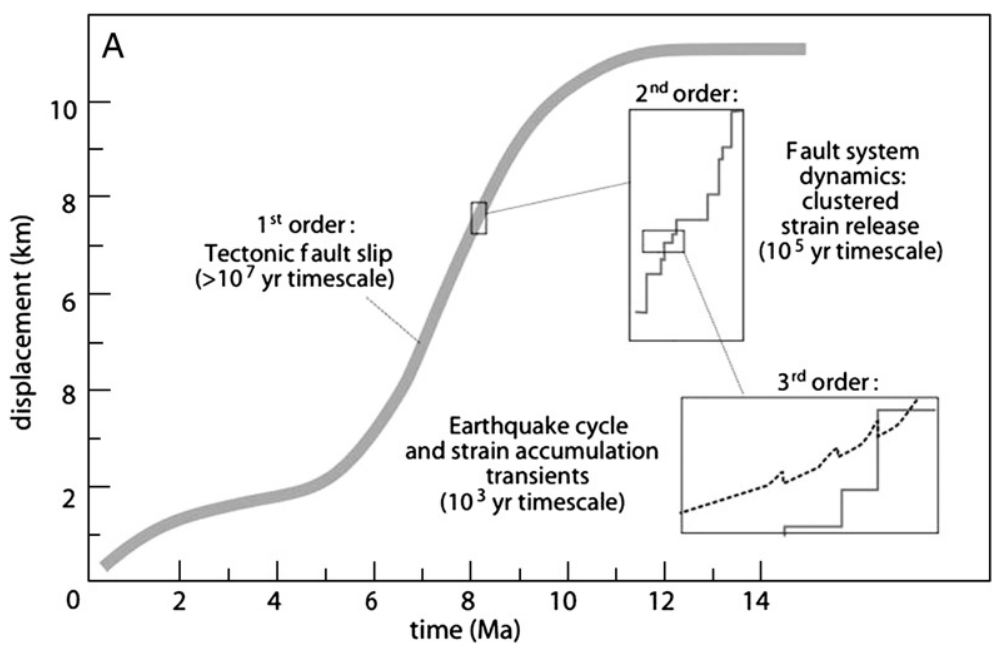

Fig. 75. Schematic diagram showing the superposition of tectonic, fault dynamic, and transient processes at three different orders and time scales (after Friedrich et al., 2003).

the scale of a single mountain front, segmentation into semi-independent seismotectonic blocks, however, also demonstrates that sustained faulting can occur over timescales of $10^{4}$ to $10^{5} \mathrm{yr}$, apparently without influencing activity on adjacent segments (Wallace, 1987; Strecker et al., 2003).

Taken together, these observations clearly demonstrate that instrumentally and historically recorded deformation does not provide sufficient information to fully understand the long-term behaviour of linked fault systems (e.g. Friedrich et al., 2003; Friedrich et al., 2004). Consequently, records of short-term fault activity may not be a good proxy for long-term behaviour, and vice versa. This dilemma becomes even more complex when regions are assessed in which plate convergence is accommodated by the reactivation of pre-existing structures, faults with different kinematics or where faulting may be associated with the effects of rapidly changing boundary conditions.

Spatial variability in strain release on geological time scales has recently been described for the western portion of California, where the San Andreas fault probably jumped inland around $5 \mathrm{Ma}$ (e.g. King et al., 2004). Consequently, the rate of activity changed on several previously existing fault systems. The precise initiation times and the magnitude of the rate change is subject of ongoing studies.

Another example of spatial deformation variability is related to the collision zone of the Arabian and the Eurasian plate, representing one of the largest regions of active intracontinental convergent deformation on Earth that extends from Turkey to Afghanistan (Fig. 76). To the west, shortening is mainly accommodated by westward escape of Anatolia (see Section 3.3 above).

Table 1

Significance of present-day and geologic displacement rate measurements for faults with significant vertical displacement (modified from Friedrich et al., 2003)

\begin{tabular}{|c|c|c|c|c|}
\hline Method & $\begin{array}{l}\text { Time } \\
\text { interval }\end{array}$ & $\begin{array}{l}\text { What is measured? } \\
\text { (typical units) }\end{array}$ & $\begin{array}{l}\text { Resolution } \\
\text { (e.g., at } 10 \mathrm{~km} \mathrm{depth})\end{array}$ & Significance of measurements \\
\hline Geodetic & $\begin{array}{l}\text { hours to } \\
\text { years }\end{array}$ & $\begin{array}{l}\text { Horizontal velocity field or strain rate } \\
(\mathrm{mm} / \mathrm{yr} \text { or nstraina/yr) }\end{array}$ & $\begin{array}{l}\text { Limited depth } \\
\text { resolution }\end{array}$ & $\begin{array}{l}\text { Sum of contemporary surface } \\
\text { strain accumulation }\end{array}$ \\
\hline Paleo-seismic & $\begin{array}{l}10^{1} \text { to } \\
10^{4} \mathrm{yr}\end{array}$ & $\begin{array}{l}\text { Earthquake recurrence interval (kyr) Net vertical } \\
\text { tectonic displacement record }(\mathrm{m})\end{array}$ & $\begin{array}{l}\text { No depth resolution, } \\
\text { excellent spatial } \\
\text { resolution }\end{array}$ & $\begin{array}{l}\text { Strain release rate via individual } \\
\text { earthquakes and temporal } \\
\text { clusters }\end{array}$ \\
\hline Geomorphic & $\begin{array}{l}10^{3} \text { to } \\
10^{6} \mathrm{yr}\end{array}$ & $\begin{array}{l}\text { Vertical displacement }(\mathrm{m}) \text { and age of offset marker } \\
\text { horizon (kyr) yield vertical displacement rate }(\mathrm{m} / \mathrm{kyr})\end{array}$ & $\begin{array}{l}\text { No depth resolution, } \\
\text { must be inferred }\end{array}$ & $\begin{array}{l}\text { Average fault displacement rates } \\
\text { of a number of seismic cycles }\end{array}$ \\
\hline Geologic/Structural & $\begin{array}{l}10^{6}- \\
10^{7} \mathrm{yr}\end{array}$ & Horizontal and vertical displacement rate $(\mathrm{km} / \mathrm{Myr})$ & $\begin{array}{l}\text { Good depth and spatial } \\
\text { resolution }\end{array}$ & $\begin{array}{l}\text { Average tectonic fault } \\
\text { displacement rates }(\mathrm{km} / \mathrm{Myr})\end{array}$ \\
\hline Thermochronologic & $\begin{array}{l}10^{6}- \\
10^{7} \mathrm{yr}\end{array}$ & Crustal cooling rates $\left({ }^{\circ} \mathrm{C} / \mathrm{Myr}\right)$ & $\begin{array}{l}\text { Moderate spatial, } \\
\text { good temporal resolution }\end{array}$ & Exhumation rates $(\mathrm{km} / \mathrm{Myr})$ \\
\hline
\end{tabular}




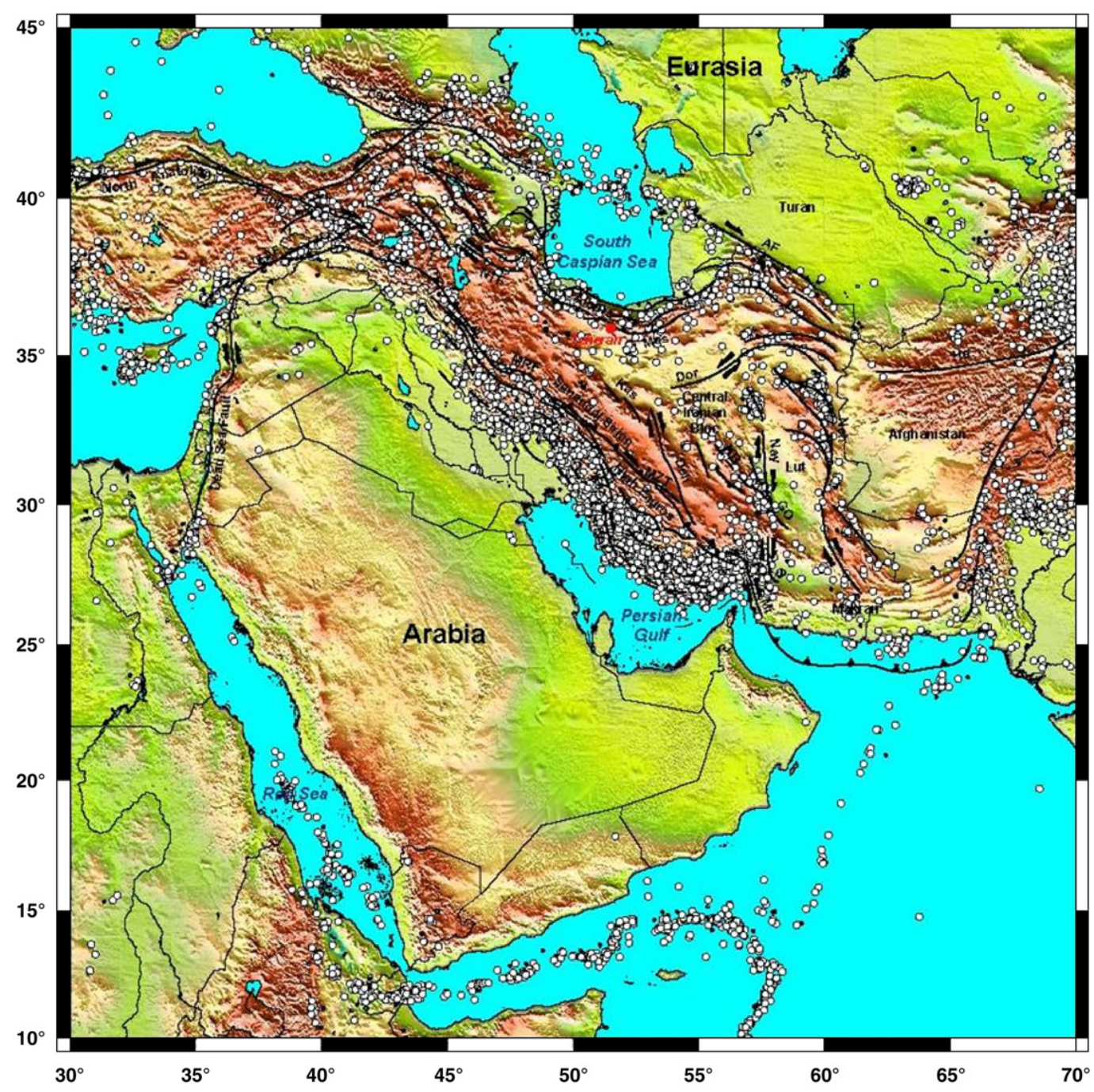

Fig. 76. Map showing the tectonic setting, seismicity and topography of the collision zone between the Arabian and Eurasian plates, involving westward extrusion of Anatolia and development of the Central Iranian Plateau (after Djamour, 2004).

To the east, in Iran, convergence is mainly accommodated by shortening in the Zagros and Elborz mountains, the Aspheron Sill, as well as a small component of SEdirected extrusion of the Central Iranian Plateau (Berberian and Yeats, 1999). Preliminary space geodetic measurements suggest NNE-directed, distributed shortening across the Iranian Plateau at a rate of $22 \pm 2 \mathrm{~mm} / \mathrm{yr}$ (Vernant et al., 2004a). Shortening in the Zagros fold and thrust belt is $7 \pm 2 \mathrm{~mm} / \mathrm{yr}, 8 \pm 2 \mathrm{~mm} / \mathrm{yr}$ in the Elborz Mountains, and $7 \pm 2 \mathrm{~mm} / \mathrm{yr}$ along the Aspheron Sill (Vernant et al., 2004a). In the Alborz Mountains the geodetic measurements show that in addition to a shortening component there is a component of leftlateral motion of $4 \pm 2 \mathrm{~mm} / \mathrm{yr}$ (Vernant et al., 2004b). In order to obtain a better understanding of the tectonic and topographic evolution of the Iranian collision zone, however, a larger number of space-geodetic surveys, remote sensing studies and field campaigns will be needed to examine the kinematics of active fault zones.

\section{Design of the TOPO-EUROPE science programme}

TOPO-EUROPE is geared for a 10 -yr multi-disciplinary, fully European Science Programme. The general objectives of this programme are:

- To advance the understanding of continental topography development and its societal implications in terms of dynamic processes inherent to the Solid- 
Earth, processes operating at the Earth's surface and their interaction.

- To promote national programmes on topography research and to integrate them into a Europe-wide collaborative network.

- To promote Europe internationally as scientific leader in the field of continental topography research.

- To provide an interdisciplinary forum for sharing technology, know-how and information in the field of European topography evolution.

- To promote the mobility and training of young researchers in the field of topography evolution and its societal relevance.

The TOPO-EUROPE science programme will focus on natural laboratories in the Alpine-MediterraneanCarpathian region, the Iberian microcontinent, the West and Central European Platform, the rifted Arctic-North Atlantic continental margins, the East-European Platform and the Africa-Arabia-Eurasian collision zone, including the Apennines-Aegean-Anatolia region and the Caucasus and Levant areas. Each of these natural laboratories addresses a specific tectonic setting under which topography dynamics are of great societal relevance (natural hazards, resources, impact on environment and climate). Each natural laboratory requires an integrated approach encompassing all 4 components of the TOPO-EUROPE Programme in order to assess these societal issues. Furthermore, these natural laboratories cover large parts of Europe and much of its population and industrial concentrations that, depending on the respective lithospheric domain, are exposed to a variety of natural hazards.

The TOPO-EUROPE Science Programme is organized as a matrix structure under which its 4 scientific approach components interface with the natural laboratories. This fosters close interaction between currently fragmented expertise and an effective knowledge transfer, both between different disciplines and at regional scales.

\subsection{Integration of distributed know-how and facilities}

An important feature of TOPO-EUROPE is the integration of existing national research capacities to reach the ambitious goal of creating a coherent panEuropean network, addressing key issues for scientific innovation and societal needs. TOPO-EUROPE offers the first European platform for the effective integration and sharing of a new generation of research facilities in Solid-Earth sciences, including integrated observation systems, surface, satellite and subsurface observatories, advanced analytical facilities and high-speed comput- ing. Information management systems will be brought together for the development of models.

A major goal of TOPO-EUROPE is the development of a virtual scientific centre based on leading infrastructures and the integrated programming of research activities. The combined infrastructure of the proposed network, presently already available, will consists of:

- Large-scale and excellent monitoring programs including satellite, surface and borehole monitoring instruments;

- State-of-the-art geomechanical, geochemical and geobiological laboratory facilities;

- Advanced geoinformation databases containing historical data on global and regional changes in combination with the vulnerability of natural and human habitats;

- State-of-the-art computer systems and experience in the development of parallel programs for complex time-dependent continuum problems;

- An up-to-date know-how base on geo-motion modelling and simulation, as well as on risk and impact assessment.

The availability to and the use of these facilities by the associated scientists, and their intention to contribute and share them in integrated research programmes will set the stage for a very competitive European position in this research domain.

\subsection{Opportunities to strengthen Europe's competitive position - an example}

The application of space-geodesy to monitor surface deformation is a relatively young science in Europe. Two decades ago the WEGENER group (IAG subcommittee) of geophysicists and geodesists used for the first time GPS and Satellite Laser Ranging (SLR) to quantify crustal motions in the Mediterranean area. Meanwhile, many institutes in Europe have engaged in one way or another into crustal motion research. An important example is the BIFROST programme of Scandinavia that focuses on strong topography change associated with postglacial rebound. Another important example is the Aegean-Anatolian region where American and European scientists made great first-order contributions to quantify active surface deformations associated with plate motion, intraplate deformation, and the activity of the Anatolian fault systems. At present a very sparse European network (EUREF) of permanent GPS stations contributes to the global IGS network. Its purpose is purely geodetic: to serve as a reference for global and 
regional measurement campaigns. Apart from the EUCOR-URGENT Project, such campaigns have shown a relative wild growth without significant coherency on the European level. While this growth is continuing (sometimes in concert with commercial applications), the European-scale organisation of crustal dynamics monitoring is at present virtually absent. Recently the WEGENER group has taken the initiative to improve this situation and, comparable to EUROARRAY, has merged with TOPOEUROPE to create the necessary synergy to achieve common observation, monitoring and process modelling goals.

\subsection{Europe is taking the lead}

Over the last decade European scientists have attained a world-leading position in such sub-disciplines of modern Solid-Earth sciences as seismic tomography, the development of new seismological techniques such as receiver functions, the study of subduction processes, inversion of multi-component seismic data, astronomically-calibrated dating, Earth materials subjected to high strains, and modelling of sedimentary basin evolution.

European scientists also play a world-leading role in geodesy and the application of new space technologies (gravity, magnetic, radar- and SAR-techniques, GPSapplications). Leading Earth monitoring satellites are such European satellites as CHAMP, Oersted, ENVISAT and ERS-2. Europe plays an important role in experimental in-situ studies (high-pressure experiments, experimental facilities like the European Synchrotron Radiation facility or HASYLAB in Hamburg). Partners in the TOPO-EUROPE Project have equipment available which is unique world-wide for the proposed activities, ranging from satellites over instrument pools to experimental facilities and modelling power. The TOPO-EUROPE research domain is most important for the economical future of Europe as it covers such aspects as natural resources (e.g. water, fossil fuels, geothermal energy), natural hazards and waste disposal.

Europe is now pioneering the rapidly growing field of coupled topographic - climate processes requiring the development of combined numerical - analogue modelling techniques and the introduction of innovative isotopic methods.

Integrated Solid-Earth System science is definitely at the forefront of modern Earth sciences. As a result of this European integration process, dedicated efforts were made in a number of leading European research labs, putting European scientists in a unique position to expand this strength to a truly European scale. Probably nowhere in the world are the conditions so favourable to establish a link between Solid-Earth processes and the System Earth at large. This effort will directly build on the foundation of previous ESF initiatives, such as EUROPROBE and the European GeoTraverse (EGT). Leading researchers from amongst others the USA, Canada and Australia have expressed a strong interest to be associated with TOPO-EUROPE. The same is true for scientists from countries at Europe's rim.

\subsection{Specific objectives and deliverables of TOPO- EUROPE}

Specific objectives of TOPO-EUROPE are:

- Modelling land subsidence in the basins and deltas of Europe.

- Quantification of land slope instabilities.

- High resolution monitoring of crustal motions in space and time to quantify sediment source-to-sink relations and to constrain earthquake and evolutionary mountain building models.

- Coupling of numerical and analogue modelling schemes for characterizing the feedback relationships between tectonics, topography, and climate.

- High-resolution tomographic images of the (dynamic) interaction between the (deep) mantle and lithosphere, and its effects on surface topography.

- Studying the effects of neotectonic processes on river and coastal evolution, with emphasis on flooding potential.

Specific deliverables for the programme at large will include:

- Deployment of EUROARRAY.

- New models for the sub-lithospheric mantle of Europe based on integration of seismic tomography data.

- New lithospheric thickness, strength and strain-rate maps for each study area and for all of Europe.

- Revised Moho depth and a crustal thickness map for Europe.

- Paleogeographic maps showing the evolution of the European drainage system, sedimentary basins and topography during the last $20 \mathrm{Myr}$.

- Compilation of regional neotectonic maps of Europe, showing uplift and subsidence as well as lateral displacement rates.

- Quantification of land subsidence rates in evolving basins and deltas and identification of controlling mechanisms.

- Quantification of land uplift rates in active orogens and identification of controlling mechanisms. 
- Quantification of intraplate uplift/subsidence rates induced by lithospheric folding and other processes.

- New concepts on tectonic controls of river systems.

- Determination of source-to-sink relations to quantify sediment budgets.

- Improved understanding of driving mechanisms controlling Aegean extension and subduction and uplift of the Apennines.

- Improved 3-D density, electrical resistivity, seismic and thermal structural information for key features.

- Evaluation and understanding of new satellite gravity and geodetic datasets.

- Shallow and deep characteristics of active fault systems.

- Improved seismic hazard maps for natural laboratories.

Examples of deliverables for some of the selected natural laboratories include:

- Physical model of stress and strain evolution during the past $10 \mathrm{kyr}$ along fault systems of the NAFZ, Aegean extension zone, and Dead Sea transform permitting to assess the stress transfer between faults and the time-dependence of seismic hazard.

- Reconstruction of the evolution of uplift, erosion, sedimentation, river systems, seismicity around the SE-Carpathians in comparison to Iberia, both of which are strongly influenced by ongoing lithospheric delamination.

- Data assimilation and modelling of the Fennoscandian uplift, concurrent large extensional earthquakes and major tsunami-creating landslides by using precise data on topography, timing and (paleo)climatic conditions.

- Balance of crustal deformation during the Quaternary and comparison with co-seismic strain rates from historical catalogues and paleo-seismicity in seismically very active areas close to plate boundaries (e.g. Iberia, Apennines, Carpathians, Greater Caucasus, Eastern-Mediterranean) and seismically moderately active intraplate areas (e.g. Rhine Graben, Fennoscandia) with the aim to constrain the relation of and conditions for a-seismic and catastrophic slip.

- Reconstruction of the evolution of Cenozoic vertical movements in the southern part of the East-European Platform to assess the role of deep mantle processes in reworking of the cratonic lithosphere.

\subsection{Relationship to ongoing and planned research initiatives}

TOPO-EUROPE is fully embedded in the mainstream of European research, as clearly demonstrated by existing links to related national or EU projects. TOPO-
EUROPE significantly augments the current momentum in integrating European Solid-Earth sciences. TOPOEUROPE benefits from a number of past Europeanscale research initiatives, including:

- ESF EGT — European GeoTraverse (1982-1990).

- ESF EUROPROBE (1992-2001).

- ESF EUCOR-URGENT (Upper Rhine Graben Evolution and Neotectonics) - Environmental Earth system dynamics network (2002-2004).

- ENTEC - Environmental Tectonics EU-FP5 Training and Research Network (2001-2004).

- PALEOSEIS - Evaluation of earthquake potential in regions of low seismic activity in Europe (EU-FP5) (1999-2002).

- SAFE - Slow Active Faults in Europe (EU-FP5 Research Programme) (2000-2003).

- EUROBASIN - Marie Curie EU-FP5 doctoral school and fellowship program (2002-2005).

- ESF support has been crucial in this respect, and has led to the highly successful European GeoTraverse, the ESF EUROPROBE programme, and the ESF EUCOR-URGENT network. TOPO-EUROPE builds directly on the success of these ESF programmes. EUFP5 networks, such as ENTEC, PALEOSEIS and SAFE were important to promote a closer link between fundamental Solid-Earth sciences and natural hazard studies, setting the stage for environmental tectonics research.

Ongoing European scale initiatives that will upon their completion yield results and expertise highly relevant to TOPO-EUROPE include:

- ESF EUROCORES EUROMARGINS (2002-2007).

- ESF EUROCORES EUROCLIMATE (2004-2007).

- CRONUS-EU — High-resolution cosmogenic isotopes. EU-FP6 training and research network (20052008).

- EU INTERREG III - Microzonation of the Greater Basel area (2004-2007).

- ENGINE - Geothermal energy EU coordinated action (EU-FP6) (2005-2008).

In a number of ESF member states, the TOPOEUROPE initiative has already triggered an intensified national interdisciplinary dialogue. In Spain a large group of researchers have initiated a national TOPO-IBERIA programme, including the PICASSO project, which will be embedded in TOPO-EUROPE. It is the synergy between these complementary and concentrated national efforts that make a TOPO-EUROPE EUROCORES 
achievable. TOPO-EUROPE will be part of the core of the ILP research agenda.

TOPO-EUROPE is backed up by a group of strong research institutes. Although a compact field in terms of absolute number of scientists, the Solid-Earth sciences in Europe have received significant exposure, in terms of quality recognisable through the prominent role Earth sciences play in the ratio of national centres of excellence (e.g. Netherlands: 1 out of 6 centres; Norway: 4 out of 12 centres). The strong connections with industry and with future young promising researchers will be promoted through, for example, the close association of the TOPOEUROPE research agenda and the European top research master on integrated basin studies BASINMASTER, currently under development with support of the European Commission and Europe's energy industry. TOPOEUROPE will also seek funding for new large-scale infrastructure through the EU 7th framework programme.

\section{Conclusions}

A prime objective for integrated Solid-Earth science is the development of scientific models for the reconstruction and forecasting of coupled deep Earth and surface processes. TOPO-EUROPE is promoting the simultaneous development of new concepts, advanced analytical techniques and the continued expansion of research avenues for computer simulation of complex geosystems. TOPO-EUROPE will open hitherto unparalleled opportunities to quantify and validate the controls on man's natural environment on the Earth's surface.

Major advances have been made in seismological methods to obtain information on the 4-D structure of the mantle and the lithosphere, in the quantitative understanding of lithospheric processes, as well as in the recognition of the key role of quantitative sedimentary basin analysis in connecting the temporal and spatial evolution of the system Earth. Similar breakthroughs have been made by $3-\mathrm{D}$ seismic imaging and inversion in the spatial resolution of structural controls on the architecture of the lithosphere and its deformation processes. Modelling of dynamic topography and landform evolution is reaching a stage at which a full coupling can be established between erosion and sediment supply to sedimentary basins at different spatial and temporal scales. A quantitative understanding of crustal and subcrustal deformation, sediment transport and climate are prerequisites for progress in integrated Solid-Earth System Dynamics. This research area bridges currently separated approaches addressing high-resolution time scales for a limited near-surface record in the Quaternary and the long-term and large-scale approaches character- istic for lithospheric-scale and basin-wide studies. Integration of these fields is a must, also considering the accumulating evidence for a feedback between lithospheric and surface processes.

Since its launching in fall 2005 TOPO-EUROPE has started to promote, coordinate and integrate national research programmes addressing the coupling between Solid-Earth and surface processes and its implications to continental topography development into a coherent European network. TOPO-EUROPE's natural laboratories provide a set of world-class opportunities to probe and quantify the entire range of plate interaction processes affecting topography in the context of presently active dynamic processes. In these areas we can obtain the highest possible resolution required to discriminate between inner and outer Earth processes, and to quantify the coupling between Solid-Earth and surface processes. The selected natural laboratories offer unique key study areas for developing a new generation of models explaining the dynamics of ongoing deformation of the lithosphere and its repercussions on continental topography. Other natural laboratories may be selected as the project advances. These will be chosen based on their merits.

\section{Acknowledgements}

TOPO-EUROPE is the regional coordinating committee for Europe of the International Lithosphere Programme (ILP). We thank ILP for financial support and recognition. Financial support to the TOPOEUROPE preparatory workshops held in Budapest and Heidelberg, received from the Academia Europaea, the Klaus Tschira Foundation, the European Science Foundation (ESF), the Netherlands Organization for Scientific Research (NWO), the Eötvös Lorant University Budapest (ELTE), and the Netherlands Research Centre for Integrated Solid Earth Science (ISES), is gratefully acknowledged. TOPO-EUROPE has been selected by ESF as a EUROCORES programme in September 2006.

\section{References}

Adamia, S.A., Lordkipanidze, M.B., Zakariadze, G.S., 1977. Evolution of an active continental margin as exemplified by the alpine history of the Caucasus. Tectonophysics 40, 183-199.

Adamia, S.A., Chkhouta, T., Kekelia, M., Lordkipanidze, M.B., Zakariadze, G.S., 1981. Tectonics of the Caucasus and adjoining areas: implications for the evolution of the Tethys ocean. Journal of Structural Geology 3, 437-447.

Agard, P., Omrani, J., Jolivet, L.F.M., 2005. Convergence history across Zagros (Iran): constraints from collisional and earlier deformation. International Journal of Earth Sciences (Geologische Rundschau) 94, 401-419. 
Aichroth, B., Prodehl, C., Thybo, H., 1992. Crustal structure along the central segment of the EGT from seismic refraction studies. Tectonophysics 207, 43-64.

Allen, M., Jackson, J., Walker, R., 2004. Late Cenozoic reorganization of the Arabia-Eurasia collision and the comparison of short-term and long-term deformation rates. Tectonics 23, 1-16.

Allmendinger, R.W., Jordan, T.E., Kay, S.M., Isacks, B.L., 1997. The evolution of the Altiplano-Puna Plateau of the Central Andes. Annual Reviews of Earth and Planetary Sciences 25, 139-174.

ANCORP-Working Group, 2003. Seismic imaging of an active continental margin - the Central Andes (ANCORP '96). Journal of Geophysical Research 108 (B7), 2328.

Andersen, N., Paul, H.A., Bernasconi, S.M., McKenzie, J., Behrens, A., Schaeffer, P., Albrecht, P., 2001. Large and rapid climate variability during the Messinian Salinity Crisis: Evidence from Deuterium concentration in individual biomarkers. Geology 29, 799-802.

Andeweg, B. 2002. Cenozoic tectonic evolution of the Iberian Peninsula: causes and effects of changing stress fields. $\mathrm{PhD}$ Thesis, Vrije Universiteit, Amsterdam. 178 pp.

Andeweg, B., Cloetingh, S.A.P.L., 2001. Evidence for an active sinistral shear zone in the western Alboran region. Terra Nova 13, $44-50$.

Andriessen, P., Garcia Castellanos, D. (Eds.), 2004. 3-D Motions of the Earth Surface: from Measurements to Physical Modelling. Physics and Chemistry of the Earth, vol. 29. 663-717.

Arger, J., Mitchell, J., Westaway, R.W.C., 2000. Neogene and Quaternary volcanism of Southeastern Turkey. In: Bozkurt, E., Winchester, J.A., Piper, J.D.A. (Eds.), Tectonics and Magmatism in Turkey and the Surrounding Area. Geological Society, London, Special Publication, vol. 173, pp. 459-487.

Argus, D.F., Gordon, R.G., DeMets, C., Stein, S., 1989. Closure of the Africa-Eurasia-North America plate motion circuit and tectonics of the Gloria Fault. Journal of Geophysical Research 94 (B5), $5585-5602$.

Artemieva, I.M., 2003. Lithospheric structure, composition, and thermal regime of the East European craton: Implications for the subsidence of the Russian Platform. Earth and Planetary Science Letters 213, 429-444.

Artemieva, I.M., 2006. Global $1^{\circ} \times 1^{\circ}$ thermal model TC1 for the continental lithosphere: implications for lithosphere growth since Archean. Tectonophysics 416, 245-277.

Artemieva, I.M., Thybo, H., Kaban, M.K., 2006. Deep Europe today: Geophysical synthesis of the upper mantle structure and lithospheric processes over 3,5 Ga. In: Gee, D., Stephenson, R. (Eds.), European Lithosphere Dynamics. Geological Society, London, Memoirs, vol. 32, pp. 11-42.

BABEL Working Group, 1993. Deep seismic reflection/refraction interpretation of crustal structure along BABEL profiles A and B in the southern Baltic Sea. Geophysical Journal International 112, 325-343.

Bada, G., Fodor, L., Ruszkiczay-Rüdiger, Z., Dunai, T., Cloetingh, S., Horváth, F., 2005a. Active tectonics and continental topography development in the Pannonian basin. Geophysical Research Abstracts 7, 09536.

Bada, G., Horvath, F.T.T., Fodor, L., Timar, G., Cloetingh, S., 2005 b. Societal aspects of ongoing deformation in the Pannonian region. In: Pinter, N., Grenerczy, G., Weber, J., Stein, S., Medak, D. (Eds.), The Adria Microplate: GPS Geodesy, Tectonics and Hazards. NATO Science Series. Springer Verlag, pp. 385-402.

Bahroudi, A., Koyi, H.A., 2004. Tectono-sedimentary framework of the Gachsara Formation in the Zagros foreland basin. Marine and Petroleum Geology 21, 1295-1310.
Baig, A.M., Dahlen, F.A., 2004. Traveltime biases in random media and the S-wave discrepancy. Geophysical Journal International 158, 922-938.

Bala, A., Radulian, M., Popescu, E., 2003. Earthquake distribution and their focal mechanism in correlation with the active tectonic zones of Romania. Journal of Geodynamics 36, 129-145.

Ballard, R.D., Coleman, D.F., Rosenberg, G.D., 2000. Further evidence of abrupt Holocene drowning of the Black Sea shelf. Marine Geology 170, 253-261.

Banks, C.J., Robinson, A.G., Williams, M.P., 1997. Structure and regional tectonics of the Achara-Trialet fold belt and the adjacent Rioni and Kartli foreland basins, Republic of Georgia. In: Robinson, A.G. (Ed.), AAPG Memoir, vol. 68. American Association of Petroleum Geologists, Tulsa, OK, United States, pp. 331-346.

Bartolini, C., D’Agostino, N., Dramis, F., 2003. Topography, exhumation, and drainage network evolution of the Apennines. Episodes 26,3 .

Becker, A., 2000. The Jura Mountains — an active foreland fold-andthrust belt? Tectonophysics 321, 381-406.

Bellahsen, N., Faccenna, C., Funiciello, F., Daniel, J.M., Jolivet, L., 2003. Why did Arabia separate from Africa? Insights from 3-D laboratory experiments. Earth and Planetary Science Letters 216, 365-381.

Ben-Avraham, Z., Ginzburg, A., 1990. Displaced terranes and crustal evolution of the Levant and the eastern Mediterranean. Tectonics 9, 613-622.

Ben-Avraham, Z., Ginzburg, A., Makris, J., Eppelbaum, L., 2002. Crustal structure of the Levant Basin, eastern Mediterranean. Tectonophysics 346, 23-43.

Bennett, R.A., Niemi, N.A., Wernicke, B., Friedrich, A.M., Davis, J.L., 2003. Contemporary strain rates in the northern Basin and Range province from GPS data. Tectonics 22, 1008. doi:10.1029/ 2001 TC001355.

Bennett, R., Furlong, K., Friedrich, A., 2004. Codependent histories of the San Andreas and San Jacinto fault zones from inversion of fault displacement rate. Geology 32, 961-964.

Berberian, M., Yeats, R.S., 1999. Patterns of Historical Earthquake Rupture in the Iranian Plateau. Bulletin of the Seismological Society of America 89, 120-139.

Berendsen, H.J.A., Stouthamer, E., 2002. Paleogeographic evolution and avulsion history of the Holocene Rhine-Meuse Delta, the Netherlands. Netherlands Journal of Geosciences-Geologie en Mijnbouw 81, 97-112.

Bernet, M., Spiegel, C. (Eds.), 2004. Detrital thermochronologyProvenance analysis, exhumation and landscape evolution of mountain belts. Geological Society of America Special Paper, vol. 378. Geological Society of America, Boulder, Colorado, p. 126.

Bertotti, G., Matenco, L.C., Cloetingh, S.A.P.L., 2003. Vertical movements in and around the south-east Carpathian foredeep: lithospheric memory and stress field control. Terra Nova 15, 299-305.

Bijwaard, H., Spakman, W., 1999. Tomographic evidence for a narrow whole mantle plume below Iceland. Earth and Planetary Science Letters 166, 121-126.

Bijwaard, H., Spakman, W., 2000. Non-linear global P-wave tomography by iterated linearized inversion. Geophysical Journal International 141, 71-82.

Bijwaard, H., Spakman, W., Engdahl, E.R., 1998. Closing the gap between regional and global travel time tomography. Journal of Geophysical Research 103 (B12), 30055-30078. 
Boenigk, W., 2002. The Pleistocene drainage pattern in the Lower Rhine basin. Netherlands Journal of Geosciences-Geologie en Mijnbouw 81, 201-209.

Bogdanova, S., Gorbatschev, R., Grad, M., Janik, T., Guterch, A., Kozlovskaya, E., Motuza, G., Skridlaite, G., Starostenko, V., Taran, L., EUROBRIDGE and POLONAISE Working Groups, 2006. EUROBRIDGE: New insight into the geodynamic evolution of the East European Craton. In: Gee, D., Stephenson, R. (Eds.), European Lithosphere Dynamics. Geological Society, London, Memoirs, vol. 32, pp. 599-626.

Bondevik, S., Løvholt, F., Harbitz, C., Mangerud, J., Dawson, A., Svendsen, J.I., 2005. The Storegga Slide tsunami - comparing field observations with numerical simulations. Marine and Petroleum Geology 22, 195-208.

Bonnet, S., Guillocheau, F., Brun, J.-P., 1998. Relative uplift measured by river incision: the case of the Armorican basement (France). Comptes Rendus de l'Academie des Sciences Series IIA Earth and Planetary Science 327, 245-251.

Bonnet, S., Guillocheau, F., Brun, J.-P., Van den Driesschen, J., 2000. Large-scale relief development related to Quaternary tectonic uplift of a Proterozoic-Paleozoic basement: the Armorican Massif, NW France. Journal of Geophysical Research 105 (B8), 19273-19288.

Bonow, J.M., 2005. Re-exposed basement landforms in the Disko region, West Greenland-disregarded data for estimation of glacial erosion and uplift modelling. Geomorphology 72, 106-127.

Bonow, J.M., Japsen, P., Lidmar-Bergström, K., Chalmers, J.A., Pedersen, A.K., 2006a. Cenozoic uplift of Nuussuaq and Disko, West Greenland - elevated erosion surfaces as uplift markers of a passive margin. Geomorphology 80, 325-337.

Bonow, J.M., Lidmar-Bergström, K., Japsen, P., 2006b. Palaeosurfaces in central West Greenland as reference for identification of tectonic movements and estimation of erosion. Global and Planetary Change 50, 161-183.

Bordoni, P., Valensise, G., 1998. Deformation of the 125 ka marine terrace in Italy: tectonic implications. In: Stewart, I., Vita Finzi, C. (Eds.), Late Quaternary coastal tectonics. Geological Society, London, Special Publications, vol. 146, pp. 71-110.

Bozkurt, E., Winchester, J.A., Piper, J.D.A. (Eds.), 2000. Tectonics and Magmatism in Turkey and the Surrounding Area. Geological Society, London, Special Publications, vol. 173, p. 521.

Brault, N., Guillocheau, F., Proust, J.-N., Nalpas, T., Brun, J.-P., Bonnet, S., Bourquin, S., 2001. Le systeme fluvio-estuarin Pleistocene moyen-superieur de Penestin (Morbihan); une paleoLoire? Bulletin de la Société Géologique de France 172, 563-572.

Brod, I.A., 1962. Structural-geomorphological investigations in the Caspian region - Strukturno-geomorfologicheskie issledovaniya v Prikaspii. Kompleksnaya Yuzhnaya Geologicheskaya Ekspeditsiya. Sbornik materialov vyp., vol. 7. Leningrad, Russia.

Brunet, M.-F., Korotaev, M.V., Ershov, A.V., Nikishin, A.M., 2003. The South Caspian Basin: a review of its evolution from subsidence modelling. Sedimentary Geology 156, 119-148.

Brunnacker, K., Boenigk, W., 1983. The Rhine Valley between the Neuwied Basin and the Lower Rhenish Embayment. In: Fuchs, K., Von Gehlen, K., Mälzer, M., Murawski, H., Semmel, A. (Eds.), Plateau Uplift, The Rhenish Shield - a case history. SpringerVerlag, Berlin, pp. 62-72.

Buiter, S.J.H., Pfiffner, O.A., 2003. Numerical models of the inversion of half-graben basins. Tectonics 22, 1057. doi:10.1029/2002TC001417.

Buiter, S.J.H., Huismans, R.S., Beaumont, C., 2004. Formation of extensional sedimentary basins: The role of surface processes in mode selection. Bollettino Geophysical 45, 187-191.
Bunge, H.-P., Richards, M.A., Lithgow-Bertelloni, C., Baumgardner, J.R., Grand, S.P., Romanowicz, B.A., 1998. Time Scales and Heterogeneous Structure in Geodynamic Earth Models. Science 280 (5360), 91-95.

Bunge, H.-P., Hagelberg, C.R., Travis, B.J., 2003. Mantle circulation models with variational data-assimilation: Inferring past mantle flow and structure from plate motion histories and seismic tomography. Geophysical Journal International 152, 280-301.

Burchfiel, C., Nakov, R., Tzankov, Z., Royden, L.H., 2000. Cenozoic extension in Bulgaria and northern Greece: the northern part of the Aegean extensional regime. In: Bozkurt, E., Winchester, J.A., Piper, J.D.A. (Eds.), Tectonics and Magmatism in Turkey and the Surrounding Area. Geological Society, London, Special Publications, vol. 173, pp. 325-352.

Bürgmann, R., Ayhan, M.E., Fielding, E.J., Wright, T.J., McClusky, S., Aktug, B., Demir, C., Lenk, O., Türkezer, A., 2002. Deformation during the 12 November 1999 Düzce, Turkey, Earthquake, from GPS and InSAR Data. Bulletin of the Seismological Society of America 91, 161-171.

Burov, E., Cloetingh, S., 1997. Erosion and rift dynamics: new thermomechanical aspects of post-rift evolution of extensional basins. Earth and Planetary Science Letters 150, 7-26.

Burov, E., Poliakov, A., 2001. Erosion and rheology controls on synand post-rift evolution: verifying old and new ideas using a fully coupled numerical model. Journal of Geophysical Research 106, 16461-16481.

Burov, E., Watts, A.B., 2006. The long-term strength of continental lithosphere: "jelly-sandwich" or "crème-brûlée"? GSA Today 16, $4-10$.

Buttler, R.H.W., McClelland, E., Jones, R.E., 1999. Calibrating the duration and timing of the Messinian Salinty Crisis in the Mediterranean: linked tectono-climatic signals in thrust-top basins of Sicliy. Journal of the Geological Society of London 156, 827-835.

Calais, E., Nocquet, J.-M., Jouanne, F., Tardy, M., 2002. Current strain regime in the Western Alps from continuous Global Positioning System measurements, 1996-2001. Geology 30, 651-654.

Calvo, J.P., Jones, B.F., Bustillo, M., Fort, R., Alonso-Zarza, A.M., Kendall, C., 1995. Sedimentology and geochemistry of carbonates from lacustrine sequences in the Madrid Basin, central Spain. Chemical Geology 123, 173-191.

Caporali, A., Martin, S., Massironi, M., 2003. Average strain rate in the Italian crust inferred from a permanent GPS network - II. Strain rate versus seismicity and structural geology. Geophysical Journal International 155, 254-268.

Carbonell, R., Gallart, J., Perez-Estaun, A., Diaz, J., Kashubin, S., Mechie, J., Wenzel, F., Knapp, J., 2000. Seismic wide-angle constraints on the crust of the southern Urals. Journal of Geophysical Research 105, 13755-13777.

Carminati, E., Wortel, M.J.R., Meijer, P.T., Sabadini, R., 1998. The two-stage opening of the western-central Mediterranean basins: a forward modelling test to a new evolutionary model. Earth and Planetary Science Letters 160, 667-679.

Carter, N.L., Tsenn, M.C., 1987. Flow properties of continental lithosphere. Tectonophysics 136, 27-63.

Cavazza, W., Roure, F., Spakman, W., Stampfli, G.M., Ziegler, P.A. (Eds.), 2004. The TRANSMED Atlas. The Mediterranean Region from Crust to Mantle: Geological and Geophysical Framework. Publication of the Mediterranean Consortium for the 32nd International Geological Congress, vol. XXIV, p. 141.

Cederbom, C., 2001. Phanerozoic, pre-Cretaceous thermotectonic events in southern Sweden revealed by fission track thermochronology. Earth and Planetary Science Letters 188, 199-209. 
Cernobori, L., Hirn, A., McBride, J., Nicolich, R., Petronio, L., Romanelli, M., 1996. Crustal image of the Ionian basin and its Calabrian margins. Tectonophysics 264, 175-189.

Chalmers, J.A., Pulvertaft, T.C.R., 2001. Development of the continental margins of the Labrador Sea: a review. In: Wilson, R.C.L., Withmarsh, R.B., Taylor, B., Froitzheim, N. (Eds.), Nonvolcanic rifting of continental margins: A comparison of evidence from land and sea. Geological Society, London, Special Publications, vol. 187 , pp. 77-105.

Chalmers, J.A., Pulvertaft, T.C.R., Marcussen, C., Pedersen, A.K., 1999. New insight into the structure of the Nuussuaq Basin, central West Greenland. Marine and Petroleum Geology 16, 197-224.

Civello, S., Margheriti, L., 2004. Toroidal mantle flow around the Calabrian slab (Italy) from SKS splitting. Geophysical Research Letters 31, L10601. doi:10.1029/2004GL019607.

Clauzon, G., Suc, J.-P., Popescu, S.-M., Marunteanu, M., Rubino, J.-L., Marinescu, F., Melinte, M.C., 2005. Influence of Mediterranean sea-level changes on the Dacic Basin (Eastern Paratethys) during the late Neogene: the Mediterranean LagoMare facies deciphered. Basin Research 17, 437-462.

Cloetingh, S.A.P.L. (Ed.), 2000. Environmental Tectonics and Climate: The Netherlands Environmental Earth System Dynamics Initiative. Global and Planetary Change, vol. 27, p. 288.

Cloetingh, S., Banda, E., 1992. Mechanical structure. In: Blundell, D., Mueller, S., Friedman, R. (Eds.), The European Geotraverse; A continent revealed. Cambridge University Press, pp. 80-91.

Cloetingh, S.A.P.L., Burov, E.B., 1996. Thermo-mechanical structure of European continental lithosphere; constraints from rheological profiles and EET estimates. Geophysical Journal International 124, 695-723.

Cloetingh, S., Cornu, T., 2005a. Surveys on environmental tectonics. Quaternary Science Reviews 24, 235-240.

Cloetingh, S.A.P.L., Cornu, T. (Eds.), 2005b. Neotectonics and Quaternary fault-reactivation in Europe's intraplate lithosphere. Quaternary Science Reviews, vol. 24, pp. 235-508.

Cloetingh, S.A.P.L., Van Wees, J.D., 2005. Strength reversal in Europe's intraplate lithosphere: transition of basin inversion to lithospheric folding. Geology 33, 285-288.

Cloetingh, S.A.P.L., Gradstein, F.M., Kooi, H., Grant, A.C., Kaminski, M., 1990. Plate reorganisation: a cause of rapid late Neogene subsidence and sedimentation around the north Atlantic? Journal of the Geological Society of London 147, 495-506.

Cloetingh, S.A.P.L., Burov, E., Poliakov, A., 1999. Lithosphere folding: Primary response to compression? (from central Asia to Paris basin). Tectonics 18, 1064-1083.

Cloetingh, S.A.P.L., Burov, E., Beekman, F.B.A., Andriessen, P.A.M., Garcia-Castellanos, D., De Vicente, G., Vegas, R., 2002. Lithospheric folding in Iberia. Tectonics 21, 1041. doi:10.1029/2001TC901031.

Cloetingh, S.A.P.L., Horváth, F., Dinu, C., Stephenson, R.A., Bertotti, G., Bada, G., Matenco, L., Garcia-Castellanos, D., TECTOP Working Group, 2003a. Probing tectonic topography in the aftermath of continental convergence in Central Europe. EOS, Transactions, American Geophysical Union, vol. 84, 89.

Cloetingh, S.A.P.L., Ziegler, P., Cornu, T., ENTEC Working Group, 2003b. Investigating environmental tectonics in northern Alpine foreland of Europe. EOS, Transactions, American Geophysical Union, vol. 84, 349, 356-357.

Cloetingh, S.A.P.L., Burov, E., Matenco, L., Toussaint, G., Bertotti, G., Andriessen, P.A.M., Wortel, M.J.R., Spakman, W., 2004. Thermo-mechanical controls on the mode of continental collision in the SE Carpathians (Romania). Earth and Planetary Science Letters $218,57-78$.
Cloetingh, S., Matenco, L., Bada, G., Dinu, C., Mocanu, V., 2005a. The evolution of the Carpathians-Pannonian system: Interaction between neotectonics, deep structure, polyphase orogeny and sedimentary basins in a source to sink natural laboratory. Tectonophysics 410, 1-14.

Cloetingh, S.A.P.L., Ziegler, P.A., Beekman, F., Andriessen, P.A.M., Matenco, L., Bada, G., Garcia-Castellanos, D., Hardebol, N.N., Dèzes, P., Sokoutis, D., 2005b. Lithospheric memory, state of stress and rheology: neotectonic controls on Europe's intraplate continental topography. Quaternary Science Reviews 24, 241-304.

Cloetingh, S., Bada, G., Matenco, L., Lankreijer, A., Horváth, F., Dinu, C., 2006a. Thermo-mechanical modelling of the PannonianCarpathian system: modes of tectonic deformation, lithospheric strength and vertical motions. In: Gee, D.G., Stephenson, R. (Eds.), European Lithosphere Dynamics. Geological Society, London, Memoirs, vol. 32, pp. 207-221.

Cloetingh, S., Cornu, T., Ziegler, P.A., Beekman, F., $2006 \mathrm{~b}$. Neotectonics and intraplate continental topography of the northern Alpine Foreland. Earth Science Reviews 74, 127-196.

Cocard, M., Kahle, H.-G., Peter, Y., Geiger, A., Veis, G., Felekis, S., Paradissis, D., Billiris, H., 1999. New constraints on the rapid crustal motion of the Aegean region: Recent results inferred from GPS measurements (1993-1998) across the West Hellenic Arc, Greece. Earth and Planetary Science Letters 172, 39-47.

Cocco, M., Rice, J.R., 2002. Pore pressure and poroelasticity effects in Coulomb stress analysis of earthquake interactions. Journal of Geophysical Research 107 (B2), 2030.

Cohen, K.M., Stouthamer, E., Berendsen, H.J.A., 2002. Fluvial deposits as a record for late Quaternary neotectonic activity in the Rhine-Meuse Delta, the Netherlands. Netherlands Journal of Geosciences, Geologie en Mijnbouw 81 (3-4), 389-405.

CSN, 1998. Proyecto SIGMA: Análisis del estado de esfuerzos tectónicos reciente y actual en la Península Ibérica. Consejo de Seguridad Nuclear. Colección Otros Documentos, Madrid, Spain, p. 239.

D'Agostino, N., Selvaggi, G., 2004. Crustal motion along the EurasiaNubia plate boundary in the Calabrian Arc and Sicily and active extension in the Messina Straits from GPS measurements. Journal of Geophysical Research 109, B11402. doi:10.1029/2004JB002998.

Dam, G., Larsen, M., Sørensen, J.C., 1998. Sedimentary response to mantle plumes: implications from Paleocene onshore successions, West and East Greenland. Geology 26, 207-210.

Davaille, A., Lees, J.M., 2004. Thermal Modeling of Subducted Plates: tear and hot spot at the Kamchatka corner. Earth and Planetary Science Letters 226, 293-304.

De Boorder, H., Spakman, W., White, S.H., Wortel, M.J.R., 1998. Late Cenozoic mineralization, orogenic collapse and slab detachment in the European Alpine Belt. Earth and Planetary Science Letters 164, 569-575.

De Bruijne, C.H., Andriessen, P.A.M., 2000. Interplay of intraplate tectonics and surface processes in the Sierra de Guadarrama (central Spain) assessed by apatite fission track analysis, erosion and tectonic movements; from measurements to physical modelling. Physics and Chemistry of the Earth 25, 555-563.

De Bruijne, C.H., Andriessen, P.A.M., 2002. Far field effects of Alpine plate tectonism in the Iberian Microplate recorded by fault-related denudation in the Spanish Central System. In: Kohn, B.P., Green, P.F. (Eds.), Low temperature thermochronology; from tectonics to landscape evolution. Tectonophysics, vol. 349, pp. 161-184.

De Vicente, G., Giner, J.L., Muñoz-Martín, A., González-Casado, J.M., Lindo, R., 1996. Determination of present-day stress tensor and neotectonic interval in the Spanish Central System and Madrid Basin, central Spain. Tectonophysics 266, 405-424. 
De Vicente, G., Vegas, R., Guimera, J., Cloetingh, S., 2004. Estructura Alpina del Antepaís Ibérico. In: Vera, J.A. (Ed.), Geología de España, vol. 7. SGE-IGME, Madrid, pp. 619-625.

De Vicente, G., Olaiz, A., Muñoz-Martin, A., Vegas, R., Cloetingh, S., Galindo, J., Rueda, J., Álvarez, J., 2006. Active stress field from Iberia to Algeria. Inversion of moment tensor focal mechanisms, $5^{\circ}$ Asamblea Hispano-Portuguesa de Geodesia y Geofisica. Sevilla, Spain.

De Vicente, G., Vegas, R., Muñoz-Martin, A., Silva, P.G., Andriessen, P., Cloetingh, S., González Casado, J.M., Van Wees, J.D, Álvarez, J., Carbó, A., Olaiz, A., 2007. Cenozoic thick-skinned deformation and topography evolution of the Spanish Central System. Global and Planetary Change 58, 335-381.

Deichmann, N., Ballarin Dolfin, D., Kastrup, U., 2000. Seismizität der Nord-und Zentralschweiz. NAGRA Technischer Bericht, Wettingen. (00-05): 93pp.

DEKORP-BASIN Research Group, 1998. Survey provides seismic insights into an old suture zone. EOS, Transactions, American Geophysical Union 79, 151-159.

Dewey, J.F., Helman, M.L., Knott, S.D., Turco, E., Hutton, D.H.W., 1989. Kinematics of the Western Mediterranean. In: Coward, M.P., Dietrich, D. (Eds.), Alpine Tectonics. Geological Society, London, Special Publications, vol. 45, pp. 265-283.

Dèzes, P., Schmid, S.M., Ziegler, P.A., 2004. Evolution of the European Cenozoic Rift System: interaction of the Alpine and Pyrenean orogens with their foreland lithosphere. Tectonophysics $389,1-33$.

Dèzes, P., Schmid, S.M., Ziegler, P.A., 2005. Reply to comments by L. Michon and O. Merle to "Evolution of the European Cenozoic rift system: interaction of the Alpine and Pyrenean orogens with their foreland lithosphere". Tectonophysics 401, 257-262.

Dinu, C., Wong, H.K., Tambrea, D., Matenco, L., 2005. Stratigraphic and structural characteristics of the Romanian Black Sea shelf. Tectonophysics 410, 417-435.

Dirkzwager, J.B., Van Wees, J.D., Cloetingh, S.A.P.L., Geluk, M.C., Dost, B., Beekman, F., 2000. Geo-mechanical and rheological modelling of upper crustal faults and their near-surface expression in the Netherlands. Global and Planetary Change 27, 67-88.

Dirkzwager, J.B., Pollitz, F.F., Nutto, M., Van der Hoeven, A.G.A., in press. Postseismic relaxation of the lithosphere vs. GPS measurements of Vrancea, Romania. Geophysical Journal International.

Djamour, Y., 2004. Contribution de la Géodésie (GPS et Nivellement) a l'etude de la déformation tectonique et de l'alea sismique sur la région de Téhéran (Montagnes Alborz, Iran). PhD Thesis, université Montpellier II, Montpellier. 180 pp.

Doglioni, C., Innocenti, F., Mariotti, G., 2001. Why Mt Etna? Terra Nova 13, 25-31.

Dotduyev, S.I., 1986. Nappe Structure of the Greater Caucasus Range. Geotectonics 20, 420-430.

Douglas, A., Beavan, J., Wallace, L., Townend, J., 2005. Slow slip on the northern Hikurangi subduction interface, New Zealand. Geophysical Research Letters 32, L16305. doi:10.1029/2005GL023607.

Dvorkin, J., Nur, A., Mavko, G., Ben-Avraham, Z., 1993. Narrow subducting slabs and the origin of backarc basins. Tectonophysics $227,63-79$.

Ebbing, J., Lundin, E., Olesen, O., Hansen, E.K., 2006. The midNorwegian margin: A discussion of crustal lineaments, mafic intrusions, and remnants of the Caledonian root by 3-D density modelling and structural interpretation. Journal of the Geological Society of London 63, 47-60.

Ehlers, T.A., Farley, K.A., 2003. Apatite (U-Th)/He thermochronometry: methods and applications to problems in tectonics and surface processes. Earth and Planetary Science Letters 206, 1-14.
Ehlers, T.A., Armstrong, P.A., Chapman, D.S., 2001. Normal fault thermal regimes and the interpretation of low-temperature thermochronometers. In: Kukkonen, I.T., Cermak, V., Kennett, B. (Eds.), Thermal studies of the Earth's structure and geodynamics. Physics of the Earth and Planetary Interiors, 126, pp. 179-194.

Eidvin, T., Brekke, H., Riis, F., Renshaw, D.K., 1998. Cenozoic stratigraphy of the Norwegian Sea continental shelf, $64^{\circ} \mathrm{N}-68^{\circ} \mathrm{N}$. Norsk Geologisk Tidsskrift 78, 125-151.

El-Havat, A.S., Shelmani, M.A., 1993. Short notes and guidebook on the geology of Al Jabal Al Akhdar. Earth Science Society of Libya, Geolibya, Benghazi. 70 pp.

Elger, K., Oncken, O., Glodny, J., 2005. Plateau-style accumulation of deformation - the Southern Altiplano. Tectonics 24, TC4020. doi:10.1029/2004TC001675.

Erdik, M.., Biro, Y.A., Onur, T., Sastyan, K., Birgoren, G., 1999. Assessment of earthquake hazard in Turkey and neighbouring regions. In: Giardiini, D. (Ed.), The Global Seismic Hazard Assessment Program (GSHAP) 1992-1999. Annali di Geofisica, vol. 42, pp. 1125-1138.

Ershov, A.V., Brunet, M.-F., Korotaev, M.V., Nikishin, A.M., Bolotov, S.N., 1999. Late Cenozoic burial history and dynamics of the Northern Caucasus molasse basin: implications for foreland basin modelling. Tectonophysics 313, 219-241.

Ershov, A.V., Brunet, M.-F., Nikishin, A.M., Bolotov, S.N., Nazarevich, B.P., Korotaev, M.V., 2003. Northern Caucasus basin: thermal history and synthesis of subsidence models. Sedimentary Geology 15, 95-118.

Evans, D., Harrison, Z., Shannon, P.M., Laberg, J.S., Nielsen, T., Ayers, S., Holmes, R., Hoult, R.J., Lindberg, B., Hasflidason, H., Long, D., Kuijpers, A., Andersen, E.S., Bryn, P., 2005. Palaeoslides and other mass failures of Pliocene to Pleistocene age along the Atlantic continental margin of NW Europe. Marine and Petroleum Geology 22, 1131-1148.

Faccenna, C., Becker, T.W., Lucente, F.P., Jolivet, L.F.R., 2001 a. History of subduction and back-arc extension in the Central Mediterranean. Geophysical Journal International 145, 809-820.

Faccenna, C., Funiciello, F., Giardini, D., Lucente, P., 2001b. Episodic Back-arc Extension during Restricted Mantle Convection in the Central Mediterranean. Earth and Planetary Science Letters 187, 105-116.

Faccenna, C., Jolivet, L., Piromallo, C., Morelli, A., 2003. Subduction and the depth of convection in the Mediterranean mantle. Journal of Geophysical Research 108, 2099. doi:10.1029/2001JB001690.

Faccenna, C., Piromallo, C., Crespo-Blanc, A., Jolivet, L., Rossetti, F., 2004. Lateral slab deformation and the origin of the western Mediterranean arcs. Tectonics 23. doi:10.1029/2002TC001488.

Faccenna, C., Civetta, L., D’Antonio, M., Funiciello, F., Margheriti, L., Piromallo, C., 2005. Constraints on mantle circulation around deforming Calabrian slab. Geophysical Research Letters 32, L06311. doi:10.1029/2004GL021874.

Faccenna, C., Bellier, O., Martinod, J., Piromallo, C., Regard, V., 2006. Slab detachment beneath eastern Anatolia: A possible cause for the formation of the North Anatolian fault. Earth and Planetary Science Letters 242, 85-97.

Fernandes, R., Ambrosius, B.A.C., Bastos, L., Noomen, R., Osorio, J., Hein, G., 2000. Crustal motions of the Azores-Gibraltar region from eight years of GPS observations. European Geophysical Society, 25th general assembly. Geophysical Research Abstracts, vol. 2. SE6.05.

Fernandez, R.M.S., Ambrosius, B.A.C., Noomen, R., Bastos, L., Wortel, M.J.R., Spakman, W., Govers, R., 2003. The relative motion between Africa and Eurasia as derived from ITRF2000 
and GPS data. Geophysical Research Letters 30 (16), 1828. doi:10.1029/2003GL017089.

Fischer, K.D., Jahr, T., Jentzsch, G., 2004. Evolution of the Variscan foreland-basin: modelling the interactions between tectonics and surface processes. Physics and Chemistry of the Earth 29, $665-671$.

Fitzgerald, P.G., Munoz, J.A., Coney, P.J., Baldwin, S.L., 1999. Asymmetric exhumation across the Pyrenean Orogen; implications for the tectonic evolution of a collisional orogen. Earth and Planetary Science Letters 173, 157-170.

Flecker, R., Ellam, R.M., 1999. Distinguishing climatic and tectonic signals in the sedimentary successions of marginal basins using $\mathrm{Sr}$ isotopes: an example from the Messinian salinity crisis, Eastern Mediterranean. Journal of the Geological Society of London 156, 847-854.

Fodor, L., Bada, G., Csillag, G., Horvath, E., Ruszkiczay-Rudiger, Z., Palotas, K., Sikhegyi, F., Timar, G., Cloetingh, S., Horvath, F., 2005. An outline of neotectonic structures and morphotectonics of the western and central Pannonian Basin. Tectonophyiscs 410, 15-41.

Foeken, J.P.T., Dunai, T.J., Bertotti, G., Andriessen, P.A.M., 2003. Late Miocene to present exhumation in the Ligurian Alps (Southwest Alps) with evidence for accelerated denudation during the Messinian salinity crisis. Geology 30, 797-800.

Fredin, O., 2002. Glacial inception and Quaternary mountain glaciations in Fennoscandia. Quaternary International 95-96, 99-112.

Friedrich, A.M., Wernicke, B., Niemi, N.A., Bennett, R.A., Davis, J.L., 2003. Comparison of geodetic and geologic data from the Wasatch region, Utah, and implications for the spectral character of Earth deformation at periods of 10 to 10 million years. Journal of Geophysical Research 108 (B4), 2199. doi:10.1029/2001JB000682.

Friedrich, A.M., Lee, J., Wernicke, B.P., Sieh, K., 2004. Geologic context of geodetic data across a Basin and Range normal fault, Crescent Valley, Nevada. Tectonics 23, TC2015. doi:10.1029/ 2003TC001528.

Fronval, T., Jansen, E. (Eds.), 1996. Late Neogene paleoclimates and paleoceanography in the Iceland-Norwegian Sea: evidence from the Iceland and Vøring plateaus, ODP Leg 151 and 104. Proceedings of the Ocean Drilling Program, Scientific results, College Station TX, vol. 151, pp. 455-468.

Fukao, Y., Widiyantoro, S., Obayashi, M., 2001. Stagnant slabs in the upper and lower mantle transition region. Reviews of Geophysics 39, 291-323.

Funiciello, F., Faccenna, C., Giardini, D., 2004. Role of Lateral Mantle Flow in the Evolution of Subduction System: Insights from 3-D Laboratory Experiments. Geophysical Journal International 157, $1393-1406$.

Gabrielsen, R.H., Braathen, A., Olesen, O., Faleide, J.I., Kyrkjebø, R., Redfield, T., 2005. Vertical movements in south-western Fennoscandia, regions and processes: a review from the Present to the Devonian. Norwegian Petroleum Society Special Publication 12, $1-28$.

Galindo-Zaldivar, J., Gonzalez-Lodeiro, F., Jabaloy, A., 1993. Stress and paleostress in the Betic-Rif cordilleras (Miocene to the present). Tectonophysics 227, 105-126.

Gamkrelidze, P.D., Rubinstein, M.M., 1974. Problems of the geology of Adzharo-Trialetia (Problemy geologii Adzharo-Trialetii). Trudy Geologicl̈eskij Institut im. A. L. DzÏanelidze 44, 184.

Gamkrelidze, P.D., Gamkrelidze, I.P., 1977. Tectonic covers of the southern slope of the Great Caucasus (in the limits of Georgia). Tbilisi 57, 80 .

Gamkrelidze, I.P., Beridze, M.A., 1991. Tectonic covers of the southern slope of the Great Caucasus (in the limits of Georgia)
(Tektonicheskie pokrovy yuzhnogo sklona bolshogo Kavkaza). Trudy - Geologicl̈eskij Institut im. A. L. DzÏanelidze 102, 188.

Garcia-Castellanos, D., Cloetingh, S., Van Balen, R., 2000. Modelling the Middle Pleistocene uplift in the Ardennes-Rhenish Massif: thermo-mechanical weakening under the Eifel. Global and Planetary Change 27, 39-52.

Garcia-Castellanos, D., Fernandez, M., Torne, M., 2002. Modeling the evolution of the Guadalquivir foreland basin (Southern Spain). Tectonics 21, 1018. doi:10.1029/2001TC001339.

Garcia-Castellanos, D., Verges, J., Gaspar-Escribano, J., Cloetingh, S., 2003. Interplay between the tectonics, climate, and fluvial transport during the Cenozoic evolution of the Ebro Basin (NE Iberia). Journal of Geophysical Research 108 (B7), 2347. doi:10.1029/2002JB002073.

Gaspar-Escribano, J.M., Ter Voorde, M., Roca, E., Cloetingh, S., 2003. Mechanical (de-) coupling of the lithosphere in the Valencia Trough (NW Mediterranean); what does it mean? Earth and Planetary Science Letters 210, 291-303.

Gattacceca, J., Speranza, F., 2002. Paleomagnetism of Jurassic to Miocene sediments from the Apenninic carbonate platform (southern Apennines, Italy): evidence for a $60^{\circ}$ counterclockwise Miocene rotation. Earth and Planetary Science Letters 201, 19-34.

Geluk, M.C., Duin, E.J.T., Dusar, M., Rijkers, R.H.B., Van den Berg, M.W., Van Rooijen, P., 1994. Stratigraphy and tectonics of the Roer Valley Graben. Geologie en Mijnbouw 73, 129-141.

Georgakopoulos, A.N., Papaconstantinou, C.M., Bapaioannou, C.A., 1995. Natural gas storage in the South Kavala field: geological and seismological characteristics. Petroleum Geosciences 1, 129-133.

Gernigon, L., Lucazeau, F., Brigaud, F., Ringenbach, J.-C., Planke, S., Le Gall, B., 2006. A moderate melting model for the Vøring margin (Norway) based on structural observations and a thermokinematical modelling: Implication for the meaning of the lower crustal bodies. Tectonophysics 412, 255-278.

Giamboni, M., Ustaszewski, K., Schmid, S.M., Schumacher, M., Wetzel, A., 2004. Plio-Pleistocene deformation in the southern Upper Rhine Graben area: geological and geomorphological evidence for on-going transpressive reactivation of Paleozoic and Paleogene faults. International Journal of Earth Sciences 93, 207-223.

Giardini, D., Jimönez, M.J., Grünthal, G., 2003. European—Mediterranean Seismic Hazard Map. Swiss Seismological Service, Zürich.

Gilmour, N., Mäkel, G., 1996. 3-D geometry and kinematics of the N.V. Turkse Shell thrustbelt oil fields, Southern Turkey. In: Ziegler, P.A., Horvàth, F. (Eds.), Structure and Prospects of Alpine Basins and Forelands, vol. 170. Musée National d'Histoire Naturelle, Paris, pp. 524-547.

Giunchi, C., Sabadini, R., Boschi, E., Gasperini, P., 1996. Dynamic models of subduction: geophysical and geological evidence in the Tyrrhenian Sea. Geophysical Journal International 126, 555-578.

Goes, S., Spakman, W., Bijwaard, H., 1999. A lower mantle source for central European volcanism. Science 286, 1928-1931.

Goes, S., Govers, R., Vacher, P., 2000a. Shallow mantle temperatures under Europe from $\mathrm{P}$ and $\mathrm{S}$ wave tomography. Journal of Geophysical Research 105 (11), 153-169.

Goes, S., Loohuis, J.J.P., Wortel, M.J.R., Govers, R., 2000b. The effect of plate stresses and shallow mantle temperatures on the tectonics of northwestern Europe. Global and Planetary Change 27, 23-38.

Gölke, M., Coblentz, D., 1996. Finite-element modelling of stress patterns along the Mid-Norwegian continental margin, $62^{\circ}$ to $68^{\circ} \mathrm{N}$. Tectonophysics $266,11-24$.

Gomez-Ortiz, D., Tejero-Lopez, R., Babin-Vich, R., Rivas-Ponce, A., 2005. Crustal density structure of the Spanish Central System 
derived from gravity data analysis (Central Spain). Tectonophysics 403, 131-149.

Gordon, R.G., Jurdy, D.M., 1986. Cenozoic global plate motions. Journal of Geophysical Research 91, 12 389-12 406.

Görür, N., Cagatay, N., Sakinç, M., Akkök, R., Tchapalyga, A., Natalin, B., 2000. Neogene Paratethyan succession in Turkey and its implications for the palaeogeography of the Eastern Paratethys. In: Bozkurt, E., Winchester, J.A., Piper, J.D.A. (Eds.), Tectonics and Magmatism in Turkey and the Surrounding Area. Geological Society, London, Special Publications, vol. 173, pp. 251-269.

Goula, X., Olivera, C., Fleta, J., Grellet, B., Lindo, R., Rivera, L.A., Cisternas, A., Carbon, D., 1999. Present and recent stress regime in the eastern part of the Pyrenees. Tectonophysics 308, 487-502.

Grad, M., Booth, D.C., Tiita, T., 2006. 2-D and 3-D crustal models of Europe, Geophysical Research Abstracts, vol. 8, 04563.

Granet, M., Wilson, M., Achauer, U., 1995. Imaging mantle plumes beneath the French Massif Central. Earth and Planetary Science Letters 136, 281-296.

Grenerczy, G., Sella, G.F., Stein, S., Kenyeres, A., 2005. Tectonic implications of the GPS velocity field in the northern Adriatic region. Geophysical Research Letters 32, L16311. doi:10.1029/ 2005 GL022947.

Guimerà, J., Más, R., Alonso, A., 2004. Intraplate deformation in the NW Iberian Chain: Mesozoic extension and contractional inversion. Journal of the Geological Society of London 16, 291-303.

Guterch, A., Grad, M., Thybo, H., Keller, R., POLONAISE Working Group, 1999. POLONAISE '97 — An international seismic experiment between Precambrian and Variscan Europe in Poland. Tectonophysics 314, 101-122.

Gvirtzman, Z., Nur, A., 1999. The formation of Mount Etna as the consequence of slab roll-back. Nature 401, 782-785.

Gvirtzman, Z., Nur, A., 2001. Residual topography, lithospheric structure and sunken slabs in the central Mediterranean. Earth and Planetary Science Letters 187, 117-130.

Haimberger, R., Hoppe, A., Schäfer, A., 2005. High-resolution seismic survey on the Rhine River in the northern Upper Rhine Graben. International Journal of Earth Sciences / Geologische Rundschau 94, 657-668.

Hardebol, N., Cloetingh, S., Beekman, F., 2003. Lithospheric strength of large-scale intraplate deformed NW Europe: constraints from interpretations of geophysical and geological datasets. EUCORURGENT Workshop.

Hatzfeld, D., 1999. The present-day tectonics of the Aegean as deduced from seismicity. In: Durand, B., Jolivet, L., Horvàth, F., Séranne, M. (Eds.), The Mediterranean Basins: Tertiary Extension within the Alpine Orogen. Geological Society, London, Special Publications, vol. 156, pp. 415-426.

Heidbach, O., Drewes, H., 2003. 3-D Finite Element model of major tectonic processes in the Eastern Mediterranean. In: Nieuwland, D. (Ed.), New insights in structural interpretation and modelling. Geological Society, London, Special Publications, vol. 212, pp. 259-272.

Hendriks, B.W.H., Andriessen, P.A.M., 2002. Pattern and timing of the post-Caledonian denudation of northern Scandinavia constrained by apatite fission track termochronology. In: Dore, A.G., Tuner, M.S., Stoker, J.A., White, N.J. (Eds.), Exhumation of the North Atlantic Margin: Timing, Mechanisms and Implications for Petroleum Exploration. Geological Society, London, Special Publications, 196, pp. 117-137.

Hendriks, B.W.H., Redfield, T.F., 2005. Apatite fission track and (U-Th)/He data from Scandinavia: An example of underestima- tion of fission track annealing in apatite. Earth and Planetary Science Letters 236, 443-458.

Hendriks, B.W.H., Redfield, T.F., Andriessen, P.A.M., Huigen, Y.D., Murrell, G.R.M., Cederbom, C., 2004. The denudation of Fennoscandia: an Apatite Fission Track Map. In: Abstracts, 26th Nordic Geological Winter Meeting, Uppsala. Geologiska Foreningen, Stockholm, Forhandlingen, 126: 81.

Hergert, T., Heidbach, O., 2006. New insights in the mechanism of postseismic stress relaxation exemplified by the June 23rd 2001 $\mathrm{Mw}=8.4$ earthquake in southern Peru. Geophysical Research Letters 33, L02307. doi:10.1029/2005GL024858.

Heumann, G., Litt, T., 2002. Stratigraphy and paleoecology of the Late Pliocene and Early Pleistocene in the open-cast mine Hambach (Lower Rhine Basin). Netherlands Journal of Geosciences 81, 193-199.

Heuret, A., Lallemand, S., 2005. Plate motions, slab dynamics and back-arc deformation. Physics of the Earth and Planetary Interiors $149,31-51$.

Hobbs, R., Klemperer, S., 1991. The BIRPS Atlas: Deep Seismic Reflection Profiles Around the British Isles. Cambridge University Press, Cambridge.

Hoernle, K., Zang, Y.-S., Graham, D., 1995. Seismic and geochemical evidence for large-scale mantle upwelling beneath the eastern Atlantic and Western and Central Europe. Nature 374, 34-39.

Hollenstein, C., Kahle, H., Geiger, A., Jenny, S., Goes, S., Giardini, D., 2003. New GPS constraints of the Africa-Eurasia plate boundary zone in southern Italy. Geophysical Research Letters 30, 1935. doi: 10.1029/2003GL017554.

Holliger, K., Levander, A., 1994. Seismic structure of gneissic/granitic upper crust; geological and petrophysical evidence from the Strona-Ceneri Zone (northern Italy) and implications for crustal seismic exploration. Geophysical Journal International 119, 497-510.

Horváth, F., Cloetingh, S.A.P.L., 1996. Stress-induced late stage subsidence anomalies in the Pannonian basin. Tectonophysics 266 , 287-300.

Huigen, Y., Andriessen, P., 2004. Thermal effects of Caledonian foreland formation, based on fission track analyses applied on basement rocks in central Sweden. Physics and Chemistry of the Earth 29, 683-694.

Iaffaldano, G., Bunge, H.P., Dixon, T.H., 2006. Feedback between mountain belt growth and plate convergence. Geology 34, 893-896.

ILIHA DSS Group, 1993. A deep seismic sounding investigation of lithospheric heterogeneity and anisotropy beneath the Iberian Peninsula. Tectonophysics 221, 35-51.

Illies, J.H., 1975. Recent and paleo-intraplate tectonics in stable Europe and the Rhinegraben system. Tectonophysics 29, 251-264.

Isacks, B.L., 1988. Uplift of the Central Andean Plateau and bending of the Bolivian Orocline. Journal of Geophysical Research 93 (B4), 3211-3231.

Jabaloy, A., Galindo-Zaldívar, J., González-Lodeiro, F., 2002. Palaeostress evolution of the Iberian Peninsula (Late Carboniferous to present-day). Tectonophysics 357, 159-186.

Japsen, P., 1998. Regional velocity-depth anomalies, North Sea Chalk: a record of overpressure and Neogene uplift and erosion. AAPG Bulletin 82, 2031-2074.

Japsen, P., 2000. Investigation of multi-phase erosion using reconstructed shale trends based on sonic data. Sole Pit axis, North Sea. Global and Planetary Change 24, 189-210.

Japsen, P., Bidstrup, T., 1999. Quantification of late Cenozoic erosion in Denmark based on sonic and vitrinite data. Bulletin of the Geological Society of Denmark 46, 79-99. 
Japsen, P., Green, P.F., Chalmers, J.A., 2005. Separation of Palaeogene and Neogene uplift on Nuussuaq, West Greenland. Journal of the Geological Society of London 162, 299-314.

Japsen, P., Bonow, J.M., Green, P.F., Chalmers, J.A., Lidmar-Bergström, K., 2006. Elevated, passive continental margins: Long-term highs or Neogene uplifts. New evidence from West Greenland. Earth and Planetary Science Letters 248, 330-339.

Jarosinski, M., 1994. Stress field measurements of the earth's crust of Poland from borehole break-out data. Prace Geologiczne 142, 996-1003.

Jiménez-Munt, I., Sabadini, R., Gardi, A., Bianco, G., 2003. Active deformation of the Mediterranean from Gibraltar to Anatolia inferred from numerical modeling and geodetic and seismological data. Journal of Geophysical Research 108 (B1), 2006. doi:10.1029/2001JB001544.

Jiménez, M.-J., Garcia-Fernandez, M., GESHAP Ibero-Maghrebian Working Group, 1999. Seismic hazard assessment in the IberoMaghrebian region. Annali di Geofisica 42, 1057-1065.

Jiménez, M.-J., Giardini, D., Grünthal, G., 2003. The ESC-SESAME Unified Hazard Model for the European-Mediterranean region. csem-emsc Newsletter 19, 2-4 (April 2003).

Jolivet, L., Patriat, M., 1999. Ductile extension and the formation of the Aegean Sea. In: Durand, B., Jolivet, L., Horvàth, F., Séranne, M. (Eds.), The Mediterranean Basins: Tertiary Extension within the Alpine Orogen. Geological Society, London, Special Publications, vol. 156 , pp. $427-456$.

Jouanne, F., Ménard, G., Darmendrail, X., 1995. Present-day vertical displacements in the north-western Alps and southern Jura: data from levelling comparisons. Tectonics 14, 606-616.

Juez-Larré, J., Andriessen, P.A.M., 2006. Tectonothermal evolution of the northeastern margin of Iberia since the break-up of Pangea to present, revealed by low-temperature fission-track and (U-Th)/He thermochronology: A case history of the Catalan Coastal Ranges. Earth and Planetary Science Letters 243, 159-180.

Jurado, M.J., Müller, B., 1997. Contemporary tectonic stress in northeastern Iberia: New results from borehole breakout analysis. Tectonophysics 282, 99-115.

Khain, V.E., 1975. Structure and main stages in the tectono-magmatic development of the Caucasus: an attempt at geodynamic interpretation. American Journal of Science 275, 131-156.

Khain, V.E. (Ed.), 1997. Zaerbaijan-Greater Caucasus. Encyclopedia of European and Asian regional geology. Chapman and Hall, London, pp. 60-63.

Kincaid, C., Griffiths, R., 2003. Laboratory models of the thermal evolution of the mantle during roll-back subduction. Nature 425, 58-62.

Kind, R., Yuan, X., Nelson, D., Sobolev, S.V., Mechie, J., Zhao, W., Kosarev, G., Ni, J., Achauer, U., Jiang, M., 2002. Seismic images of crust and upper mantle beneath Tibet: Evidence for Eurasian plate subduction. Science 298, 1219-1221.

King, G.C.P., Stein, R.S., Lin, J., 1994. Static Stress Changes and the Triggering of Earthquakes. Bulletin of the Seismological Society of America 84, 935-953.

King, G., Friedrich, A.M., Bowman, D., Gaudemer, Y., Armijo, R., 2004. Speculations on the evolution of the Eastern California Shear Zone, Western United States. Plate Boundary Observatory Workshop, LakeTaho, June 2004.

Klett, M., Eichhorst, F., Schäfer, A., 2002. Facies interpretation from well logs applied to the Tertiary Lower Rhine basin fill. Netherlands Journal of Geosciences 81, 167-176.

Kooi, H., 2000. Land subsidence due to compaction in the coastal area of The Netherlands: the role of lateral fluid flow and constraints from well-log data. Global and Planetary Change 27, 207-222.
Kopp, M.L., 2005. Mobilistic tectonics of the East European Platform. Nauka, Moscow. 338 pp.

Kopp, M.L., Shcherba, I.G., 1985. Late Alpine development of the East great Caucasus. Geotectonics 19, 497-507.

Kral, J., Gurbanov, A.G., 1996. Apatite fission track data from the Great Caucasus pre-alpine basement. Chemie der Erde 56, 177-192.

Krijgsman, W., Blanc-Valeron, M.M., Flecker, R., Hilgen, F.J., Kouwenhoven, T.J., Merle, D., Orszag-Sperber, F., Rouchy, J.M., 2002. The onset of the Messinian Salinity Crisis in the Eastern Mediterranean (Pissouri Basin, Cyprus). Earth and Planetary Science Letters 194, 299-310.

Kukkonen, I.T., Joeleht, A., 2003. Weichselian temperatures from geothermal heat flow data. Journal of Geophysical Research 108 (B3), 2163.

Lamb, S., Davis, P., 2003. Cenozoic climate change as a possible cause for the rise of the Andes. Nature 425, 792-797.

Lankreijer, A.C., Bielik, M., Cloetingh, S., Majcin, D., 1999. Rheology predictions across the Western Carpathians, Bohemian massif and the Pannonian basin: Implications for tectonic scenarios. Tectonics 18, 1139-1153. doi:10.1029/1999TC900023.

Le Pichon, X., Angelier, J., 1979. The Hellenic arc and trench system: a key to the neotectonic evolution of the eastern Mediterranean area. Tectonophysics $60,1-42$.

Le Pichon, X., Chamot-Rooke, N., Lallemant, S., Noomen, R., Veis, G., 1995. Geodetic determination of the kinematics of central Greece with respect to Europe: Implications for eastern Mediterranean tectonics. Journal of Geophysical Research 100, 12675-12690.

Lenk, O., Türkezer, A., Ergintav, S., Kurt, A.I., Belgen, A., 2003. Monitoring the Kinematics of Anatolia Using Permanent GPS Network Stations. Turkish Journal of Earth Sciences 12, 55-65.

Lenôtre, N., Thierry, P., Blanchin, R., Brochard, G., 1999. Current vertical movements demonstrated by comparative levelling in Brittny (northwestern France). Tectonophysics 301, 333-344.

Leydecker, G., 2003. Earthquake Catalogue for the Federal Republic of Germany and Adjacent Areas for the Years 800-2002. Federal Institute for Geosciences and Natural Resources, Germany.

Lidmar-Bergstrom, K., Naslund, J.O., 2002. Landforms and uplift in Scandinavia. In: Dore, A.G., Cartwright, J.A., Stoker, M.S., Turner, J.P., White, N. (Eds.), Exhumation of the North Atlantic Margin: Timing, Mechanisms and Implications for Petroleum Exploration. Geological Society, London, Special Publications, vol. 196 , pp. 27-45.

Lindner, L., Bogutsky, A., Gozhik, P., Marks, L., Lanczont, M., Wojtanowicz, J., 2006. Correlation of Pleistocene deposits in the area between the Baltic and Black Sea, Central Europe. Geological Quarterly 50, 195-210.

Lippolt, H.J., 1983. Distribution of volcanic activity in space and time. In: Fuchs, K., Von Gehlen, K., Mälzer, M., Murawski, H., Semmel, A. (Eds.), Plateau Uplift, The Rhenish Shield - a case history. Springer-Verlag, Berlin, pp. 112-120.

Lips, A.L.W., Wijbrans, J.B., White, S.H., 1999. New insight from 40Ar/39Ar laserprobe dating of white mica fabrics from the Pelion Massif, Pelagonian Zone, Internal Hellenides, Greece: implications for timing of metamorphic episodes and tectonic events in the Aegean region. In: Durand, B., Jolivet, L., Horvàth, F., Séranne, M. (Eds.), The Mediterranean Basins: Tertiary Extension within the Alpine Orogen. Geological Society, London, Special Publications, vol. 156, pp. 457-474.

Lithgow-Bertelloni, C., Richards, M.A., 1998. The dynamics of Cenozoic and Mesozoic plate motions. Reviews of Geophysics 36, 27-78. 
Lonergan, L., White, N., 1997. Origin of the Betic-Rif mountain belt. Tectonics 16, 504-522.

Lopes Cardozo, G.G.O., Granet, M., 2003. New insight in the tectonics of the Southern Rhine Graben using local earthquake seismology. Tectonics 22, 1078. doi:10.1029/2002TC001442.

Lopes Cardozo, G.G.O., Granet, M., 2005. A multi-scale approach to study the lithospheric structure of the Upper Rhine Graben: from seismic tomography through reflection seismics to surface geology. International Journal of Earth Sciences 94, 615-620.

Lopes Cardozo, G.G.O., Edel, J.B., Granet, M., 2005. Detection of active crustal structures in the Upper Rhine Graben using local earthquake tomography, gravimetry and reflection seismics. Quaternary Science Reviews 24, 337-344.

Lybéris, N., 1984. Tectonic evolution of the North Aegean trough. In: Dixon, J.E., Robertson, A.H.F. (Eds.), The geological evolution of the eastern Mediterranean. Geological Society, London, Special Publications, 17, pp. 709-725.

Makris, J., Yegorova, T., 2006. A 3-D density-velocity model between the Cretan Sea and Libya. Tectonophysics 417, 201-220.

Malinverno, A., Ryan, W., 1986. Extension in the Tyrrhenian sea and shortening in the Apennines as result of arc migration driven by sinking of the lithosphere. Tectonics 5, 227-245.

Malkovsky, M., 1975. Paleogeography of the Miocene of the Bohemian Massif. VestnikUstredniho ustavu geologickeho 50, 27-31.

Malkovsky, M., 1979. Tektogeneze Platformního Pokryvu Ceskéo Masívu. Yvdal Ustredníustav geologicky, Praha. 176 pp.

Malkovsky, M., 1987. The Mesozoic and Tertiary basins of the Bohemian Massif and their evolution. Tectonophysics 137, 31-42.

Mälzer, H., Hein, G., Zippelt, K., 1983. Height changes in the Rhenish Massif: determination and analysis. In: Fuchs, K., Von Gehlen, K., Mälzer, M., Murawski, H., Semmel, A. (Eds.), Plateau Uplift, The Rhenish Shield - a case history. Springer-Verlag, Berlin, pp. 165-176.

Mangerud, J., Jansen, E., Landvik, J.Y., 1996. Late Cenozoic history of the Scandinavian and Barents sea ice sheets. Global and Planetary Change 12, 11-26.

Marani, M.P., Trua, T., 2002. Thermal constriction and slab tearing at the origin of a superinflated spreading ridge: Marsili volcano (Tyrrhenian Sea). Journal of Geophysical Research 107, 2188. doi:10.1029/2001JB000285.

Mart, Y., Ryan, W.B.F., Vachtman, D., 2004. Fluvial erosion in the bathial SE Mediterranean during the Messinian dessication, vol. 30. University of Haifa.

Mart, Y., Ryan, W.B.F., Lunina, O.V., 2005. Review of the tectonics of the Levant Rift system: the structural significance of oblique continental breakup. Tectonophysics 395, 209-232.

Martin, M., Wenzel, F., CALIXTO Working Group, 2006. High-resolution teleseismic body wave tomography beneath SE-Romania - II. Imaging of a slab detachment scenario. Geophysical Journal International 164, 579-595.

Matenco, L., Bertotti, G., 2000. Tertiary tectonic evolution of the external East Carpathians (Romania). Tectonophysics 316, 255-286.

Matenco, L., Bertotti, G., Cloetingh, S., Dinu, C., 2003. Subsidence analysis and tectonic evolution of the external CarpathianMoesian platform region during Tertiary times. Sedimentary Geology 156, 71-94.

Matenco, L., Bertotti, G., Leever, K., Cloetingh, S., Schmid, S.M., Tărăpoancă, M., Dinu, C., in press. Large scale deformation in a locked collisional boundary: interplay between subsidence and uplift, intraplate stress and inherited lithospheric structure in the late stage of the SE Carpathians evolution. Tectonics.
Mattei, M., Petrocelli, V., Lacava, D., Schiattarella, M., 2004 Geodynamic implications of Pleistocene ultrarapid vertical-axis rotations in the Southern Apennines, Italy. Geology 32, 789-792.

Maystrenko, Y., Stovba, S., Stephenson, R., Bayer, U., Menyoli, E., Gajewski, D., Huebscher, C., Rabbel, W., Saintot, A., Starostenko, V., Thybo, H., Tolkunov, A., 2003. Crustal-scale pop-up structure in cratonic lithosphere: DOBRE deep seismic reflection study of the Donbas Foldbelt, Ukraine. Geology 31, 733-736.

Mazzoli, S., Helman, M.L., 1994. Neogene patterns of relative plate motion for Africa-Europe: some implications for recent central Mediterranean tectonics. International Journal of Earth Sciences 83, 464-468.

McClusky, S., Balassanian, S., Barka, A., Demir, C., Ergintav, S., Georgiev, I., Gurkan, O., Hamburger, M., Hurst, K., Kahle, H., Kastens, K., Kekelidze, G., King, R., Kotzev, V., Lenk, O., Mahmoud, S., Mishin, A., Nadariya, M., Ouzounis, A., Paradissis, D., Peter, Y., Prilepin, M., Reilinger, R., Sanli, I., Seeger, H., Tealab, A., Toksöz, M.N., Veis, G., 2000. Global Positioning System constraints on plate kinematics and dynamics in the eastern Mediterranean and Caucasus. Journal of Geophysical Research 105, 5695-5719.

McKenzie, D., Yilmaz, Y., 1991. Deformation and volcanism in western Turkey and the Aegean. Bulletin of the Istanbul Technical University $345-373$.

Melbourne, T.I., Webb, F.H., Stock, J.M., Reigber, C., 2002. Rapid postseismic transients in subduction zones from continuous GPS. Journal of Geophysical Research 107 (B10), 2241. doi:10.1029/ 2001JB000555.

Merten, S., Andriessen, P.A.M., Juez-Larré, J., Bertotti, G., Dunai, T.J., 2005. Dating the exhumation of the Romanian Carpathians: Firs results from apatite (U-Th)/He thermochronology. Geophysical Research Abstracts 7, 08138.

Meyer, W., Stets, J., 1998. Junge Tektonik im Rheinischen Schiefergebirge und ihre Quantifizierung. Zeitschrift der Deutschen Gesellschaft für Geowissenschaften 149, 359-379.

Meyer, W., Stets, J., 2002. Pleistocene to Recent tectonics in the Rhenish Massif (Germany). Netherlands Journal of Geosciences 81, 217-221.

Michon, L., van Balen, R.T., Merle, O., Pagnier, H., 2003. The Cenozoic evolution of the Roer Valley rift system integrated at a European scale. Tectonophysics 367, 101-126.

Mihalffy, P., Steinberger, B., Schmeling, H., in press. The effect of the large-scale mantle flow field on the Iceland hotspot track. Tectonophysics.

Mikhailov, V.O., Panina, L.V., Polino, R., Koronovsky, N.V., Kiseleva, E.A., Klavdieva, N.V., Smolyaninova, E.I., 1999. Evolution of the North Caucasus foredeep: Constraints based on the analysis of subsidence curves. Tectonophysics 307, 361-379.

Moisio, K., Kaikkonen, P., Beekman, F., 2000. Rheological structure and dynamical response of the DSS profile BALTIC in the SE Fennoscandian shield. Tectonophysics 320, 175-194.

MONA LISA Working Group, 1997. Deep seismic investigations of the lithosphere in the southeastern North Sea. Tectonophysics $269,1-19$

Montelli, R., Nolet, G., Dahlen, F.A., Masters, G., Engdahl, E.R., Hung, S.H., 2004. Finite-frequency tomography reveals a variety of plumes in the mantle. Science 303, 338-343.

Mosar, J., 2003. Scandinavias North Atlantic Passive margin. Journal of Geophysical Research 108 (B8), 2360.

Mueller, R.D., Gaina, C., Sdrolias, M., Heine, C., 2005. Reconstructing vanished ocean basins. Geophysical Research Abstracts 7, 06223 . 
Müller, B., Wehrle, V., Zeyen, H., Fuchs, K., 1997. Short-scale variations of tectonic regimes in the western European stress province north of the Alps and Pyrenees. Tectonophysics 275, 199-219.

Müller, W.H., Naef, H., Graf, H.R., 2002. Geologische Entwicklung der Nordwestschweiz, Neotektonik und Langzeitszenarien Zürcher Weinland. NAGRA Technischer Bericht, Wettingen 99, 237.

Munoz, J.A., 1992. Evolution of a continental collision belt: ECORSPyrenees crustal balanced cross-section. In: McClay, K. (Ed.), Thrust Tectonics. Chapman \& Hall, London, pp. 235-246.

Murrell, G.R., Andriessen, P.A.M., 2004. Unravelling a long-term multi-event thermal record in the cratonic interior of southern Finland through apatite fission track thermochronology. Physics and Chemistry of the Earth 29, 695-706.

Necea, D., Fielitz, W., Matenco, L., 2005. Late Pliocene-Quaternary tectonics in the frontal part of the SE Carpathians: Insights from tectonic geomorphology. Tectonophysics, 410, 111-137.

Newman, A.V., Stein, S., Weber, J.C., Engeln, J.F., Mao, A., Dixon, T.H., 1999. Slow Deformation and Implied Long Earthquake Recurrence Intervals From GPS Surveys Across the New Madrid Seismic Zone. Science 284, 619-621.

Nielsen, L., Thybo, H., Egorkin, A.V., 2002. Implications of seismic scattering below the 8 degrees discontinuity along PNE profile Kraton. Tectonophysics 358, 135-150.

Nikishin, A.M., Ziegler, P.A., Panov, D.I., Nazarevich, P.B., Brunet, M.-F., Stephenson, R.A., Bolotov, S.N., Kootaev, M.V., Tikhomirov, P.L., 2001. Mesozoic and Cainozoic evolution of the Scythian Platform-Black Sea-Caucasus domain. In: Ziegler, P.A., Cavazza, W., Robertson, A.H.F., Crasquin-Soleau, S. (Eds.), PeriTethys Memoir 6: Peri-Tethyan Rift/Wrench Basins and Passive Margins, vol. 186, pp. 295-346.

Nikishin, A.M., Korotaev, M.V., Ershov, A.V., Brunet, M.-F., 2003. The Black Sea basin: tectonic history and Neogene-Quaternary rapid subsidence modelling. Sedimentary Geology 156, 149-168.

Nilforoushan, F., Vernant, P., Masson, F., Vigny, C., Martinod, J., Abbassi, M., Nankali, H., Hatzfeld, D., Bayer, R., Tavakoli, F., Ashtiani, A., Doerflinger, E., Daignières, M., Collard, P., Chéry, J., 2003. GPS network monitors the Arabia-Eurasia collision deformation in Iran. Journal of Geodesy 77, 411-422.

O’Connel, S., Cremer, M., Stein, R., Wolf-Welling, T.C.W., 1996. Neogene paleoceanography and paleoclimate history from Fram Strait: changes in accumulation rates (ODP Leg 151). In: Thiede, J., Myhre, A.M., Firth, J. (Eds.), Proceedings of the Ocean Drilling Program, Scientific results, College Station, TX, vol. 151, pp. $569-582$.

Okay, A.I., Tüysüz, O., 1999. Tetyan sutures of Turkey. In: Durand, B., Jolivet, L., Horvàth, F., Séranne, M. (Eds.), The Mediterranean Basins: Tertiary Extension within the Alpine Orogen. Geological Society, London, Special Publications, vol. 156, pp. 475-515.

Oncescu, M.C., Trifu, C.I., 1987. Depth variation of moment tensor principal axes in Vrancea Romania seismic region. Annales Geophysicae 5, 149-154.

Oncescu, M.C., Bonjer, K.-P., 1997. A note on the depth recurrence and strain release of large Vrancea earthquakes. Tectonophysics 27, 291-302.

Oncken, O., Hindle, D., Kley, J., Elger, K., Victor, P., Schemmann, K., 2006. Deformation of the Central Andean Upper Plate System Facts, Fiction, and Constraints for Plateau Models. In: Oncken, O., Chong, G., Franz, G., Giese, P., Götze, H.-J., Ramos, V., Strecker, M., Wigger, P. (Eds.), The Andes - Active Subduction Orogeny. Springer, pp. 3-27.

Pamic, J., Balen, D., Herak, M., 2002. Origin and geodynamic evolution of Late Paleogene magmatic associations along the
Periadriatic-Sava-Vardar magmatic belt. Geodynamica Acta 15, 209-231.

Panien, M., Buiter, S.J.H., Schreurs, G., Pfiffner, O.A., 2006. Inversion of a symmetric basin: insights from a comparison between analogue and numerical experiments. In: Buiter, S.J.H., Schreurs, G. (Eds.), Analogue and numerical modelling of crustal-scale processes. Geological Society, London, Special Publications, vol. 253, pp. 253-270.

Panin, N., 2003. The Danube Delta. Geomorphology and Holocene Evolution: a Synthesis. Géomorphologie: Relief, Processus, Environnement 4, 247-262.

Papanikolaou, D., Barghati, H., Dabovski, C., Dimitriu, R., El-awat, A., D., I., Kranis, H., Obeidi, A., Oaie, C., Seghedi, A., Zogorchev, I., 2004. Transect VII: East European Craton-Scythian PlatformDobrogea-Balkanides-Rhodope Massif-Hellenides-East Mediterranean-Cyrenaica. In: Cavazza, W., Roure, F., Spakman, W., Stampfli, G.M. and Ziegler, P.A. (Eds.), The TRANSMED Atlas The Mediterranean Region from Crust to Mantle. Springer, Berlin Heidelberg, CD-ROM.

Pascal, C., 2006. On the role of heat flow, lithosphere thickness and lithosphere density on gravitational potential stresses. Tectonophysics 425, 83-99.

Patacca, E., Sartori, R., Scandone, P., 1990. Tyrrhenian basin and Apenninic arcs: Kinematic relations since late Tortonian times. Memoire della Societa Geologica Italia 45, 425-451.

Patzwahl, R., Mechie, J., Schulze, A., Giese, P., 1999. Twodimensional velocity models of the Nazca plate subduction zone between $19.5 \mathrm{~S}$ and $25 \mathrm{~S}$ from wide angle seismic measurements during the CINCA95 project. Journal of Geophysical Research 104, 7293-7317.

Peltzer, G., Crampé, F., Hensley, S., Rosen, P., 2001. Transient strain accumulation and fault interaction in the Eastern California shear zone. Geology 29, 975-978.

Persson, K.S., Garcia-Castellanos, D., Sokoutis, D., 2004. River transport effects on compressional belts; first results from an integrated analogue-numerical model. Journal of Geophysical Research 109, B01409. doi:10.1029/2002JB002274.

Peters, G., Van Balen, R.T., 2007a. Pleistocene tectonics inferred from fluvial terraces of the northern Upper Rhine Graben, Germany. Tectonophysics 430, 41-65.

Peters, G., Van Balen, R.T., 2007b. Tectonic Geomorphology of the northern Upper Rhine Graben, Germany. Global and Planetary Change 58, 309-333.

Peters, G., Buchmann, T., Connolly, P., Van Balen, R.T., Wenzel, F., Cloetingh, S.A.P.L., 2005. Interplay between tectonic, fluvial and erosional processes along the Western Border Fault of the northern Upper Rhine Graben, Germany. Tectonophysics 406, 39-66.

Philip, H., Cisternas, A., Gvishiani, A., Gorshkov, A., 1989. The Caucasus: an actual example of the initial stages of continental collision. Tectonophysics 161, 1-21.

Piasecki, S., Larsen, L.M., Pedersen, A.K., Pedersen, G.K., 1992. Palynostratigraphy of the Lower Tertiary volcanics and marine clastic sediments in the southern part of the West Greenland Basin: implications for the timing and duration of the volcanism. Rapport Grønlands Geologiske Undersøgelse 154, 13-31.

Piromallo, C., Morelli, A., 1997. Imaging the Mediterranean upper mantle by P-wave travel time tomography. Annales Geofisica 40, 963-979.

Piromallo, C., Morelli, A., 2003. P wave tomography of the mantle under the Alpine-Mediterranean area. Journal of Geophysical Research 108 (B2), 2065. doi:10.1029/2002JB001757. 
Plenefisch, T., Bonjer, K.-P., 1997. The stress field in the Rhine Graben area inferred from earthquake focal mechanisms and estimations of frictional parameters. Tectonophysics 275, 71-97.

Polino, R., Stephenson, R., CAUCASUS colleagues, 1996. CAUCASUS: Geodynamics of collision-related basins. In: Gee, D., Zeyen, H. (Eds.), EUROPROBE 1996: Lithosphere Dynamics: Origin and Evolution of Continents EUROPROBE Secretariat. Uppsala University, Uppsala, Sweden, pp. 110-115.

Pollitz, F.F., 1997. Gravitational viscoelastic postseismic relaxation on a layered spherical Earth. Journal of Geophysical Research 102, 17921-17941.

Pollitz, F.F., 2003. Post-seismic relaxation theory on laterally heterogeneous viscoelastic model. Geophysical Journal International $155,57-78$.

Popescu, I., Lericolais, G., Panin, N., Wong, H.K., Droz, L., 2001. Late Quaternary channel avulsions on the Danube deep sea fanm, Black Sea. Marine Geology 179, 25-37.

Popov, S.V., Rögl, F.R., Rozanov, A.Y., Steininger, F.F., Shcherba, I.G., Kovac, M., 2004. Lithological-Paleogeographic maps of Paratethys. 10 maps Late Eocene to Pliocene. Courier Forschungsinstitut Senckenberg 250, 46.

Poprawa, P., Šliaupa, S., Stephenson, R.A., Lazauskiene, J., 1999. Late Vendian-Early Palaeozoic tectonic evolution of the Baltic basin: regional implications from subsidence analysis. Tectonophysics $314,219-239$.

Porter, S.C., 1989. Some geological implications of average glacial conditions. Quaternary Research 32, 245-261.

Priestley, K., Baker, C., Jackson, J., 1994. Implications of earthquake focal mechanism data for the active tectonics of the south Caspian Basin and surrounding regions. Geophysical Journal International $118,111-141$.

Rădoane, M., Rădoane, N., Dumitriu, D., 2003. Geomorphological evolution of longitudinal river profiles in the Carpathians. Geomorphology 50, 293-306.

Redfield, T.F., Torsvik, T.H., Andriessen, P.A.M., Gabrielsen, R.H., 2004. Mesozoic and Cenozoic tectonics of the Møre-Trøndelag Fault Complex, central Norway: constraints from new apatite fission track data. Physics and Chemistry of the Earth 29, 673-682.

Redfield, T.F., Osmundsen, P.T., Hendriks, B.W.H., 2005. The role of fault reactivation and growth in the uplift of western Fennoscandia. Journal of the Geological Society of London 162, 1013-1030.

Reiners, P.W., Ehlers, T.A. (Eds.), 2005. Low-temperature thermochronolog: Techniques, Interpretations, and Applications. Reviews in Mineralogy \& Geochemistry, vol. 58, p. 662.

Ribeiro, A., Baptista, R., Cabral, J., Matias, L., 1996. Tectonic stress patterns in Portugal Mainland and the adjacent Atlantic region (west Iberia). Tectonics 15, 641-659.

Riis, F., 1996. Quantification of Cenozoic vertical movements of Scandinavia by correlation of morphological surfaces with offshore data. Global and Planetary Change 12, 331-357.

Rise, E., Ottesen, D., Berg, K., Lundin, E., 2005. Large-scale development of the Mid-Norwegian margin during the last 3 million years. Marine and Petroleum Geology 22, 33-44.

Ritsema, J., Van Heijst, H.J., 2000. Seismic imaging of structural heterogeneity in Earth's mantle: Evidence for large-scale mantle flow. Science Progress 83, 243-259.

Ritter, J.R.R., Jordan, M., Christensen, U.R., Achauer, U., 2001. A mantle plume below the Eifel volcanic fields, Germany. Earth and Planetary Science Letters 186, 7-14.

Roberts, G.P., Ganas, A., 2000. Fault-slip directions in central and southern Greece measured from striated and corrugated faults planes: Comparison with focal mechanism and geodetic data. Journal of Geophysical Research 105 (B10), 23443-23462.

Robertson, A.H.F., 2000. Mesozoic-Tertiary tectonic-sedimentary evolution of a south Tethyan oceanic basin and its margins in southern Turkey. In: Bozkurt, E., Winchester, J.A., Piper, J.D.A. (Eds.), Tectonics and Magmatism in Turkey and the Surrounding Area. Geological Society, London, Special Publications, vol. 173, pp. 97-138.

Rocca, E., 2001. The northwest Mediterranean Basin (Valencia Trough, Gulf of Lions and Liguro-Provençal basins: structure and geodynamic evolution. In: Ziegler, P.A., Cavazza, W., Robertson, A.H.F., Crasquin-Soleau, S. (Eds.), Peri-Tethys Memoir 6, Peri-Tethyan Rift/Wrench Basins and Passive Margins. Mémoires du Muséum national d'Histoire Naturelle, Paris, vol. 186, pp. 671-706.

Rockwell, T.K., Lindvall, S., Herzberg, D., Murbach, D., Dawson, T., Berger, G., 2000. Paleo-seismology of the Johnson Valley, Kickapoo, and Homestead Valley faults: clustering of earthquakes in the eastern California shear zone. Bulletin of the Seismological Society of America 90, 1200-1236.

Roest, W.R., Srivastava, S.P., 1991. Kinematics of the plate boundaries between Eurasia, Iberia, and Africa in the North Atlantic from the Late Cretaceous to the present. Geology 19, 613-616.

Rohrman, M., Van der Beek, P.A., Andriessen, P.A.M., Cloetingh, S., 1995. Meso-Cenozoic morphotectonic evolution of southern Norway Neogene domal uplift inferred from apatite fission track thermochronology. Tectonics 14, 704-718.

Rohrman, M., Van der Beek, P.A., Van der Hilst, R.D., Reemst, P., 2002. Timing and mechanisms of North Atlantic Cenozoic uplift: evidence for mantle upwelling. In: Dore, A.G., Cartwright, J.A., Stoker, M.S., Turner, J.P., White, N. (Eds.), Exhumation of the North Atlantic Margin: Timing, Mechanisms and Implications for Petroleum Exploration. Geological Society, London, Special Publications, vol. 196, pp. 27-45.

Romanowicz, B., Gung, Y., 2002. Superplumes from the core-mantle boundary to the lithosphere: Implications for heat flux. Science 296, 513-516.

Rosenbaum, G., Lister, G.S., Duboz, C., 2002. Relative motion of Africa, Iberia and Europe during Alpine orogeny. Tectonophysics $359,117-129$

Roure, F., Brun, J.-P., Colletta, B., Vially, R., 1994. Multiphase extensional structures, fault reactivation, and petroleum plays in the Alpine foreland Basin of southeastern France. In: Mascle, A. (Ed.), Hydrocarbon and Petroleum Geology of France. European Association of Petroleum Geoscience, Special Publications, vol. 4. Springer-Verlag, Berlin, pp. 245-268.

Royden, L.H., 1993. Evolution of retreating subduction boundaries formed during continental collision. Tectonics 12, 629-638.

Rozsa, S., Mayer, M., Westerhaus, M., Seitz, K., Heck, B., 2005. Towards the determination of displacements in the Upper Rhine Graben area using GPS measurements and precise antenna modelling. Quaternary Science Reviews 24, 425-438.

Ruszkiczay-Rudiger, Z., Dunai, T., Bada, G., Fodor, L., Horvath, E., 2005. Middle to late Pleistocene uplift rate of the Hungarian Mountain Range at the Danube Bend, (Pannonian Basin) using in situ produced ${ }^{3}$ He. Tectonophysics 410, 157-173.

Ryan, W., Pitman, W., 1999. Noah's Flood: The new scientific discoveries about the event that changed history. Simon \& Schuster, New York. ISBN 0684810522.

Ryberg, T., Tittgemeyer, M., Wenzel, F., 2000. Finite difference modelling of P-wave scattering in the upper mantle. Geophysical Journal International 141, 787-800. 
Saintot, A., Stephenson, R., Stovba, S., Brunet, M.-F., Yegorova, T., Starostenko, V., 2006. The evolution of the southern margin of eastern Europe (Eastern European and Scythian Platforms) from the latest Precambrian-Early Palaeozoic to the Early Cretaceous. In: Gee, D., Stephenson, R. (Eds.), European Lithosphere Dynamics. Geological Society, London, Memoirs, vol. 32, pp. 481-506.

Salas, R., Guimera, J., Mas, R., Martin-Closas, C., Melédez, A., Alonso, A., 2001. Evolution of the Mesozoic Central Iberian rift system and its Cainozoic inversion (Iberian chain). In: Ziegler, P.A., Cavazza, W., Robertson, A.H.F., Crasquin-Soleau, S. (Eds.), Peri-Tethys Memoir 6, Peri-Tethyan Rift/Wrench Basins and Passive Margins. Mémoires du Muséum national d'Histoire Naturelle, Paris, 186, pp. $145-185$.

Sanders, C., Andriessen, P., Cloetingh, S., 1999. Life cycle of the East Carpathian Orogen: erosion history of a doubly convergent critical wedge assessed by fission track thermochronology. Journal of Geophysical Research 104, 29,095-29,112.

Savostin, L.A., Sibuet, J.C., Zonenshain, L.P., Le Pichon, X., Roulet, M.J., 1986. Kinematic evolution of the Tethys belt from the Atlantic Ocean to the Pamirs since the Triassic. Tectonophysics 123, 1-35.

Schindler, A., Jurado, M.J., Muller, B., 1998. Stress orientation and tectonic regime in the northwestern Valencia Trough from borehole data. Tectonophysics 300, 63-78.

Schmid, S., Pfiffner, O., Froitzheim, N., Schoenborn, G., Kissling, E., 1996. Geophysical-geological transect and tectonic evolution of the Swiss-Italian Alps. Tectonics 15, 1036-1064.

Schmid, S.M., Fuegenschuh, B., Kissling, E., Schuster, R., 2004. Three lithospheric transects across the Alps and their forelands. Swiss Geoscience Meeting, Lausanne.

Schmidt, A.G., Riisager, P., Abrahamsen, N., Riisager, J., Pedersen, A.K., Van der Voo, R., 2005. Palaeomagnetism of Eocene Talerua Member lavas on Hareøen, West Greenland. Bulletin of the Geological Society of Denmark 52, 27-39.

Schumacher, M.E., 2002. Upper Rhine Graben: the role of pre-existing structures during rift evolution. Tectonics 21, 1006. doi:10.1029/ 2001TC900022.

Selvaggi, G., Chiarabba, C., 1995. Seismicity and P-wave velocity image of the Southern Tyrrhenian subduction zone. Geophysical Journal International 122, 818-826.

Shackleton, N.J., Backman, J., Zimmerman, H., Kent, D.V., Hall, M.A., Roberts, D.G., Schnitker, D., Baldauf, J.G., Desprairies, A., Homrighausen, R., Huddlestun, P., Keene, J.B., Kaltenback, A.J., Krumsiek, K.A.O., Morton, A.C., Murray, J.W., Westerberg-Smith, J., 1984. Oxygen isotope calibration of the onset of ice rafting and history of glaciation in the North Atlantic region. Nature 307, $620-623$.

Shapiro, N.M., Ritzwoller, M.H., 2002. Monte-Carlo inversion for a global shear velocity model of the crust and upper mantle. Geophysical Journal International 151, 1-18.

Shearer, P.M., Earle, P.S., 2004. The Global short-period wavefield modelled with a Monte Carlo seismic phonon method. Geophysical Journal International 158, 1103-1117.

Shirinov, N.S., 1973. Geomorphological structure of the Kura-Araksa depression (Geomorfologicheskoe stroenie Kura-Araksinskoi depressii). Baku 215.

Shirinov, N.S., 1975. Latest tectonics and development of the relief of the Kura-Araska depression (Noveishaya tektonika i razvitie relyefa Kura-Araksin-skoi depressii). Baku 190.

Sholpo, V.N., 1993. Strucure of inversion anticlinoria in the core of the Greater Caucasus: an advection hypothesis. Geotectonics 23, $245-251$.
Sibuet, J-C., Srivastava, S.P., Spakman, W., 2004. Pyrenean orogeny and plate kinematics. Journal of Geophysical Research 109, B08104. doi:10.1029/2003JB002514.

Sim, L., Bryantseva, G., Karabanov, A.K., Levkov, E., Aizberg, R., 1995. The Neotectonic stress of Belorus and the Baltic countries. Technika Poszukiwan Geologicznych 3, 53-56.

Sissingh, W., 1998. Comparative Tertiary stratigraphy of the Rhine Graben, Bresse Graben and Molasse Basin: correlation of Alpine foreland events. Tectonophysics 300, 249-284.

Sissingh, W., 2003. Tertiary paleogeographic and tectonostratigraphic evolution of the Rhenish triple junction. Palaeogeography, Palaeoclimatology, Palaeoecology 196, 229-263.

Sissingh, W., 2006. Syn-kinematic palaeogeographic evolution of the West European Platform; correlation with Alpine plate collision and foreland deformation. In: van de Graaff, W.J.E. (Ed.), Tertiary evolution of the West European Platform; syn-kinematic stratigraphy and palaeogeography. Netherlands Journal of Geosciences, vol. 85 , pp. $131-180$.

Sliaupa, S., Ershov, A., 2000. Influence of the lithosphere strength variations to geometry of the Baltic basin. Geophysical Journal International 22 (4), 128.

Sliaupa, S., Sliaupa, A., Zakarevicius, A., Ilginyte, V., 2004. Tectonic processes during the neotectonic stage and their prognoses. In: Baltrunas (Ed.), Geological Development and Resources, Vilnius, pp. 610-613.

Sliaupa, S., Fokin, P., Lazauskiene, J., Stephenson, R., 2006. The Vendian-Early Palaeozoic sedimentary basins of the East European Craton. In: Gee, D., Stephenson, R. (Eds.), European Lithosphere Dynamics. Geological Society, London, Memoirs, vol. 32, pp. 449-462.

Sobornov, K.O., 1994. Structure and petroleum potential of the Dagestan thrust belt, northeastern Caucasus, Russia. Bulletin of Canadian Petroleum Geology 42, 352-364.

Sobornov, K.O., 1996. Lateral variations in structural styles of tectonic wedging in the northeastern Caucasus, Russia. Bulletin of Canadian Petroleum Geology 44, 385-399.

Sokolov, V., Bonjer, J.-P., Rizescu, M. (Eds.), 2004. Assessment of site effect in Romania during the intermediate depth Vrancea Earthquakes using different techniques, Earthquake, hazard, risk and strong ground motion, IUGG Special Volume, p. 295.

Sokoutis, D., Burg, J.P., Bonini, M., Corti, G., Cloetingh, S., 2005. Lithospheric-scale structures from the perspective of analogue continental collision. Tectonophysics 406, 1-15.

Spakman, W., Wortel, R., 2004. A tomographic view of the Western Mediterranean Geodynamics. In: Cavazza, W., Roure, F., Spakman, W., Stampfli, G.M., Ziegler, P.A. (Eds.), The TRANSMED Atlas - The Mediterranean Region from Crust to Mantle. Springer-Verlag, Berlin, pp. 31-52.

Spakman, W., Van der Lee, S., van der Hilst, R., 1999. Travel-time tomography of the European mantle down to $1400 \mathrm{~km}$. Physics of the Earth and Planetary Interiors 79, 3-74.

Sperner, B., Ioane, D., Lillie, R.J., 2004. Slab behaviour and its surface expression: new insights from gravity modelling in the SECarpathians. Tectonophysics 382, 51-84.

Springer, M., 1999. Interpretation of heat-flow density in the Central Andes. Tectonophysics 306, 377-395.

Srivastava, S.P., Schouten, H., Roest, W.R., Klitgord, K.D., Kovacs, L.C., Verhoef, J., Macnab, R., 1990. Iberian plate kinematics: a jumping plate boundary between Eurasia and Africa. Nature 344, 756-759.

Stampfli, G.M., Borel, G.D., 2004. The TRANSMED Transects in space and time; Constraints on the palaeotectonic evolution of the Mediterranean Domain. In: Cavazza, W., Roure, F., Spakman, W., 
Stampfli, G.M., Ziegler, P.A. (Eds.), The TRANSMED Atlas The Mediterranean Region from Crust to Mantle. Springer-Verlag, Berlin, Heidelberg, pp. 53-80.

Stampfli, G.M., Borel, G., Cavazza, W., Mosar, J., Ziegler, P.A., 2001. The Paleotectonic Atlas of the PeriTethys Domain. European Geophysical Society.

Stampfli, G.M., Borel, G.D., Marchant, R., Mosar, J., 2002. Western Alps geological constraints on Western Tethys reconstructions. Journal of the Virtual Explorer 8, 77-106.

Stapel, G., Cloetingh, S., Pronk, B., 1996. Quantitative subsidence analysis of the Mesozoic evolution of the Lusitanian Basin (western Iberian margin). In: Cloetingh, S., Ben-Avraham, Z., Sassi, W., Horvath, F. (Eds.), Dynamics of extensional basins and inversion tectonics. Tectonophysics, vol. 266, pp. 493-507.

Stein, R.S., Barka, A.A., Dietrich, J.H., 1997. Progressive failure on the North Anatolian fault since 1939 by earthquake stress triggering. Geophysical Journal International 128, 594-604.

Steinberger, B., 2000. Plumes in a convecting mantle: Models and observations for individual hotspots. Journal of Geophysical Research 105 (11), 127-152.

Steinberger, B., 2007. Effect of latent heat release at phase boundaries on flow in the Earth's mantle, phase boundary topography and dynamic topography at the Earth's surface. Physics of the Earth and Planetary Interiors (in revision).

Steinberger, B., O'Connell, R.J., 1997. Changes of the Earth's rotation axis owing to advection of mantle density heterogeneities. Nature 387, 169-173.

Stephenson, R.A., Stovba, S.M., Starostenko, V.I., 2001. PripyatDniepr-Donets Basin: implications for rift geodynamics and northern Peri-Tethyan tectonic history. In: Ziegler, P.A., Cavazza, W., Robertson, A.H.F., Crasquin-Soleau, S. (Eds.), Peri-Tethyan Rift/Wrench Basins and Passive Margins, Peri-Tethys memoir 6. Memoires du Museum National d'Histoire Naturelle, 186, pp. 369-406.

Stephenson, R., Marti, Y., Okay, A., Robertson, A.H.F., Saintot, A., Stovba, S., Khriachtchevskaia, O., 2004. Transect VIII: Eastern European Craton-Crimea-Black Sea-Anatolia-Cyprus-Levant Sea-Red Sea. In: Cavazza, W., Roure, F., Spakman, W., Stampfli, G.M., Ziegler, P.A. (Eds.), The TRANSMED Atlas — The Mediterranean Region from Crust to Mantle. Springer, Berlin, Heidelberg.

Stephenson, R., Yegorova, T., Brunet, M.-F., Stovba, S., Wilson, M., Starostenko, V., Saintot, A., Kusznir, N., 2006. Late Palaeozoic intra- and pericratonic basins on the East European Craton and its margins. In: Gee, D., Stephenson, R. (Eds.), European Lithosphere Dynamics. Geological Society, London, Memoirs, vol. 32, pp. 463-480.

Storey, M., Duncan, R.A., Pedersen, A.K., Larsen, L.M., Larsen, H.C., 1998. 40Ar/39Ar geochronology of the West Greenland Tertiary volcanic province. Earth and Planetary Science Letters 160, 569-586.

Strecker, M.R., Hilley, G., Arrowsmith, J.R., Coutand, I., 2003. Differential structural and geomorphic mountain-front evolution in an active continental collision zone: the NW Pamir, southern Kyrgyzstan. Geological Society of America Bulletin 115, $166-181$

Suk, M., 1984. Metamorphic history. In: Suk, M. (Ed.), Geological history of the territory of the Czech Socialist Republic. Academia Publishing House, Prague, pp. 263-288.

Tărăpoancă, M., Bertotti, G., Matenco, L., Dinu, C., Cloetingh, S., 2003. Architecture of the Focsani depression: A $13 \mathrm{~km}$ deep basin in the Carpathians bend zone (Romania). Tectonics 22, 1074. doi:10.1029/2002TC001486.
Tassara, A., 2005. Interaction between the Nazca and South American plates and formation of the Altiplano-Puna plateau; review of a flexural analysis along the Andean margin $\left(15^{\circ}-34^{\circ} \mathrm{S}\right)$. In: Gerbault, M., Herail, G., Martinod, J. (Eds.), Andean geodynamics; main issues and contributions from the 5th ISAG. Tectonophysics, vol. 399. pp. 39-57.

Tavares Martins, L., 1999. Cretaceous alkaline magmatism in Algarve Littoral (south Portugal): a basanite-Lamprophyr rock suite. GeoLines, Praha 9, 84-91.

Ten Veen, J.H., Woodside, J.M., Zitter, T.A.C., Dumont, J.F., Mascle, J., Volkonskaia, A., 2005. Neotectonic evolution of the Anaximander Mountains at the junction of the Hellenic and Cyprus arcs. Tectonophysics 391, 35-65.

Ter Voorde, M., de Bruijne, C.H., Cloetingh, S.A.P.L., Andriessen, P.A.M., 2004. Thermal consequences of thrust faulting: simultaneous versus successive fault activation and exhumation. Earth and Planetary Science Letters 223, 395-413.

Tesauro, M., Hollenstein, C., Egli, R., Geiger, A., Kahle, H.-G., 2005. Continuous GPS and broad-scale deformation across the Rhine Graben and the Alps. International Journal of Earth Sciences (Geol. Rundschau) 94, 525-537.

Thybo, H., 2006. The heterogeneous Upper Mantle Low Velocity Zone. Tectonophysics 416, 53-79.

Thybo, H., Perchuc, E., 1997. The seismic 8 degrees discontinuity and partial melting in continental mantle. Science 275, 1626-1629.

Thybo, H., Anderson, D.L. (Eds.), 2006. The Heterogeneous Mantle. Tectonophysics, vol. 416, p. 309.

Thybo, H., Janik, T., Omelchenko, V.D., Grad, M., Garetsky, R.G., Belinsky, A.A., Karatayev, G.I., Zlotski, G., Knudsen, M.E., Sand, R., Yliniemi, J., Tiira, T., Luosto, U., Komminaho, K., Giese, R., Guterch, A., Lund, C.E., Kharitonov, O.M., Ilchenko, T., Lysynchuk, D.V., Skobelev, V.M., Doody, J.J., 2003. Upper lithospheric seismic velocity structure across the Pripyat Trough and the Ukrainian Shield along the EUROBRIDGE'97 profile. Tectonophysics 371, 41-79.

Triep, E.G., Abers, G.A., Lerner-Lam, A., Mishatkin, V., Zhacherenko, N., Staravoit, O., 1995. Active thrust front of the Greater Caucasus: The April 29, 1991, Racha earthquake sequence and its tectonic implications. Journal of Geophysical Research 100, 4011-4033.

Trua, T., Serri, G., Marani, M.P., 2003. Lateral flow of African mantle below the nearby Tyrrhenian plate: geochemical evidence. Terra Nova 5, 433-440.

Tsikalas, F., Faleide, J.I., Eldholm, O., Wilson, J., 2005. Late MesozoicCenozoic structural and stratigraphic correlations between the conjugate mid-Norway and NE Greenland continental margins, 6th Petroleum Geology Conference. Petroleum Geology: North West Europe and Global Perspectives. Geological Society 785-801.

Turgut, S., Türkasian, M., Prinçek, D., 1991. Evolution of the Thrace Basin and its hydrocarbon prospectivity. In: Spencer, A.M. (Ed.), Generation, Accumulation and Production of Europe's Hydrocarbons. Special Publication, European Association of Petroleum Geoscientists, vol. 1, pp. 415-437.

Ulminshek, G.F., 2001. Petroleum geology and resources of the Middle Caspian Basin, former Soviet Union. U.S. Geological Survey Bulletin 2201-A (38), 42.

Ungureanu, G.V., Stãnicã, A., 2000. Impact of human activities on the evolution of the Romanian Black Sea beaches. Lakes and Reservoirs: Research and Management 5, 111-115.

Van Balen, R.T., Houtgast, R.F., Van der Wateren, F.M., Vandenberghe, J., Bogaart, P.W., 2000. Neotectonics of the Roer Valley Rift System, the Netherlands. Global and Planetary Change 27, 131-146. 
Van Balen, R.T., Houtgast, R.F., Cloetingh, S.A.P.L., 2005. Neotectonics of The Netherlands: a review. Quaternary Science Reviews 24, 439-454.

Van der Hoeven, A., Schmitt, G., Dinter, G., Mocanu, V., Spakman, W., 2004. GPS Probes the Kinematics of the Vrancea Seismogenic Zone. EOS, Transactions 85, 185-196.

Van Eck, T., Davenport, C., 1994. Seismotectonics and seismic hazard in the Roer Valley Graben; with emphasis on the Roermond earthquake of April 13th, 1992. Geologie en Mijnbouw 73, 91-92.

Van Hinsbergen, D.J.J., Hafkenscheid, H., Spakman, W., Meulenkamp, J.E., Wortel, R., 2005a. Nappe stacking resulting from subduction of oceanic and continental lithosphere below Greece. Geology 33, 325-328.

Van Hinsbergen, D.J.J., Langereis, C.G., Meulenkamp, J.E., 2005 b. Revision of the timing and distribution of Neogene rotation in the western Aegean region. Tectonophysics 396, 1-34.

Van Wees, J.D., Cloetingh, S.A.P.L., 1996. 3-D flexure and intraplate compression in the North Sea area. Tectonophysics 266, 343-359.

Vasiliev, I., Krijgsman, W., Langereis, C.G., Panaiotu, C.E., Matenco, L., Bertotti, G., 2004. Magnetostratigraphic dating and astronomical forcing of the Mio-Pliocene sedimentary sequences of the Focsani basin (Eastern Paratethys-Romania). Earth and Planetary Science Letters 227, 231-247.

Vasiliev, I., Krijgsman, W., Stoica, M., Langereis, C.G., 2005. MioPliocene magnetostratigraphy in the southern Carpathian foredeep and Mediterranean-Paratethys correlations. Terra Nova 17, 376-384.

Vegas, R., 1985. Tectónica del area Ibero-Magrebí. In: Udías, A., Muñoz, D., Buforn, E. (Eds.), Mecanismo de los terremotos y tectónica. Madrid, pp. 195-215.

Vergéz, J.M., Garcia-Senez, J., 2001. Mesozoic evolution and Cainozoic inversion of the Pyrenean rift. In: Ziegler, P.A., Cavazza, W., Robertson, A.H.F., Crasquin-Soleau, S. (Eds.), Peri-Tethys Memoir 6, Peri-Tethyan Rift/Wrench Basins and Passive Margins. Mémoires du Muséum national d'Histoire Naturelle, Paris, vol. 186, pp. 187-212.

Vernant, P., Nilforoushan, F., Hatzfeld, D., Abbassi, M.R., Vigny, C., Masson, F., Nankali, H., Martinod, J., Ashtiani, A., Bayer, R., Tavakoli, F., Chéry, J., 2004a. Present-day crustal deformation and plate kinematics in the Middle East constrained by GPS measurements in Iran and northern Oman. Geophysical Journal International 157, 381-398.

Vernant, P., Nilforoushan, F., Chery, J., Bayer, R., Djamour, Y., Masson, F., Nankali, H., Ritz, J.F., Sedighi, M., 2004b. Deciphering oblique shortening of central Alborz in Iran using geodetic data. Earth and Planetary Science Letters 224, 177-185.

Vinnik, L.P., Green, R.W.E., Nicolaysen, L.O., Kosarev, G.L., Petersen, N.V., 1996. Deep seismic structure of the Kaapvaal Craton. Tectonophysics 262, 67-75.

Wallace, R.E., 1987. Grouping and migration of surface faulting and variation in slip rates on faults in the Great Basin province. Bulletin of the Seismological Society of America 77, 868-877.

Walpersdorf, A., Baize, S., Calais, E., Tregoning, P., Nocquet, J.M., 2006. Deformation in the Jura Mountains (France): First results from semi-permanent GPS measurements. Earth and Planetary Science Letters 245, 365-372.

Wdowinski, S., Bock, Y., Baer, G., Prawirodirdjo, L., Bechor, N., Naaman, S., Knafo, R., Forrai, Y., Melzer, Y., 2004. GPS measurements of current crustal movement along the Dead Sea Fault. Journal of Geophysical Research 109, BO05403.

Wenzel, F., Achauer, U., Enescu, E., Kissling, E., Russo, R., Mocanu, V., Musacchio, G., 1998. Detailed look at final stage of plate break-off is target of study in Romania. EOS, Transactions 79, 589-594.

Wenzel, F., Lorenz, F., Sperner, B., Oncescu, M.C., 1999. Seismotectonics of the Romanian Vrancea area. In: Wenzel, F., Lungu, D., Novak, O. (Eds.), Vrancea Earthquakes: Tectonics, Hazard and Risk Mitigation. Kluwer Academic Publishers, Dordrecht, Netherlands, pp. 15-26.

Westaway, R., 1993. Quaternary uplift of southern Italy. Journal of Geophysical Research 98, 21722-21741.

Wigger, P., Schmitz, M., Araneda, M., Asch, G., Baldzuhn, S., Giese, P., Heinsohn, W.-D., Martinez, E., Ricaldi, E., Roewer, P., Viramonte, J., 1994. Variation of the crustal structure of the southern Central Andes deduced from seismic refraction investigations. In: Reutter, K.-J., Scheuber, E., Wigger, P. (Eds.), Tectonics of the Southern Central Andes. Springer, Berlin, pp. 23-48.

Willingshofer, E., Cloetingh, S., 2003. Present-day lithospheric strength of the Eastern Alps and its relationship to neotectonics. Tectonics 22, 1075. doi:10.1029/2002TC001463.

Wilson, M., Bianchini, G., 1999. Tertiary-Ouaternary magmatism within the Mediterranean and surrounding regions. In: Durand, B., Jolivet, L., Horvath, F., Séranne, M. (Eds.), The Mediterranean Basins: Tertiary Extension within the Alpine Orogen. Geological Society, London, Special Publications, vol. 156, pp. 141-168.

Wilson, M., Patterson, R., 2001. Intraplate magmatism related to shortwavelength convective instabilities in the upper mantle: Evidence from the Tertiary-Quaternary volcanic province of Western and Central Europe. Geological Society of America Bulletin, Special book series 352, 37-58.

Wong, H.K., Panin, N., Dinu, C., Georguescu, P., Rahn, C., 1994. Morphology and post-Chaudian (Late Pleistocene) evolution of the submarine Danube fan complex. Terra Nova 6, 502-511.

World Stress Map, 2003. World Stress Map. homepage: http://www. world-stress-map.org/.

Wortel, M.J.R., Spakman, W., 2000. Subduction and slab detachment in the Mediterranean-Carpathian region. Science 290, 1910-1917.

Yilmaz, A., Adamia, S., Chabukiani, A., Chkhotua, T., Erdogan, K., Tuzcu, S., Karabiyikoglu, M., 2000a. Structural correlation of the southern Transcaucasus (Georgia)-eastern Opontides (Turkey). In: Bozkurt, E., Winchester, J.A., Piper, J.D.A. (Eds.), Tectonics and Magmatism in Turkey and the Surrounding Area. Geological Society, London, Special Publications, vol. 173, pp. 171-182.

Yilmaz, Y., 1993. New evidence and model of the evolution of the southeast Anatolian orogen. Geological Society of America Bulletin $15,251-271$.

Yilmaz, Y., Genç, S.C., Gürer, F., Bozcu, M., Yilmaz, K., Karacik, Z., Altunkaynak, S., Elmas, A., 2000b. When did the western Anatolian grabens begin to develop? In: Bozkurt, E., Winchester, J.A., Piper, J.D.A. (Eds.), Tectonics and Magmatism in Turkey and the Surrounding Area. Geological Society, London, Special Publications, vol. 173, pp. 353-384.

Yuan, X., Sobolev, S.V., Kind, R., Oncken, O., 2000. New constraints on subduction and collision processes in the Central Andes from comprehensive observations of $\mathrm{P}$ to $\mathrm{S}$ converted seismic phases. Nature 408, 958-961.

Yurtmen, S., Rowbotham, G., Isler, F., Floyd, P.A., 2000. Petrogenesis of basalts from southern Turkey: the Plio-Quaternary volcanism to the north of Iskendrun Gulf. In: Bozkurt, E., Winchester, J.A., Piper, J.D.A. (Eds.), Tectonics and Magmatism in Turkey and the Surrounding Area. Geological Society, London, Special Publications, 173, pp. 489-512.

Zakarevicius, A., Stanionis, A., Sliaupa, S., Stephenson, R., 2005. Crustal deformations of the GPS polygon of the Ignalina NPP: 
Application of finite element modelling for geodynamic implications. In: Cygas, D., Froehner, K.D. (Eds.), The 6th International Conference: Environmental Engineering, Vilnius, pp. 1041-1047.

Zeck, H.P., 1999. Alpine plate kinematics in the western Mediterranean: a westward-directed subduction regime followed by slab roll-back and slab detachment. In: Durand, B., Jolivet, L., Horvath, F., Séranne, M. (Eds.), The Mediterranean Basins: Tertiary Extension within the Alpine Orogen. Geological Society, London, Special Publications, vol. 156, pp. 109-120.

Zeck, H.P., Monie, P., Villa, I.M., Hansen, B.T., 1992. Very high rates of cooling and uplift in the Alpine Belt of the Betic Cordilleras, southern Spain. Geology 20, 79-82.

Ziegler, P.A., 1988. Evolution of the Arctic-North Atlantic and the Western Tethys. American Association of Petroleum Geologists Memoir, 46. 198 pp.

Ziegler, P.A., 1990. Geological Atlas of Western and Central Europe, vol. 2. Geological Society Publishing House Bath, London. 239 pp.

Ziegler, P.A., 1992. European Cenozoic rift system. Tectonophysics 208, 91-111.

Ziegler, P.A., 1993. Plate-moving mechanisms: Their relative importance. Journal of the Geological Society of London 150, 927-940.
Ziegler, P.A., Dèzes, P., 2007. Neogene uplift of Variscan Massifs in the Alpine foreland: Timing and controlling mechanisms. Global and Planetary Change 58, 237-269. doi:10.1016/j.gloplacha.2006. 12.004.

Ziegler, P.A., Van Wees, J.-D., Cloetingh, S.A.P.L., 1998. Mechanical controls on collision-related compressional intraplate deformation. Tectonophysics 300, 103-129.

Ziegler, P.A., Bertotti, G., Cloetingh, S.A.P.L., 2002. Dynamic processes controlling foreland development - the role of mechanical (de) coupling of orogenic wedges and forelands. In: Bertotti, G., Schulmann, K., Cloetingh, S.A.P.L. (Eds.), Continental collision and the tectono-sedimentary evolution of forelands. Stephan Mueller Special Publications, vol. 1, pp. 17-57.

Zijerveld, L., Stephenson, R., Cloetingh, S.A.P.L., Duin, E., Van den Berg, M.W., 1992. Subsidence analysis and modelling of the Roer Valley Graben (SE Netherlands). Tectonophysics 208, 159-171.

Zonenshain, L.P., Kuzmin, M.I., Natapov, L.M., 1990. Geology of the USSR: A plate tectonic synthesis. Geodynamic Series, vol. 21. American Geophysical Union, Washington. 242 pp. 